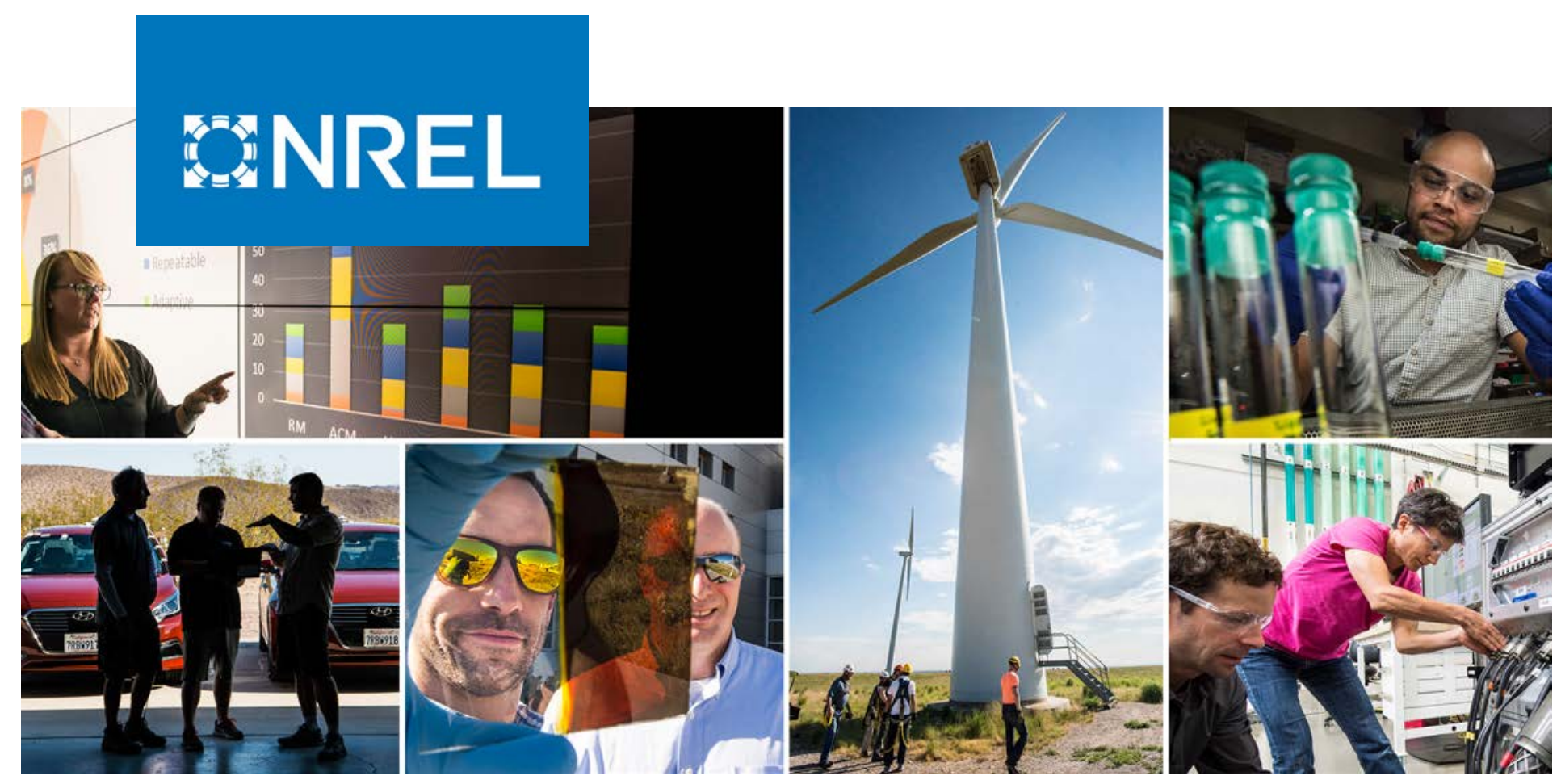

\title{
Characterization of Medium- and Heavy-Duty Vehicle Operations from In-Use Data: An Analysis of Starts, Soak Time, and Warm-Up Duration
}

Chen Zhang, Eric Miller, Andrew Kotz, Kenneth Kelly, and Matthew Thornton

\section{National Renewable Energy Laboratory}

Produced under direction of the Manufacturers of Emission Controls Association (MECA) by the National Renewable Energy Laboratory (NREL) under Technical Services Agreement TSA-18-01137.

NREL is a national laboratory of the U.S. Department of Energy Office of Energy Efficiency \& Renewable Energy

Operated by the Alliance for Sustainable Energy, LLC

This report is available at no cost from the National Renewable Energy Laboratory (NREL) at www.nrel.gov/publications.
Strategic Partnership Project Report NREL/TP-5400-74725

November 2019 


\title{
GNREL
}

Characterization of Medium- and Heavy-Duty Vehicle Operations from In-Use Data: An Analysis of Starts, Soak Time, and Warm-Up Duration

\author{
Chen Zhang, Eric Miller, Andrew Kotz, Kenneth Kelly, \\ and Matthew Thornton
}

National Renewable Energy Laboratory

\section{Suggested Citation}

Zhang, Chen, Miller, Eric, Kotz, Andrew, Kenneth, Kelly, and Matthew Thornton. 2019. Characterization of Medium- and Heavy-Duty Vehicle Operations from In-Use Data: An Analysis of Starts, Soak Time, and Warm-Up Duration. Golden, CO: National Renewable Energy Laboratory. NREL/TP-5400-74725. https://www.nrel.gov/docs/fy20osti/74725.pdf.

NREL is a national laboratory of the U.S. Department of Energy Office of Energy Efficiency \& Renewable Energy Operated by the Alliance for Sustainable Energy, LLC

This report is available at no cost from the National Renewable Energy Laboratory (NREL) at www.nrel.gov/publications.

Contract No. DE-AC36-08GO28308
Strategic Partnership Project Report NREL/TP-5400-74725 November 2019

National Renewable Energy Laboratory 15013 Denver West Parkway Golden, CO 80401 303-275-3000 • www.nrel.gov 


\section{NOTICE}

This work was authored by the National Renewable Energy Laboratory, operated by Alliance for Sustainable Energy, LLC, for the U.S. Department of Energy (DOE) under Contract No. DE-AC36-08GO28308. Support for the work was also provided by the Manufacturers of Emission Controls Association (MECA) under Technical Services Agreement TSA-18-01137. The views expressed in the article do not necessarily represent the views of the DOE or the U.S. Government. The U.S. Government retains and the publisher, by accepting the article for publication, acknowledges that the U.S. Government retains a nonexclusive, paid-up, irrevocable, worldwide license to publish or reproduce the published form of this work, or allow others to do so, for U.S. Government purposes.

This report is available at no cost from the National Renewable Energy Laboratory (NREL) at www.nrel.gov/publications.

U.S. Department of Energy (DOE) reports produced after 1991 and a growing number of pre-1991 documents are available free via www.OSTI.gov.

Cover Photos by Dennis Schroeder: (clockwise, left to right) NREL 51934, NREL 45897, NREL 42160, NREL 45891, NREL 48097, NREL 46526.

NREL prints on paper that contains recycled content. 


\section{Acknowledgments}

The authors would like to express their sincere gratitude to Manufacturers of Emission Controls Association (MECA) for their financial support of this project. Special thanks to Rasto Brezny and Michael Geller from MECA as well as Chris Sharp from the Southwest Research Institute (SwRI) for their instructive discussions and support during the project. The authors would also like to appreciate Kanok Boriboonsomsin, Thomas Durbin, and Kent Johnson of the University of California at Riverside, College of Engineering, Center for Environmental Research \& Technology for providing access and approving the use of the CE-CERT in-use data set.

The authors would also like to thank Jonathan Burton and Petr Sindler of the NREL Renewable Fuels and Lubricants (ReFUEL) Laboratory for providing valuable test data of multiple heavyduty engines running the Federal Test Procedure (FTP) cycle. 


\section{List of Acronyms}

CARB

CAN

CalEPA

CE-CERT

$\mathrm{CNG}$

$\mathrm{CO}$

$\mathrm{CSV}$

DOC

DPF

ECU

FTP

GPS

GVWR

$\mathrm{HC}$

LAFY

LANF

MECA

mph

NOx

NREL

NYNF

ReFUEL

rpm

SCR

SwRI
California Air Resources Board

Controller Area Network

California Environmental Protection Agency

University of California at Riverside, College of Engineering, Center for Environmental Research \& Technology

compressed natural gas

carbon monoxide

constant volume sampling

diesel oxidation catalyst

diesel particulate filter

engine control unit

Federal Test Procedure

global positioning system

gross vehicle weight rating

hydrocarbons

Los Angeles Freeway

Los Angeles Non-Freeway

Manufacturers of Emission Controls Association

mile per hour

oxides of nitrogen

National Renewable Energy Laboratory

New York Non-Freeway

renewable fuels and lubricants

revolutions per minute

selective catalytic reduction

Southwest Research Institute 


\section{Table of Contents}

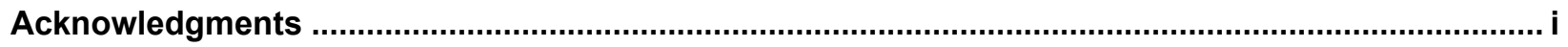

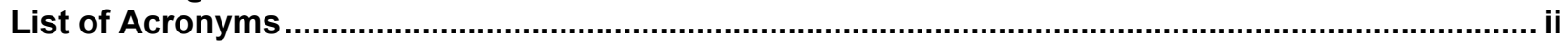

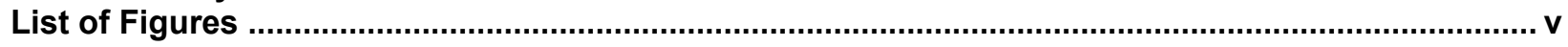

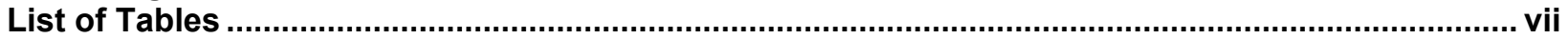

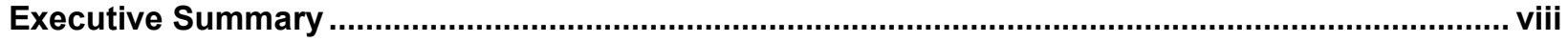

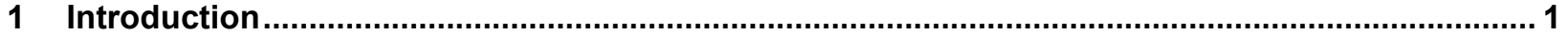

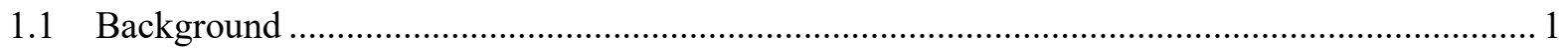

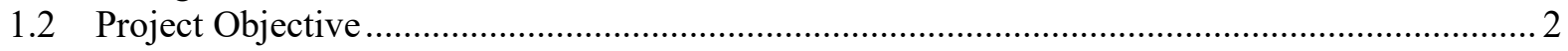

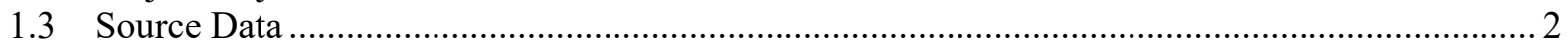

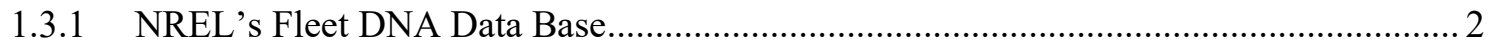

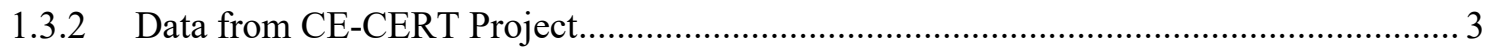

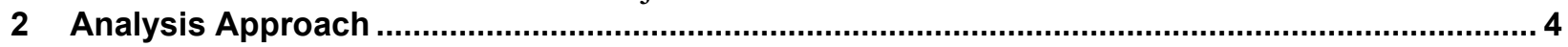

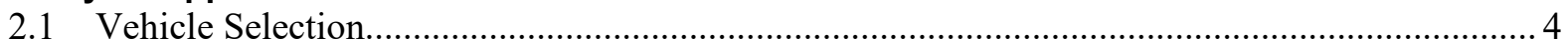

2.1.1 Fleet DNA Data Base ........................................................................ 4

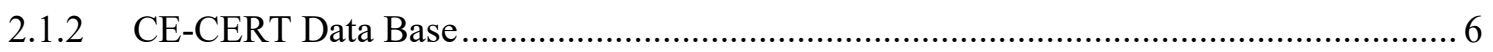

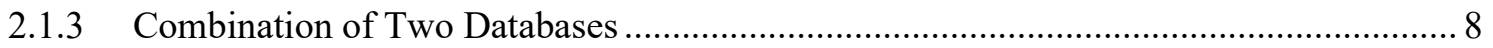

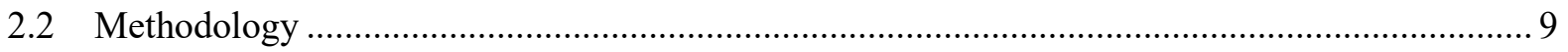

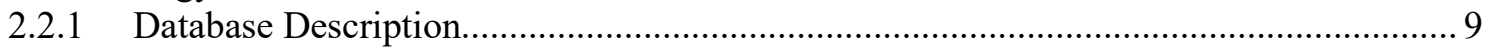

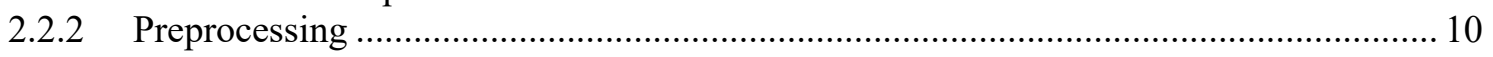

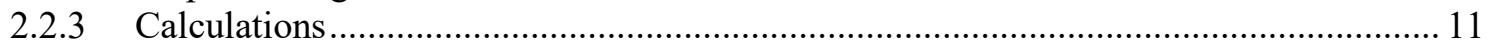

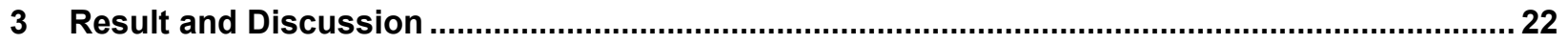

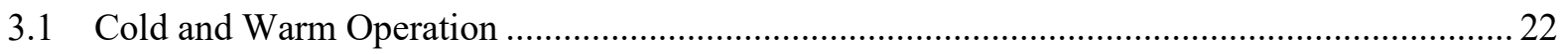

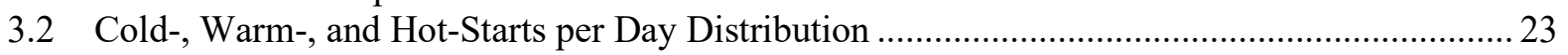

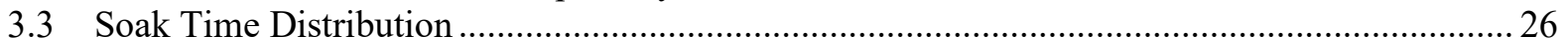

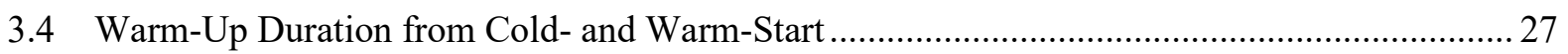

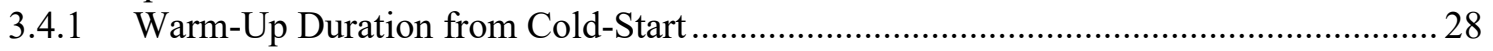

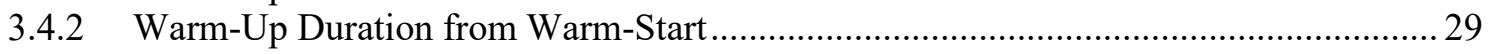

3.4.3 Average Power through Warm-Up versus Warm-Up Duration ..................................... 30

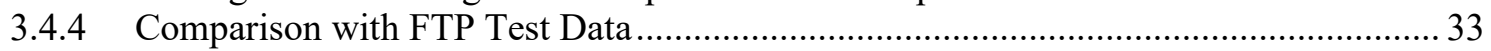

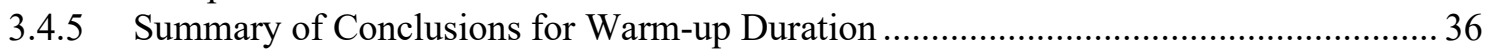

3.5 Temperature of Exhaust Gases Entering the SCR System (SCR Temperature) ......................... 36

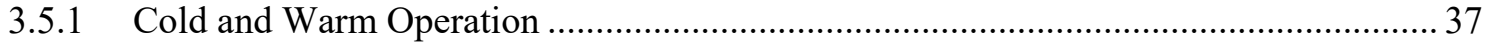

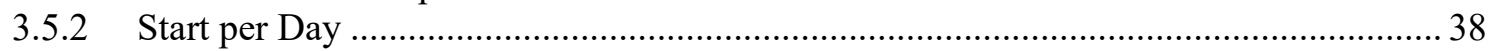

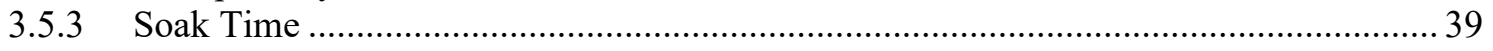

3.5.4 Warm-Up Duration from Each Kind of Engine Start............................................... 40

3.5.5 Summary of Conclusions for SCR System Temperature Analysis ............................. 41

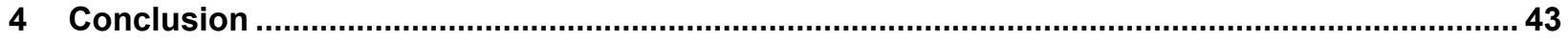

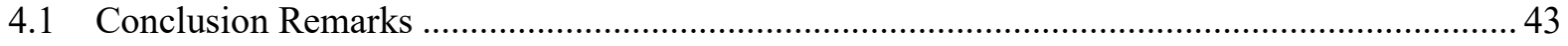

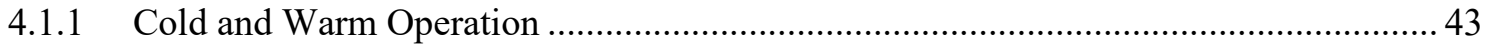

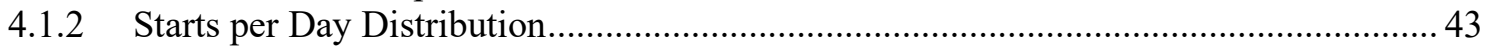

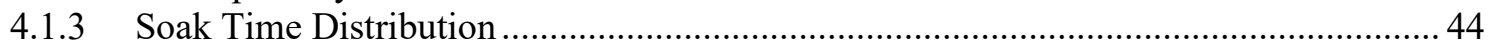

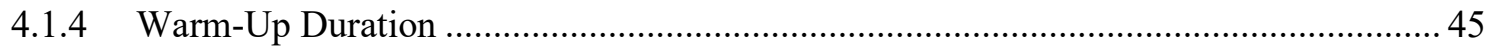

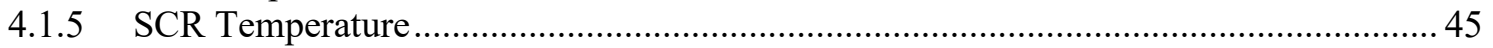

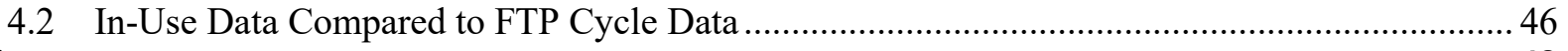

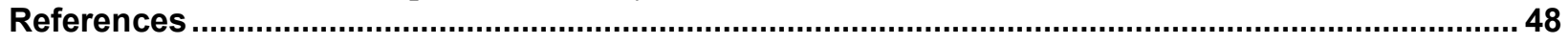

Appendix A: SCR Temperature VS Engine Coolant Temperature at Engine-Start ..........................49

Appendix B: Distribution of Cold-, Warm-, and Hot-Starts per Day Segmented by Vocations ........ 55

Appendix C: Distribution of Cold, Warm, and Hot Soak Time Segmented by Vocations ................. 59

Appendix D: Warm-Up Duration from Cold-Start in Real World Driving ..........................................63

Appendix E: Vehicles Samples including Engine Power Information .................................................. 65 
Appendix F: Engine Output Power vs. Cold Warm-Up Duration....................................................6 66

Appendix G: Engine Output Power vs. Warm Warm-Up Duration ................................................ 72

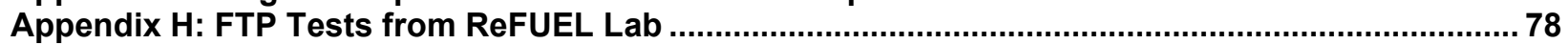

Appendix I: Compare Cold Warm-Up Duration from On-Road Data with the FTP Test Data............ 81

Appendix J: Compare Warm Warm-Up Duration from On-Road Data with the FTP Test Data ......... 84

Appendix K: Vehicles Samples including SCR Temperature Information .......................................... 87 


\section{List of Figures}

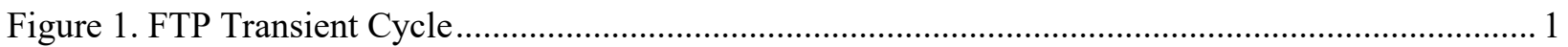

Figure 2. Diagram of Fleet DNA Database File Structure......................................................................... 10

Figure 3. Example Data Used to Identify (a) Cold-Start and (b) Warm- and Hot-Start Conditions........... 13

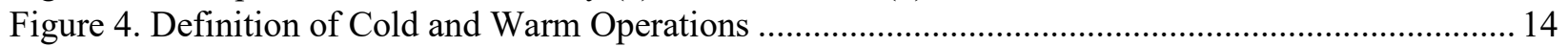

Figure 5. Definition of Warm-Up Duration from (a) Cold-Start and (b) Warm-Start .............................. 18

Figure 6. Specific Data Profiles of a Heavy-Duty Vehicles After a Cold-Start........................................ 19

Figure 7. SCR Temperature versus Engine Coolant Temperature at Engine Starts (Line Haul)............... 21

Figure 8. Fraction of Cold and Warm Operational Time Segmented by Vocations .................................. 22

Figure 9. Percentage of Cold-, Warm-, and Hot-Start in Different Vocations .......................................... 24

Figure 10. Average Cold-, Warm-, and Hot-Start Per Day in Different Vocations.................................... 25

Figure 11. Average Soak Time before Engine-Starts Segmented by Vocations ..................................... 26

Figure 12. Warm-Up Duration from Cold-Start Segmented by Eight Vocational Groups........................ 28

Figure 13. Warm-Up Duration from Warm-Start Segmented by Eight Vocations................................... 30

Figure 14. Average Power vs Warm-Up Duration from Cold Start in Line Haul from Fleet DNA ........... 31

Figure 15. Average Power vs Warm-Up Duration from Cold Start in Local Delivery from Fleet DNA ... 32

Figure 16. Average Power vs Warm-Up Duration from Warm Start in Line Haul from Fleet DNA......... 32

Figure 17. Average Power vs Warm-Up Duration from Warm Start in Local Delivery from Fleet DNA. 33

Figure 18. Comparison of Different Operational Time from On-Road Data and FTP Test Data............... 34

Figure 19. Comparison of Cold Warm-Up Duration in Line Haul from On-Road and FTP Test Data...... 35

Figure 20. Comparison of Warm Warm-Up Duration in Line Haul from On-Road and FTP Test Data ... 35

Figure 21. Fraction of Different Operational Times Segmented by Vocations (with SCR) ..................... 37

Figure 22. Percentage of Five Kinds of Engine Starts (with SCR) ..................................................... 38

Figure 23. Average Five Kinds of Engine Starts Per Day (with SCR) ….............................................. 39

Figure 24. Average Soak Times Segmented by Vocations (with SCR) ................................................. 40

Figure 25. Warm-Up Duration Segmented by Vocations (with SCR) .................................................. 41

Figure A. 1. SCR VS Coolant Temperature at Engine-Start (Fleet DNA: Transit) ................................... 49

Figure A. 2. SCR VS Coolant Temperature at Engine-Start (Fleet DNA: Vocation)................................ 49

Figure A. 3. SCR VS Coolant Temperature at Engine-Start (Fleet DNA: Local Delivery) ....................... 50

Figure A. 4. SCR VS Coolant Temperature at Engine-Start (Fleet DNA: Drayage)................................. 50

Figure A. 5. SCR VS Coolant Temperature at Engine-Start (Fleet DNA: Refuse) ................................... 51

Figure A. 6. SCR VS Coolant Temperature at Engine-Start (Fleet DNA: Parcel Delivery) ..................... 51

Figure A. 7. SCR VS Coolant Temperature at Engine-Start (CE-CERT: Drayage).................................. 52

Figure A. 8. SCR VS Coolant Temperature at Engine-Start (CE-CERT: Line Haul) ............................... 52

Figure A. 9. SCR VS Coolant Temperature at Engine-Start (CE-CERT: Local Delivery) ......................... 53

Figure A. 10. SCR VS Coolant Temperature at Engine-Start (CE-CERT: Refuse) ................................. 53

Figure A. 11. SCR VS Coolant Temperature at Engine-Start (CE-CERT: Transit) ................................... 54

Figure A. 12. SCR VS Coolant Temperature at Engine-Start (CE-CERT: Vocation).............................. 54

Figure B. 1. Distribution of Cold-, Warm- and Hot-Starts per Day in Line Haul .................................... 55

Figure B. 2. Distribution of Cold-, Warm-, and Hot-Starts per Day in Drayage ...................................... 55

Figure B. 3. Distribution of Cold-, Warm-, and Hot-Starts per Day in Refuse Pickup ............................. 56

Figure B. 4. Distribution of Cold-, Warm-, and Hot-Starts per Day in Parcel Delivery........................... 56

Figure B. 5. Distribution of Cold-, Warm-, and Hot-Starts per Day in Local Delivery............................ 57

Figure B. 6. Distribution of Cold-, Warm-, and Hot-Starts per Day in Transit ....................................... 57

Figure B. 7. Distribution of Cold-, Warm-, and Hot-Starts per Day in School Bus .................................. 58

Figure B. 8. Distribution of Cold-, Warm-, and Hot-Starts per Day in Vocation ....................................... 58

Figure C. 1. Distribution of Cold, Warm, and Hot Soak Times in the Line Haul ....................................59

Figure C. 2. Distribution of Cold, Warm, and Hot Soak Times in the Drayage .......................................5 59

Figure C. 3. Distribution of Cold, Warm, and Hot Soak Times in the Refuse Pickup Category................ 60

Figure C. 4. Distribution of Cold, Warm, and Hot Soak Times in the Parcel Delivery............................. 60 
Figure C. 5. Distribution of Cold, Warm, and Hot Soak Times in the Local Delivery ........................... 61

Figure C. 6. Distribution of Cold, Warm, and Hot Soak Times in the Transit ........................................ 61

Figure C. 7. Distribution of Cold, Warm, and Hot Soak Times in the School Bus .................................. 62

Figure C. 8. Distribution of Cold, Warm, and Hot Soak Times in the Vocation ....................................... 62

Figure D. 1. Case 1 of On-Road Warm-Up Duration from Cold-Start (8 minutes).................................. 63

Figure D. 2. Case 2 of On-Road Warm-Up Duration from Cold-Start (30 minutes)................................ 63

Figure D. 3. Case 3 of On-Road Warm-Up Duration from Cold-Start (60 minutes)................................ 64

Figure F. 1. Average Power vs. Warm-Up Duration from Cold-Start in Drayage from Fleet DNA .......... 66

Figure F. 2. Average Power vs. Warm-Up Duration from Cold-Start in Parcel Delivery from Fleet DNA

Figure F. 3. Average Power vs. Warm-Up Duration from Cold-Start in Refuse from Fleet DNA ........... 67

Figure F. 4. Average Power vs. Warm-Up Duration from Cold-Start in Transit from Fleet DNA ............ 67

Figure F. 5. Average Power vs. Warm-Up Duration from Cold-Start in Vocation from Fleet DNA ......... 68

Figure F. 6. Average Power vs. Warm-Up Duration from Cold-Start in Drayage from CE-CERT ........... 68

Figure F. 7. Average Power vs. Warm-Up Duration from Cold-Start in Line Haul from CE-CERT ........ 69

Figure F. 8. Average Power vs. Warm-Up Duration from Cold-Start in Local Delivery from CE-CERT. 69

Figure F. 9. Average Power vs. Warm-Up Duration from Cold-Start in Refuse from CE-CERT ............. 70

Figure F. 10. Average Power vs. Warm-Up Duration from Cold-Start in Transit from CE-CERT .......... 70

Figure F. 11. Average Power vs. Warm-Up Duration from Cold-Start in Vocation from CE-CERT ........ 71

Figure G. 1. Average Power vs. Warm-Up Duration from Warm-Start in Drayage from Fleet DNA ....... 72

Figure G. 2. Average Power vs. Warm-Up Duration from Warm-Start in Parcel Delivery from Fleet DNA

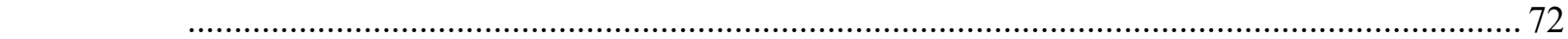

Figure G. 3. Average Power vs. Warm-Up Duration from Warm-Start in Refuse from Fleet DNA.......... 73

Figure G. 4. Average Power vs. Warm-Up Duration from Warm-Start in Transit from Fleet DNA ......... 73

Figure G. 5. Average Power vs. Warm-Up Duration from Warm-Start in Vocation from Fleet DNA ...... 74

Figure G. 6. Average Power vs. Warm-Up Duration from Warm-Start in Drayage from CE-CERT ........ 74

Figure G. 7. Average Power vs. Warm-Up Duration from Warm-Start in Line Haul from CE-CERT...... 75

Figure G. 8. Average Power vs. Warm-Up Duration from Warm-Start in Local Delivery from CE-CERT

.

Figure G. 9. Average Power vs. Warm-Up Duration from Warm-Start in Refuse from CE-CERT.......... 76

Figure G. 10. Average Power vs. Warm-Up Duration from Warm-Start in Transit from CE-CERT ........ 76

Figure G. 11. Average Power vs. Warm-Up Duration from Warm-Start in Vocation from CE-CERT ..... 77

Figure H. 1. Picture of Cummins ISB Engine in ReFUEL Lab............................................................... 78

Figure H. 2. Picture of Navistar Maxxforce 10 Diesel Engine in ReFUEL Lab .................................... 79

Figure H. 3. Picture of Cummins ISL Diesel Engine in ReFUEL Lab .................................................. 79

Figure H. 4. FTP Transient Engine Dynamometer Cycle Test using Cummins Diesel ISL345 Engine .... 80

Figure I. 1. Comparison of Cold Warm-Up Duration in Local Delivery from On-Road and FTP Test Data

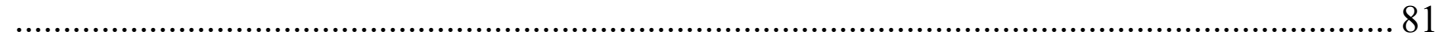

Figure I. 2. Comparison of Cold Warm-Up Duration in Refuse from On-Road and FTP Test Data ......... 81

Figure I. 3. Comparison of Cold Warm-Up Duration in Transit from On-Road and FTP Test Data ......... 82

Figure I. 4. Comparison of Cold Warm-Up Duration in Vocation from On-Road and FTP Test Data...... 82

Figure I. 5. Comparison of Cold Warm-Up Duration in Drayage from On-Road and FTP Test Data ....... 83

Figure J. 1. Comparison of Warm Warm-Up Duration in Drayage from On-Road and FTP Test Data .... 84

Figure J. 2. Comparison of Warm Warm-Up Duration in Local Delivery from On-Road and FTP Test

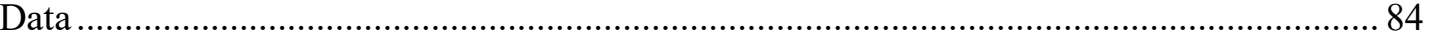

Figure J. 3. Comparison of Warm Warm-Up Duration in Refuse from On-Road and FTP Test Data ....... 85

Figure J. 4. Comparison of Warm Warm-Up Duration in Transit from On-Road and FTP Test Data....... 85

Figure J. 5. Comparison of Warm Warm-Up Duration in Vocation from On-Road and FTP Test Data ... 86 


\section{List of Tables}

Table ES 1. Engine Coolant Temperature Ranges Indicating Different Engine Starts............................viii

Table ES 2. Engine Starts Classification by Both Engine Coolant and SCR Temperature ........................ ix

Table 1. Population of Conventional Diesel-Powered Heavy-Duty Vehicles in Fleet DNA....................... 4

Table 2. Vocational Makeup for Line Haul and Vocation Categories...................................................... 5

Table 3. Vocational Makeup for Local Delivery and Drayage Categories ................................................ 5

Table 4. Geographic Distribution of Data by Vehicle Vocations ......................................................... 6

Table 5. Final Vehicles Sample in CE-CERT Database [7] ............................................................. 7

Table 6. Population of Conventional Diesel-Powered Heavy-Duty Vehicles in CE-CERT Database ......... 8

Table 7. Vocational Makeup for Vocation, Drayage, and Local Delivery in the CE-CERT Database ........ 8

Table 8. Vocation Makeup for Refuse Pickup, Transit, and Line Haul in the CE-CERT Database............. 8

Table 9. Population of All the Vehicles in the Combination of Two Databases ...................................... 9

Table 10. Engine Coolant Temperature Ranges Indicating Different Engine Starts ............................... 12

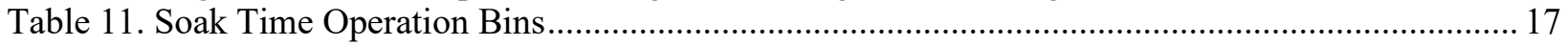

Table 12. Engine Starts Classification by Both Engine Coolant and SCR Temperature ........................... 21

Table 13. Statistical Results of Warm-Up Duration from Cold-Start ....................................................... 29

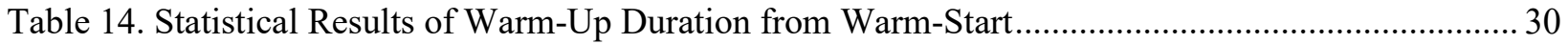

Table E. 1 Population of Vehicles in Fleet DNA with Power Information ............................................. 65

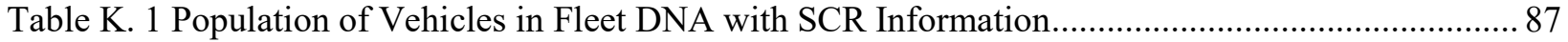

Table K. 2 Population of Vehicles in CE-CERT with SCR Information................................................ 87 


\section{Executive Summary}

In recent years, advanced technologies for emission control have developed so significantly that exhaust emissions from hot-stabilized operation can be reduced to almost zero. Thereby, the emissions from cold operations contribute the most significant portion of the total emissions from a trip. As such, the Manufactures of Emissions Controls Association (MECA) was interested in conducting a quantitative assessment of the engine cold-start operations for medium- and heavy-duty vehicles, using real-world operational data. In addition to providing valuable information to MECA, this study will also be valuable to engine manufacturers for developing more specific emission control technology strategies targeted on engine cold-start performance, fleet managers for determining more suitable driving cycles for their fleets to further reduce fuel cost and engine emissions, and policymakers for gaining a better understanding of the real-world emissions impacts from cold-start operations.

MECA sponsored the National Renewable Energy Laboratory (NREL) to leverage its experience and expertise with medium- and heavy-duty vehicle activity data to investigate the above questions related to cold-start emissions. For this study, two major data sources were used: 1 . the NREL Fleet DNA database which includes 435 conventional, diesel-power vehicles from 25 different vocations and from 24 fleets across the United States; 2. The data from University of California at Riverside, College of Engineering, Center for Environmental Research \& Technology (CE-CERT) projects supported by California Air Resources Board (CARB), which consists of 79 diesel-powered vehicles from 10 different vocations, and 23 fleets operating in California.

In this study, appropriate coolant temperature ranges representing cold, warm, and hot operation were identified, as shown in Table ES 1

Table ES 1. Engine Coolant Temperature Ranges Indicating Different Engine Starts

\begin{tabular}{|c|c|}
\hline Engine Start & Coolant Temperature Range \\
\hline Cold & T_coolant $\leq 40^{\circ} \mathrm{C}$ \\
\hline Warm & $40^{\circ} \mathrm{C}<\mathrm{T}_{-}$coolant $\leq 75^{\circ} \mathrm{C}$ \\
\hline Hot & $75^{\circ} \mathrm{C}<\mathrm{T}$ _coolant \\
\hline
\end{tabular}

Then, the fraction of engine operational time spent within cold and warm temperature range was characterized for the fleets and across different vocations. In addition, the distributions of cold-, warm-, and hot-starts per day in these vocations, and the soak times before each start were determined. A comprehensive analysis on the warm-up duration from cold and warm starts was also conducted and the corresponding results were compared with engine dynamometer tests over the U.S. EPA Federal Test Procedure (FTP) for heavy-duty engine emissions certification. Lastly, a detailed analysis base on the temperature of exhaust gases entering the selective catalytic reduction (SCR) systems at engine-start was conducted. In this analysis, the engine starts were separated into five groups, as shown in Table ES 2. 
Table ES 2. Engine Starts Classification by Both Engine Coolant and SCR Temperature

\begin{tabular}{|c|c|c|}
\hline Engine Start & Coolant Temperature & SCR Temperature \\
\hline Cold & T_coolant $\leq 40^{\circ} \mathrm{C}$ & $\sim$ \\
\hline Warm-Cold & $40^{\circ} \mathrm{C}<$ T_coolant $\leq 75^{\circ} \mathrm{C}$ & T_SCR $\leq 60^{\circ} \mathrm{C}$ \\
\hline Warm & $40^{\circ} \mathrm{C}<$ T_coolant $\leq 75^{\circ} \mathrm{C}$ & $60^{\circ} \mathrm{C}<\mathrm{T}$ SCR $\leq 200^{\circ} \mathrm{C}$ \\
\hline Hot-Warm & T_coolant $>75^{\circ} \mathrm{C}$ & T_SCR $\leq 200^{\circ} \mathrm{C}$ \\
\hline Hot & T_coolant $>75^{\circ} \mathrm{C}$ & T_SCR $>200^{\circ} \mathrm{C}$ \\
\hline
\end{tabular}

This technical report includes an introduction of the background and objective of this study, a full description of the two data sources, an explanation of the analytical approaches, a presentation of the graphical results and a discussion and detailed summary of the conclusions including: cold and warm operation, starts per day distribution, soak time distribution, warm-up duration, and SCR intake gases temperature.

Some key conclusions from these five areas are shown below:

- Cold and Warm Operation:

- Line Haul and Drayage exhibit the smallest cold operational time from both the Fleet DNA and CE-CERT data, which was around 1\%.

○ Local Delivery showed the longest duration operating at cold and warm conditions, which were $2.7 \%$ and $11.4 \%$ respectively.

- Combining the cold and warm operations together, Refuse Pickups have the shortest duration of the total operating time under this condition, which is only $4.3 \%$.

- Starts Per Day Distribution

- More than $60 \%$ of the vehicle-days from the Line Haul category had zero coldstarts and warm-starts since these trucks typically do no soak overnight and the engine will keep idling for auxiliary power.

○ Drayage vehicles had 0.87 cold-starts per day on average. They also exhibited more warm-starts per day (2.61 on average) and hot-starts per day (9.16 on average) than the Line Haul, likely due to frequent stops for queuing, loading and unloading cargo.

- Most of the vehicle days in the Refuse category had one cold-start, and zero warm- and hot-starts. This is because refuse pickup vehicles have few enginestops during normal operation.

- Vehicles in the Parcel Delivery category have the largest number of hot-starts per day on average, with more than 90 . Such a frequent number of daily hot-starts is the result of specific policies employed by some fleets, which require drivers to turn off the engine when they leave the vehicles to deliver packages. 
○ More than 50\% vehicle-days for the School Bus category had two cold-starts per day. This result is expected since school buses typically pick up students in the morning and drive student back home in the afternoon, with a soak in-between.

- For the Vocation group, the cold-starts per day distributions were similar from the two data sets. But the warm- and hot-starts were different, likely due to the wide diversity of vocations included in this group.

- Soak Time Distribution

- Most starts, no matter whether they are cold, warm, or hot, had 30 to 60 minutes of soak duration in the Line Haul category.

- For the Drayage, Refuse, and Vocation categories, most of the hot-starts occurred after a soak time of less than 6 minutes, while most of cold-starts had a soak duration longer than 12 hours.

$\circ$ Due to the specific driving behavior of the Parcel Delivery vehicles, the fractions of soak times with less than 6 minutes are high for all types of starts, which are $40 \%$ for cold-starts, over $65 \%$ for warm-starts, and nearly $93 \%$ for hot-starts.

- Unlike the other vocations, the Transit category had the largest fraction of coldstarts in the "6 to 12 hours" time bin.

- For the School Bus category, most of the engine-starts were in the "less than 6 minutes" and "over 12 hours" time bins. This result demonstrates that during the normal operation, School Buses usually only stop for a few minutes to load or unload students.

- Warm-Up Duration

- From the statistical analysis of the warm-up duration from cold-start, most vehicles need about 15 to 20 minutes to warm-up on average. The Line Haul, Local Delivery and Transit categories showed longer warm-up times (around 20 minutes), while Drayage, Vocation, Refuse, and School Bus categories took less time on average (around 15 minutes). The Parcel Delivery trucks have the shortest duration of warm-up time on average (less than 10 minutes). In addition, from the on-road data, it was observed that some cold warm-up durations in real-world driving can be almost 60 minutes. This is due to the existence of excessive engine-off time in this period, driven by multiple short trips with many key-off events.

- The warm-up duration from warm-start is much shorter than the cold warm-up duration on average. Even though some warm, warm-up durations can last 30 minutes, the average warm-up duration, from warm-starts, is less than 10 minutes. For some vocations, warm, warm-up durations are even shorter than 5 minutes, (e.g. Vocation, Refuse, Local Delivery, Transit, and Parcel Delivery). In addition, it is also possible for engines to take only 1 minute or less to warm-up since the coolant temperature may be very close to $75^{\circ} \mathrm{C}$ at engine start.

O In this study, the average engine output power was chosen as a metric to represent the driving behavior across the warm-up duration. Usually, smaller engines with lower output power lead to longer warm-up durations. In addition, the engine 
warm-up duration usually falls into two groups. One includes the engine-off time, and the other does not. Typically, if the warm-up duration from cold-start is longer than 20 minutes, or the warm-up duration from warm-start is longer than 15 minutes, the warm-up duration is likely to include one or more engine-off events.

- FTP cycle test data were also compared with the data derived from the on-road data sets. From a comparison, even though all the data are in the same range, the FTP test data are crowded in a smaller region compared to the wide distribution of real-world, on-road operating data. This is mainly caused by the fact that the FTP test cycle has no engine-off time included during the warm-up duration.

- SCR Inlet Gases Temperature

- Based on the engine coolant temperature and the temperature of exhaust gases entering the SCR system, the engine starts were separated into five groups, as shown in Table ES 2. More emphasis should be placed on the analysis of hotwarm starts, of which coolant temperature is higher than $75^{\circ} \mathrm{C}$, but the $\mathrm{SCR}$ temperature is lower than $200^{\circ} \mathrm{C}$. Under these conditions, the NOx emission can still be significant due to the lower SCR operating temperatures.

$\bigcirc$ From the perspective of operational time, the hot-warm operations are significant in several groups. For example, Drayage, Local Delivery, Vocation, and Parcel Delivery possess $35.8 \%, 26.1 \%, 28.4 \%$, and $26.5 \%$ of total operational time under the hot-warm condition.

- Both fraction and average starts per day show that the hot-warm starts represent a larger portion of total engine starts. Focusing on the Line Haul trucks as an example, $69.8 \%$ of engine starts are hot-warm starts, which indicates that novel approaches are still required to raise the SCR temperature quickly after engine starts in order to control NOx emissions.

- Usually, if the engine soaks for 4 to 5 minutes, the next engine-start is likely to be a hot-start. However, if the engine soaks 7 to 10 minutes, even though the coolant temperature is stabilized, the SCR temperature can be lower than $200^{\circ} \mathrm{C}$, and the corresponding engine-start should be considered as a hot-warm start as defined by this study.

O The in-use data reveals that the vehicles still take 4 to 5 minutes (varied based on the vocational group) to warm-up the SCR system from the hot-warm engine. This period may have been neglected by previous studies since the coolant temperature is high enough and the engine is considered hot.

In addition, the analytical results from this study were also used to validate the representativeness of the current FTP cycle. Some observations are listed below:

- The analysis from the in-use data reflects that on average, there are about $12.0 \%(11.4 \%$ from Fleet DNA and 18.2\% from CE-CERT) of engine starts are cold-starts. The current weight for cold-start emission for the FTP cycle is $1 / 7$ or $14.3 \%$.

- The cold-operational time from the FTP cycle, based on the three engines that were sampled for this study, was $1.5 \%$, which is comparable to the average value of the in-use 
data (1.3\%). However, the warm-operational time is $21.8 \%$ from the FTP cycle, which is much larger than the in-use data $(7.2 \%)$. This is likely attributed to the fact that the current 20-minute FTP cycle does not cover enough hot-operational time.

- If only considering cold-start and hot-start cases, the required soak times (20 minutes for hot tests, and at least 12 hours for cold tests) to determine the category of engine-starts from the current FTP cycle are reasonable.

- However, based on the analysis of this study, it is much better to separate the enginestarts into five groups according to engine coolant temperature and SCR system temperature. If the related cost and time are limited, at least the hot-warm start case should be distinguished from the hot-start case in the FTP cycle. If four kinds of engine starts are employed, the corresponding weights for cold-, warm-, hot-warm, and hot-start cases would be $14 \%, 16 \%, 50 \%$, and $20 \%$ respectively.

- Changing the soak time before engine start is a convenient way to achieve various engine start cases. Enlightened by the study, the required soak time for each of the five kinds of engine starts can be derived. For example, the cold-start case is achieved after the engine has soaked for 10-hours or longer. In addition, the required soak time for the warm case, hot-warm case, and hot case would be 60,20, and 5 minutes respectively.

- Another issue for the current FTP cycle is that it does not include any engine-off period during the warm-up duration. Typically, the engine under the FTP test will continuously operate during the entire test. However, from the in-use data, the real-world driving behaviors include one or more engine-off periods and thus, extending the warm-up duration. To be more representative, the FTP cycle would be better to include this specific period. Further investigation of this issue is required. 


\section{Introduction}

\subsection{Background}

Increasingly stringent emission regulations for both medium- and heavy-duty diesel vehicles are being introduced globally [1-2]. As a result, the emission control technologies for the commercial vehicles have also been improved substantially. These technologies have become so effective recently that the measurement of regulated pollutants, such as carbon monoxide (CO), hydrocarbons (HC), and oxides of nitrogen (NOx), are close to detection limits during hotstabilized operation [3]. However, during cold start, the catalysts in the emission control systems are not operating in the proper temperature. Thereby the emission conversion efficiency is limited, and the vehicles still produce lots of emissions. Therefore, the analysis of emissions during vehicles' cold-start operations becomes an important research topic since it is a primary contributor to emission inventories.

The current approach to identify cold-start emissions from medium- and heavy-duty diesel engines in the United States, involves the use of the Federal Test Procedure (FTP) cycle [4]. The developed FTP cycle includes a variety of heavy-duty truck and bus driving patterns in different U.S. cities, as well as traffic information on local roads and highways. The related four phases are shown in Figure 1, namely (1) New York Non-Freeway (NYNF) phase representing light urban traffic with frequent stops and starts, (2) Los Angeles Non-Freeway (LANF) phase representing crowded urban traffic with few stops, (3) Los Angeles Freeway (LAFY) phase simulating crowded highway traffic in Los Angeles, follow by (4) a repetition of the first NYNF phase.

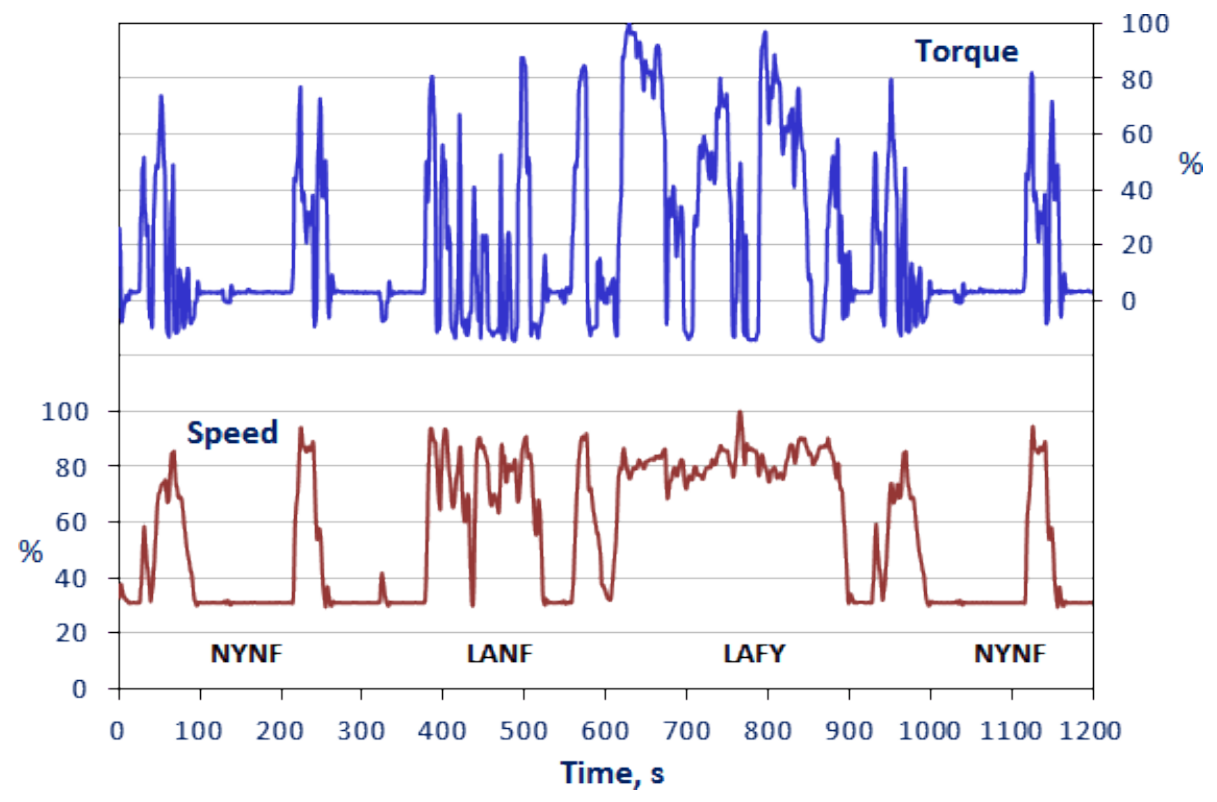

Figure 1. FTP Transient Cycle

For certification purpose, the cycle is examined with both cold- and hot-starts. For the cold-start test, the engine is required to soak overnight or at least 12 hours, while for the hot-start test, the engine is soaked for only 20 minutes. The composite, FTP brake-specific emissions results are 
obtained by dividing the mass emissions and fuel consumption (in grams) by the mechanical work (in brake horsepower-hour (bhp-hr)), using a weighting factor of 1/7 and 6/7 for the coldand hot-start results, respectively [4].

The FTP cycle is the most influential test cycle for emission certification in the U.S., especially since it includes cold-start emission levels, but there are concerns about how representative it is of current vehicle and engine operation. Derived from data almost four decades ago, the FTP cycle represents behaviors of vehicles in the 1970s, some of which had gear ratios limiting maximum vehicle speed. Its development was also based on the performance of engines with lower power densities and lower turbocharger boost than its current counterparts. Furthermore, the FTP attempts to capture a variety of operations in both freeway and urban road, without any consideration of distinct driving behavior from different vehicle vocations [5]. Lastly, the weighting of cold- and hot-start operation is also questioned, as it may not reflect the real-world driving scenarios of current medium- and heavy-duty vehicles. The appropriateness of these weighting numbers relative to observed in-use cold-start operations in the current fleet is a key question that this study aims to answer.

\subsection{Project Objective}

To fully characterize current medium- and heavy-duty vehicles' cold-operational time, start performance, soak times before each start as well as the corresponding warm-up operations, the Manufacturers of Emissions Controls Association (MECA) was interested in conducting a quantitative assessment of above performance using real-world operational data. The primary objective of this study was to identify the fraction of engine operational time spent within different engine coolant temperature ranges, segmented by vehicles vocations. This was accomplished by using the National Renewable Energy Laboratory (NREL) Fleet DNA database and recent vehicle activity data from University of California at Riverside, College of Engineering, Center for Environmental Research \& Technology (CE-CERT) projects supported by the California Air Resources Board (CARB). The secondary objective was to characterize multiple cold-start operational conditions for different vocations, such as coolant temperature ranges indicating cold-, warm-, and hot-starts, distribution of cold-, warm-, and hot-starts per day, distribution of vehicle soak times before each start, warm-up duration after cold- and warmstarts, as well as, the cold-start performance from the perspective of selective catalytic reduction (SCR) system temperatures. The corresponding results were also used to validate the representativeness of the FTP cycle.

\subsection{Source Data}

Two major data sources were used for this study: 1. The NREL Fleet DNA database, which includes 435 conventional diesel-power vehicles from 25 vocations and 24 fleets across the United States and 2. The data from CE-CERT projects supported by CARB, which consists of 79 conventional diesel-powered vehicles from 10 vocations and 23 fleets operating in California.

\subsubsection{NREL's Fleet DNA Data Base}

In collaboration with fleet and industry partners across the country, the Commercial Vehicle Technologies team in NREL's Transportation and Hydrogen Systems Center focuses on evaluating the real-world performance of alternative fuel and advanced vehicle technologies deployed in medium- and heavy-duty commercial fleets throughout the nation. The team has 
instrumented vehicles operating in the field with data recording devices to capture $1-\mathrm{Hz}$ telematics and Controller Area Network (CAN) data. These data are then used to calculate in-use fuel economy and performance drive-cycle characterization and system-level duty-cycle analysis, which can be complemented by chassis dynamometer emissions and fuel economy data. These results are used to provide feedback to stakeholders such as fleets, technology providers, researchers, and government agencies, helping to inform and provide insight on the performance of advanced technologies and fuels operating under real-world conditions. The data for these evaluation projects are stored in the Fleet DNA database along with additional externally sourced data that have been supplied by Fleet DNA project partners. This online database and tool are available at http://www.nrel.gov/fleetdna. For more information about the Fleet DNA database project, please consult the fleet DNA web site above [6].

\subsubsection{Data from CE-CERT Project}

To characterize the activity profiles of heavy-duty diesel vehicles in different types of vocations and identify the fraction of vehicle operations that SCR system may not function effectively, the CARB sponsored University of California at Riverside, College of Engineering - Center for Environmental Research and Technology to collect both vehicle and engine activity data from 90 heavy-duty vehicles operating in California state. These vehicles consist of 19 different groups defined by a combination of vocational uses, gross vehicle weight rating (GVWR), and geographic region. Almost all the vehicles are of model year 2010 or newer and are equipped with SCR system. The collected data included vehicle position, speed, and engine parameters and were then used to analyze several vehicle activity statistics related to engine-start, enginesoak, idle activity, and the temperatures of exhaust gases entering the SCR system. For more information about this database, please refer to the CE-CERT report related to the project [7]. 


\section{Analysis Approach}

To achieve the objectives of this project, NREL first reviewed both the Fleet DNA and CECERT databases, confirmed the population of several key parameters, including time, vehicle speed, engine speed, engine coolant temperature, temperature of exhaust gases entering the SCR system (SCR temperature), and engine torque, and coordinated with MECA to identify the final database subsets to be used in this project. Then, NREL investigated the engine coolant temperature data to determine the appropriate range defining cold-start operation for the vehicles and conducted a comprehensive investigation on distribution of starts per day, vehicle soak times, and engine warm-up duration for vehicles in different vocations. Comparisons between the influence of coolant temperature and SCR temperature as well as the real-world driving behavior relative to the FTP test cycle were also examined.

\subsection{Vehicle Selection}

While both the Fleet DNA and CE-CERT data include vehicles with a wide range of powertrains and fuels, a more limited-down selection containing only conventional diesel vehicles (battery electric, hybrids, and compressed natural gas (CNG) vehicles were removed) was identified for this project to ensure the analysis was representative of traditional operation and not modified to accommodate vehicle architecture. In addition, vehicles with missing or erroneous engine data were filtered out.

\subsubsection{Fleet DNA Data Base}

Within the Fleet DNA database, there are 435 total vehicles possessing conventional diesel engine powertrain architectures. These vehicles were recorded or provided from 24 fleets at 15 distinct locations across the United States. One issue existing in the database is that the vocations are mainly self-reported by the collecting agency making the vocational descriptions somewhat subjective. As a result, there were 25 different vocations in the database originally, which raised some challenges for the appropriate classification of vehicles by vocation. Therefore, consolidation of vehicle vocations was performed based on several objective metrics such as daily mean trip length, daily average vehicle speed, daily starts per day, and average soak time duration. Through this process, the 435 vehicles were separated into eight simplified, but representative, vocational categories, as shown in Table 1.

Table 1. Population of Conventional Diesel-Powered Heavy-Duty Vehicles in Fleet DNA

\begin{tabular}{|l|l|l|}
\hline Vocation & Vehicles in Fleet DNA & Days of Data \\
\hline Line Haul & 190 & 30,015 \\
\hline Local Delivery & 68 & 3,553 \\
\hline Drayage & 57 & 1,258 \\
\hline Vocation & 41 & 6,719 \\
\hline Refuse Pickup & 32 & 382 \\
\hline Parcel Delivery & 30 & 460 \\
\hline Transit & 13 & 210 \\
\hline School Bus & 4 & 37 \\
\hline Total & 435 & 42,634 \\
\hline
\end{tabular}


The first four groups listed in Table 1, namely Line Haul, Local Delivery, Drayage, and Vocation, include multiple vocational categories as originally reported. The corresponding vocational makeups for these groups are shown in Table 2 and Table 3 respectively.

Table 2. Vocational Makeup for Line Haul and Vocation Categories

\begin{tabular}{|l|l|l|l|}
\hline Line Haul & Number of vehicles & Vocation & Number of vehicles \\
\hline Line Haul & 74 & Snow Plow & 11 \\
\hline Freight & 22 & Utility & 20 \\
\hline Tanker & 25 & Towing & 1 \\
\hline Refrigerated Truck & 6 & Shredder & 1 \\
\hline Long Haul & 11 & Dump Truck & 4 \\
\hline Regional Haul & 52 & Propane Tanker & 1 \\
\hline & & Concrete & 3 \\
\hline Total & 190 & Total & 41 \\
\hline
\end{tabular}

It should be noted that the objective metrics used in the group consolidations are considered with higher priority compared to the vocational description from the original data collection effort. For example, in Table 2, a fleet labeled as "Regional Haul" in the original vocational description was included in the consolidate category of Line Haul since its daily average trip distance is above 400 miles, which is much higher than the value of vehicles in the Local Delivery category. In addition, the Propane Tanker is grouped into the Vocation category because its daily average trip distance, average soak time duration, and cold-start fraction are much closer to the other vehicles in the Vocation group.

Table 3. Vocational Makeup for Local Delivery and Drayage Categories

\begin{tabular}{|l|l|l|l|}
\hline Local Delivery & Number of vehicles & Drayage & Number of vehicles \\
\hline Local Delivery & 4 & Drayage & 29 \\
\hline Warehouse Delivery & 9 & Transfer Truck & 28 \\
\hline Linen Delivery & 17 & & \\
\hline Food Delivery & 31 & & \\
\hline Beverage Delivery & 7 & & $\mathbf{5 7}$ \\
\hline Total & $\mathbf{6 8}$ & Total & \\
\hline
\end{tabular}

Each vocational group is further divided by state to indicate the diversity of regional information included in the Fleet DNA dataset. Table 4 lists the geographic distribution of all the vehicles in each vocation. One thing to note here is that the informed state in Line Haul category reflects the depot state of each vehicle. However, since the Line Haul truck typically travels for a long distance across several states in the nation, the related operation data may also include regional information from the other states. 
Table 4. Geographic Distribution of Data by Vehicle Vocations

\begin{tabular}{|l|r|}
\multicolumn{2}{|c}{ Line Haul } \\
\hline State & \# of vehicles \\
\hline CA & 16 \\
\hline CO & 15 \\
\hline FL & 3 \\
\hline GA & 3 \\
\hline IL & 4 \\
\hline MD & 1 \\
\hline MT & 5 \\
\hline NJ & 1 \\
\hline NY & 1 \\
\hline OH & 26 \\
\hline OR & 10 \\
\hline TX & 34 \\
\hline WA & 9 \\
\hline Unknown & 62 \\
\hline Total & 190 \\
\hline
\end{tabular}

\begin{tabular}{|l|r|}
\multicolumn{2}{|c}{ Local Delivery } \\
\hline State & \# of vehicles \\
\hline CA & 35 \\
\hline CO & 20 \\
\hline TX & 1 \\
\hline WA & 11 \\
\hline WI & 1 \\
\hline Total & 68 \\
\hline
\end{tabular}

\begin{tabular}{|l|r|}
\multicolumn{2}{|c}{ Parcel Delivery } \\
\hline State & \# of vehicles \\
\hline CA & 15 \\
\hline MN & 4 \\
\hline OH & 11 \\
\hline Total & 30 \\
\hline
\end{tabular}

\begin{tabular}{|c|c|}
\hline \multicolumn{2}{|c|}{ Drayage } \\
\hline State & \# of vehicles \\
\hline CA & 57 \\
\hline Total & 57 \\
\hline \multicolumn{2}{|c|}{ Transit } \\
\hline State & \# of vehicles \\
\hline $\mathrm{CO}$ & 4 \\
\hline $\mathrm{MN}$ & $s$ \\
\hline Total & 13 \\
\hline \multicolumn{2}{|c|}{ School Bus } \\
\hline State & \# of vehicles \\
\hline CA & 4 \\
\hline Total & 4 \\
\hline
\end{tabular}

\begin{tabular}{|l|r|}
\multicolumn{2}{|c}{ Vocation } \\
\hline State & \# of vehicles \\
\hline CA & 20 \\
\hline IN & 9 \\
\hline MD & 4 \\
\hline TX & 3 \\
\hline Unknown & 5 \\
\hline Total & 41 \\
\hline
\end{tabular}

\section{Refuse}

\begin{tabular}{|l|r|}
\hline State & \# of vehicles \\
\hline CO & 7 \\
\hline FL & 6 \\
\hline IN & 13 \\
\hline OH & 4 \\
\hline Unknown & 2 \\
\hline Total & 32 \\
\hline
\end{tabular}

\subsubsection{CE-CERT Data Base}

The CE-CERT database was compiled by CE-CERT researchers in 2017. This dataset provides an accurate characterization of current heavy-duty vehicle activity in California aimed to enlighten the regional emission inventory for on-road heavy-duty mobile sources. This database includes vehicle and engine activity data from 90 heavy-duty vehicles in 23 fleets that make up 19 different groups defined by a combination of vocational use, GVWR, and geographic region [7]. The final vehicle samples in the CE-CERT database are summarized in Table 5. 
Table 5. Final Vehicles Sample in CE-CERT Database [7]

\begin{tabular}{|c|c|c|c|c|}
\hline No. & Vocation & No. of Vehicles & No. of Fleets & Region \\
\hline $1 \mathrm{a}$ & Line Haul - out of state & 3 & 1 & North California \\
\hline $1 b$ & Line Haul - in state & 3 & 1 & South California \\
\hline $2 a$ & Drayage & 1 & 1 & North California \\
\hline $2 b$ & Drayage & 5 & 1 & South California \\
\hline 3 & Agricultural & 8 & 1 & South California \\
\hline $4 a$ & Construction & 6 & 3 & Both \\
\hline $4 b$ & Cement Mixers & 5 & 2 & Both \\
\hline $5 a$ & Food Distribution & 5 & 1 & South California \\
\hline $5 b$ & Beverage Distribution & 6 & 1 & South California \\
\hline $5 c$ & Local Moving & 1 & 1 & South California \\
\hline 6 & Airport Shuttle & 5 & 1 & North California \\
\hline 7 & Refuse & 6 & 1 & North California \\
\hline $8 a$ & Urban buses & 6 & 1 & North California \\
\hline $8 b$ & Express Buses & 5 & 1 & South California \\
\hline $9 a$ & Freeway Work & 5 & 1 & Both \\
\hline $9 b$ & Sweeping & 5 & 1 & Both \\
\hline $9 c$ & Municipal Work & 3 & 1 & South California \\
\hline $9 d$ & Towing & 7 & 2 & Both \\
\hline \multirow[t]{2}{*}{10} & Utility Repair & 5 & 1 & North California \\
\hline & Total & 90 & 23 & \\
\hline
\end{tabular}

A detailed investigation was conducted on these vehicles in terms of the fuel and the related powertrain architecture. As a result, 5 vehicles in Urban buses category (NO.8a category) and 6 vehicles in the Express Buses category (No.8b category) were excluded for the study since the former one used $\mathrm{CNG}$ as the fuel and the latter one included diesel-powered hybrid powertrain architectures. In order to keep a consistent definition of vocational groups in this study, the same eight consolidated vocational categories used for the Fleet DNA database were applied in the CE-CERT dataset. This was based on the vocational description in the CE-CERT database and the final population of conventional diesel-powered vehicles in CE-CERT database, and are listed in the following Table 6. 
Table 6. Population of Conventional Diesel-Powered Heavy-Duty Vehicles in CE-CERT Database

\begin{tabular}{|l|l|l|}
\hline Vocation & Vehicles in CE-CERT data & Days of Data \\
\hline Line Haul & 6 & 318 \\
\hline Local Delivery & 12 & 619 \\
\hline Drayage & 25 & 796 \\
\hline Vocation & 25 & 1,310 \\
\hline Refuse Pickup & 6 & 373 \\
\hline Parcel Delivery & 0 & 0 \\
\hline Transit & 5 & 660 \\
\hline School Bus & 0 & 0 \\
\hline Total & 79 & 4,076 \\
\hline
\end{tabular}

As can be seen in Table 6, there are no Parcel Delivery or School Buses in the CE-CERT database. The detailed makeups of vocations are shown in Table 7 and Table 8.

Table 7. Vocational Makeup for Vocation, Drayage, and Local Delivery in the CE-CERT Database

\begin{tabular}{|l|l|l|l|l|l|}
\hline Vocation & Vehicles & Drayage & Vehicles & Local Delivery & Vehicles \\
\hline Freeway Work & 5 & Drayage & 6 & Food Distribution & 5 \\
\hline Sweeping & 5 & Agriculture & 8 & Beverage Distribution & 6 \\
\hline Municipal Work & 3 & Construction & 6 & Local Moving & 1 \\
\hline Towing & 7 & Cement Mixers & 5 & & \\
\hline Utility Repair & 5 & & & & 12 \\
\hline Total & $\mathbf{2 5}$ & Total & $\mathbf{2 5}$ & Total & 12 \\
\hline
\end{tabular}

Table 8. Vocation Makeup for Refuse Pickup, Transit, and Line Haul in the CE-CERT Database

\begin{tabular}{|l|l|l|l|l|l|}
\hline Refuse Pickup & Vehicles & Transit & Vehicles & Line Haul & Vehicles \\
\hline Refuse & 6 & Airport Shuttle & 5 & Line Haul - out of state & 3 \\
\hline & & & & Line Haul - in state & 3 \\
\hline Total & $\mathbf{6}$ & Total & $\mathbf{5}$ & Total & $\mathbf{6}$ \\
\hline
\end{tabular}

\subsubsection{Combination of Two Databases}

Since the vehicles in the two databases were separated into the same vocational groups, it was possible to combine them together and form the final data set that was used for this project. The general information of these combined databases, including the total number of vehicles and the total vehicles days in each vocational group, is listed in Table 9. 
Table 9. Population of All the Vehicles in the Combination of Two Databases

\begin{tabular}{|l|l|l|l|l|}
\hline Vocation & $\begin{array}{l}\text { Vehicles in } \\
\text { Fleet DNA }\end{array}$ & $\begin{array}{l}\text { Vehicles in CE- } \\
\text { CERT }\end{array}$ & Total Vehicles & Total Vehicles Days \\
\hline Line Haul & 190 & 6 & 196 & 30,333 \\
\hline Local Delivery & 68 & 12 & 80 & 4,172 \\
\hline Drayage & 57 & 25 & 82 & 2,054 \\
\hline Vocation & 41 & 25 & 66 & 8,029 \\
\hline Refuse Pickup & 32 & 6 & 38 & 755 \\
\hline Parcel Delivery & 30 & 0 & 30 & 460 \\
\hline Transit & 13 & 5 & 18 & 870 \\
\hline School Bus & 4 & 0 & 4 & 37 \\
\hline Total & 435 & $\mathbf{7 9}$ & $\mathbf{5 1 4}$ & $\mathbf{4 6 , 7 1 0}$ \\
\hline
\end{tabular}

\subsection{Methodology}

\subsubsection{Database Description}

Both databases include latitude, longitude, elevation, vehicle speed, and time data from the standard global positioning system (GPS) channels and other engine control unit (ECU) 1-Hz data broadcast over the vehicle Controller Area Network (CAN) bus per SAE J1939 standards. For this project, the following parameters were selected for subsequent analysis: vehicle speed, engine speed, time, engine coolant temperature, SCR inlet gases temperature, actual enginepercent torque, nominal friction - percent torque and engine referenced torque. Prior to calculation and preprocessing, the selected parameters were extracted from each vehicle day and combined as several single one-dimensional data arrays. As a result, the related parametric analyses were conducted on a daily basis or as an entire trip. The diagram of the Fleet DNA database file structure is shown in Figure 2, while the structure of the CE-CERT database is similar. 


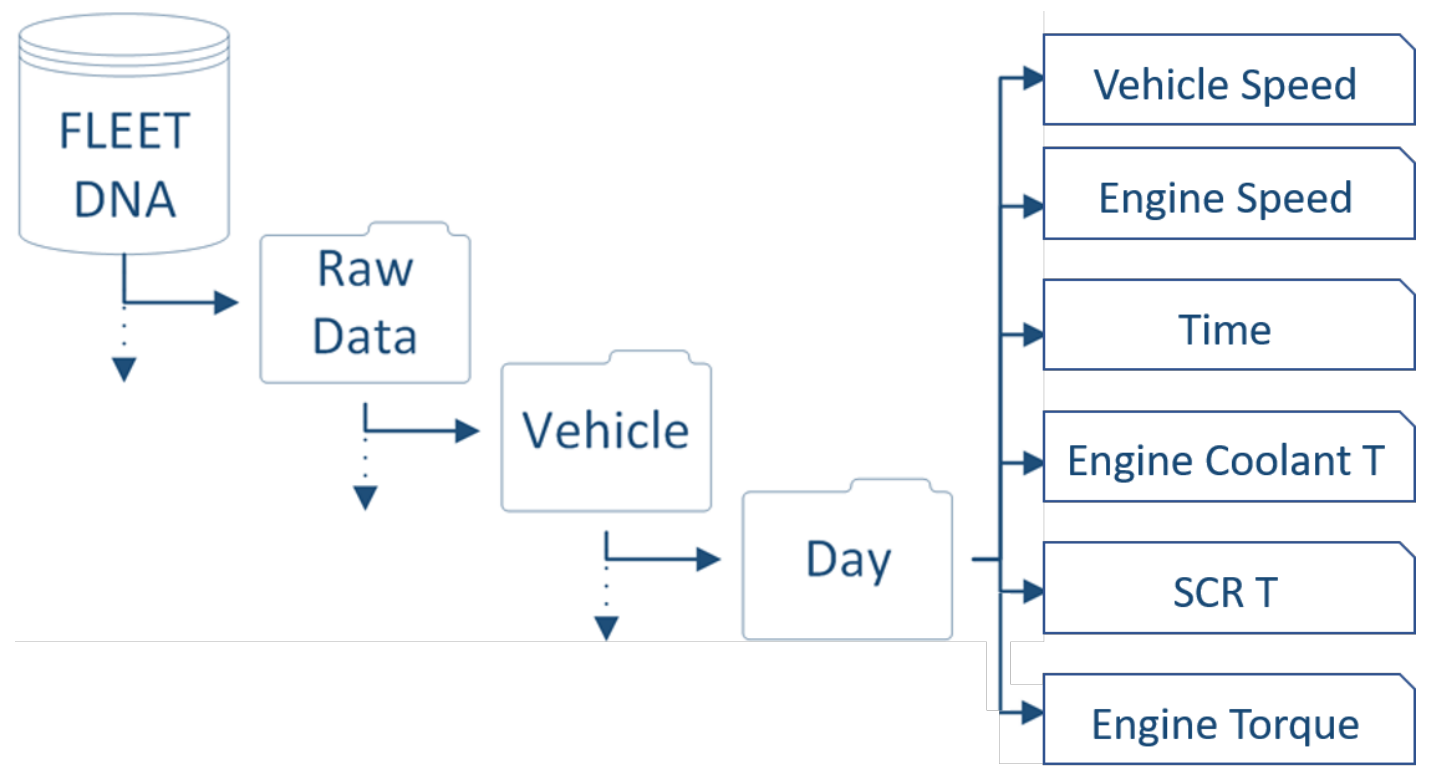

Figure 2. Diagram of Fleet DNA Database File Structure

\subsubsection{Preprocessing}

An important parameter for this study was the engine speed (revolutions per minute (rpm)). Engine speeds greater than zero indicated that the vehicle engine was running. In this analysis, vehicle starts were calculated by identifying the transition from an engine speed of zero to greater than zero, vehicle soak time is defined as the length of time between engine off (engine speed of zero) and the next time the engine is started (engine speed greater than zero). The accurate characterization of vehicle start performance depends on accurate reporting of the engine speed data as well as the other parameters, therefore data preprocessing was performed to eliminate erroneous information.

The first preprocessing step was to filter out parameter values that were unrealistic. Some vehicle CAN bus signals will report meaningless default values (usually this is the "FF" or highest value in hex notation) prior to powering down, which can cause the engine speed signal to falsely exceed 8,000 rpm after the engine shuts off and could then be mischaracterized as a new start. In order to account for this issue, a preprocessing filter was developed to remove data points with engine speeds greater than 7,000 rpm. Similarly, other preprocessing filters were also applied to remove unrealistic and errant data points such as coolant temperature lower than $-30^{\circ} \mathrm{C}$ and higher than $150^{\circ} \mathrm{C}$, vehicle speed higher than 150 mile per hour (mph), actual engine torque percentage larger than $120 \%$, nominal frictional torque percentage larger than $130 \%$ and less than $-125 \%$, and reference engine torque larger than 10,000 N.m.

Another common vehicle data characteristic is "jumps" or "gaps" in timestamps between data points. It is reasonable to expect that a vehicle may slow to zero, shut down the engine and soak for long periods, such that the next timestamp recorded is an hour or more from the previous timestamp. Alternatively, the GPS may cause a gap in time (generally an hour) when it updates the data logger's clock as the vehicle crosses a time zone, or a gap in time may be generated by the data logger if the recording is paused while saving a log file to memory. Furthermore, if the logger was taken off a vehicle on the West Coast and placed on a vehicle on the East Coast, it is 
possible for the timestamp to jump three hours at the beginning of logging once the GPS updates the internal clock to local time. These are trivial instances in which there is a logical explanation for a gap in time with near-contiguous data that are valuable to keep. However, in some instances, a data logger will shut off prior to recording a zero for engine speed, and it is unclear from the data if the engine turned off. As a result, a corresponding soak time and start may be inaccurately categorized or missed altogether.

The next step in the data preprocessing was to use a gap-filling algorithm to try and infer engine stops and starts that may have been missed in these non-trivial events, discussed above, by identifying "leaps" or "gaps" in timestamp from one data point to the next. If the algorithm finds a time gap larger than a predetermined value of gap length, a zero is added to the start and end of the engine speed data to trigger a shutoff and start determination. To prevent counting trivial time gaps as instances where the engine has shut off, 20 minutes was selected as an appropriate length of time, or "gap length," beyond which we assume an engine-off event has occurred.

In addition, a specific zero-speed drift filter was developed and employed in the data preprocessing. Zero-speed drift appears when the engine is stopped for a prolonged period while the vehicle key is still on. During such an extended-duration soak time, the installed data logger may record a very small engine speed due to the sudden signal jump. Such a small fluctuation on engine speed, if not removed, would incorrectly be considered as an engine start and trigger the record of the corresponding coolant temperature for subsequent analysis. To remove the zerospeed drift, the designed filter examined the value of each individual engine speed point in the data set in relation to its nearest neighbor. If a given engine speed recorded value was non-zero and the neighboring points on each side are both zero, the non-zero engine speed point is replaced by zero to eliminate the zero-speed drift. This simple filter improved the continuity of the raw data and the characterization of the start performance significantly.

Finally, the first and last days of data were eliminated to avoid counting incomplete or unrepresentative operation when the data logger is being installed or removed. The summary of the preprocessing steps was as follows:

1. Filter out values that were unrealistic

2. Fill time gaps greater than 20 minutes with an engine start

3. Apply the zero-speed drift filter

4. Remove the first and last days of data

\subsubsection{Calculations}

In order to clearly quantify the start performance of the medium- and heavy-duty vehicles, NREL and MECA first determined the definition of cold-, warm-, and hot-start based on the engine coolant temperature information. Second, NREL calculated the fraction of engines' operational times spent in different coolant temperature ranges segmented by vocation. In addition, the distributions of the number of cold-, warm-, and hot-start events per day, soak time duration before each start, warm-up duration from the cold- and warm-starts, as well as the related analyses with respect to SCR temperature, were also conducted with the aim to provide a more detailed assessment of cold-start operations. 
It is worth noting that all the statistical analyses of the above parameters were conducted across all vehicles within the same vocational group rather than average each parameter calculated from individual vehicles. The latter approach may have created unrealistically high values for vehicles that had very little operational time since vehicles with low-operational time were given equal weight with the other vehicles. The following sections will describe the analysis approach in more detail.

\subsubsection{Cold-, warm-, and hot-start definition}

To date, there is no clear definition in the literature to categorize the cold-, warm-, and hot-start using engine coolant temperature. For certification purposes, the cold start is achieved by soaking the engine/vehicle for 12 hours or longer and thereby the initial coolant temperature assumed to be the ambient temperature, nominally $20^{\circ} \mathrm{C}$. After discussions with MECA and Southwest Research Institute (SwRI), it was decided that in this study, appropriate engine coolant temperature ranges for cold-, warm-, and hot-start would be lower than $40^{\circ} \mathrm{C}$, higher than $40^{\circ} \mathrm{C}$ but lower than $75^{\circ} \mathrm{C}$, and higher than $75^{\circ} \mathrm{C}$, respectively, as summarized in Table 10 .

\section{Table 10. Engine Coolant Temperature Ranges Indicating Different Engine Starts}

\begin{tabular}{|c|c|}
\hline Engine Start & Coolant Temperature Range \\
\hline Cold & T_coolant $\leq 40^{\circ} \mathrm{C}$ \\
\hline Warm & $40^{\circ} \mathrm{C}<\mathrm{T}_{-}$coolant $\leq 75^{\circ} \mathrm{C}$ \\
\hline Hot & $75^{\circ} \mathrm{C}<$ T_coolant \\
\hline
\end{tabular}

These categories were chosen based on observations of the in-use data. That is, typical cold-start conditions are below $40^{\circ} \mathrm{C}$, warm-up conditions are observed to be transient between $40^{\circ} \mathrm{C}$ and $75^{\circ} \mathrm{C}$ and the coolant temperature, typically stabilized around $75^{\circ} \mathrm{C}-80^{\circ} \mathrm{C}$, defined as hot running conditions with the open thermostat. As an example, Figure 3 shows the data recorded from inuse vehicle operations, showing the cold-, warm-, and hot-start conditions for a Transfer Truck with 10.8L Cummins ISM-384 diesel engine. From the top to the bottom, it shows the time series of engine speed, coolant temperature, and vehicles speed respectively. Specifically, Figure 3(a) represents the cold-start condition and Figure 3(b) shows the warm- and hot-start conditions. As can be seen in Figure 3(a), when engine speed increases from 0 to $750 \mathrm{rpm}$, the coolant temperature is still ambient at about $30^{\circ} \mathrm{C}$. As such, this type of engine start is defined as a coldstart (blue arrow). In Figure 3(b), the first engine-start happens when coolant temperature is approximately $50^{\circ} \mathrm{C}$. Thus, this start is defined as a warm-start (yellow arrow). After 10 minutes of operation, the engine stops and soaks for another 17 minutes. When it starts again (red arrow), the coolant temperature is near $80^{\circ} \mathrm{C}$ and the start is considered as a hot one since the coolant temperature is stabilized over $75^{\circ} \mathrm{C}$. The above method was used to categorize all the engine starts in the databases. 

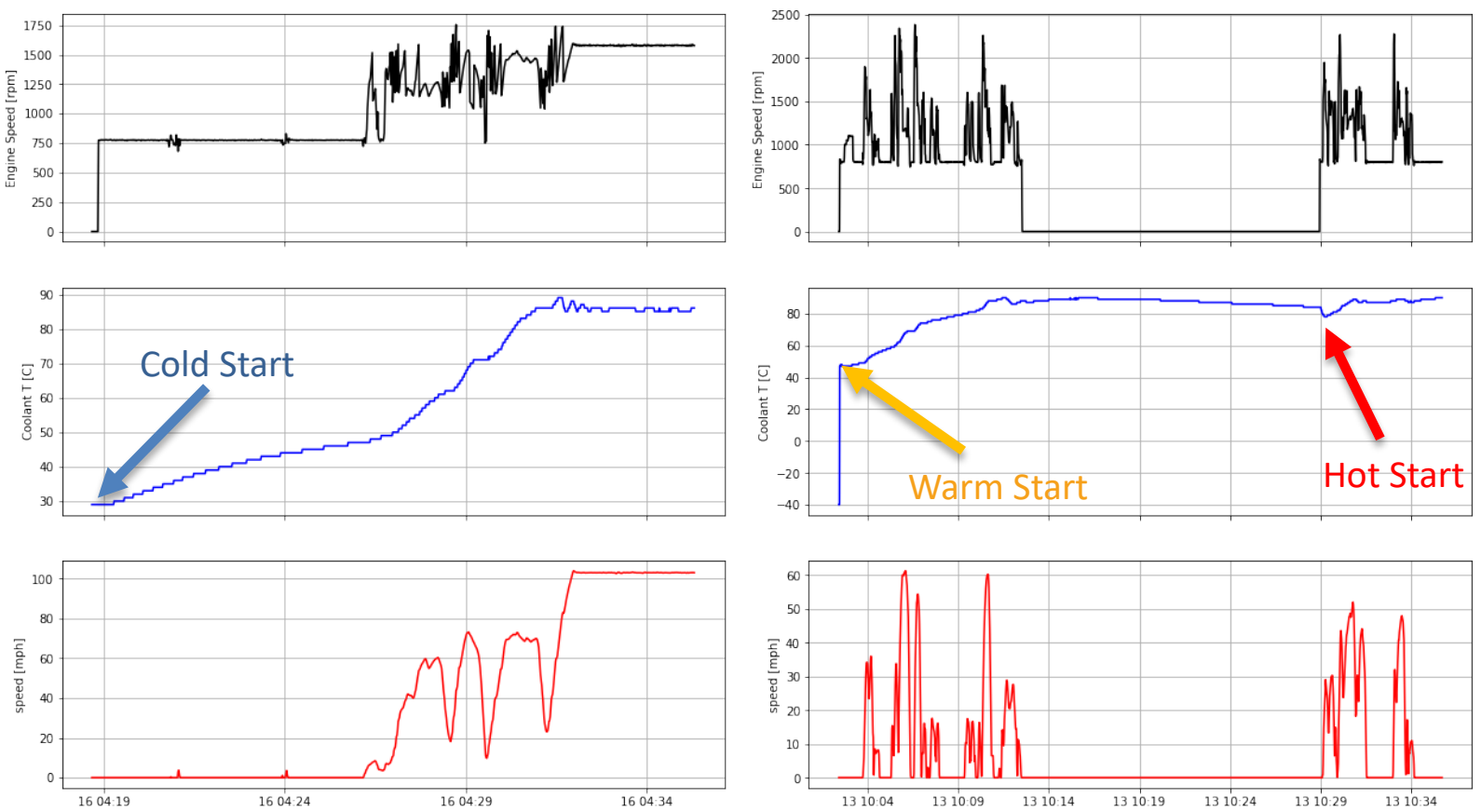

(a)

(b)

Figure 3. Example Data Used to Identify (a) Cold-Start and (b) Warm- and Hot-Start Conditions

\subsubsection{Cold and warm operation}

One primary objective of this project was to quantify the fraction of engine operational time spent at cold- and warm-engine coolant temperature ranges. Given Table 10, showing different coolant temperature ranges, the corresponding percentages of cold and warm operation were derived. Figure 4 shows the schematics for the cold and warm operation definition using the same time series data in Figure 3. As can be seen in Figure 4(a), the cold operation represents the duration while the engine is operating and the coolant temperature is less than $40^{\circ} \mathrm{C}$ (within the blue dashed lines). 


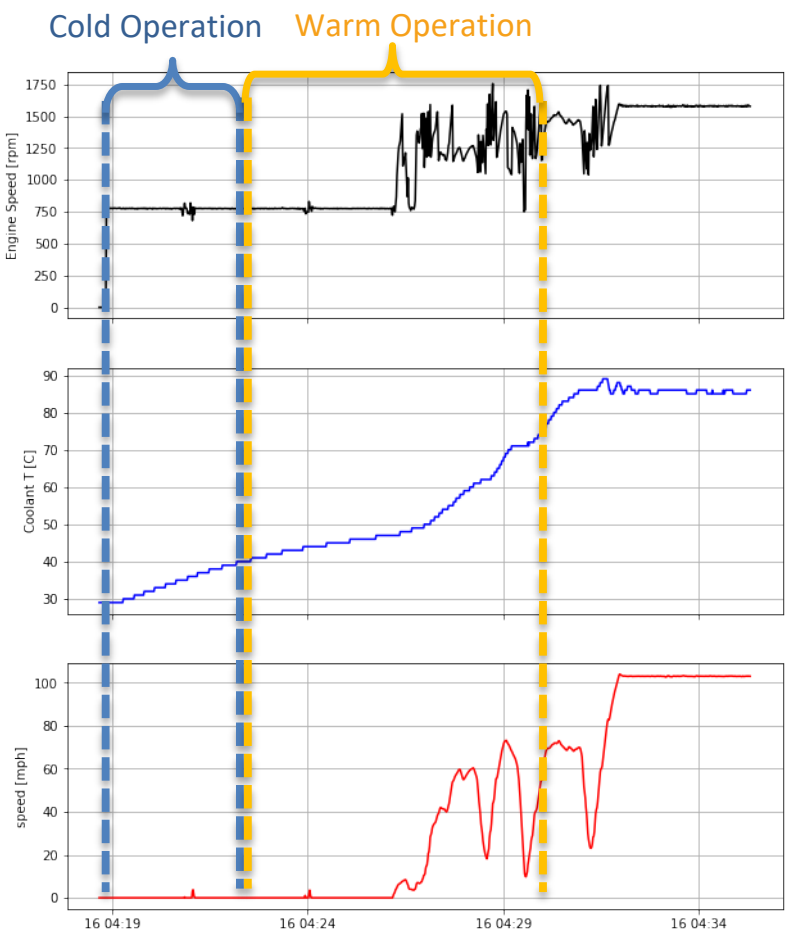

(a)

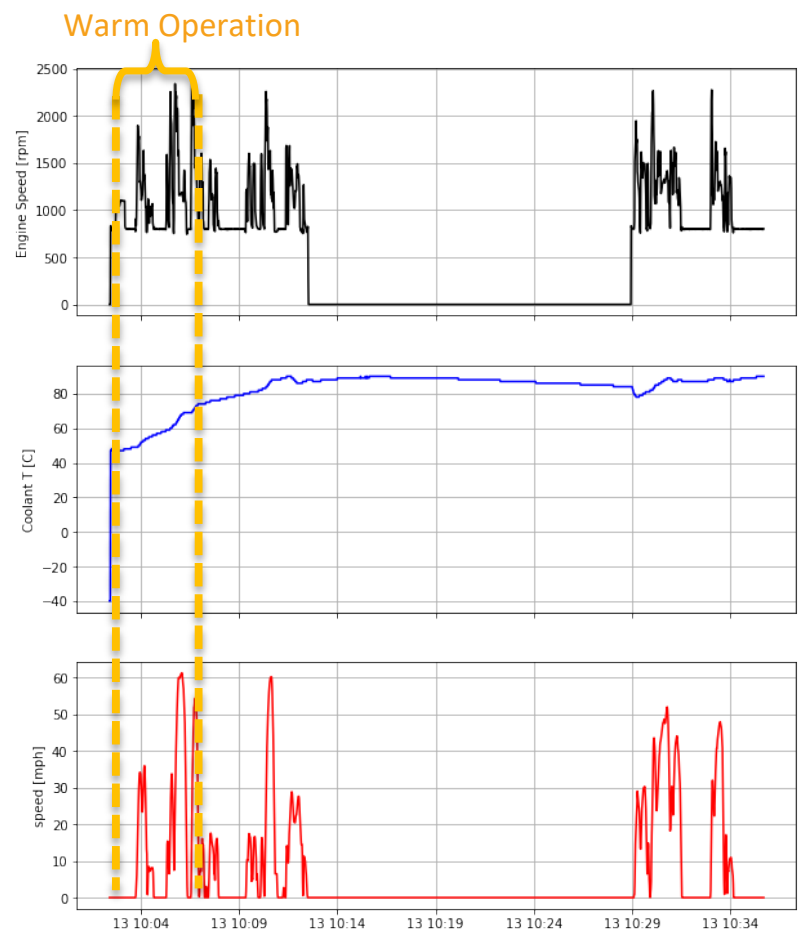

(b)

Figure 4. Definition of Cold and Warm Operations

Given such a definition, there must be a cold operation duration after each cold-start.

Furthermore, we can achieve the percentage of cold operation over total operating time for different vocational groups using Equation 1.

$$
P_{-} C O_{v}=\frac{\sum t_{-} C O_{v, i}}{\sum t_{-} E O_{v, i}}
$$

where $v$ represents the index for each vocational group, $i$ is the individual vehicle IDs in vocational group $v, P_{-} C O_{v}$ is the fraction of the cold operation in vocation group $v, t_{-} C O_{v, i}$ is the cold operation time for vehicle $i$ in vocational group $v$, and $t E E O_{v, i}$ is the total engine operational time for vehicle $i$ in vocational group $v$.

Similarly, the warm operation reflects the duration while the engine is operating and the coolant temperature is within $40^{\circ} \mathrm{C}$ to $75^{\circ} \mathrm{C}$ (as shown in Figure 4 within the yellow dashed lines). Such operation will exist after both cold-start and warm-start. The percentage of warm operation is defined by Equation 2.

$$
P_{-} W O_{v}=\frac{\sum t_{-} W O_{v, i}}{\sum t_{-} E O_{v, i}}
$$

where $v$ and $i$ are same indexes as in Equation 1, $P_{-} W O_{v}$ is the fraction of the warm operation in vocation group $v$, and $t_{-} W O_{v, i}$ is the warm operation time for vehicle $i$ in vocational group $v$.

Repeating Equation (1) and (2) for all the eight vocational groups in the databases, the distribution of cold and warm operational times segmented by vocations can be achieved. 


\subsubsection{Cold, warm and hot start per day}

For the individual vehicle $i$ in vocational group $v$, the total number of starts on day $d$, Total_start ${ }_{v, i, d}$, can be determined by checking the engine speed data and identifying instances when the engine rpm transitions from zero to non-zero. Afterward, the cold-, warm-, and hotstart for this specific vehicle day can be obtained by employing the criteria in Table 10, notating them as Cold_start ${ }_{v, i, d}$,Warm_start Wri,d $_{\text {, }}$ and Hot_start ${ }_{v, i, d}$ respectively. After deriving these parameters for all the vehicle days in each vocational group, the distribution of cold-, warm-, and hot-start per day segmented by vocation was determined.

Beyond the detailed distribution, some high-level information related to engine-starts were also determined, including the average cold-, warm-, and hot-start per day and the fraction of cold-, warm-, and hot-start per day for each vocational group. To achieve the average information of starts per day, the sum of the cold-, warm-, and hot-starts taking place in the specific vehicle days, were divided by the sum of the vehicle days respectively, as shown in Equation 3, 4, and 5.

$$
\begin{aligned}
A v e_{-} \text {cold_start } & =\frac{\sum_{i} \sum_{d} \text { Cold_start }_{v, i, d}}{\sum_{i} \sum_{d} 1} \\
A v e_{-} \text {warm_start }_{v} & =\frac{\sum_{i} \sum_{d} \text { Warm_start }_{v, i, d}}{\sum_{i} \sum_{d} 1} \\
A v e_{-} \text {hot_start }_{v} & =\frac{\sum_{i} \sum_{d} \text { Hot }_{\text {start }} \text { sti,d }_{v}}{\sum_{i} \sum_{d} 1}
\end{aligned}
$$

where Ave_cold_start, Ave_warm_start, Ave_hot_start ${ }_{v}$ are average cold-, warm-, and hot-start per day in vocational group $v$ respectively.

To calculate the fraction of different starts per day, the total numbers of the cold-, warm-, and hot-starts taking place in the specific vehicle day were divided by the sum of the total starts in this day respectively, as shown in Equation 6, 7, and 8.

$$
\begin{gathered}
\text { Frac_cold_start }_{v}=\frac{\sum_{i} \sum_{d} \text { Cold_start }_{v, i, d}}{\sum_{i} \sum_{d} \text { Total_start }_{v, i, d}} \\
\text { Frac_warm_start }_{v}=\frac{\sum_{i} \sum_{d} \text { Warm_start }_{v, i, d}}{\sum_{i} \sum_{d} \text { Total_start }_{v, i, d}} \\
\text { Frac_hot_start }_{v}=\frac{\sum_{i} \sum_{d} \text { Hot_start }_{v, i, d}}{\sum_{i} \sum_{d} \text { Total_start }_{v, i, d}}
\end{gathered}
$$

where Frac_cold_start, Frac_warm_start, Frac_hot_start were fraction of cold-, warm-, and hot-start per day in vocational group $\bar{v}$ respectively.

\subsubsection{Soak time duration}

Vehicle soak time was defined as the period that begins when the engine stops and ends at the next engine start. This was calculated by taking the time difference between the time when the engine speed transitions from positive speed to zero and the time when engine speed transitions from zero to a positive one. This calculation can be shown in Equation 9. 


$$
t_{-} \operatorname{soak}_{n}=T i m e_{-} e n g i n e_{-} s t a r t_{n+1}-T i m e \_e n g i n e_{-} s t o p_{n}
$$

where $t_{-} s_{s} a k_{n}$ is the duration of the $n$th engine soak, Time_engine_start ${ }_{n+1}$ is the time instance when the $(n+1)$ th engine-start happens, and Time_engine_stop $n_{n}$ is the time instance when the $n$th engine-stop happens.

Since we do not know the time instance when the engine stops before the first engine-start for any given vehicle, the total number of soak duration data points is less than the total number of engine-starts by one, in each vocational group. It is also intuitive that the soak durations can be categorized based on the characterization of following engine-starts, (e.g.t_soak_cold, t_soak_warm, and t_soak_hot), representing the soak duration before the cold-, warm-, and hotstart respectively. Given all the soak durations for different engine-starts, the average soak duration can be achieved through Equation 10, 11, and 12.

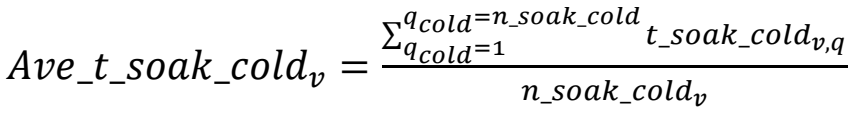

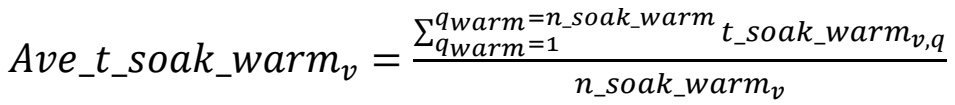

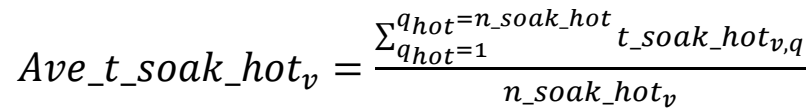

where Ave_t_soak_cold $v$, Ave_t_soak_warm $v_{v}$ Ave_t_soak_hot $v_{v}$ are the average soak duration before cold-, warm-, and hot-start in vocational group $v$ respectively. $n \_s o a k$ cold $v$, n_soak_warm,$n_{v}$ soak $_{-} h t_{v}$ are the number of soak duration before cold-, warm-, and hot-start for vocational group $v$. Therefore, Equation 13 holds:

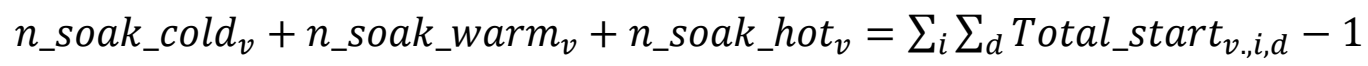

It is possible that some cold soak times are longer than two days since the vehicles do not always operate during the recording process. To avoid the bias on average number caused by such large numbers, any soak times longer than 3,000 minutes were excluded for the following analyses.

A detailed distribution of the soak duration has also been examined by binning $t \_s o a k \_c o l d v, q$, $t_{-}$soak_warm $_{v, q}$, and $t_{-}$soak_hot $_{v, q}$ into different bins which are defined in Table 11 . 
Table 11. Soak Time Operation Bins

\begin{tabular}{|c|c|}
\hline Bin Number & Soak Length Bin Description \\
\hline 1 & Soak Time $<6$ minutes \\
\hline 2 & 6 minutes $\leq$ Soak Time $<30$ minutes \\
\hline 3 & 30 minutes $\leq$ Soak Time $<60$ minutes \\
\hline 4 & 60 minutes $\leq$ Soak Time $<90$ minutes \\
\hline 5 & 90 minutes $\leq$ Soak Time $<120$ minutes \\
\hline 6 & 120 minutes $\leq$ Soak Time $<150$ minutes \\
\hline 7 & 150 minutes $\leq$ Soak Time $<180$ minutes \\
\hline 8 & 180 minutes $\leq$ Soak Time $<240$ minutes \\
\hline 9 & 240 minutes $\leq$ Soak Time $<360$ minutes \\
\hline 10 & 360 minutes $\leq$ Soak Time $<720$ minutes \\
\hline 11 & 720 minutes $\leq$ Soak Time \\
\hline
\end{tabular}

Then, the cold-, warm-, and hot-soak fractions were derived using Equation 14, 15, and 16.

$$
\begin{aligned}
& F r a c \_c o l d \_s o a k_{v, b}=\frac{n_{-} \operatorname{soak}_{-} \operatorname{cold}_{v, b}}{n_{-} \operatorname{soa}_{-} \operatorname{cold}_{v}}
\end{aligned}
$$

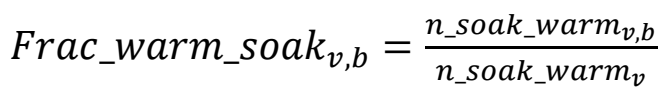

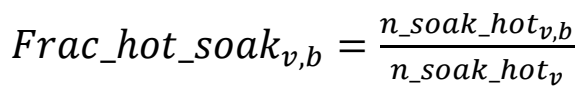

where Frac_cold_soak,b, Frac_warm_soak, $k_{v, b}$, and Frac_hot_soak, $k_{v, b}$ are fractions of cold-, warm-, and hot-soak duration in soak length bin $b$ and vocational group $v$ respectively. $n \_s o a k \_c o l d v, b, n \_s o a k \_w a r m v, b, n \_s o a k \_h_{v} t_{v, b}$ are the numbers of soak duration before cold-, warm-, and hot-start in soak length bin $b$ and vocational group $v$.

\subsubsection{Warm-up duration and average engine power during this period}

Besides the cold and warm operational time, it was also important to quantify how long it takes for the coolant temperature to rise from cold or warm to hot conditions. Thus, it was useful to define the warm-up duration, which begins at cold- or warm-starts and ends when the engine coolant temperature reaches $75^{\circ} \mathrm{C}$, indicating the engine is hot. Figure 5 shows the schematics to define the warm-up duration from cold-start and warm-start respectively using two in-use examples. 


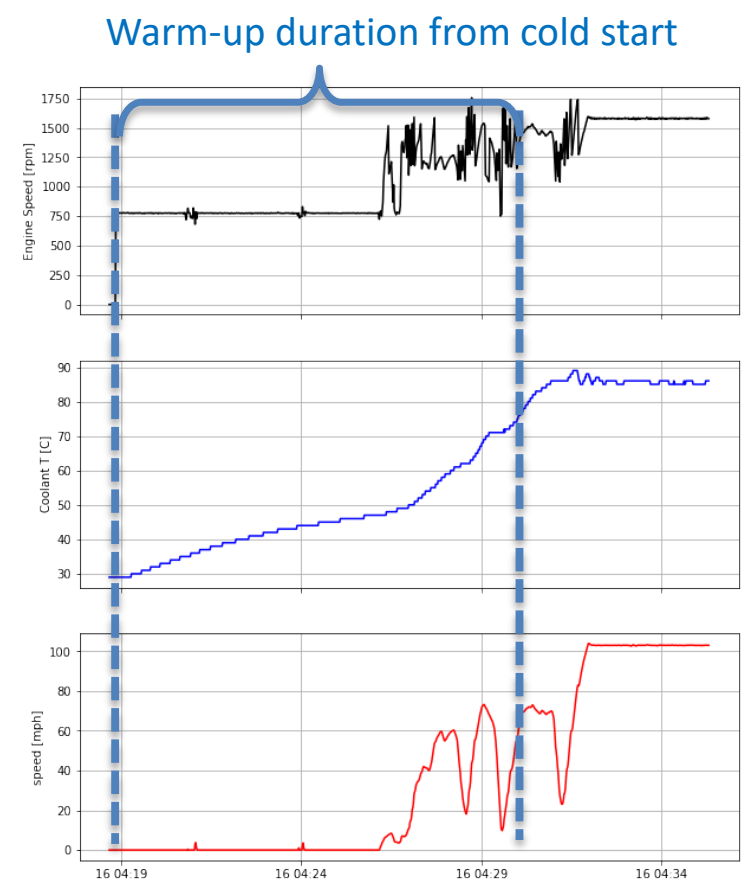

(a)
Warm-up duration from warm start

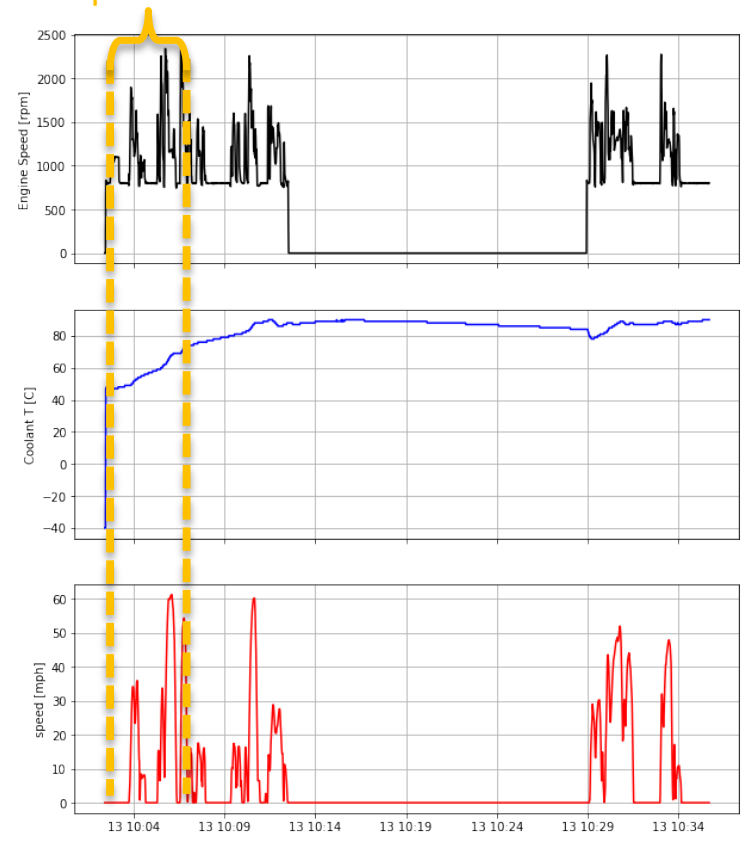

(b)

Figure 5. Definition of Warm-Up Duration from (a) Cold-Start and (b) Warm-Start

As can be seen in Figure 5, the warm-up duration can be classified into two groups based on the characterization of the engine start: 1. warm-up from cold-start and 2. warm-up from warm-start. Typically, the warm-up duration from warm-start will be relatively shorter compared to coldstart conditions. Statistical analysis for all the warm-up durations from cold- and warm-starts in each vocational group was conducted and will be presented in the following sections.

In addition, the warm-up duration is also affected by driving behavior. For example, if the driver prefers or is required to idle the engine for a while before actually moving the vehicle (as shown in Figure 5(a)), the corresponding warm-up duration will be longer than the time when the driver starts the engine and drives away immediately. In order to examine the relationship between the warm-up duration and the real-world driving behavior, the time-averaged engine output power during each warm-up duration was derived. Since the derivation of this term is identical for each warm-up duration from cold- or warm-start, only one equation (Equation 17) is provided to show the calculation process.

$$
\text { Power }=\frac{\sum_{d t=1}^{d t=t_{1} w u} P_{d t}}{t_{-} w u}
$$

where Power is the time-averaged power along the warm-up duration. $t_{-} w u$ is the entire duration of the warm-up process, $P_{d t}$ is the instantaneous engine output power at time instant $d t$ during the warm-up duration. If there are total $n_{\text {cold }}$ times cold-starts and $n_{\text {warm }}$ times warm-starts in vocational group v, then Equation (17) $n_{\text {cold }}+n_{\text {warm }}$ is repeated to achieve all the timely-averaged engine output power for each warm-up duration from cold- and warm-starts.

The calculation of the $P_{d t}$ is achieved through Equation (18) by given instantaneous engine speed $W_{-} E n g_{d t}$, percentage of actual torque $P \_a c t_{d t}$, percentage of frictional torque $P \_$fri $i_{d t}$, and 
reference of engine torque $R e f_{-} T$. It is worth noting that $W_{-} E n g_{d t}, P_{-} a c t_{d t}$, and $P \_$fri $i_{d t}$ will be changed at different time instant, but Ref_T is kept as a constant for each vehicle.

$$
P_{d t}=W_{-} E n g_{v, d t} \times \frac{2 \pi}{60} \times\left(P_{-} a c t_{v, d t}-P_{-} f r i_{v, d t}\right) \times R e f_{-} T
$$

\subsubsection{Temperature of exhaust gases entering SCR system}

Vehicle start and activity patterns have significant implication for heavy-duty vehicles that employ SCR technology to meet current $\mathrm{NO}_{\mathrm{x}}$ emission standards. Typically, SCR inlet temperatures need to be at least $200^{\circ} \mathrm{C}$ before significant $\mathrm{NO}_{\mathrm{x}}$ reduction is achieved [7], but there are operational periods while this temperature requirement may not be met, such as right after engine start and/or during low load operations experienced when the engine is idling or when the vehicle is moving slowly on flat terrain. Due to differences in thermal capacity of the engine coolant system and SCR system, it is also possible that the engine coolant temperature is not an appropriate surrogate for defining cold operation as it relates to emissions impacts. That is, there are conditions where the coolant temperature will be at hot stabilized conditions (i.e. $>75^{\circ} \mathrm{C}$ ), but the SCR system temperature will not be adequate for optimal control of NOx emissions (i.e. $<200^{\circ} \mathrm{C}$ ).
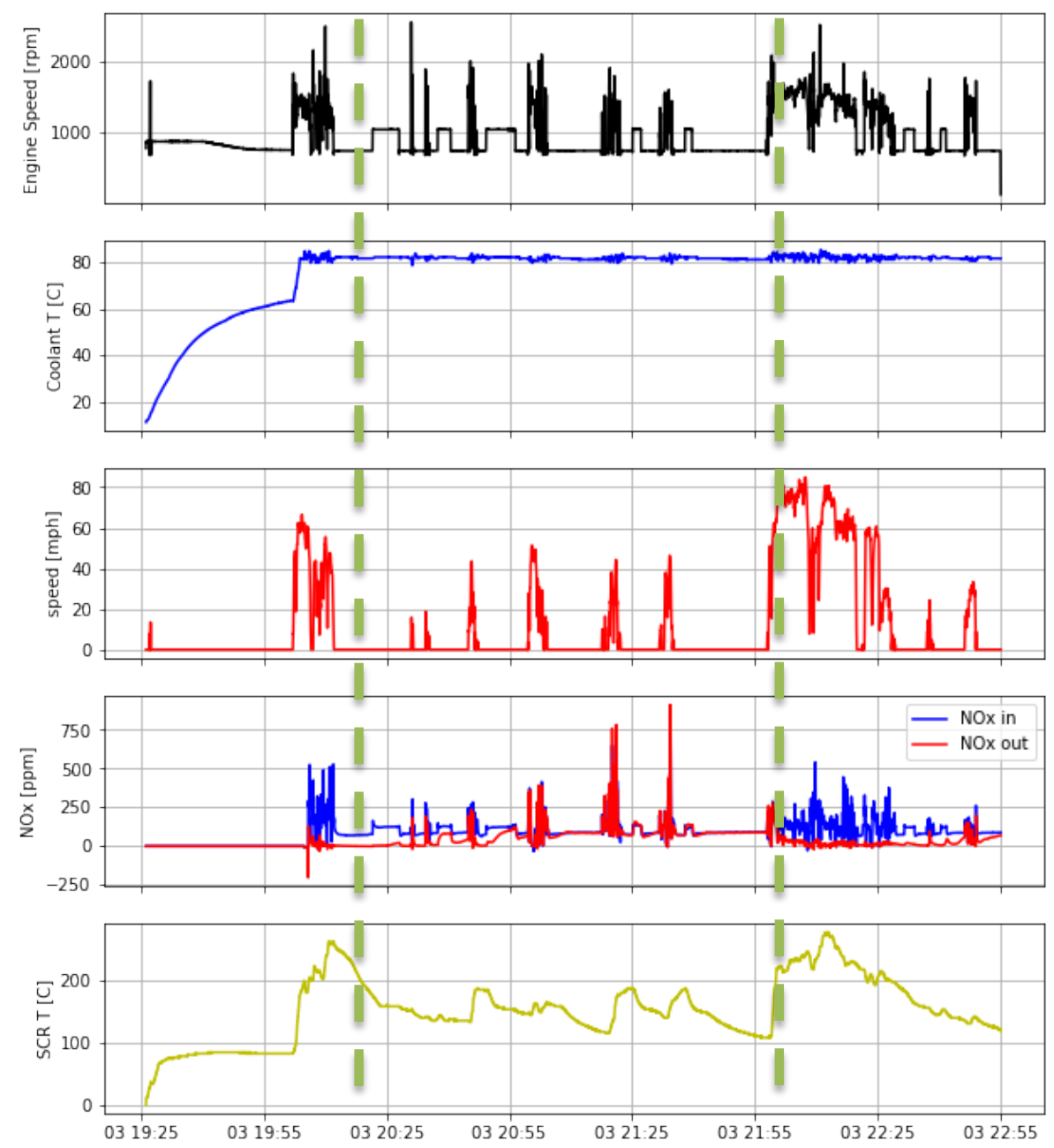

Figure 6. Specific Data Profiles of a Heavy-Duty Vehicles After a Cold-Start 
For example, Figure 6 shows a specific data profile during a typical cold-start from a heavy-duty vehicle. From the top to the bottom, Figure 6 describes engine speed, engine coolant temperature, vehicle speed, NOx emission before the SCR system (i.e. engine out NOx), NOx emission after the SCR system (i.e. tailpipe NOx), and temperature of exhaust gases entering the SCR system respectively (SCR Temperature). Even during the period which the engine coolant temperature is sustained above $80^{\circ} \mathrm{C}$ (shown between the green dashed lines in Figure 6), the SCR temperature can still be fluctuating from $120^{\circ} \mathrm{C}$ to $200^{\circ} \mathrm{C}$, where SCR conversion efficiency is reduced or urea injection is not occurring. From Figure 6, it is also clear that the SCR temperature decreases when the engine is idling while the coolant temperature holds consistently near $80^{\circ} \mathrm{C}$.

Enlightened by this observation, NREL also characterized the start performance of heavy-duty vehicles based on the SCR temperature and examined the difference between the analyses using both the SCR temperature and engine coolant temperature as the criterion to define cold, warm, and hot operation. It should be noted that in both the Fleet DNA and CE-CERT data sets, the sample sizes of vehicles broadcasting the SCR information are limited. For instance, among all the 435 vehicles in Fleet DNA, there are only 110 vehicles satisfying the requirement for SCR analysis. Thus, the corresponding SCR analyses were conducted as the final investigation.

The first step for the SCR analysis was to identify the cold-, warm-, and hot-starts from this perspective. Figure 7 shows scatter points representing the temperature of inlet gases into the SCR system and engine coolant temperature at each engine-start for vehicles in the Line Haul application. Similar figures for other vocational groups are listed in Appendix A.

In Figure 7, each point indicates the instantaneous engine coolant temperature and the corresponding SCR temperature at each engine-start event. The three colored boxes in the background show the cold-, warm-, and hot-zone as defined by the engine coolant temperature. The blue and red dashed lines reflect the SCR temperature at $60^{\circ} \mathrm{C}$ and $200^{\circ} \mathrm{C}$ respectively. These two SCR temperature setpoints were chosen based on general SCR conversion performance and known urea dosing limits and agreed upon after a joint discussion among NREL, MECA, and SwRI [7]. As can be seen, almost all the points are distributed across five zones, namely cold zone, warm-cold zone, warm zone, hot-warm zone, and hot zone, identified by the three colored boxes and the two dashed lines.

Based on Figure 7, one immediate concern was related to engine-starts in the hot-warm zone. Previously, they were defined as hot-starts based on coolant temperature. However, these enginestarts may still result in significantly higher NOx emissions since the SCR temperature is below $200^{\circ} \mathrm{C}$. Therefore, it was necessary to examine the similar characterization of engine-starts from the perspective of SCR temperature and compare them with the analysis based on engine coolant temperature for more insightful and complete understanding of cold- and warm-start impacts. 


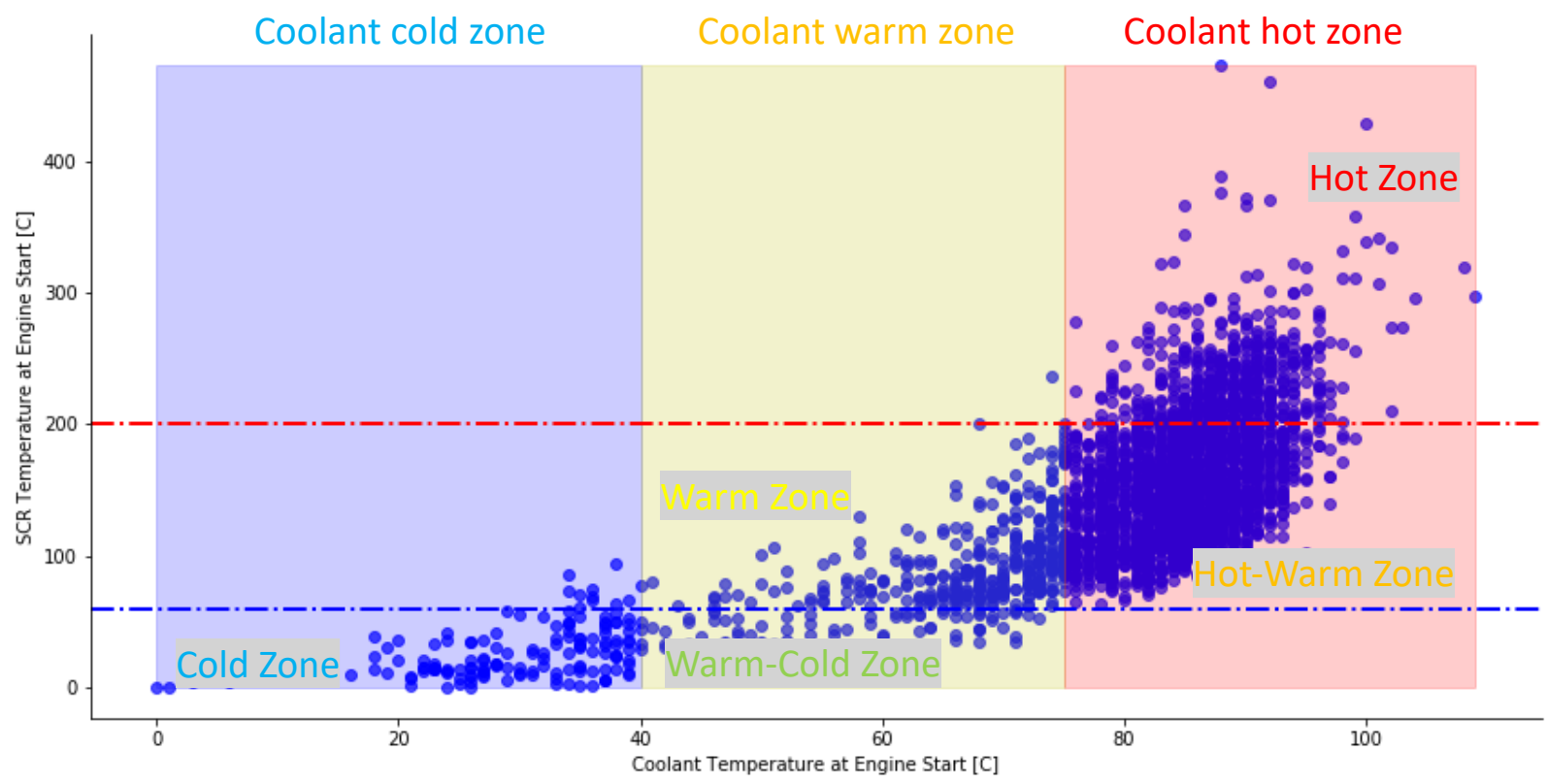

Figure 7. SCR Temperature versus Engine Coolant Temperature at Engine Starts (Line Haul)

It should be noted that the above trend is consistent for all vocational groups in the study. Thus, to analyze the effect of SCR temperature on the engine starts, the characterizations of enginestarts were classified into five groups based on both engine coolant temperature and SCR temperature, as summarized in Table 12. Therefore, the analysis of operational time, distribution of engine-starts per day, distribution of soak time, as well as the warm-up duration was reconducted based on this new classification. Comparison between this analysis and the analysis using coolant temperature solely will be discussed in the following sub-sections.

Table 12. Engine Starts Classification by Both Engine Coolant and SCR Temperature

\begin{tabular}{|c|c|c|}
\hline Engine Start & Coolant Temperature & SCR Temperature \\
\hline Cold & T_coolant $\leq 40^{\circ} \mathrm{C}$ & $\sim$ \\
\hline Warm-Cold & $40 \mathrm{C}<\mathrm{T}_{\text {_coolant }} \leq 75^{\circ} \mathrm{C}$ & T_SCR $\leq 60^{\circ} \mathrm{C}$ \\
\hline Warm & $40 \mathrm{C}<\mathrm{T}_{-}$coolant $\leq 75^{\circ} \mathrm{C}$ & $60^{\circ} \mathrm{C}<\mathrm{T}$ SCR $\leq 200^{\circ} \mathrm{C}$ \\
\hline Hot-Warm & T_coolant $>75^{\circ} \mathrm{C}$ & T_SCR $\leq 200^{\circ} \mathrm{C}$ \\
\hline Hot & T_coolant $>75^{\circ} \mathrm{C}$ & T_SCR $>200^{\circ} \mathrm{C}$ \\
\hline
\end{tabular}




\section{Result and Discussion}

This section presents the analytical results of the in-use cold-start performance discussed in the previous sections. First, the vocational based cold and warm operational time as a percentage of the total engine operational time will be presented in Section 3.1. Then, to allow for crosscomparison of vehicle-start performances among the different vocational groups, plots of distributions of cold-, warm-, and hot-start per day as well as the corresponding soak duration will be provided in Section 3.2 and Section 3.3 respectively. Detailed analysis related to the warm-up duration from cold- and warm-start in each vocation will follow in Section 3.4. Lastly, the above characterizations will be re-evaluated based on the classification of engine-starts according to the combination of engine coolant and temperature of exhaust gases entering the SCR system. The corresponding results, as well as the related discussion including SCR system temperature, will be described in Section 3.5.

\subsection{Cold and Warm Operation}

Figure 8 shows the fractions of cold and warm operational times in each vocational group based on coolant temperature as well as the fractions of total vehicles in the database combining the FleetDNA and CE-CERT, regardless of vocation (indicated by the "Total" bar). For this figure, the blue bars show the fraction of cold operation ( $\mathrm{T}$ _coolant $\leq 40^{\circ} \mathrm{C}$ ) and the yellow bar show the fraction of the warm operation $\left(40^{\circ} \mathrm{C}<\mathrm{T}_{-}\right.$coolant $\left.\leq 75^{\circ} \mathrm{C}\right)$. The number above each blue or yellow portion of the bar represents the numerical value of each fraction, and the number at the far right describes the sum of the cold- and warm-fraction for each vocation. For instance, on average, the vehicles for Local Delivery spend $2.7 \%$ of operational time when coolant temperature is cold, $11.4 \%$ of time when coolant temperature is warm, and $14.2 \%$ of time when coolant temperature is not hot $\left(<75^{\circ} \mathrm{C}\right)$.

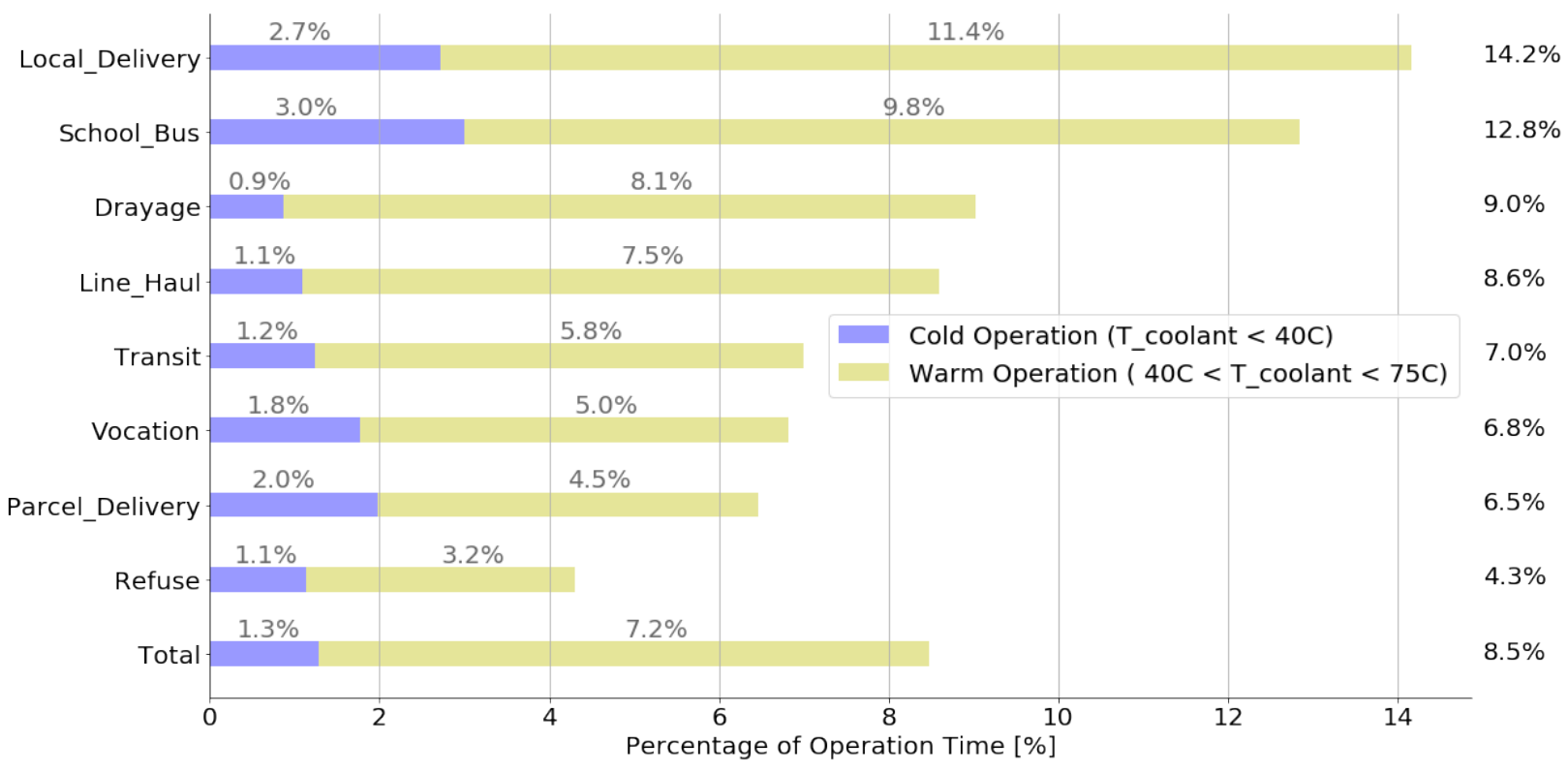

Figure 8. Fraction of Cold and Warm Operational Time Segmented by Vocations

As can be seen from Figure 8 , the cold operations of all vocations are less than $3 \%$. School Bus (3\%) and Local Delivery $(2.7 \%)$ have relatively longer cold operational times compared to the 
other vocations. Parcel Delivery and Vocation groups have shorter cold operational duration, which are $2 \%$ and $1.8 \%$ respectively. The cold operation of the four other vocations - Drayage, Line Haul, Transit and Refuse Pickup - are similar around 1\%. Due to the narrow range of cold coolant temperature, the duration of cold operation mainly depends on the number of cold-starts and ambient temperature. This conclusion can be supported by the following analysis of the distribution of cold-starts per day.

On the other hand, the warm operation duration is affected by several aspects, including the number of cold- and warm-starts, driving behavior, and the engine size. Usually, a greater number of cold- and warm-starts, larger engine size, and driving behavior characterized by longer idling and multiple starts-and-stops extend the warm operation time. Thus, Local Delivery, School Bus, and Drayage possess a much longer warm operation fraction of over $8 \%$. This could be partially explained by the operation of these vehicles and multiple starts-and-stops or idling conditions due to the loading and unloading of passengers and cargo. In addition, the drivers in Line Haul vehicles tend to idle their engines during a large portion of their operations in order to run axillaries, such as the AC system for cabin temperature control, and thus has relatively longer warm operation of $7.5 \%$. The warm operations of vehicles in the rest of vocations are similar, ranging from $3.2 \%$ to $5.8 \%$.

As a summary, the cold operational time of all the vocations were less than $3 \%$ of the total operational time. The warm operations varied significantly across the different vocations, from $3.2 \%$ to $11.4 \%$. The variation in warm operation was influenced by several aspects, including the number of cold- and warm-start per day, driving behavior and the engine size. When considering the total vehicles across all vocations, the cold and warm operational times were $1.3 \%$ and $7.2 \%$. Further observations are listed below:

- The cold operational time is defined as the period when the engine is operating with a coolant temperature lower than $40^{\circ} \mathrm{C}$. The warm operational time is the period when the engine is operating with coolant temperature higher than $40^{\circ} \mathrm{C}$ but lower than $75^{\circ} \mathrm{C}$.

- Line Haul and Drayage possess the smallest cold operational time from both the Fleet DNA and CE-CERT data, which was around $1 \%$.

- Local Delivery showed the longest duration operating at cold and warm conditions, which were $2.7 \%$ and $11.4 \%$ respectively.

- Combining the cold and warm operations together, Refuse has the shortest duration of the total operating time under this condition.

\subsection{Cold-, Warm-, and Hot-Starts per Day Distribution}

Due to the diversity of operation and driving behaviors, the characterizations of cold-, warm-, and hot-start per day are vastly different across the various vocations. Figure 9 shows the fraction of cold-, warm- and hot-starts to the total engine starts in each vocation. The corresponding information related to the entire database, regardless of the vocation, is also included-indicated by "Total." 


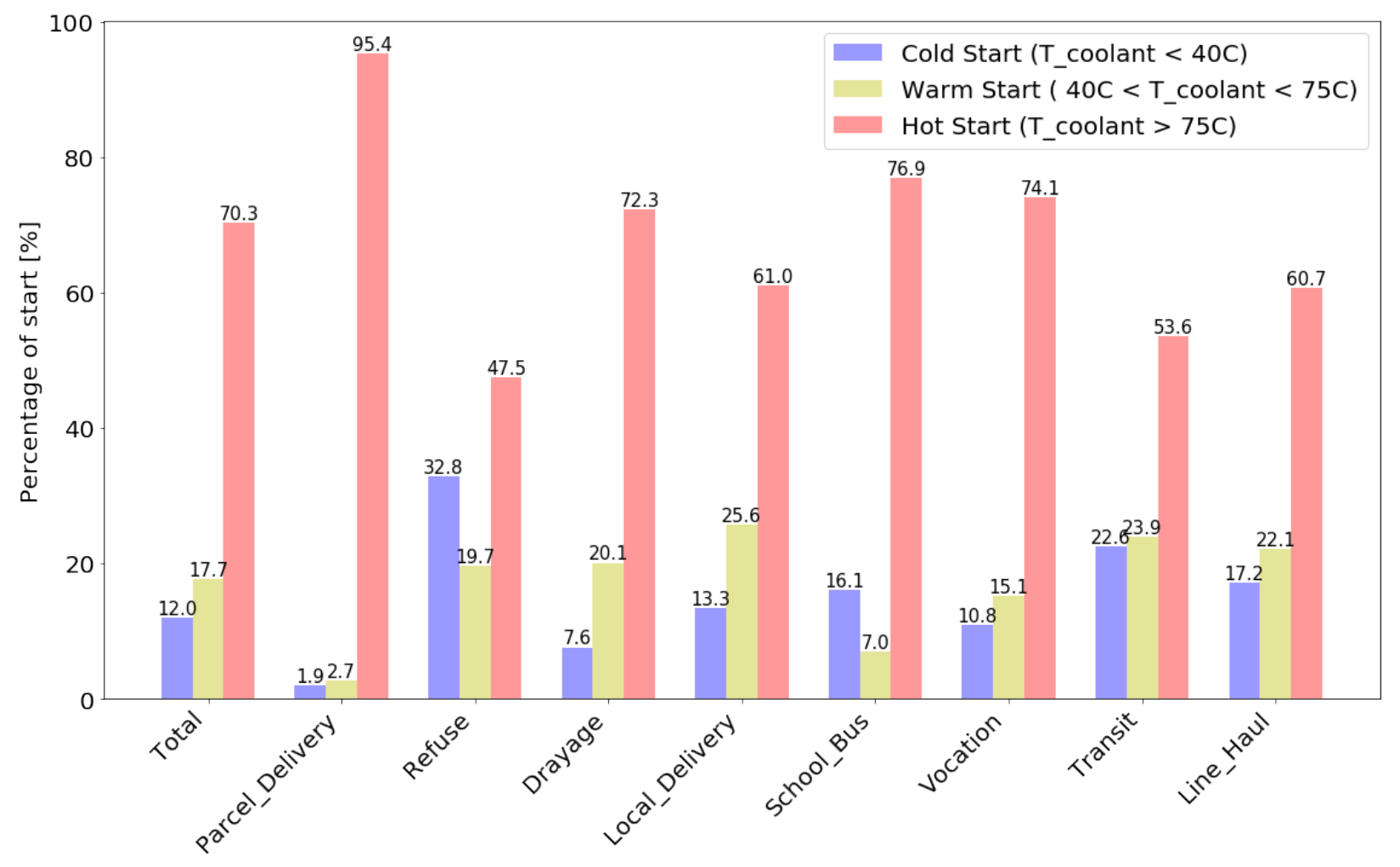

Figure 9. Percentage of Cold-, Warm-, and Hot-Start in Different Vocations

As can be seen in Figure 9, for all the vehicles under investigation, $12.0 \%$ of the starts are cold, $17.7 \%$ are warm, and $70.3 \%$ are hot. However, the characterizations of these distributions change significantly according to vehicle vocation. For example, the majority of engine-starts in the Parcel Delivery vocation are hot-starts, which consist of $95.4 \%$, while the cold-starts represent only $1.9 \%$ and warm-starts $2.7 \%$; over $50 \%$ of engine-starts in Refuse Pickup are cold (32.8\%) and warm $(19.7 \%)$, while the hot-starts are $47.5 \%$. Unlike the rest of the vocations, the vehicles in the School Bus group have more cold-starts (16.1\%) compared to the warm-starts (7.0\%). More details related to the other vocations can be extracted from Figure 9.

Besides the fraction of each type of engine start, NREL also examined the average cold-, warm-, and hot-starts per day for all the eight vocational groups, as shown in Figure 10. One feature that needs to be noted here is that the vehicles in Parcel Delivery have over 90 hot-starts per day on average. Such a high amount of hot-starts is mainly caused by specific policies employed by parcel delivery fleets, which require the drivers to stop the engine while delivering packages. In addition, the Line Haul and the Refuse pickup groups have much fewer hot-starts per day (around two starts) compared to the rest of vocations (from 3.7 to 10.9 starts on average).

Regarding the number of cold-starts per day, it is notable to recognize that Parcel Delivery, Local Delivery, Transit, and School Bus have around two cold-starts per day on average. This is intuitive since the vehicles in these groups, such as School Buses, are usually operated in the morning and afternoon and display a long midday soak period. Conversely, Refuse, Drayage, and Vocation that do not typically have any midday soak periods only have one cold-start daily. 
Furthermore, the average cold-starts per day for the Line Haul category is less than 1 due to the operation in this category commonly spilling over from one day to the next.

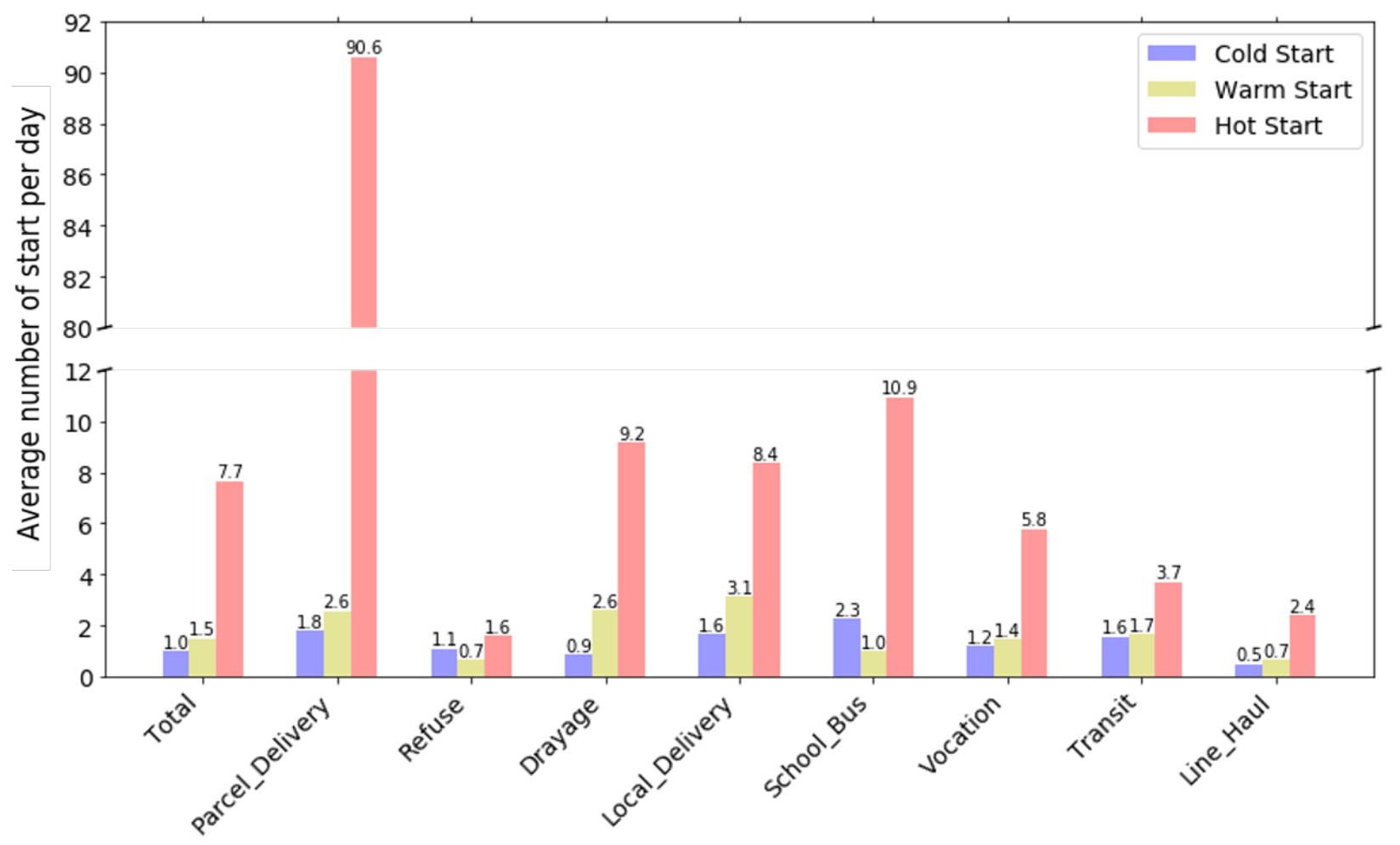

Figure 10. Average Cold-, Warm-, and Hot-Start Per Day in Different Vocations

In addition, this analysis also shows that on average, the in-use data possess cold-starts of $12.0 \%$ (11.4\% form Fleet DNA and 18.2\% from CE-CERT). As a note, the current weighting for coldstarts in the FTP cycle is $1 / 7$ or $14.8 \%$. This comparison is discussed in more detail in later sections.

The detailed distributions of cold-, warm-, and hot-start per day for each vocation are summarized in Appendix B.

To conclude, the distribution of starts per day for different vocations were separated into three groups, namely cold-starts per day, warm-starts per day, and hot-starts per day. Both fractions of total starts and average starts per day were investigated. From the perspective of start fractions, the entire vehicle set from Fleet DNA had $12.0 \%$ cold-starts, $17.7 \%$ warm-starts, and $70.3 \%$ hotstarts. From the perspective of average number of starts, there were 1.0 cold-starts per day, 1.5 warm-starts per day, and 7.7 hot-starts per day. More details related to each vocation are described in the following:

- More than $60 \%$ of the vehicle-days from the Line Haul category had zero cold-starts and warm-starts since these trucks typically do no soak overnight and the engine will keep idling for auxiliary power.

- Drayage vehicles had 0.87 cold-starts per day on average. They also possessed more warm-starts per day (2.61 on average) and hot-starts per day ( 9.16 on average) than the 
Line Haul category, likely due to frequent stops for queuing, loading, and unloading cargo.

- Most of vehicle days in the Refuse category had one cold-start and zero warm- and hotstarts. This is because refuse pickup vehicles have few engine-stops during normal operation.

- Vehicles in the Parcel Delivery category have the largest number of hot-starts per day on average, with more than 90 . Such a frequent number of daily hot-starts is the result of specific policies employed by some fleets which require drivers to turn off the engine when they leave the vehicles to deliver packages.

- More than 50\% vehicle-days for the School Bus category had two cold-starts per day. This result is expected since school buses typically pick up students in the morning and drive student back home in the afternoon with a soak in-between.

- For the Vocation group, the cold-starts per day distributions were similar from the two data sets. But the warm- and hot-starts were different, likely due to the wide diversity of vocations included in this group.

\subsection{Soak Time Distribution}

Soak time before engine-start is a critical parameter to determine the classification of enginestarts. For the FTP test, the cold-start test is only valid after at least 12 hours (720 minutes) engine soak duration, while the soak duration for the hot-start cycle is 20 minutes. Intuitively, the soak duration before a cold-start should be the longest, and shortest for a hot-start. Figure 11 shows the average soak time duration before each different start classification, each vocation, as well as the entire dataset (indicated by "Total"), which supports the above test specification.

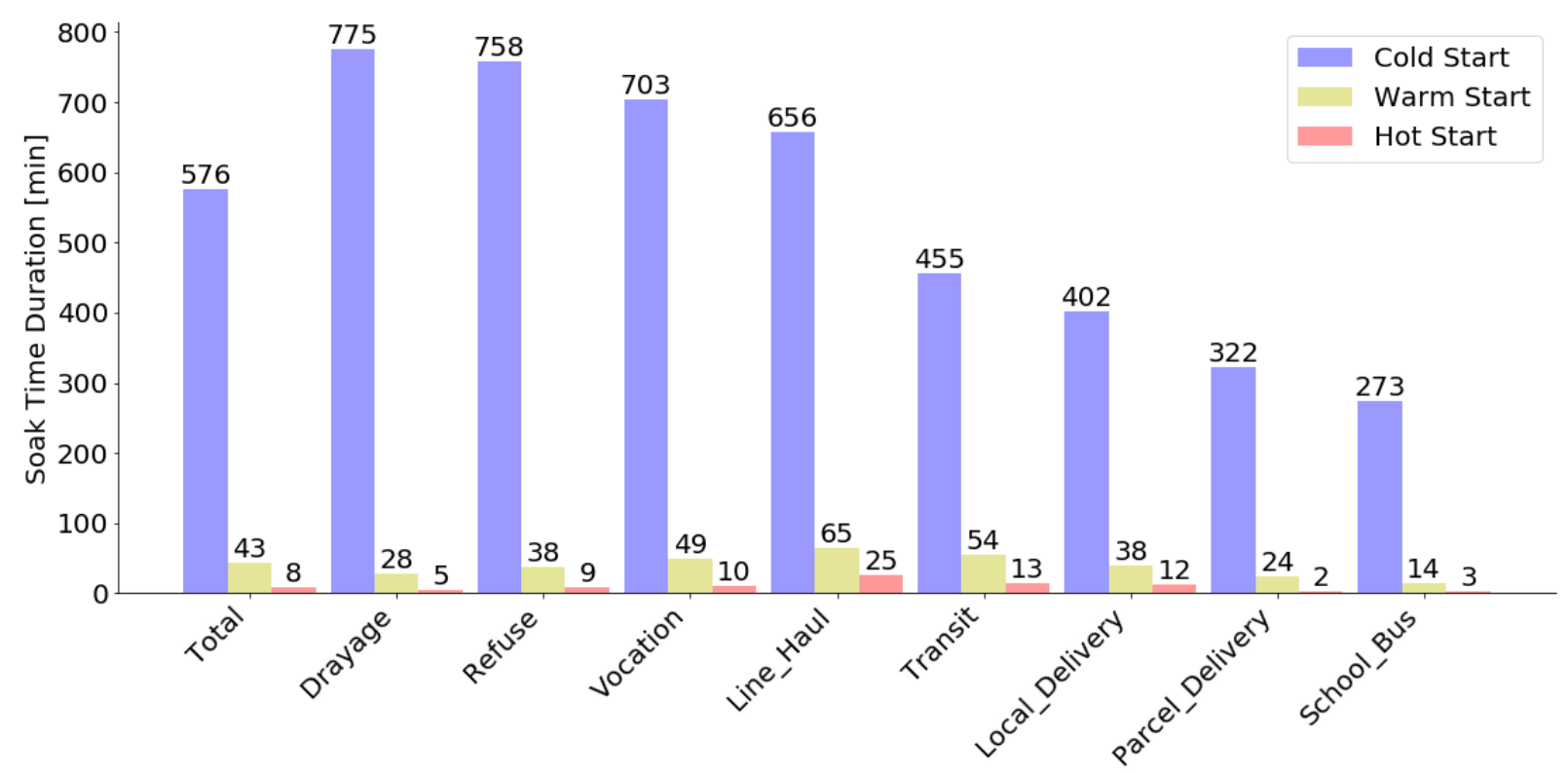

Figure 11. Average Soak Time before Engine-Starts Segmented by Vocations

As can be seen in Figure 11, most of the average soak durations before hot-starts (hot soak) are less than or near 10 minutes in real-world driving-except Line Haul whose average hot soak time is about 25 minutes. One reason for this difference is that the thermal mass of the engine 
used for Line Haul trucks is usually larger than the other vocations, which extend the required soak time to further reduce the coolant temperature. In addition, using the average cold-soak duration, the eight vocations can be separated roughly into two groups. The first, Drayage, Line Haul, Vocation, and Refuse Pickup, of which average cold-soaks last 10 hours or longer. The average cold-soaks for the rest of the four vocations are much less.

NREL also examined the distribution of soak duration by quantifying the fraction of the soak duration by 11 soak bins (Table 11). It should be noted that based on this study, there are zero hot-starts after one hour of soak and zero warm-start after 6 hours of soak for all the vehicles in the eight vocations. Further discussion for each vocation from the databases is described and compared in Appendix C.

From the above analysis of the soak time distributions, it is clear that most of the engine hotstarts occurred after approximately 10 minutes of soak time, and the warm-starts occurred after 20-30 minutes of soak time. In addition, as indicated by the average cold-soak duration, the vocational groups from the two data sets can be separated into two categories. Drayage, Line Haul, Vocation and Refuse Pickup as one, of which average cold soaks lasted 10 hours or longer. The average cold soaks for the rest, namely Transit, Local Delivery, Parcel Delivery, and School Bus, were less than 7 hours.

Furthermore, the distribution of soak duration was also examined by quantifying the fraction of the soak duration separated into 11 different time bines (see Table 11). Based on this examination of the in-use data, there were zero hot-starts after one hour of soak and zero warm start after 6 hours of soak. Some additional observations from each vocation are described in the following:

- Most starts - no matter whether they are cold, warm, or hot - have 30 to 60 minutes of soak duration in Line Haul category.

- For the Drayage, Refuse, and Vocation categories, most of the hot-starts occurred after a soak time of less than 6 minutes, while most cold-starts had a soak duration longer than 12 hours.

- Due to the specific driving behavior of the Parcel Delivery vehicles, the fractions of soak times with less than 6 minutes are high for all types of engine-starts, which were $40 \%$ for cold-starts, over $65 \%$ for warm-starts, and nearly $93 \%$ for hot-starts.

- Unlike the other vocations, the Transit category had the largest fraction of cold-starts in the "6 to 12 hours" time bin.

- For the School bus category, most of the engine-starts were in the "less than 6 minutes" and "over 12 hours" time bins. This result demonstrates that during the normal operation, School Buses usually only stops for a few minutes to load or unload students.

\subsection{Warm-Up Duration from Cold- and Warm-Start}

The definition of warm-up duration was described in Figure 5, which shows the period beginning at engine-start and ending when the coolant temperatures reach $75^{\circ} \mathrm{C}$. A shorter warm-up duration is significantly beneficial from the perspective of both engine efficiency and emissions performance. However, the warm-up duration is affected by many aspects, including ambient temperature, the size of engine thermal mass, and more importantly, the driving behaviors of 
specific vocational groups. In the following sub-section, the warm-up duration from both coldstarts and warm-starts are investigated and presented. Such examinations were repeated for all the vocations in both data sets. In addition, the average engine power during each warm-up duration was calculated to show the relationship between the driving behavior and the corresponding warm-up duration. The analytical results above are also compared with test data from three heavy-duty diesel engines running the FTP cycle to provide more insights into the relationship between real-world data and the FTP certification cycle.

\subsubsection{Warm-Up Duration from Cold-Start}

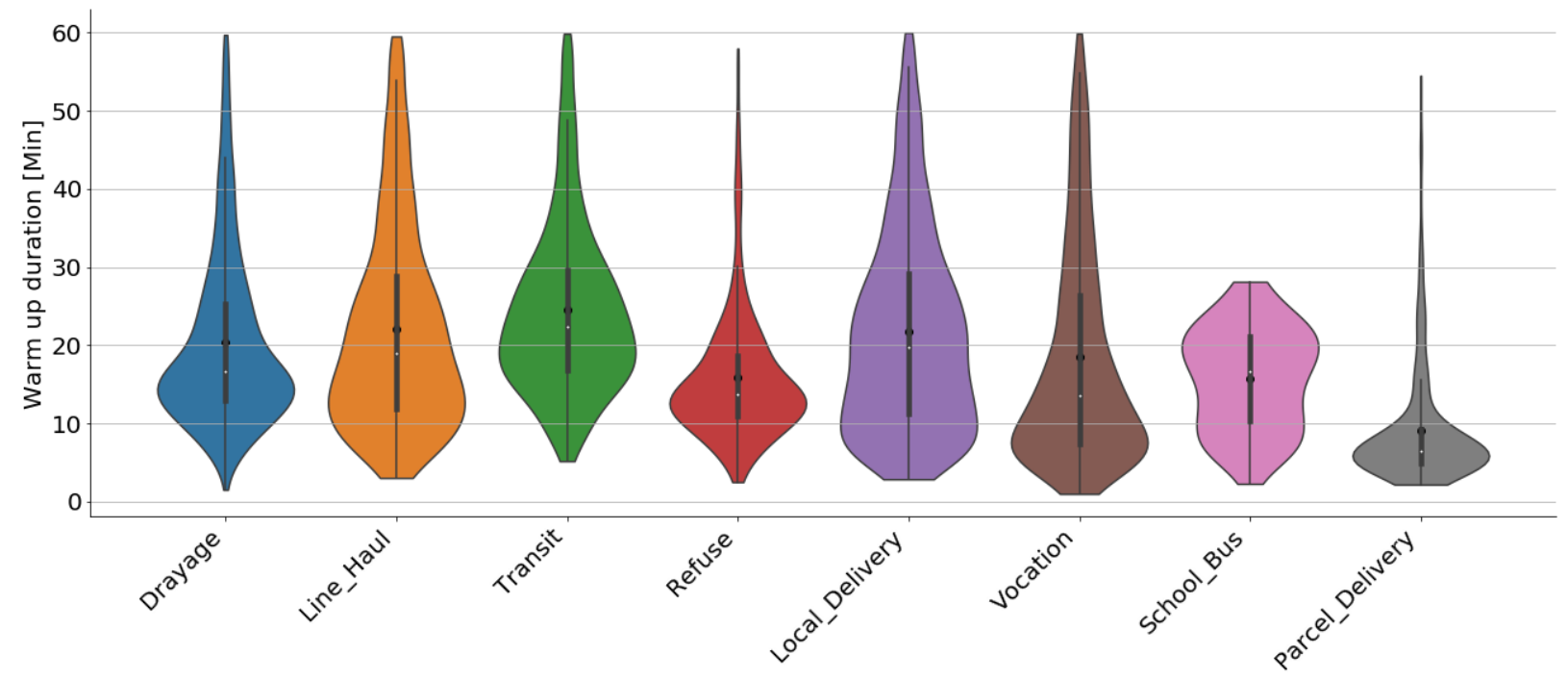

Figure 12. Warm-Up Duration from Cold-Start Segmented by Eight Vocational Groups

Figure 12 shows the violin plots of warm-up duration from cold-start (cold warm-up duration) segmented by eight vocational groups from the dataset. As can be seen, eight violin plots represent each vocational group respectively. For each violin plot, the white dot in the middle is the median value and the black dot shows the average value. In addition, the thick bar in the center represents the interquartile range, and the thin black line extended from that point represents the upper (max) and the lower (min) adjacent values in the data. The most important feature of a violin plot, compared to a conventional box plot, is that the shape of it shows the density distribution of the data. Taking the Drayage data as an example, the related violin plot conveys that a large fraction of warm-up duration data is within 10 to 20 minutes.

Table 13 lists all the statistical analysis for this warm-up duration data, which includes average values, $25 \%, 50 \%$ (median values), and $75 \%$ of data values. From the violin plots (Figure 12), it can be seen that for all of the vocational groups, a large fraction of data is within 20 minutes, and the warm-up durations longer than 30 minutes have very small densities. Thus, it is more reasonable to use the median value to represent the characterization of the data to avoid the bias of small amounts of data with larger values. 
Table 13. Statistical Results of Warm-Up Duration from Cold-Start

\begin{tabular}{|c|c|c|c|c|}
\hline Vocation & Mean [Mins] & $\mathbf{2 5 \%}[$ Mins] & $\mathbf{5 0 \%}$ (Median) [Mins] & $\mathbf{7 5 \%}[$ Mins] \\
\hline Drayage & 20.37 & 12.90 & 16.65 & 25.33 \\
\hline Line Haul & 22.10 & 11.91 & 19.00 & 28.84 \\
\hline Local Delivery & 21.82 & 11.26 & 19.72 & 29.13 \\
\hline Transit & 24.57 & 16.74 & 22.44 & 29.68 \\
\hline Vocation & 18.55 & 7.33 & 13.63 & 26.36 \\
\hline Refuse & 15.83 & 10.92 & 13.72 & 18.71 \\
\hline School Bus & 15.79 & 10.30 & 16.63 & 21.21 \\
\hline Parcel Delivery & 9.15 & 5.00 & 6.55 & 9.27 \\
\hline
\end{tabular}

It should be noted from Figure 12 that some cold warm-up durations in real-world driving can be as long as 60 minutes. This can be caused by the driver idling the engine for a long time or even turning off the engine before the vehicle moves in real-world driving. The detailed case study for this driving behavior is shown and explained in Appendix D.

\subsubsection{Warm-Up Duration from Warm-Start}

This sub-section shows the statistical results of warm-up duration from warm-start (warm warmup). As in the previous section, Figure 13 shows the violin plots of these warm warm-up durations. Table 14 lists the corresponding statistical results of these warm warm-up durations. The average warm warm-up duration is shorter than the cold warm-up duration, which is expected. Also, almost all the warm warm-up durations are less than 30 minutes. It is also possible for engines to only take one minute or even less to warm up since the coolant temperature may already be very close to $75^{\circ} \mathrm{C}$ at engine start. 


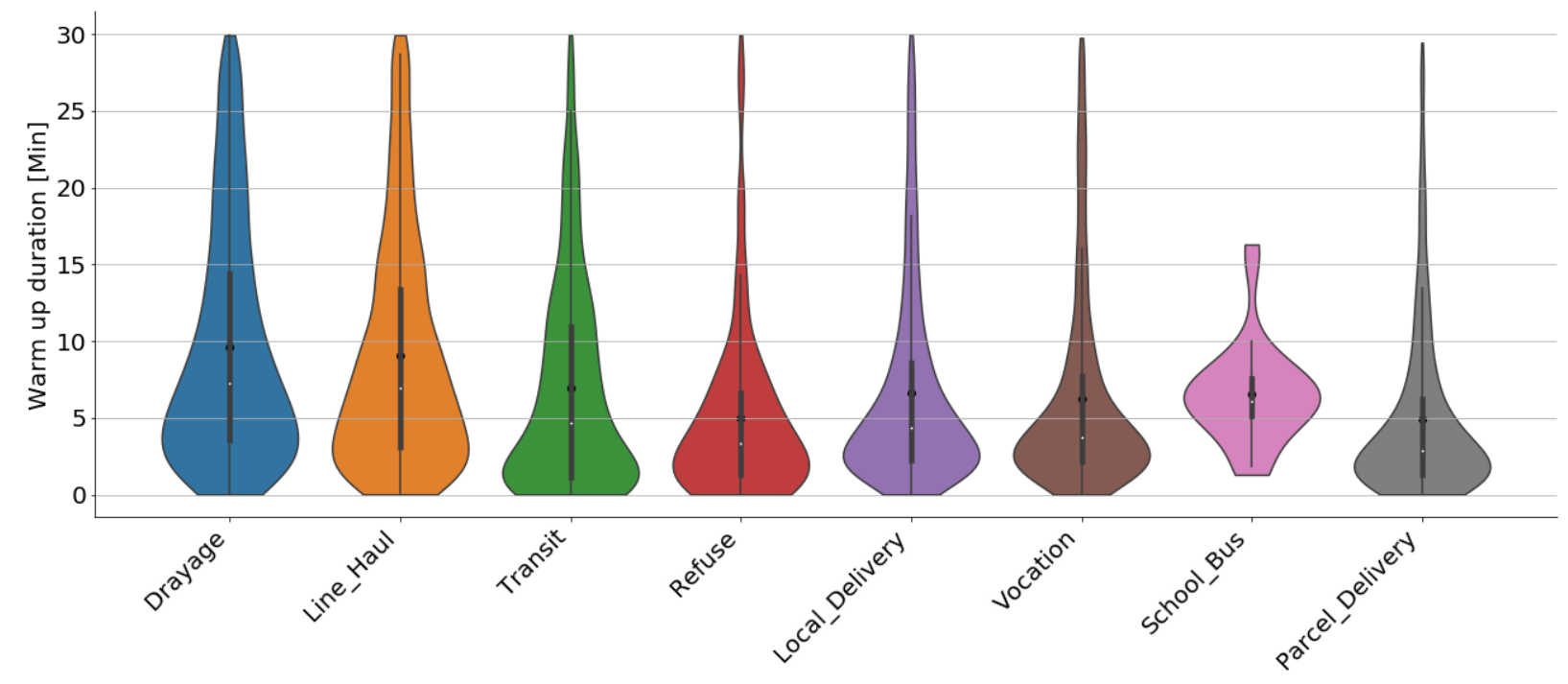

Figure 13. Warm-Up Duration from Warm-Start Segmented by Eight Vocations

Table 14. Statistical Results of Warm-Up Duration from Warm-Start

\begin{tabular}{|c|c|c|c|c|}
\hline Vocation & Mean [Mins] & $\mathbf{2 5 \%}[$ Mins] & $\mathbf{5 0 \%}$ (Median) [Mins] & $\mathbf{7 5 \%}[$ Mins] \\
\hline Drayage & 9.64 & 3.55 & 7.30 & 14.37 \\
\hline Line Haul & 9.05 & 3.13 & 6.92 & 13.35 \\
\hline Local Delivery & 6.65 & 2.23 & 4.33 & 8.62 \\
\hline Transit & 6.92 & 1.16 & 4.64 & 10.96 \\
\hline Vocation & 6.27 & 2.15 & 3.76 & 7.71 \\
\hline Refuse & 4.96 & 1.26 & 3.36 & 6.65 \\
\hline School Bus & 6.53 & 5.15 & 6.06 & 7.60 \\
\hline Parcel Delivery & 4.93 & 1.33 & 2.89 & 6.21 \\
\hline
\end{tabular}

\subsubsection{Average Power through Warm-Up versus Warm-Up Duration}

Since there may be one or even multiple engine-stop periods during a warm-up duration, it is reasonable to characterize such different driving behavior with a metric that shows the relationship between the corresponding warm-up duration and these specific metrics. In this study, NREL decided to use the average engine output power to represent the characterization of driving behavior within the warm-up duration. It is intuitive that when an engine is idled or being turned off, the output power should be much smaller compared to the power when the engines are operating under other conditions. The following section discusses this analysis in detail. 
It should also be noted that in the Fleet DNA dataset, not all the vehicles in the previous analysis possess the information for the calculation of engine output power. Among all the 435 vehicles in Fleet DNA, there are only 185 vehicles providing the required engine output power calculation data. Further information about the vehicle sampling of the Fleet DNA data in this category are shown in Appendix E. The CE-CERT data have no similar data limitation.

\subsubsection{Analysis for average power versus cold warm-up duration}

Figure 14 is a scatter plot representing the relationship between the average engine output power and the related warm-up duration from the cold-start of the vehicles in the Fleet DNA's Line Haul group. As can be seen, only two fleets, namely regional haul and long-haul fleets, broadcast the required data for engine output power calculation. It is clear from the plot that smaller engine output power on average usually indicate longer warm-up durations. It is intuitive since smaller average engine power is achieved by idling the engine for a long time or turning off the engine for a period. Usually, the engine coolant temperature cannot be raised quickly during the engine idling condition or even be reduced if an engine has been turned off. The bubbles in the red dashed box of Figure 14 represent such conditions, while the warm-up durations from the coldstarts includes some engine-off time. On the other hand, the bubbles in the blue dashed line show the cases where the vehicles do not have any engine-off time during the warm-up duration. The engine output powers in the latter box are significantly larger than the cases in the former box, while the related warm-up duration is much shorter.

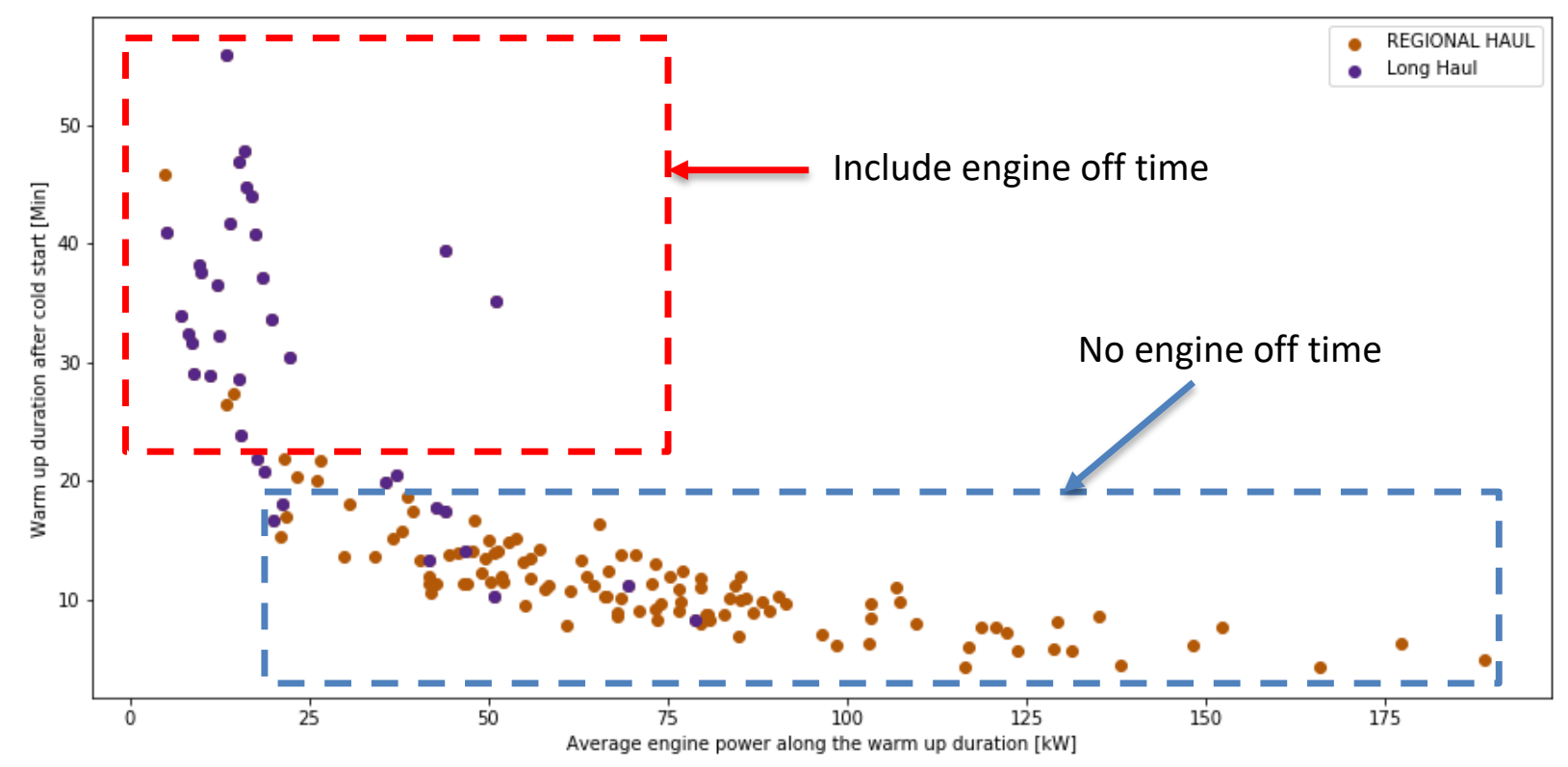

Figure 14. Average Power vs Warm-Up Duration from Cold Start in Line Haul from Fleet DNA

Figure 15 shows the relationship between engine power and cold warm-up duration from the Fleet DNA's Local Delivery. In this category, there are three fleets included, Beverage Delivery, Food Delivery, and Linen Delivery. As can be seen, all the points can still be separated into two groups, where one group includes engine-off time and the other one does not. 


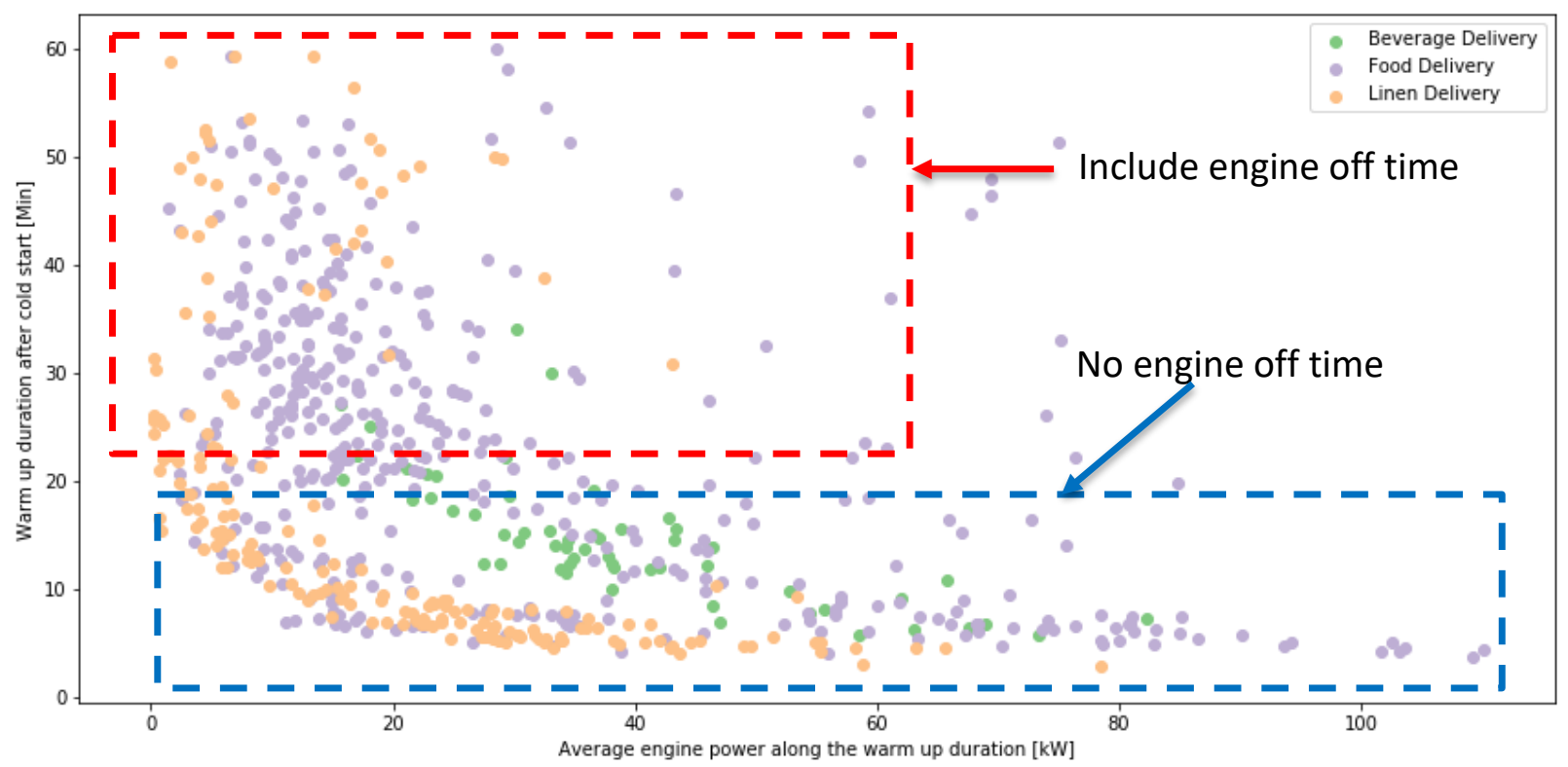

Figure 15. Average Power vs Warm-Up Duration from Cold Start in Local Delivery from Fleet DNA

Two groups indicating different characterization of cold warm-up duration also appeared in the other vocational categories from the Fleet DNA dataset as well as the CE-CERT data. The corresponding scatter plots showing the relationship for the other groups and CE-CERT data are listed in Appendix F.

\subsubsection{Analysis for average power versus warm warm-up duration}

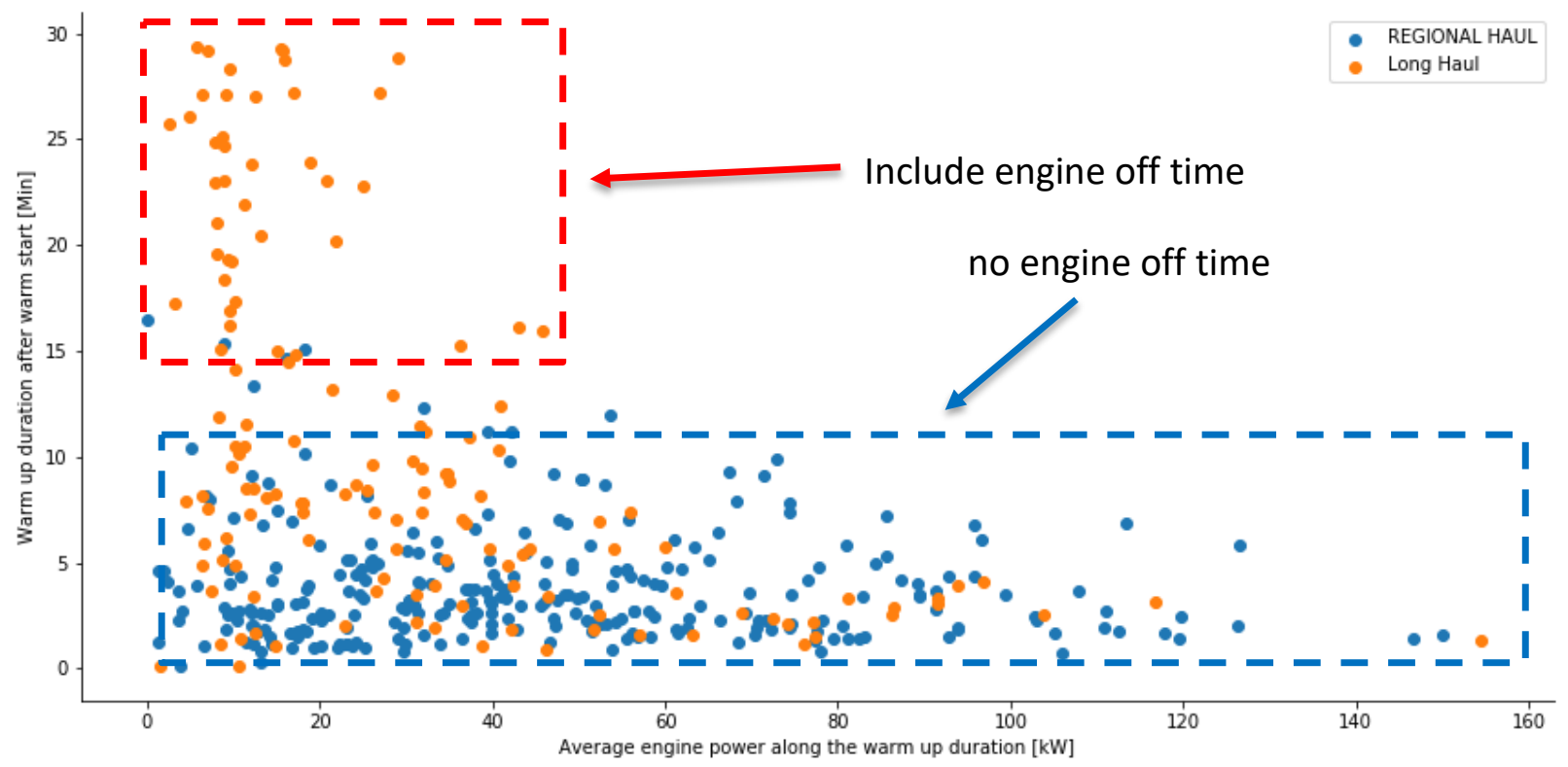

Figure 16. Average Power vs Warm-Up Duration from Warm Start in Line Haul from Fleet DNA 


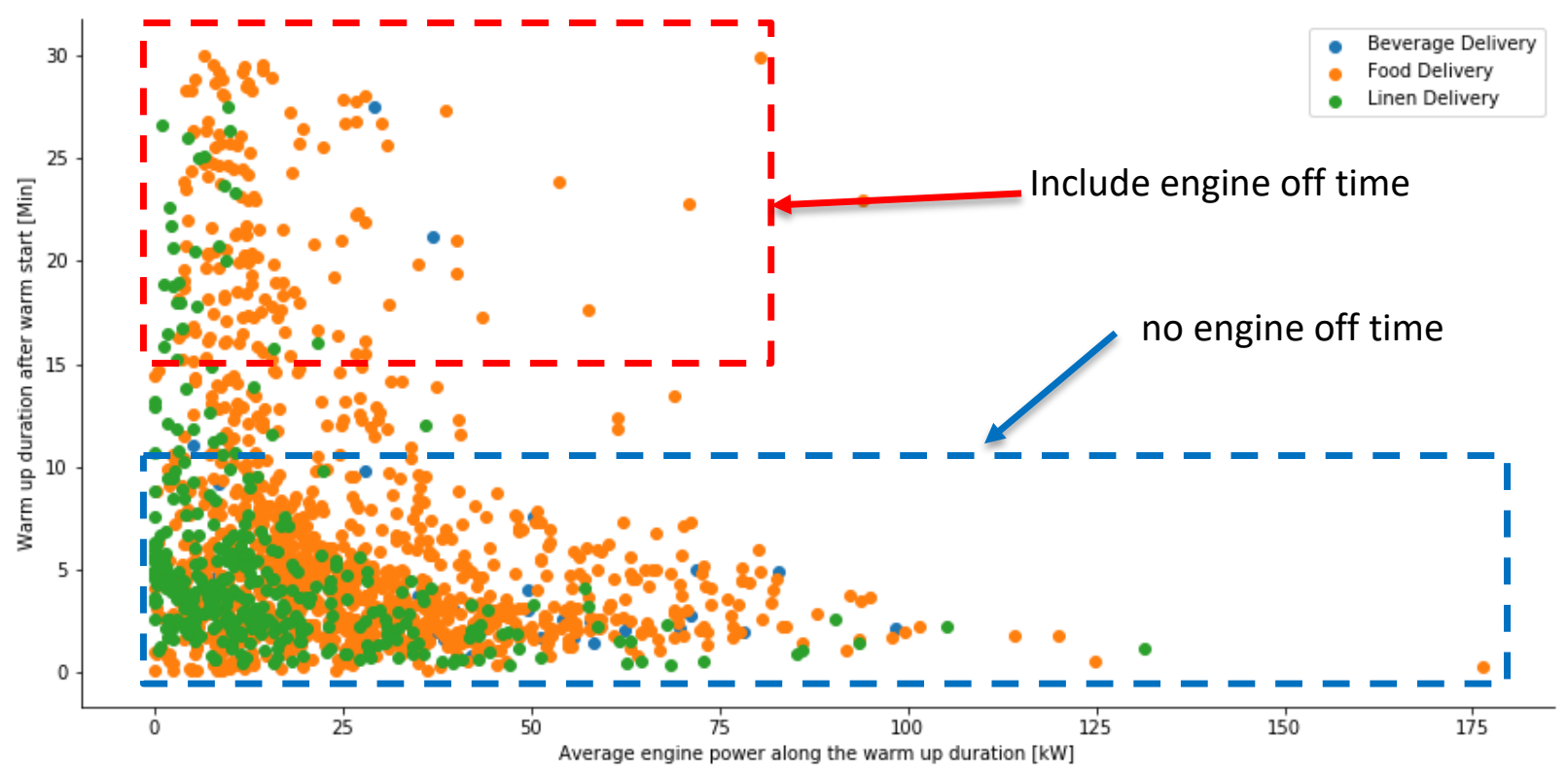

Figure 17. Average Power vs Warm-Up Duration from Warm Start in Local Delivery from Fleet DNA

Figure 16 and Figure 17, show the relationship between the engine power and warm-up duration from warm-starts in the Line Haul and Local Delivery categories from the Fleet DNA data. Considering the warm warm-up condition, some points indicate the duration can be as short as one minute or less and the related power can be small. This is because at these conditions, the engine coolant temperature is very close to the temperature threshold of $75^{\circ} \mathrm{C}$ when the engine starts. Like the cold warm-up duration analysis, the same two groups separating the points exist and there are some engine-off times appearing when the warm-up duration is longer than 15 minutes. Not surprisingly, this trend also exists for the other vocational groups. The corresponding analyses of other vocations in Fleet DNA and CE-CERT data are shown in Appendix G.

\subsubsection{Comparison with FTP Test Data}

To investigate whether the FTP certification cycle is representative of current real-world driving behavior, the warm-up durations observed from the Fleet DNA and CE-CERT data were compared with the engine test results from the FTP cycle.

The engine test data were provided by NREL's Renewable Fuels and Lubricants (ReFUEL) Laboratory, which is a state-of-the-art research and evaluation facility for advanced fuels and vehicles. In this study, the ReFUEL Lab provided test data from three heavy-duty diesel engines that had run the FTP cycle under both cold-start and hot-start conditions. These engines were the Cummins ISB diesel engine, Cummins ISL diesel engine, and Navistar Maxx Force 10 engine. Further information related to the engines and the tests is described in Appendix $\mathrm{H}$. 


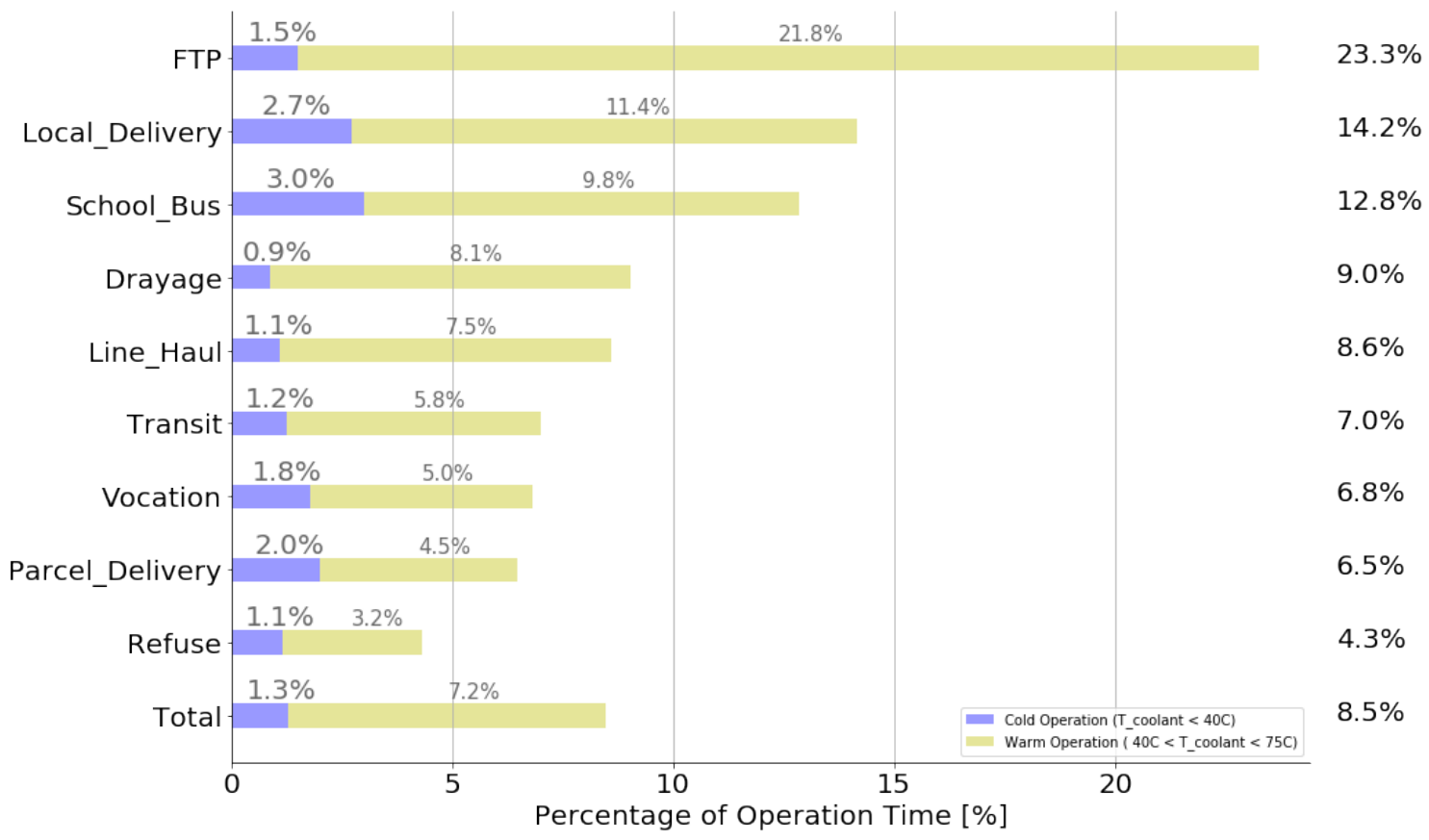

Figure 18. Comparison of Different Operational Time from On-Road Data and FTP Test Data

Figure 18 shows the comparison of the cold and warm operational times between the FTP test data and on-road data set. As can be seen, the cold operational time fraction (which is $1.5 \%$ ) from the FTP test data is similar to the average result $(1.3 \%)$ from this in-use data. However, the warm operational time $(21.8 \%)$ is much larger than the corresponding result from each vocation. One reason for this difference is attributed to the fact that the current FTP cycle only lasts about 20 minutes. As a result, such a short test duration cannot include enough hot operational time after the warm-up duration. Usually, the warm-up duration from the cold-start takes about 8-10 minutes, and so the current FTP cycle can only record about 10 minutes hot-operation data. However, in the on-road data, the vehicles may operate for hours after the warm-up.

Figure 19 shows the comparison of cold warm-up duration of Line Haul with the FTP test data. As can be seen, the pink bubbles show the corresponding data from Fleet DNA and the purple ones from the CE-CERT project data. The other bubbles show the test data of three heavy-duty diesel engines respectively. This figure shows that even though they are all in the same range, the FTP test data are crowded in a smaller region compared to the wide distribution of real-world onroad data. This is partly due to the fact that the FTP test cycle has no engine-off time included in the cycle, as can be seen in Figure 1. On the other hand, the diversity of engines in the Fleet DNA and CE-CERT data are much larger than the three engines used in FTP tests. 


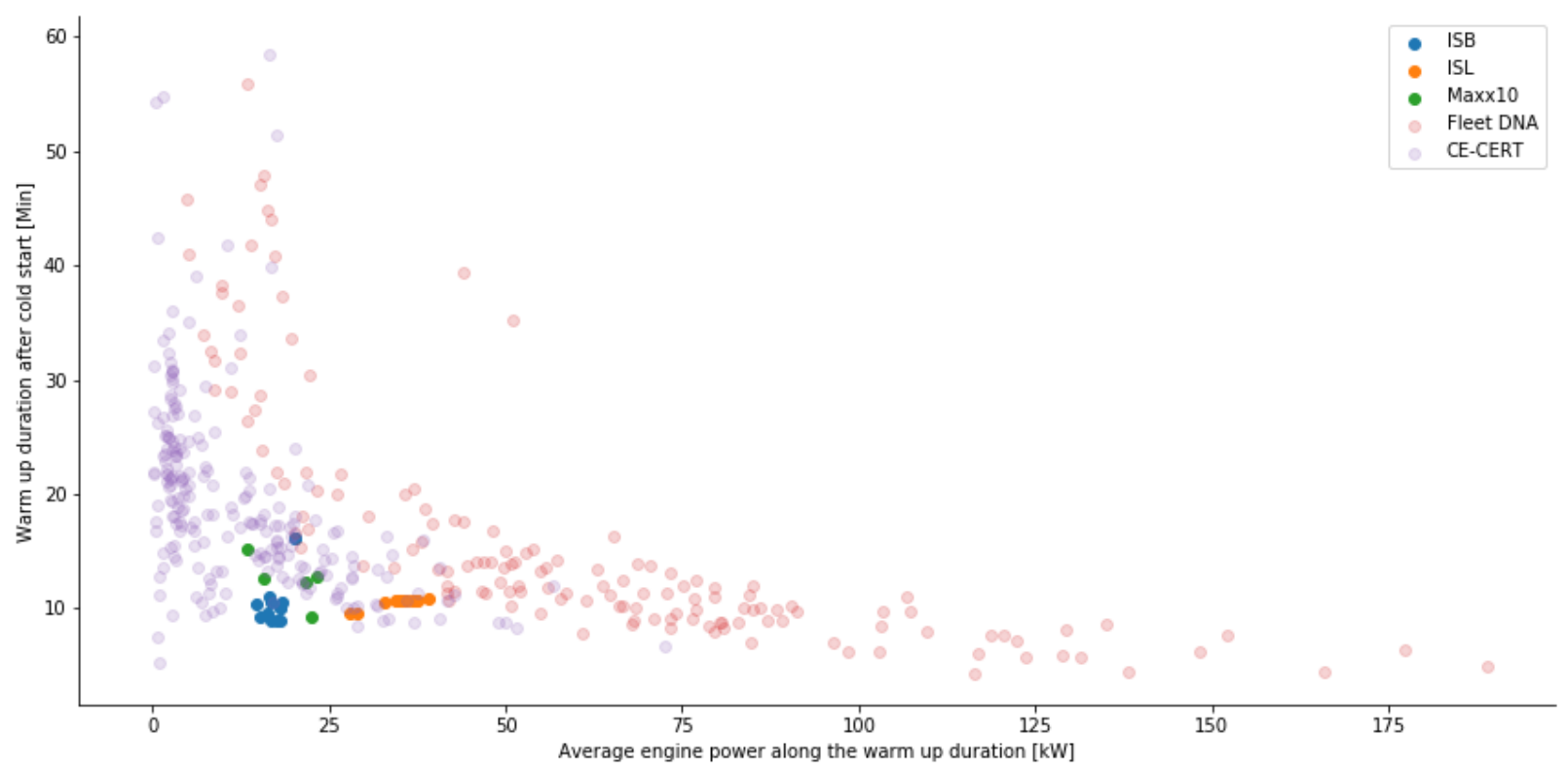

Figure 19. Comparison of Cold Warm-Up Duration in Line Haul from On-Road and FTP Test Data

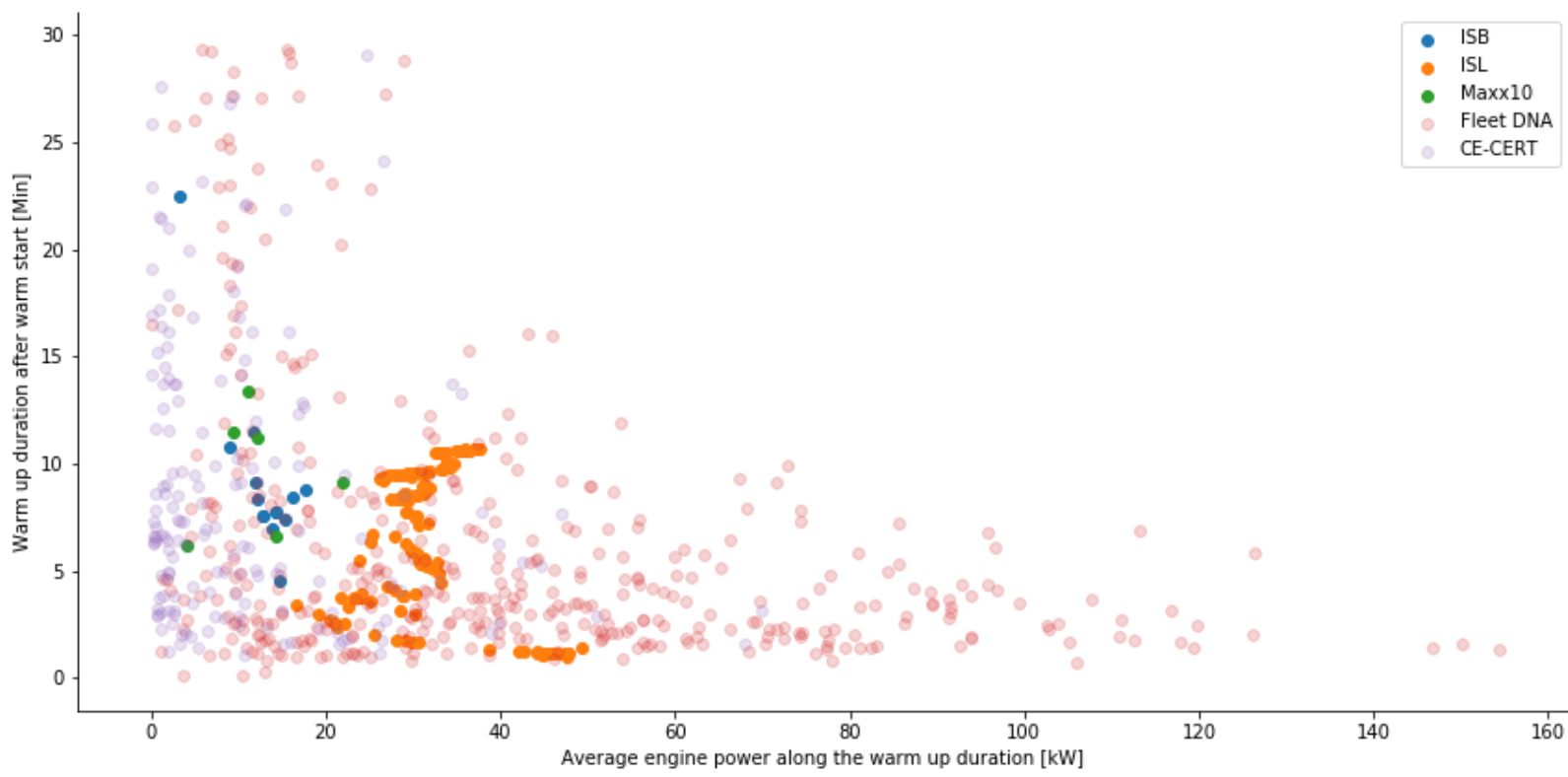

Figure 20. Comparison of Warm Warm-Up Duration in Line Haul from On-Road and FTP Test Data

The related comparison of warm warm-up duration in Line Haul is shown in Figure 20. The test data and the in-use data agree to each other quite well to a large extent. However, the in-use data still possesses a significantly wider range of operation compared to the corresponding FTP test. In addition to the diversity of engine sizes and the inclusion of engine-off time in the warm-up duration, a wide range of operation is also attributed to various engine coolant temperatures at warm-start in real-world driving, while the coolant temperature at the beginning of the warm FTP cycle is typically within $50^{\circ} \mathrm{C}$ to $60^{\circ} \mathrm{C}$. 
The same analysis is repeated for the other vocations in the Fleet DNA and CE-CERT datasets. The related results according to cold warm-up duration and warm warm-up duration are shown in Appendix I and Appendix J respectively.

\subsubsection{Summary of Conclusions for Warm-up Duration}

In summary, the warm-up duration from engine-start is a critical parameter for evaluating the engine emissions performance of a vehicle. From this analysis, the warm-up duration derived from the on-road data present some informative insights, especially after benchmarking with the test data against the FTP cycle:

- From the statistical analysis for the warm-up duration from cold-start, most vehicles need about 15 to 20 minutes to warm-up on average. The Line Haul, Local Delivery, and Transit categories showed longer warm-up times (around 20 minutes), while Drayage, Vocation, Refuse and School Bus categories took less time on average (around 15 minutes). The Parcel Delivery trucks have the shortest duration of warm-up time on average (less than 10 minutes). In addition, from the on-road data, it was observed that some cold warm-up durations in real-world driving can be almost 60 minutes. This is due to the existence of excessive engine-off time in this period, driven by multiple short trips with many key-off events.

- The warm-up duration from warm-start is much shorter than the cold warm-up duration on average. Even though some warm warm-up durations can last 30 minutes, the average warm-up duration, from warm-starts, is less than 10 minutes. For some vocations, warm warm-up durations are even shorter than 5 minutes, (e.g. Vocation, Refuse, Local Delivery, Transit, and Parcel Delivery). In addition, it is also possible for engines to take only 1 minute or less to warm-up since the coolant temperature may be very close to $75^{\circ} \mathrm{C}$ at engine start.

- In this study, the average engine output power was chosen as a metrics to represent the driving behavior across the warm-up duration. Usually, smaller engines lower output powers leading to longer warm-up durations. From the scatter plots in Section 3.4.4 which includes the relationship between average engine output power and corresponding warm-up duration, it can be seen that the engine warm-up duration falls into two groups. One includes the engine-off time and the other does not. Typically, if the warm-up duration from cold-start is longer than 20 minutes, or the warm-up duration from warmstart is longer than 15 minutes, the warm-up duration is likely to include one or more engine-off events.

- FTP cycle test data were also compared with the data derived from the on-road data sets. From a comparison, it is clear that even though all the data are in the same range, the FTP test data are crowded in a smaller region compared to the wide distribution of real-world on-road data. This is mainly caused by the fact that the FTP test cycle has no engine-off time included during the warm-up duration.

\subsection{Temperature of Exhaust Gases Entering the SCR System (SCR Temperature)}

It is widely accepted that the SCR temperature needs to be at least $200^{\circ} \mathrm{C}$ before significant $\mathrm{NOx}$ reduction is achieved [7], but there are times when this temperature requirement may not be met, such as right after engine start. In addition, there are times when the engine coolant temperature 
is stabilized, but the SCR temperature is still lower than $200^{\circ} \mathrm{C}$, as shown in Figure 6 . That is, coolant temperature alone is not always sufficient to identify cold-start conditions when considering the potential impact on emission performance. As a result, a comprehensive examination of cold-start performance from the perspective of the temperature of exhaust gases entering the SCR system was also conducted using the Fleet DNA and CE-CERT datasets. The corresponding analytical results are described in the following section.

Unfortunately, as with the engine output power data, not all the vehicles from Fleet DNA have the required SCR temperature information. Some vehicles do not broadcast these data, or some others broadcast un-reasonable value instead. In fact, among all the 435 vehicles in Fleet DNA, there are only 110 vehicles that satisfy the requirement needed to derive the SCR temperature information. On the other hand, there are 10 vehicles in Drayage group from the CE-CERT data that did not broadcast SCR temperature data. The detailed vehicles sampling of Fleet DNA and CE-CERT data sets for SCR analysis is shown in Appendix K.

It should also be noted again that based on the combined SCR temperature and engine coolant temperature, the engine-start as well as the related engine operational times were separated into five groups, as seen in Table 12. All five kinds of engine-starts have been considered in the following analysis.

\subsubsection{Cold and Warm Operation}

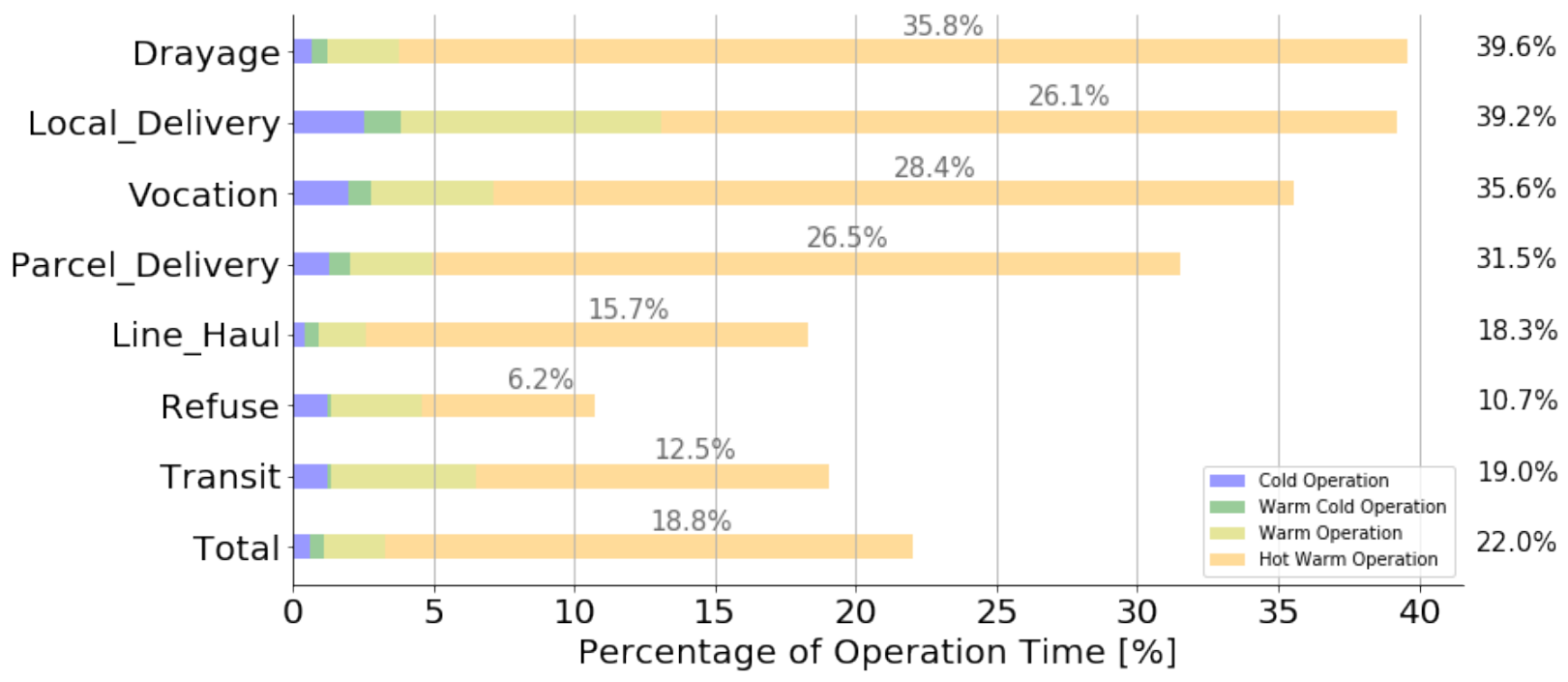

Figure 21. Fraction of Different Operational Times Segmented by Vocations (with SCR)

Figure 21 shows the related percentage of different groups of operational time (as defined in Table 12) segmented by vocations. As can be seen, the hot-warm operation, which indicates the period while engine coolant temperature is larger than $75^{\circ} \mathrm{C}$, but the SCR temperature is lower than $200^{\circ} \mathrm{C}$, are significant for several groups. For example, Drayage, Local Delivery, Vocation, and Parcel Delivery respectively possess $35.8 \%, 26.1 \%, 28.4 \%$, and $26.5 \%$ of total operational time under the hot-warm condition. In addition, the hot-warm operation for all the vehicles in the data sets reaches the fraction as high as $18.8 \%$. 
It should also be noted that the Fleet DNA and CE-CERT data have a good agreement on the sum of the cold, warm-cold, and warm fractions. The significant fraction of hot-warm operational times shared by such vocational groups from both data sets reflect the importance of thermal management on the SCR system for effective NOx emissions reduction. Besides the engine coolant temperature, novel approaches are still required to raise and maintain the SCR temperature after an engine start.

\subsubsection{Start per Day}

NREL investigated the percentage and the daily average of each engine-starts to characterize the engine-start performance from the perspectives of both engine coolant and SCR temperatures.

Figure 22 shows the percentage information in the Fleet DNA and CE-CERT datasets. As can be seen, on average, $48.1 \%$ of engine-starts are hot-warm starts, representing a large portion of total engine-starts. Some vocations, such as Line Haul, Parcel Delivery, Drayage, and Local Delivery have even higher portions of hot-warm starts, which are $67.1 \%, 64.1 \%, 58.8 \%$, and $52.1 \%$ respectively. This feature emphasizes again that specific approaches must be implemented to handle the emission issue related to the hot-warm engine-start.

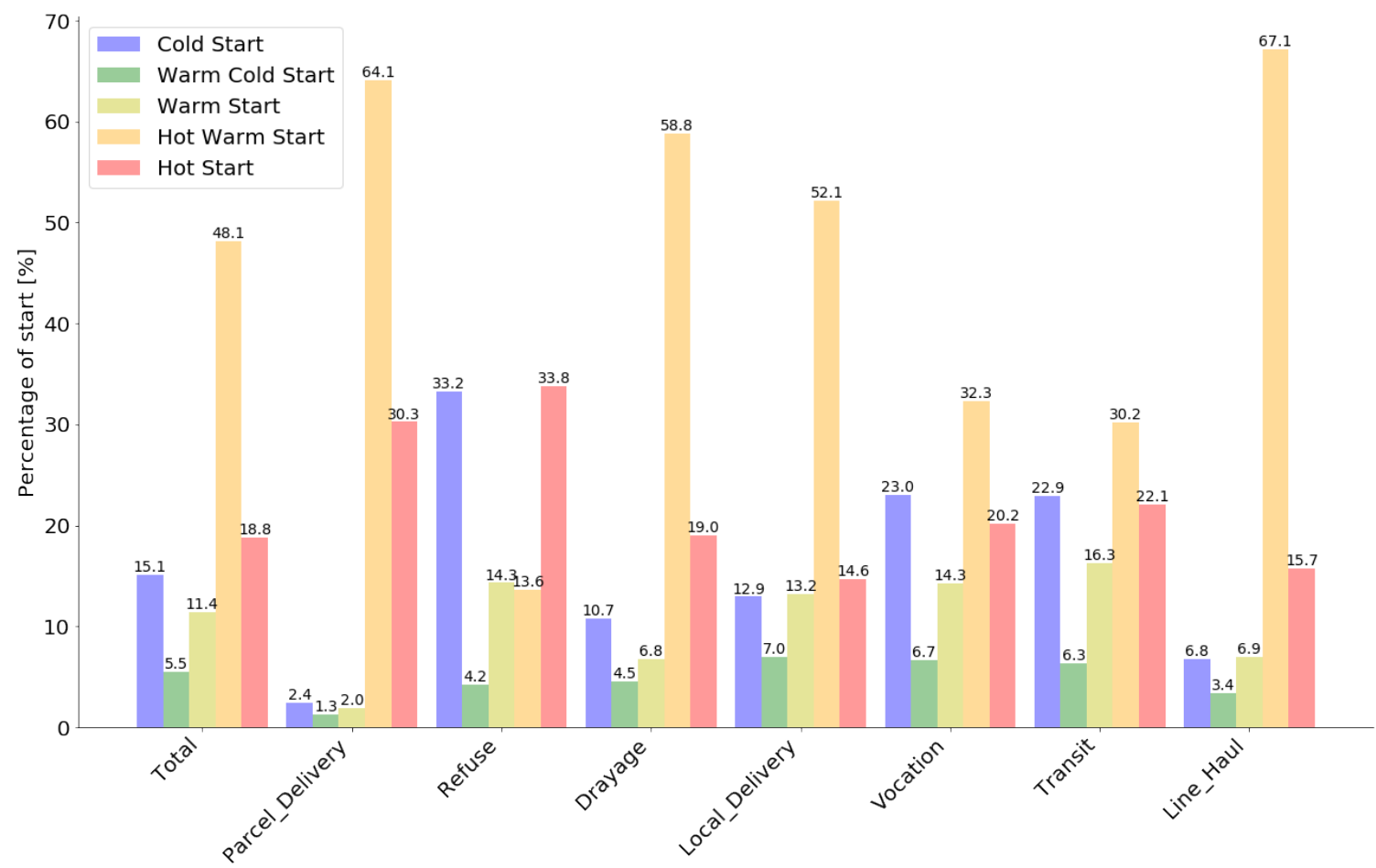

Figure 22. Percentage of Five Kinds of Engine Starts (with SCR)

Figure 23 shows the corresponding average numbers of these engine-starts from the Fleet DNA and the CE-CERT data. As can be seen, on average, there are about 3.6 times hot-warm enginestarts for all the vehicles. The situation is more severe for Parcel Delivery, Local Delivery, Line Haul, and Drayage applications, which possess about 41.0, 6.5, 4.9, and 4.6 times hot-warm start per day. 


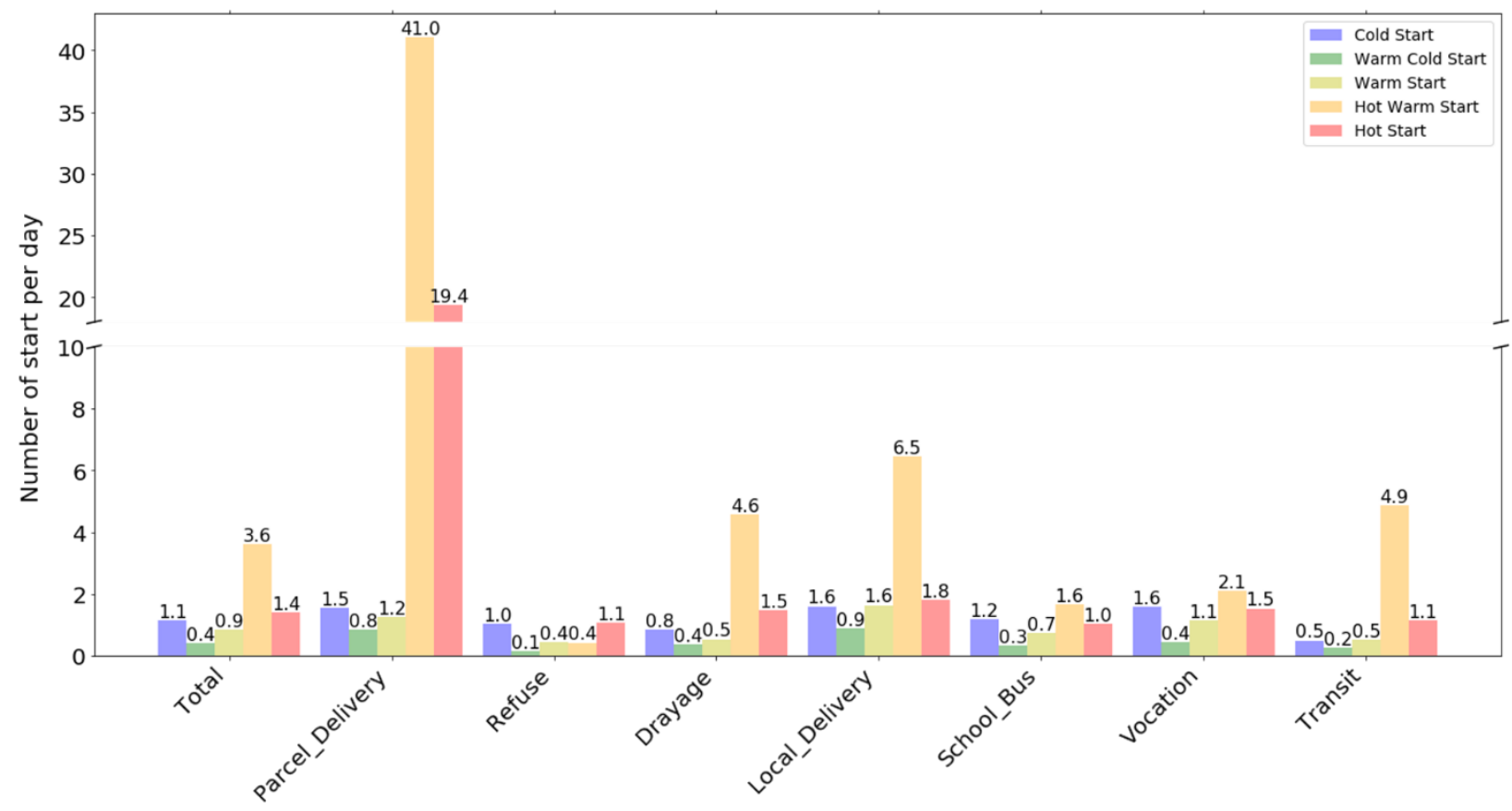

Figure 23. Average Five Kinds of Engine Starts Per Day (with SCR)

\subsubsection{Soak Time}

Figure 24 shows the average soak time before each of the five engine-start categories segmented by the seven vocational groups. Usually, cold-starts occur after the longest soak time while hotstarts possess the shortest soak periods. As can be seen, Drayage Refuse, Vocation, and Line Haul still have over 10-hour soak times before their cold-starts on average. The rest of the three, namely Transit, Local Delivery, and Parcel Delivery, have similar average cold soak times compared to Figure 11.

Figure 24 also offers us a metric to differentiate the categories of engine-start. Looking at the results of Line Haul as an example, the soak time is less than 5 minutes, the related engine-starts are most likely to be hot-starts. When the soak time is extended to 11 minutes, the engine-starts are likely hot-warm starts, while the engine coolant temperature is still $75^{\circ} \mathrm{C}$, but the $\mathrm{SCR}$ temperature is below $200^{\circ} \mathrm{C}$. Such metrics can also be used to determine other kinds of enginestarts for Line Haul vehicles as well as the other vocational groups. 


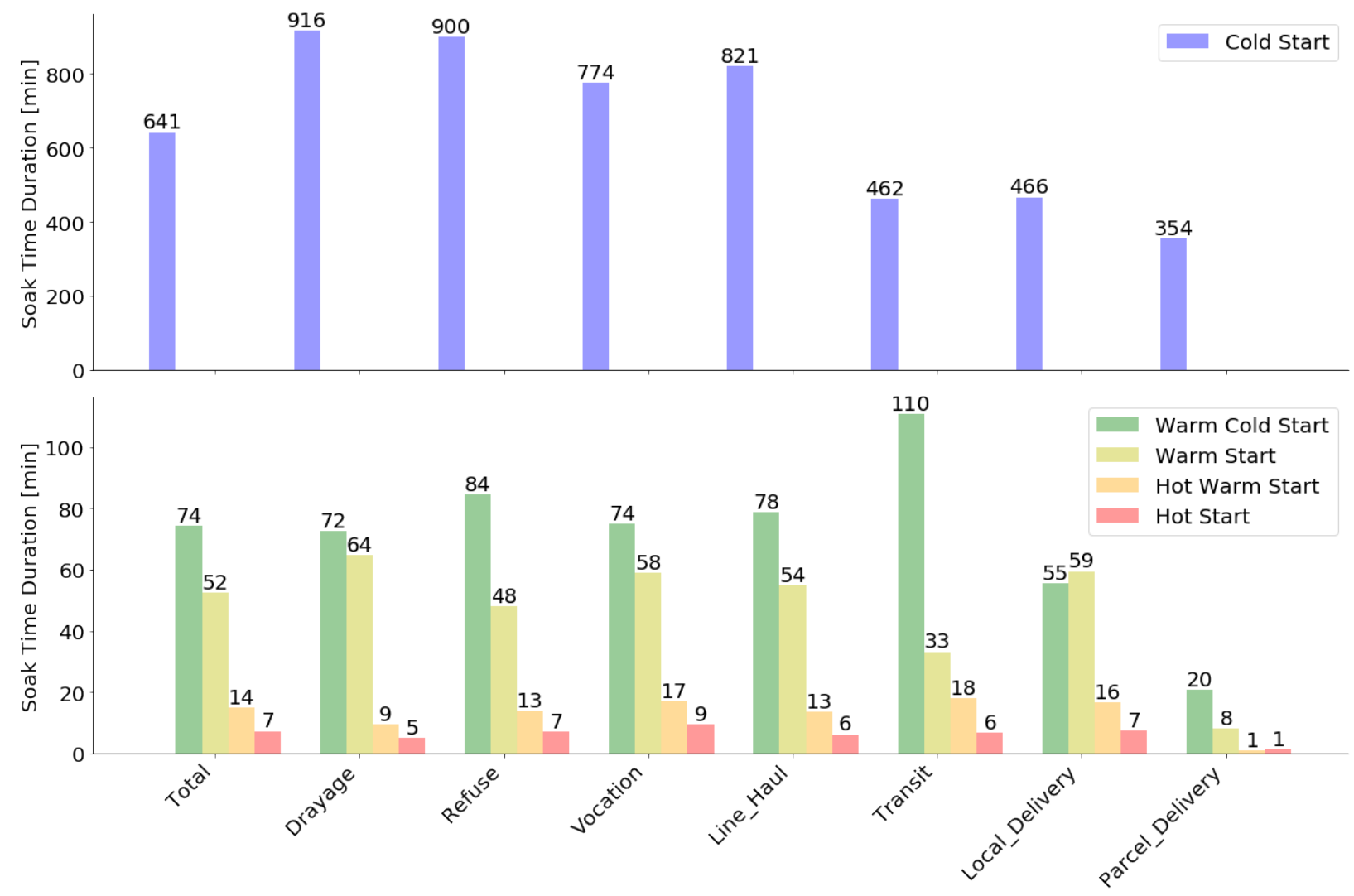

Figure 24. Average Soak Times Segmented by Vocations (with SCR)

\subsubsection{Warm-Up Duration from Each Kind of Engine Start}

Figure 25 shows the average warm-up duration from each kind of engine-start segmented by different vocations in the Fleet DNA and CE-CERT datasets. The cold start takes a longer duration to warm-up and the hot-warm start needs less time for warm-up. The average values of each engine-start from the total of all vehicles across the two data sets give us more insights on the relationship between the engine-start performance during the warm-up duration. To be more specific, the vehicles on average has a 19 minutes warm-up duration from cold-start, 11 minutes from warm-cold, 7 minutes from warm, and 4 minutes from hot-warm start respectively. 


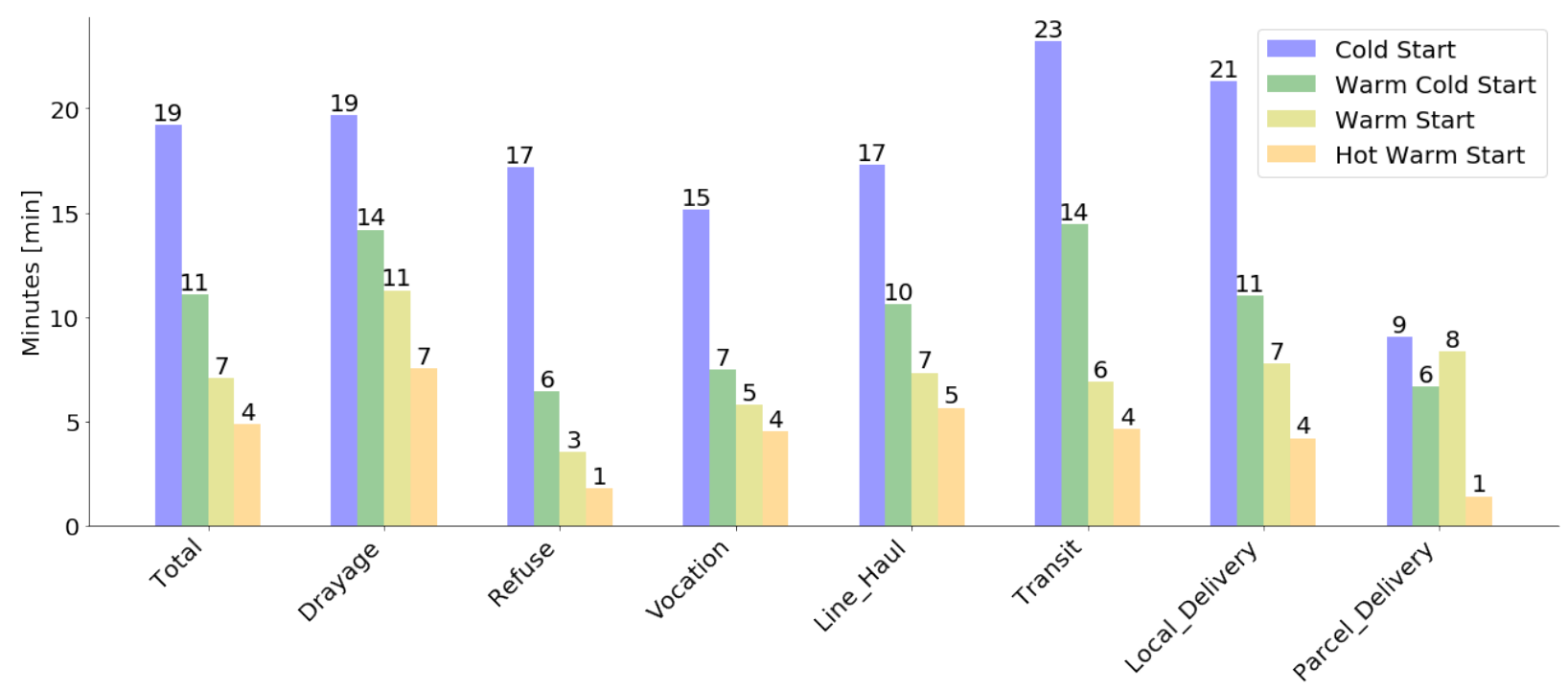

Figure 25. Warm-Up Duration Segmented by Vocations (with SCR)

It is also worth mentioning that from Figure 25, the on-road vehicles still need about 5 minutes to warm-up the SCR system from the hot-warm engine-start. So, in this period, even though the engine coolant temperature is stabilized, the vehicle can still produce significant NOx emission due to the relatively low SCR temperatures.

\subsubsection{Summary of Conclusions for SCR System Temperature Analysis}

Since it is possible that an engine can be operating with a stabilized (hot) coolant temperature higher than $75^{\circ} \mathrm{C}$, but the SCR system can be simultaneously operating below its ideal temperature of $200^{\circ} \mathrm{C}$, this study evaluated cold-start characteristics under both coolant and SCR temperatures regimes. The corresponding useful conclusions are listed in the following:

- Based on the engine coolant temperature and SCR inlet temperature, the engine-starts were separated into five groups, as shown in Table 12. More empathizes should be placed on the analysis of hot-warm starts, of which coolant temperature is higher than $75^{\circ} \mathrm{C}$, but the SCR temperature is lower than $200^{\circ} \mathrm{C}$.

- From the perspective of operational time, the hot-warm operations are significant in several groups. For example, Drayage, Local Delivery, Vocation, and Parcel Delivery possess $35.8 \%, 26.1 \%, 28.4 \%$, and $26.5 \%$ of total operational time under the hot-warm condition.

- Both fraction and average start per day show that the hot-warm starts represent a large portion of total engine-starts. Focusing on the Line Haul trucks as an example, $69.8 \%$ of engine starts are hot-warm starts, which indicates that novel approaches are still required to raise up the SCR temperature quickly after engine-starts in order to control NOx emissions.

- Usually, if the engine soaks for 4 to 5 minutes, the next engine-start is likely to be a hotstart. However, if the engine soaks 7 to 10 minutes, even though the coolant temperature is still stabilized, the SCR temperature can be lower than $200^{\circ} \mathrm{C}$, and the corresponding engine-start should be considered as a hot-warm start as defined by this study. 
- The in-use data reveals that the vehicles still take 4 to 5 minutes (varied based on the vocational group) to warm-up the SCR system from the hot-warm engine. This period may have been neglected by previous studies since the coolant temperature is high enough and the engine is considered hot. Under these conditions, the NOx emission can be still significant due to the lower SCR operating temperatures. 


\section{Conclusion}

In this study, NREL has investigated the characterization of cold-start performance of mediumduty and heavy-duty diesel engine equipped vehicles from the Fleet DNA and CE-CERT data sets. With the support of MECA, NREL identified appropriate engine coolant temperature ranges defining cold, warm, and hot operation. The fractions of operational time when engines were within cold and warm temperature ranges were characterized for different vocations across the two data sets. In addition, the distributions of cold-, warm-, and hot-start per day, as well as the soak times before each type of engine-starts, was derived and discussed. A statistical analysis of the warm-up duration from cold- and warm-starts was also conducted. In addition, the average engine output power, was used to represent driving behavior during the warm-up duration. The relationship between the engine output power and the warm-up duration from the in-use data were then derived and the corresponding results were also benchmarked with engine dynamometer tests over the FTP. Finally, a detailed analysis of the temperature of the SCR system at engine-start was conducted from the perspectives of operational time, starts per day, soak time, and the warm-up duration. The following section will highlight the instructive conclusions that have been developed from the study.

\subsection{Conclusion Remarks}

Based on the analysis of the study, the concluding remarks were summarized from five perspectives, which are cold and warm operation, start per day distribution, soak time distribution, warm-up duration, and the temperature of exhaust gases entering the SCR system.

\subsubsection{Cold and Warm Operation}

From both data sets used for this study, the cold operational time of all the vocations were less than $3.0 \%$ of the total operational time. The warm operations varied significantly across the different vocations, from $3.2 \%$ to $11.4 \%$. The variation in warm operation was influenced by several aspects, including the number of cold- and warm-starts per day, driving behavior and the engine size. When considering the total vehicles across all vocations, the cold and warm operational times were $1.3 \%$ and $7.2 \%$ respectively. Further observations are listed in the following:

- The cold operational time is defined as the period when the engine is operating with coolant temperature lower than $40^{\circ} \mathrm{C}$. The warm operational time is the period when the engine is operating with coolant temperature higher than $40^{\circ} \mathrm{C}$ but lower than $75^{\circ} \mathrm{C}$.

- Line Haul and Drayage categories exhibit the smallest amount of cold operational time from both the Fleet DNA and CE-CERT data, which was around 1\%.

- Local Delivery showed the longest duration of operating at cold and warm conditions, which were $2.7 \%$ and $11.4 \%$ respectively.

- Combining the cold and warm operations together, Refuse has the shortest duration of the total operating time under this condition, which is only $4.3 \%$.

\subsubsection{Starts per Day Distribution}

The distribution of starts per day for different vocations was separated into three groups, namely cold-starts per day, warm-starts per day, and hot-starts per day. Both fractions of total starts and average starts per day were investigated. From the perspective of start fractions, the entire 
vehicle dataset has $12.0 \%$ cold-starts, $17.7 \%$ warm-starts, and $70.3 \%$ hot-starts respectively. From the perspective of average number of starts, there were 1.0 cold-starts per day, 1.5 warmstarts per day, and 7.7 hot-starts per day. More details related to each vocation are described in the following:

- More than $60 \%$ of the vehicle-days from the Line Haul category had zero cold-starts and warm-starts since these trucks typically do no soak overnight and the engine will idle for auxiliary power.

- Drayage vehicles had 0.87 cold-starts per day on average. They also possessed more warm-starts per day (2.61 on average) and hot-starts per day ( 9.16 on average) than the line haul category, likely due to frequent stops for queuing, loading, and unloading cargo.

- Most vehicle days in the Refuse category had one cold-start and zero warm- and hotstarts. This is due to the fact that refuse pickup vehicles have few engine-stops during normal operation.

- Vehicles in the Parcel Delivery category have the largest number of hot-starts per day on average, more than 90 . Such a frequent number of daily hot-starts is the result of specific policies employed by some fleets, which require drivers to turn off the engine when they leave the vehicles to deliver packages.

- More than 50\% vehicle-days for the School Bus category had two cold-starts per day. This result is expected since school buses typically pick up students in the morning and drive students back home in the afternoon, with a soak in-between.

\subsubsection{Soak Time Distribution}

From the analysis of the soak time distributions, it is clear that most of the engine hot-starts occurred after approximately 10 minutes of soak time, and the warm-starts occurred after 25-50 minutes of soak time. In addition, as indicated by the average cold soak duration, the vocational groups from the two data sets can be separated into two categories. Drayage, Line Haul, Vocation, and Refuse Pickup are the first one, of which average cold soaks lasted 10 hours or longer. The average cold soaks for the rest, namely Transit, Local Delivery, Parcel Delivery, and School Bus, were less than 7 hours.

Furthermore, the distribution of soak duration was also examined by quantifying the fraction of the soak duration separated into 11 different time bins (see Table 11). Based on this examination, of the in-use data, there were zero hot-starts after one hour of soak and zero warm starts after 6 hours of soak. Some additional observations from each vocation are described in the following:

- Most starts - no matter if they are cold, warm, or hot - possess 30 to 60 minutes of soak duration in Line Haul category.

- For the Drayage, Refuse, and Vocation categories, most of the hot-starts occurred after a soak time of less than 6 minutes, while most of cold-starts had a soak duration longer than 12 hours.

- Due to the specific driving behavior of the Parcel Delivery vehicles, the fractions of soak times with less than 6 minutes are high for all types of engine-starts, which were $40 \%$ for cold-starts, over $65 \%$ for warm-starts, and nearly $93 \%$ for hot-starts.

- Unlike the other vocations, the Transit category had the largest fraction of cold-starts in the "6 to 12 hours" time bin. 
- For the School bus category, most of the engine-starts were in the "less than 6 minutes" and "over 12 hours" time bins. This result demonstrates that during the normal operation, School Buses usually only stops for a few minutes to load or unload students.

\subsubsection{Warm-Up Duration}

The warm-up duration from engine-start is a critical parameter for evaluating the engine emission performance of a vehicle. From this analysis, the warm-up duration derived from the on-road data present some informative insights, especially after benchmarking with the test data against the FTP cycle:

- From the statistical analysis for the warm-up duration from cold-start, most vehicles need about 15 to 20 minutes to warm up on average. The Line Haul, Local Delivery, and Transit categories showed longer warm-up times (around 20 minutes), while Drayage, Vocation, Refuse, and School Bus categories took less time on average (around 15 minutes). The Parcel Delivery trucks have the shortest duration of warm-up time on average (less than 10 minutes). In addition, from the on-road data, it was observed that some cold warm-up durations in real-world driving can be almost 60 minutes. This is due to the existence of excessive engine-off time in this period, driven by multiple short trips with many key-off events.

- The warm-up duration from warm-start, is much shorter than the cold warm-up duration on average. Even though some warm warm-up durations can last 30 minutes, the average warm-up duration, from warm-starts, is less than 10 minutes. Warm warm-up durations, for some vocations are even shorter than 5 minutes, (e.g. Vocation, Refuse, Local Delivery, Transit, and Parcel Delivery). In addition, it is also possible for engines to only take 1 minute or less to warm-up, since the coolant temperature may be very close to $75^{\circ} \mathrm{C}$ at engine-start.

- In this study, the average engine output power was chosen to represent the driving behavior across the warm-up duration. Usually, smaller engines lower output powers leading to longer warm-up durations. From the scatter plots in Section 3.4.4, which includes the relationship between average engine output power and corresponding warmup duration, it can be seen that the engine warm-up duration falls into two groups. One includes the engine-off time and the other does not. Typically, if the warm-up duration from cold-start is longer than 20 minutes, or the warm-up duration from warm-start is longer than 15 minutes, the warm-up duration is likely to include one or more engine-off events.

- FTP cycle test data were also compared with the data derived from the on-road data sets. From a comparison, it is clear that even though all the data are in the same range, the FTP test data are crowded in a smaller region compared to the wide distribution of real-world on-road data. This is mainly caused by the fact that the FTP test cycle has no engine-off time included during the warm-up duration.

\subsubsection{SCR Temperature}

Since it is possible that an engine can be operating with a stabilized (hot) coolant temperature higher than $75^{\circ} \mathrm{C}$, but the SCR system can be simultaneously operating below its ideal temperature of $200^{\circ} \mathrm{C}$, this study evaluated cold-start characteristics under both coolant and SCR temperatures regimes. The corresponding useful conclusions are listed in the following: 
- Based on the engine coolant temperature and SCR inlet temperature, the engine-starts were separated into five groups, as shown in Table 12. More emphasis should be placed on the analysis of hot-warm starts, of which coolant temperature is higher than $75^{\circ} \mathrm{C}$, but the SCR temperature is lower than $200^{\circ} \mathrm{C}$. Under these conditions, the NOx emission can be still significant due to the lower SCR operating temperatures.

- From the perspective of operational time, the hot-warm operations are significant in several groups. For example, Drayage, Local Delivery, Vocation, and Parcel Delivery possess $35.8 \%, 26.1 \%, 28.4 \%$, and $26.5 \%$ of total operational time under the hot-warm condition.

- Both fraction and average starts per day show that the hot-warm starts represent a large portion of total engine-starts. Focusing on the Line Haul trucks as an example, $69.8 \%$ of engine-starts are hot-warm starts, which indicates that novel approaches are still required to raise up the SCR temperature quickly after engine-starts in order to control NOx emissions.

- Usually, if the engine soaks for 4 to 5 minutes, the next engine-start is likely to be a hotstart. However, if the engine soaks 7 to 10 minutes, even though the coolant temperature is still stabilized, the SCR temperature can be lower than $200^{\circ} \mathrm{C}$, and the corresponding engine-start should be considered as a hot-warm start as defined by this study.

- The in-use data reveals that the vehicles still take 4 to 5 minutes (varied based on the vocational group) to warm-up the SCR system from the hot-warm engine. This period may have been neglected by previous studies since the coolant temperature is high enough and the engine is considered hot.

\subsection{In-Use Data Compared to FTP Cycle Data}

One critical objective of this study was to validate the representativeness of the FTP cycle. Based on the analytical result, some conclusions related to the current FTP cycle are listed below:

- The analysis from the in-use data reflects that on average, there are about $12.0 \%(11.4 \%$ from Fleet DNA and 18.2\% from CE-CERT) of engine cold-starts. The current weight for cold-start emission for the FTP cycle is $1 / 7$ or $14.3 \%$.

- The cold operational time from the FTP cycle, based on the three engines that were sampled for this study, is $1.5 \%$, which is comparable to the average value of the in-use data ( $1.3 \%$ from on-road data base). However, the warm operational time is $21.8 \%$ from the FTP cycle, which is much larger than the in-use data (7.2\%). This is highly attributed to the fact that the current 20-minute FTP cycle does not cover enough hot operational time.

- If only considering cold-start and hot-start cases, the required soak times (20 minutes for hot tests, and at least 12 hours for cold tests) to determine the category of engine-start from the current FTP cycle are reasonable.

- However, based on the analysis of this study, it is much better to separate the enginestarts into five groups according to engine coolant temperature and SCR system temperature. If the related cost and time are limited, at least the hot-warm start case should be distinguished from the hot-start case in the FTP cycle. If four kinds of engine starts are employed, the corresponding weights for cold-, warm-, hot-warm-, and hot-start case can be $14 \%, 16 \%, 50 \%$, and $20 \%$ respectively. 
- Changing the soak time before engine-start is a convenient way to achieve various engine-start cases. Enlightened by the study, the required soak time for each of the five kinds of engine-start can be derived. For example, the cold-start case is achieved after the engine has soaked for 10 hours or longer. In addition, the required soak time for warm case, hot-warm case, and hot case would be 60, 20, and 5 minutes respectively.

- Another issue for the current FTP cycle is that it does not include any engine-off period during the warm-up duration. Typically, the engine under the FTP test will continuously operate during the entire test. However, from the in-use data, the real-world driving behaviors include one or more engine-off periods and thus, extending the warm-up duration. To be more representative, the FTP cycle would be better to include this specific period. Further investigation of this issue is required. 


\section{References}

1. EPA. 2015. "Phase 2 Greenhouse Gas Emissions Standards and Fuel Efficiency Standards for Medium- and Heavy-Duty Engines and Vehicles." Available from: http://www3.epa.gov/otaq/climate/refs-heavy-duty.htm.

2. EU. 2011. Commission Regulation (EU) No 582/2011 of 25 May 2011. Implementing and Amending Regulation (EC) No 595/2009 of the European Parliament and of the Council with Respect to Emissions from Heavy Duty vehicles (Euro VI) and Amending Annexes I and III to Directive 2007/46/EC of the European Parliament and of the Council Off. J. Eur, Union (L167/1).

3. Favez, Jean-Yves, Weilenmann, Martin, and Jan Stilli. 2009. "Cold Start Extra Emissions as a Function of Engine Stop Time: Evolution over the Last 10 Years." Atmospheric Environment, 43: 996-1007.

4. Protection of Environment. CFR, Part 86, Title 40, 2004.

5. Zhen, Feng, Clark, Nigel N., Bedick, Clinton R., Gautam, Mridul, Wayne, W. Scott, Thompson, Gregory J., and Donald W. Lyons. 2009. "Development of a Heavy Heavy-Duty Diesel Engine Schedule for Representative Measurement of Emissions," Journal of the Air \& Waste Management Association, 59:8, 950-959, DOI: 10.3155/1047-3289.59.8.950

6. Walkowicz, Kevin, Kelly, Kenneth, Duran, Adam, and E. Burton. 2014. "Fleet DNA Project Data." National Renewable Energy Laboratory. Available from: http://www.nrel.gov/fleetdna

7. Boriboonsomsin, Kanok, Johnson, Kent, and George Scora. 2017. "Collection of Activity Data from On-Road Heavy-Duty Diesel Vehicles.” Technical Report for California Air Resources Board. Available from: http://ww3.arb.ca.gov/research/apr/past/13-301.pdf 


\section{Appendix A: SCR Temperature VS Engine Coolant Temperature at Engine-Start}

\section{A.1 Fleet DNA}

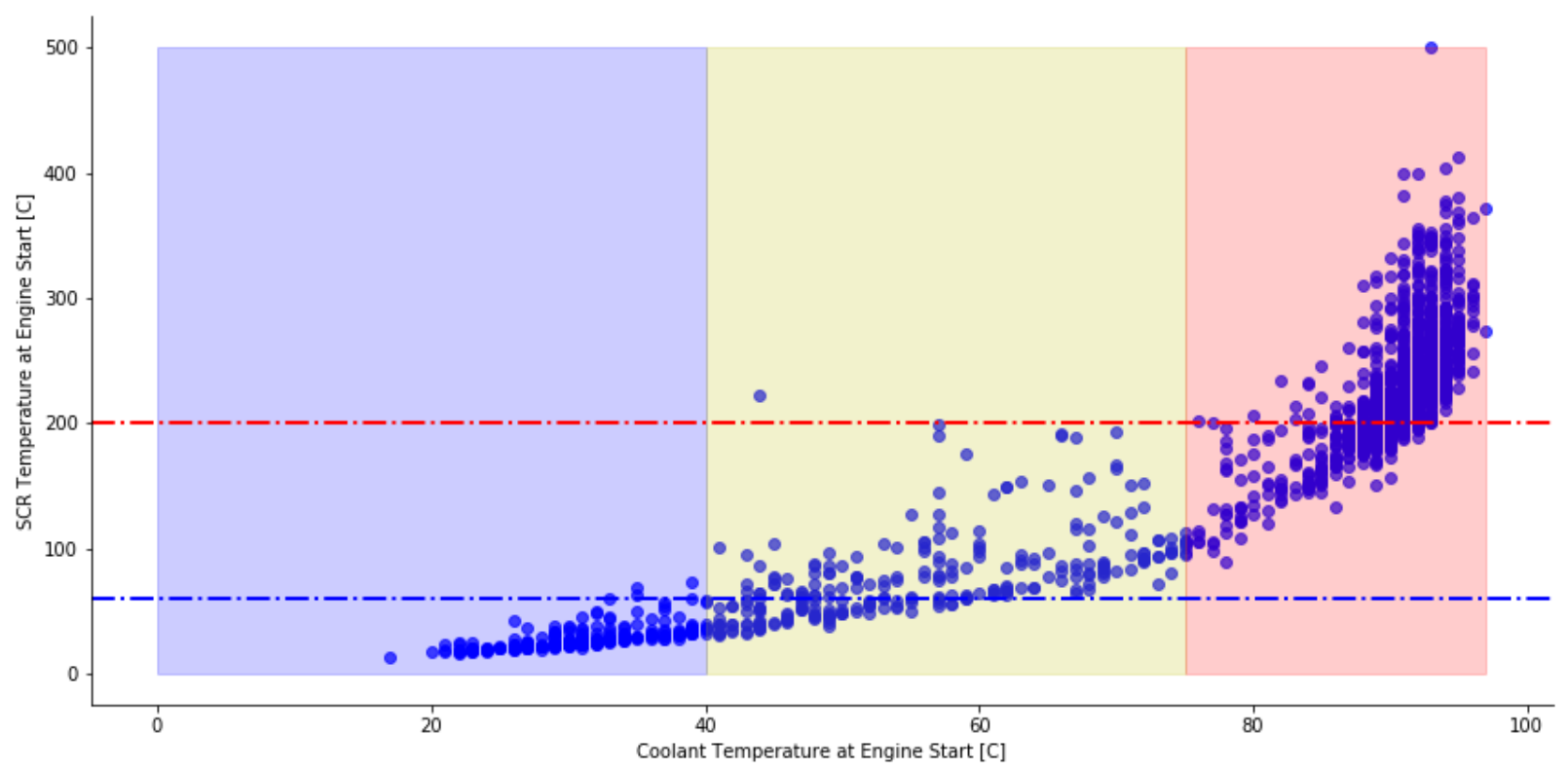

Figure A. 1. SCR VS Coolant Temperature at Engine-Start (Fleet DNA: Transit)

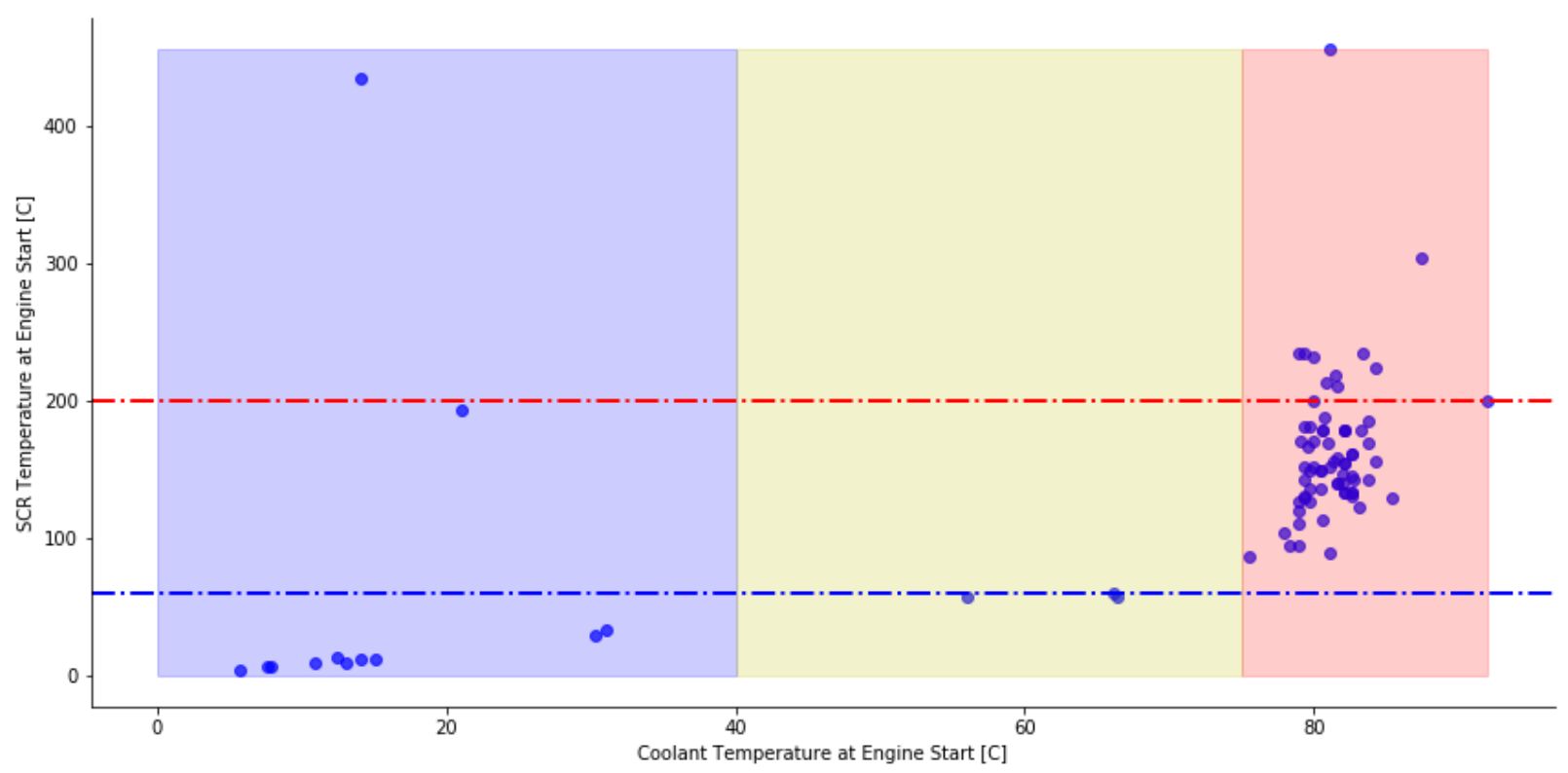

Figure A. 2. SCR VS Coolant Temperature at Engine-Start (Fleet DNA: Vocation) 


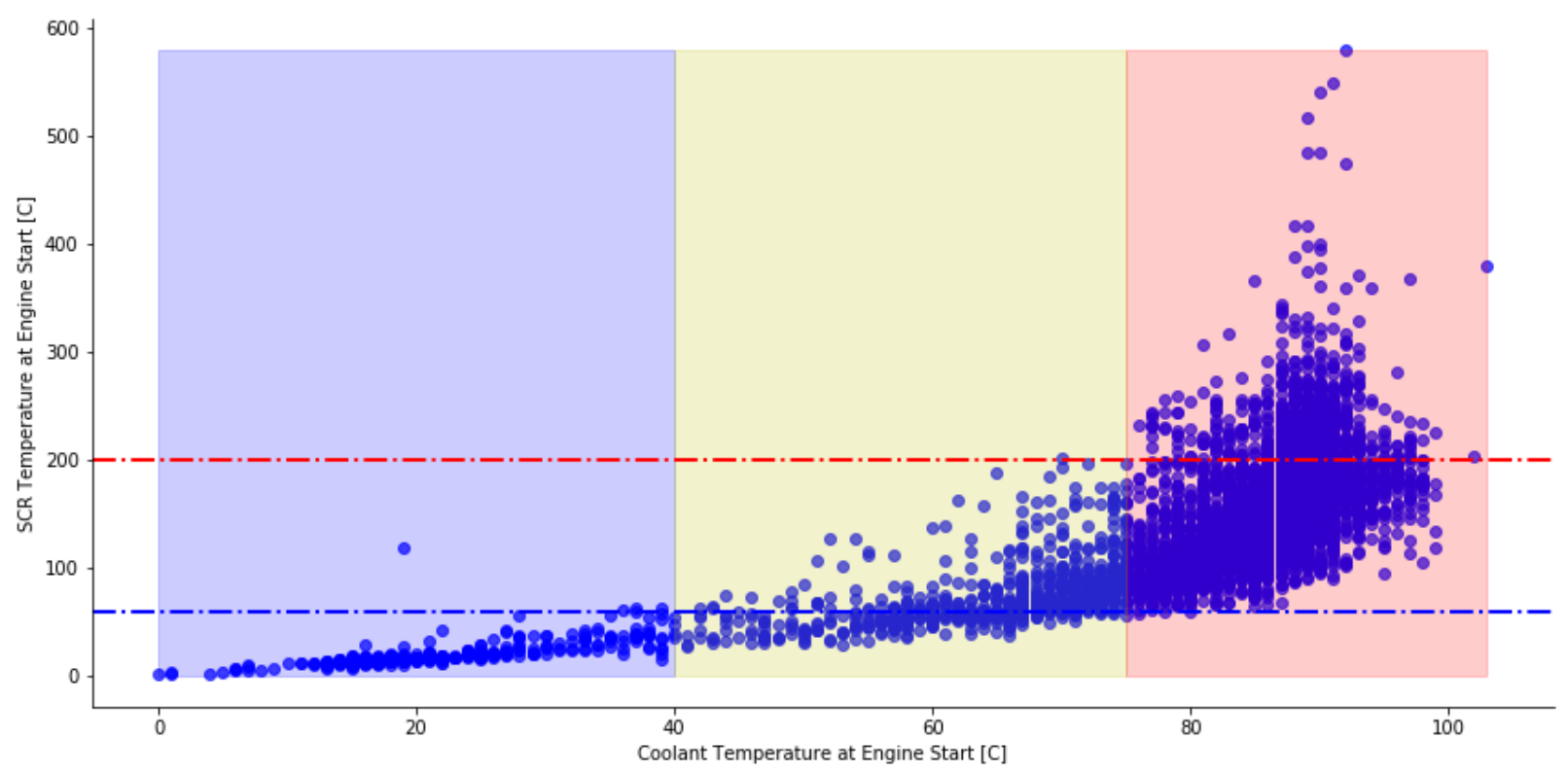

Figure A. 3. SCR VS Coolant Temperature at Engine-Start (Fleet DNA: Local Delivery)

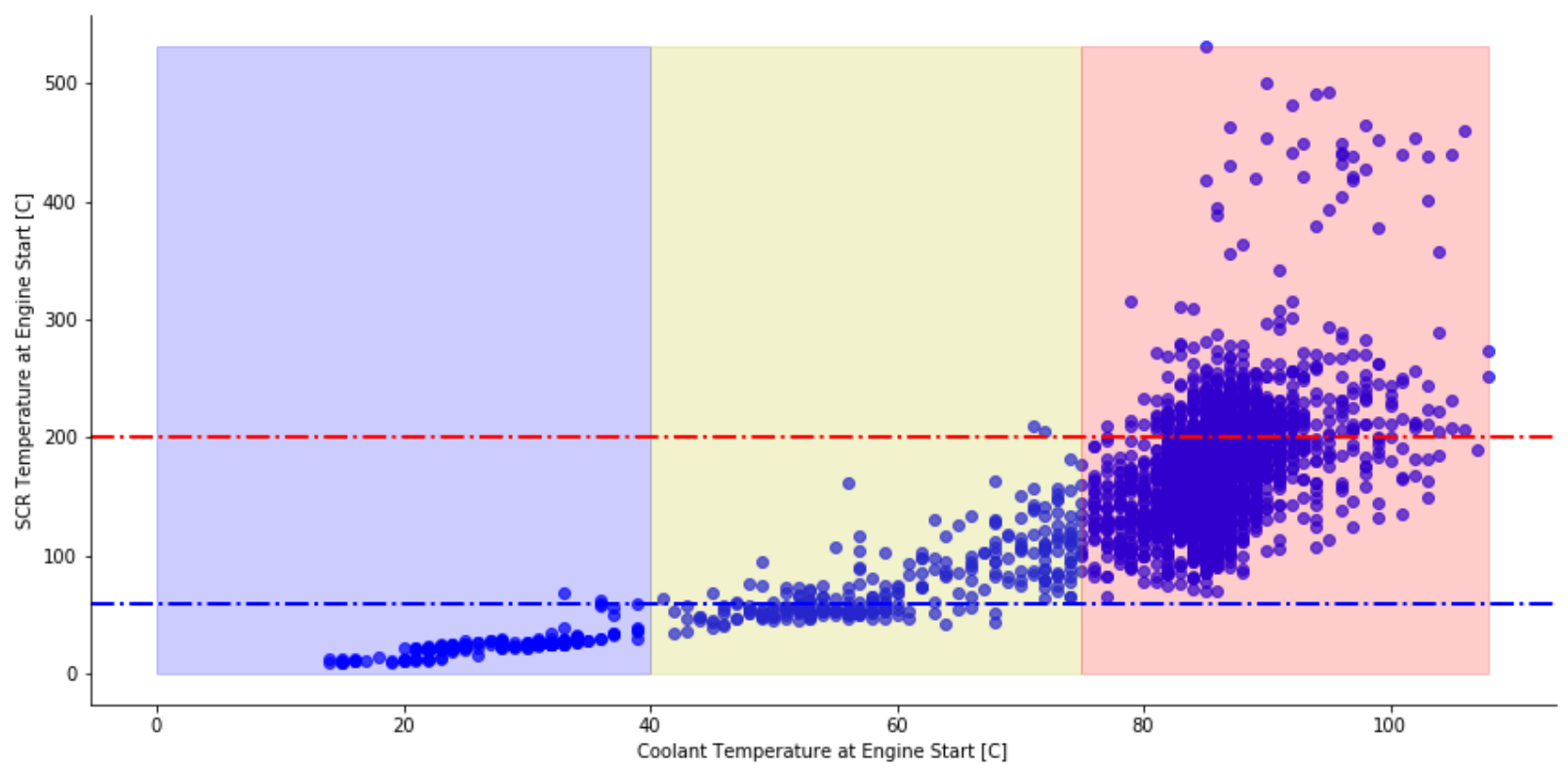

Figure A. 4. SCR VS Coolant Temperature at Engine-Start (Fleet DNA: Drayage) 


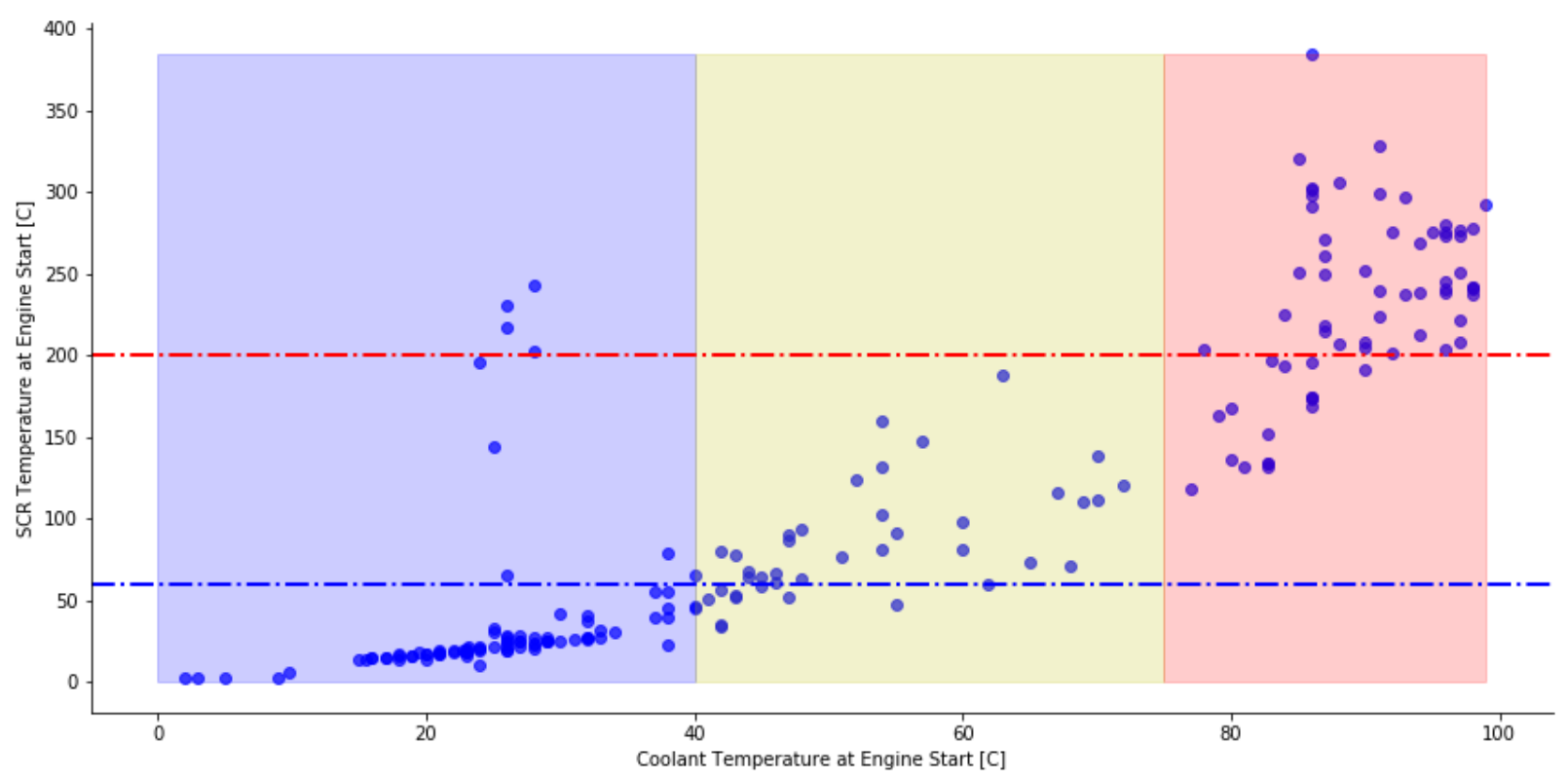

Figure A. 5. SCR VS Coolant Temperature at Engine-Start (Fleet DNA: Refuse)

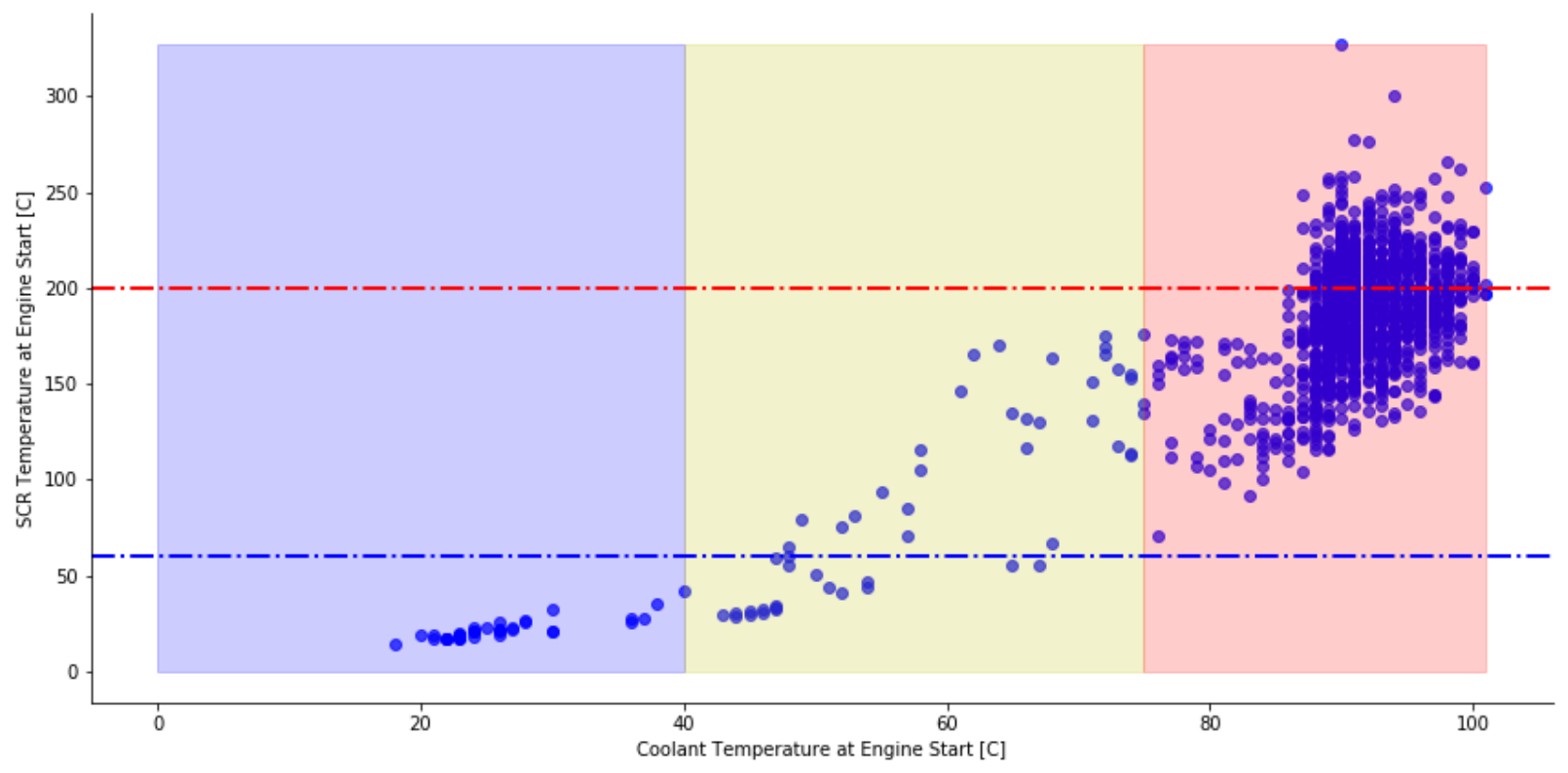

Figure A. 6. SCR VS Coolant Temperature at Engine-Start (Fleet DNA: Parcel Delivery) 


\section{A.2 CE-CERT}

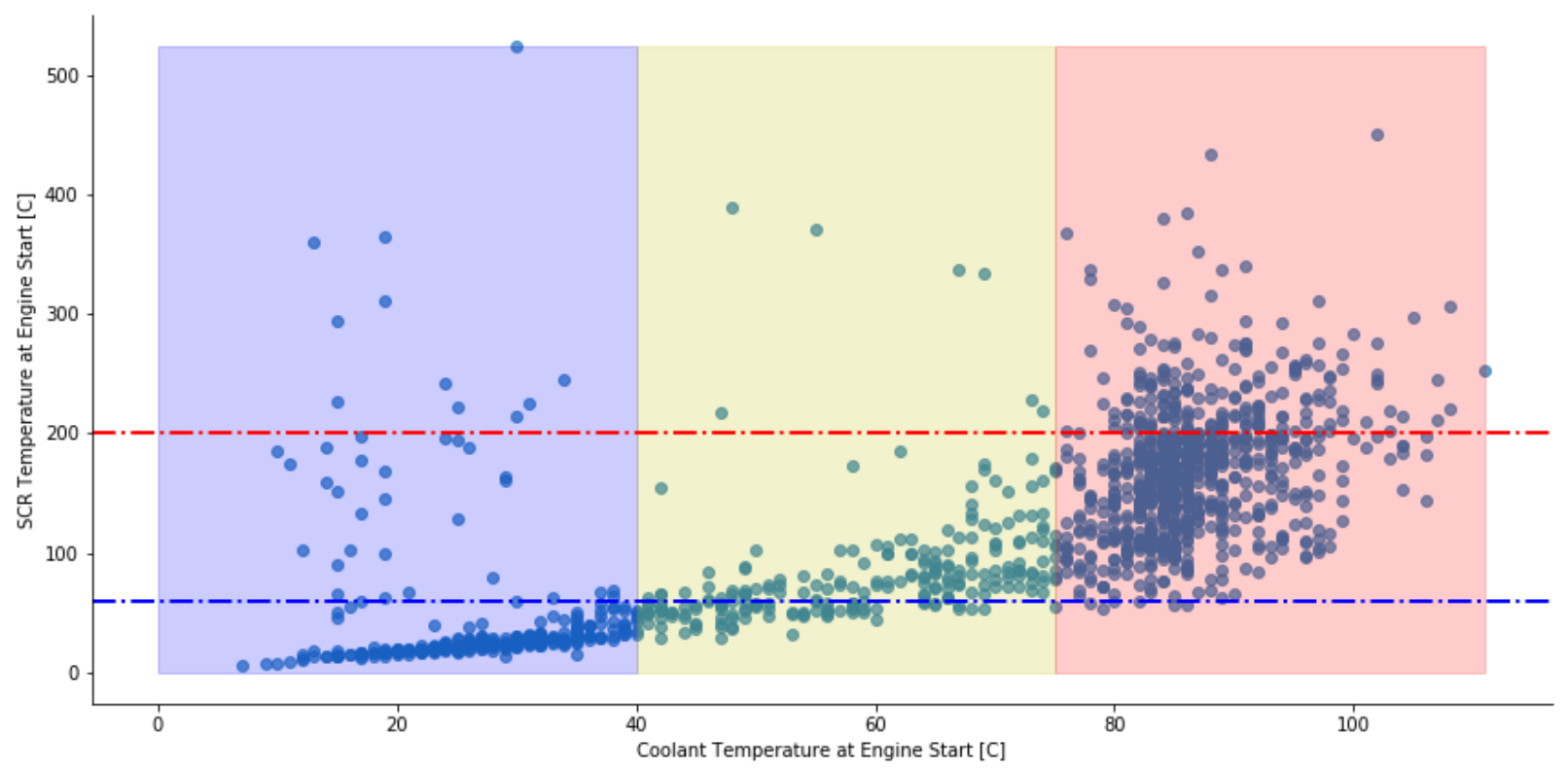

Figure A. 7. SCR VS Coolant Temperature at Engine-Start (CE-CERT: Drayage)

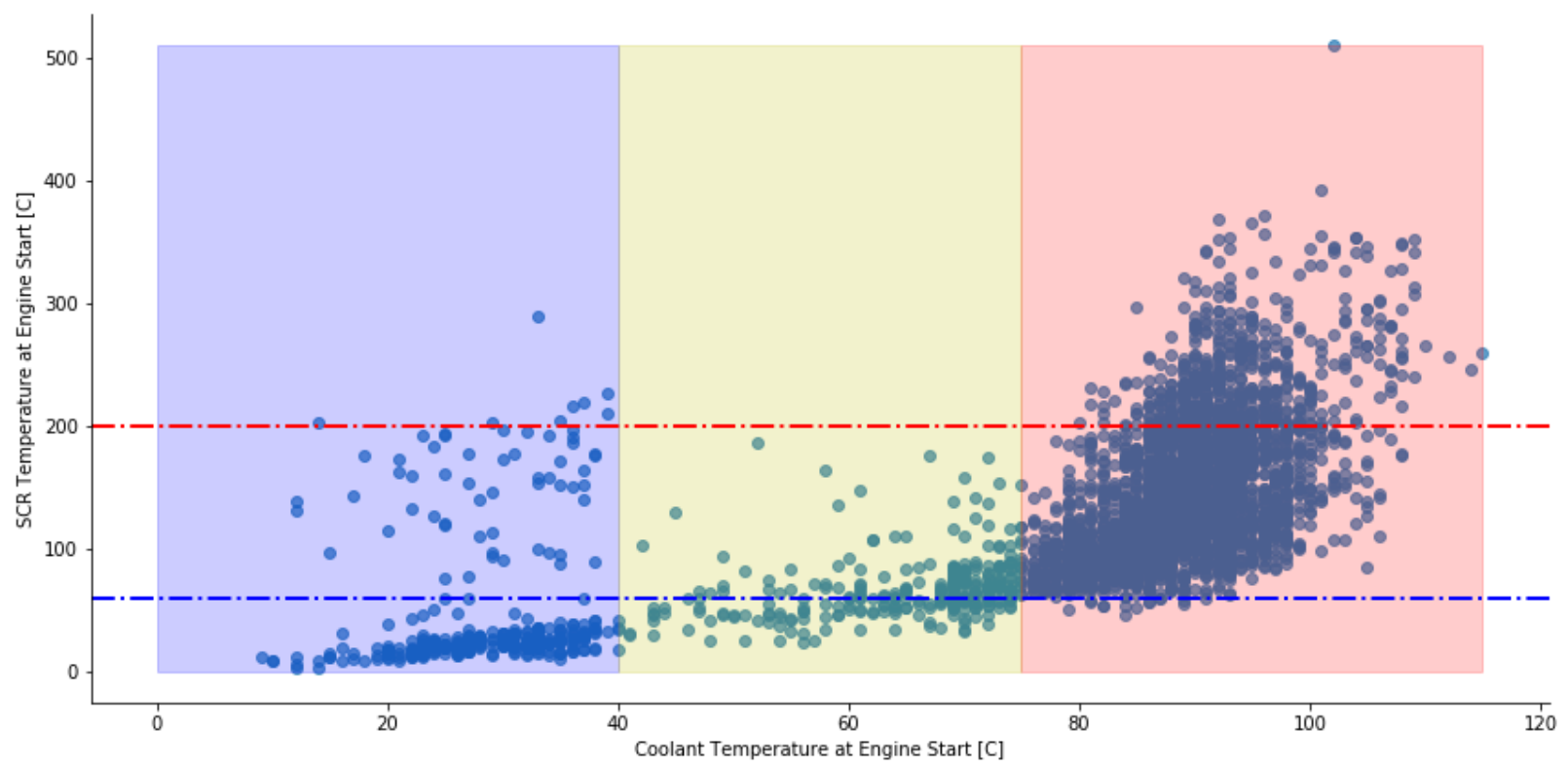

Figure A. 8. SCR VS Coolant Temperature at Engine-Start (CE-CERT: Line Haul) 


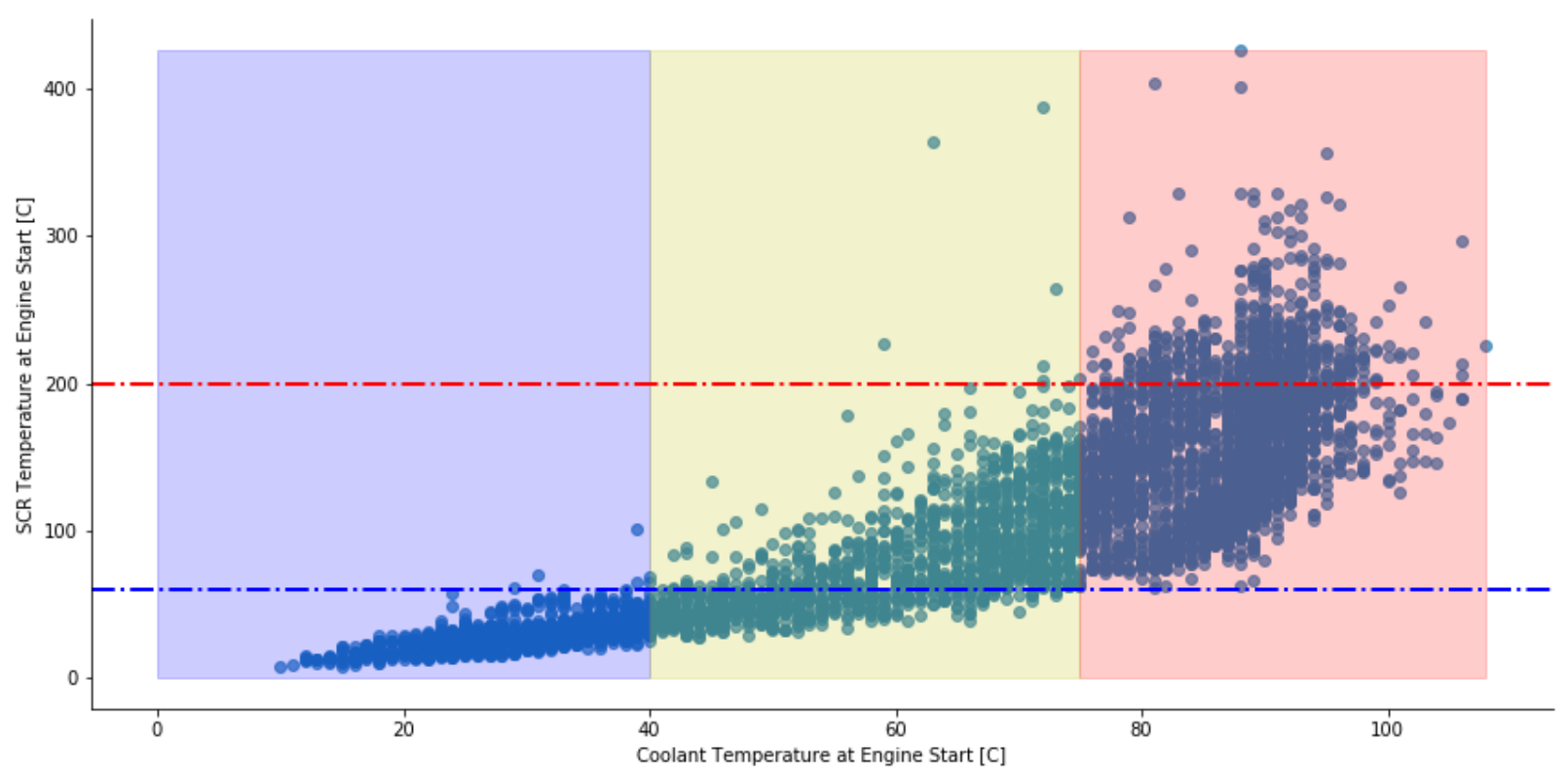

Figure A. 9. SCR VS Coolant Temperature at Engine-Start (CE-CERT: Local Delivery)

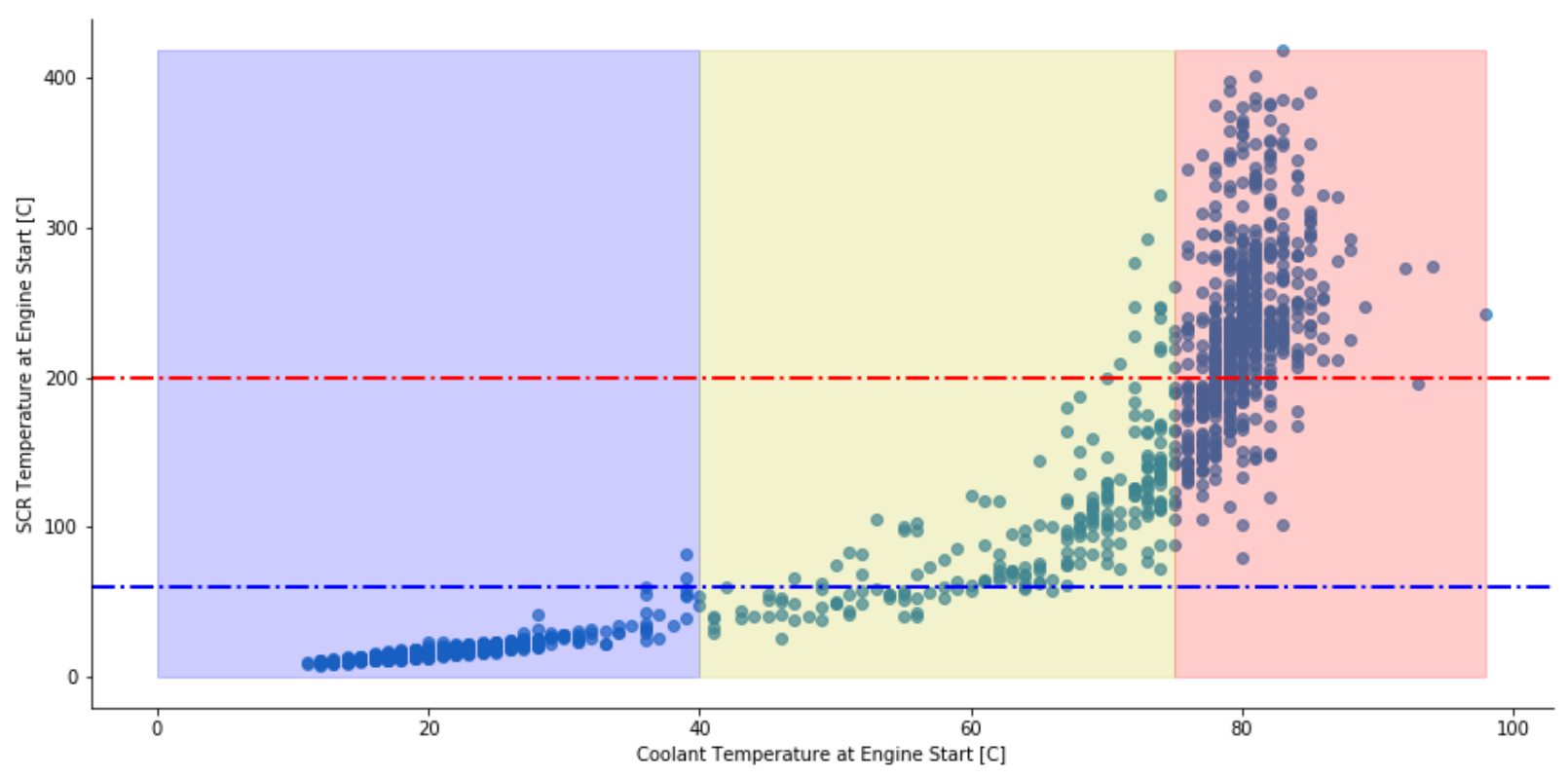

Figure A. 10. SCR VS Coolant Temperature at Engine-Start (CE-CERT: Refuse) 


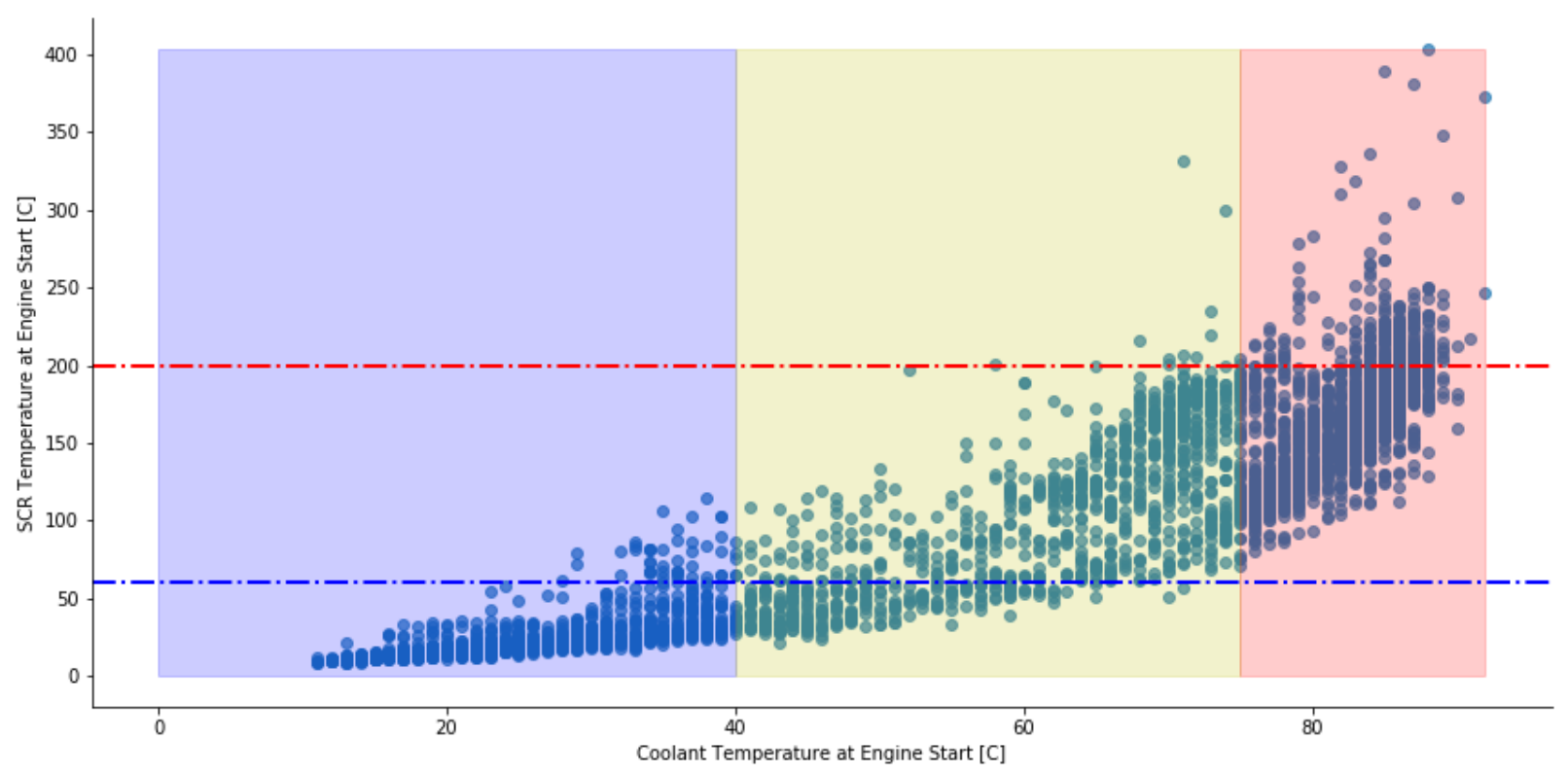

Figure A. 11. SCR VS Coolant Temperature at Engine-Start (CE-CERT: Transit)

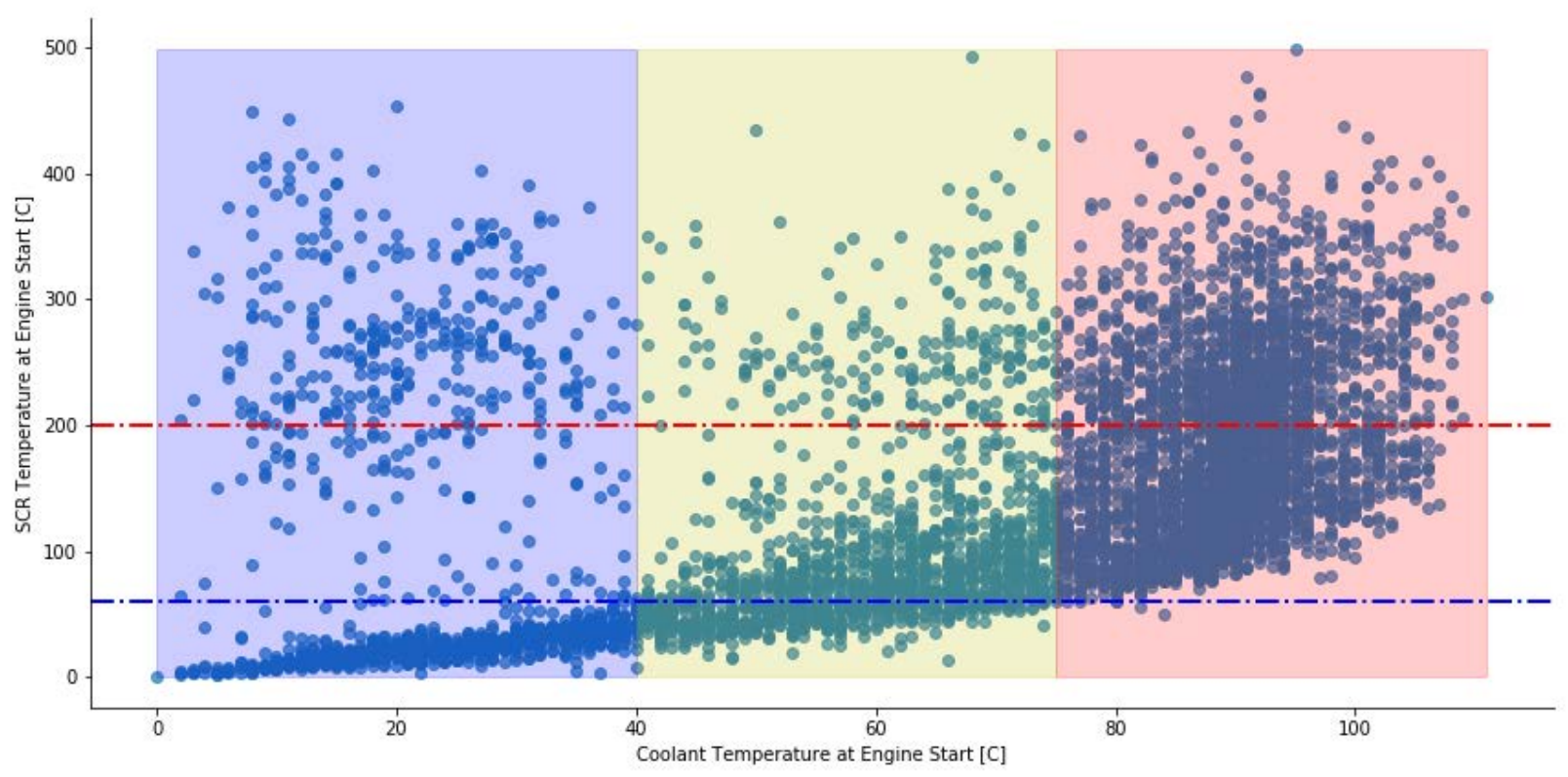

Figure A. 12. SCR VS Coolant Temperature at Engine-Start (CE-CERT: Vocation) 


\section{Appendix B: Distribution of Cold-, Warm-, and Hot- Starts per Day Segmented by Vocations}

\section{B.1. Line Haul}

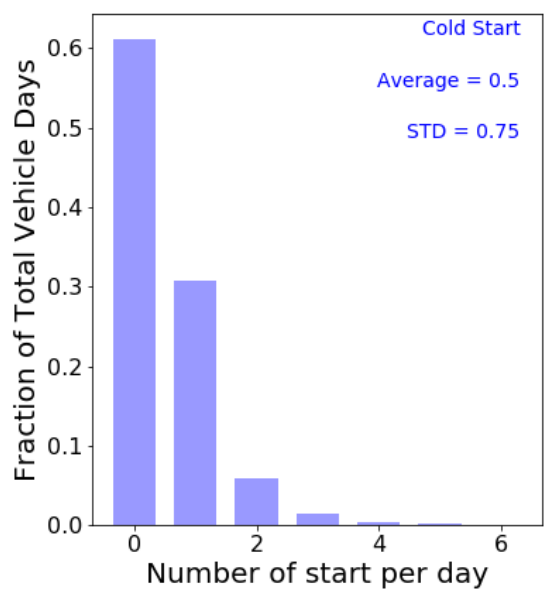

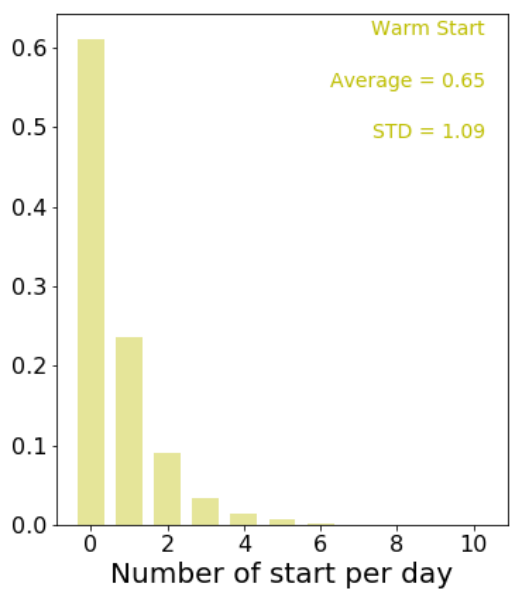

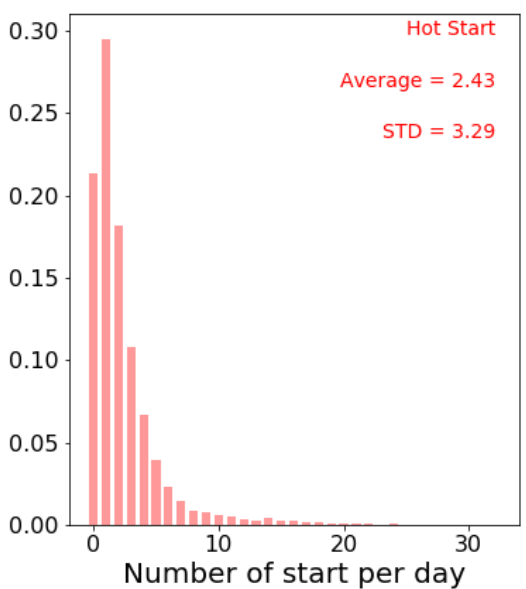

Figure B. 1. Distribution of Cold-, Warm- and Hot-Starts per Day in Line Haul

Figure B. 1 shows the distribution of daily cold-, warm-, and hot-starts for Line Haul category. Clearly, the vehicles in this group have a relatively small amount of starts per day compared with the other groups. Specifically, more than $60 \%$ of vehicle-days have zero cold-starts or warmstarts. This is because these trucks do not soak overnight, and the drivers typically sleep inside with the engine idling to power the air conditioning and other auxiliary systems.

\section{B.2. Drayage}
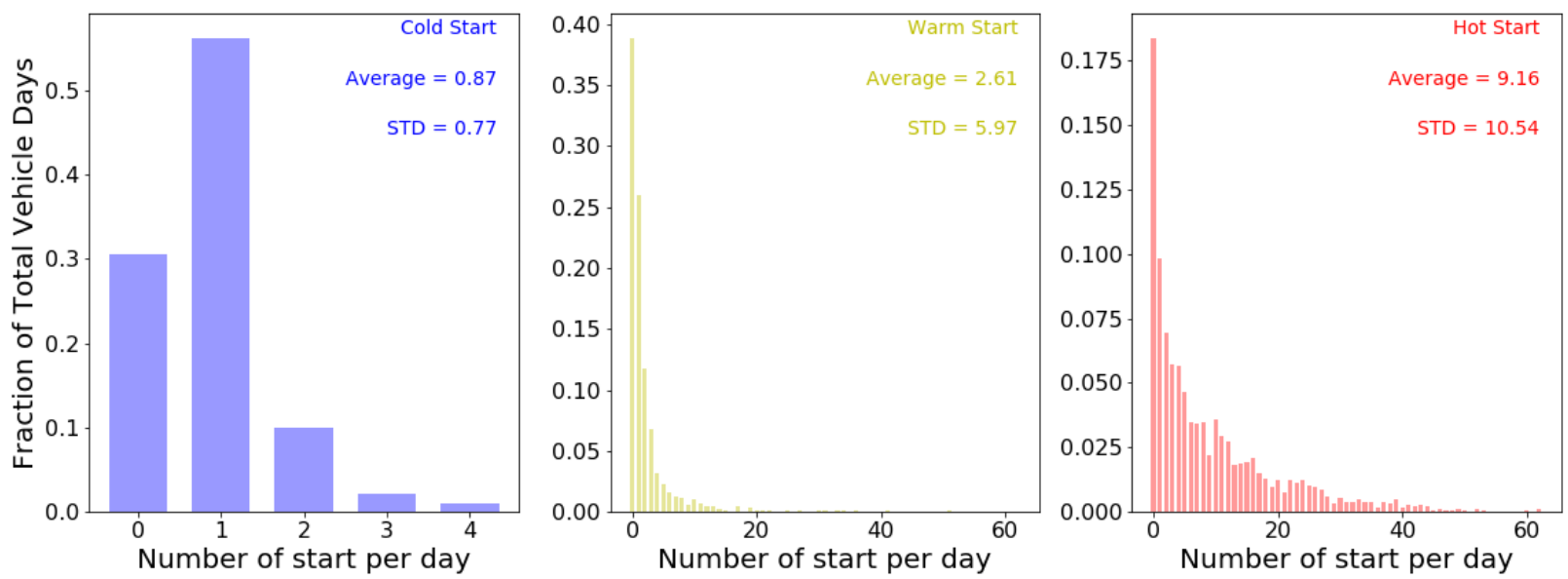

Figure B. 2. Distribution of Cold-, Warm-, and Hot-Starts per Day in Drayage

As can be seen in Figure B. 2, Drayage vehicles have only one cold-start in more than $50 \%$ of the vehicle-days and on average 0.87 cold-starts per day. They also possess more warm-starts per day (2.61 on average) and hot-starts per day ( 9.16 on average), likely due to frequent stops for loading and unloading cargo. 


\section{B.3. Refuse Pickup}
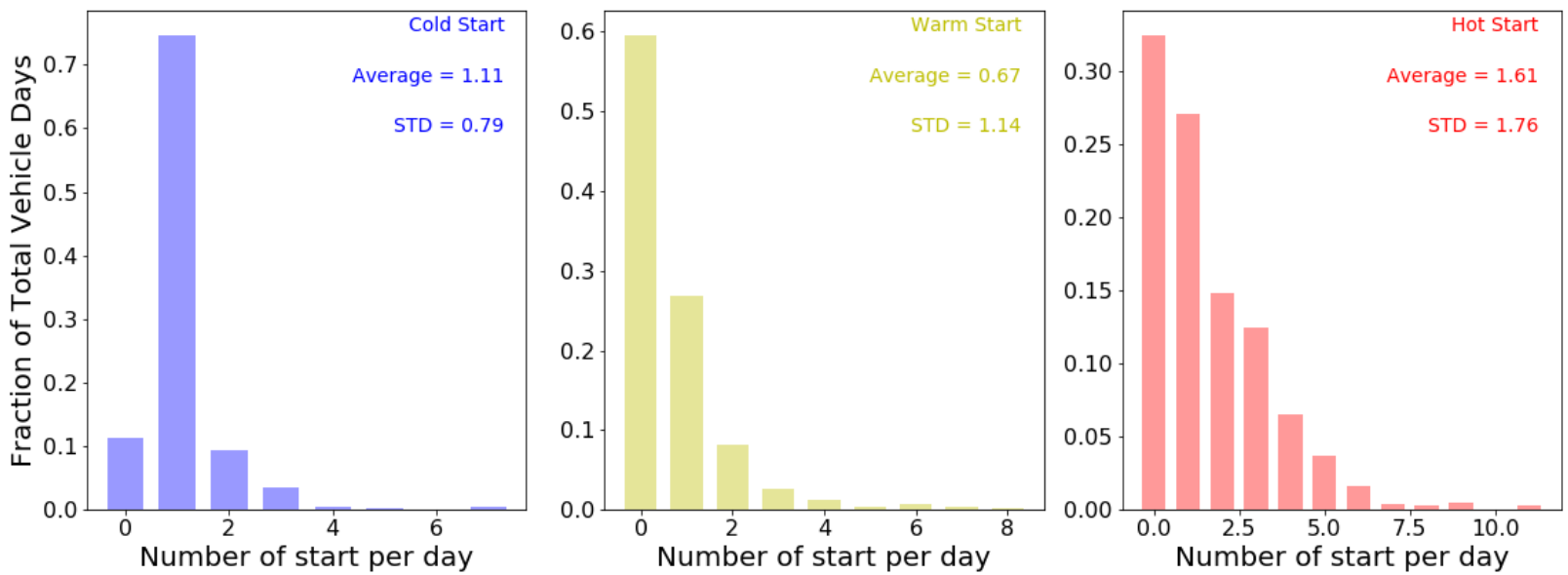

Figure B. 3. Distribution of Cold-, Warm-, and Hot-Starts per Day in Refuse Pickup

Figure B. 3 compares the three kinds of starts per day in Refuse Pickup from both the Fleet DNA and CE-CERT data. As can be seen from the result, over $70 \%$ of vehicle-days have one cold-start per day, almost $60 \%$ of vehicle days have zero warm-starts and more than $30 \%$ vehicle days have no hot-starts.

\section{B.4. Parcel Delivery}
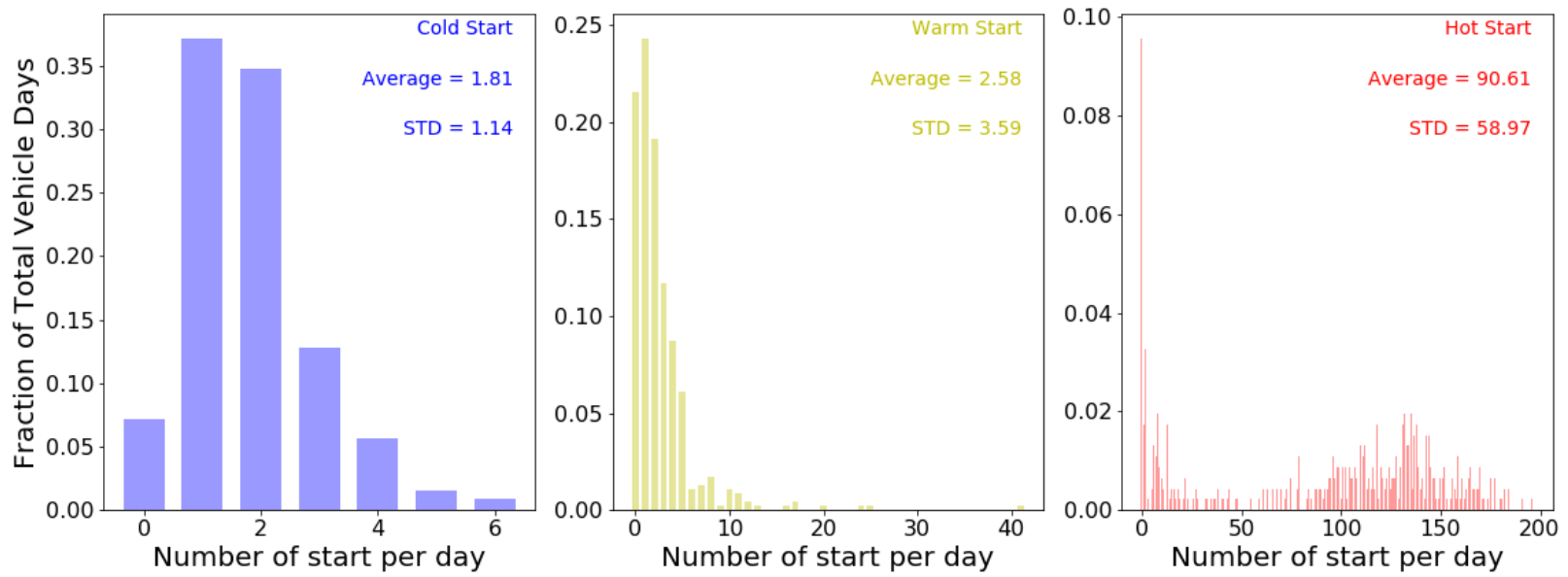

Figure B. 4. Distribution of Cold-, Warm-, and Hot-Starts per Day in Parcel Delivery

Only the Fleet DNA database has vehicles representing the Parcel Delivery category, and Figure B. 4 shows the related start distributions. As shown, more than $70 \%$ of vehicle-days in this group have one or two cold-starts per day. In addition, vehicles in the Parcel Delivery category have the largest number of hot-starts per day on average, more than 90 per day. Such a frequent daily hotstart occurrence is the result of specific policies employed by some fleets, which require drivers to turn off the engine when they leave the vehicle to deliver packages. 


\section{B.5. Local Delivery}
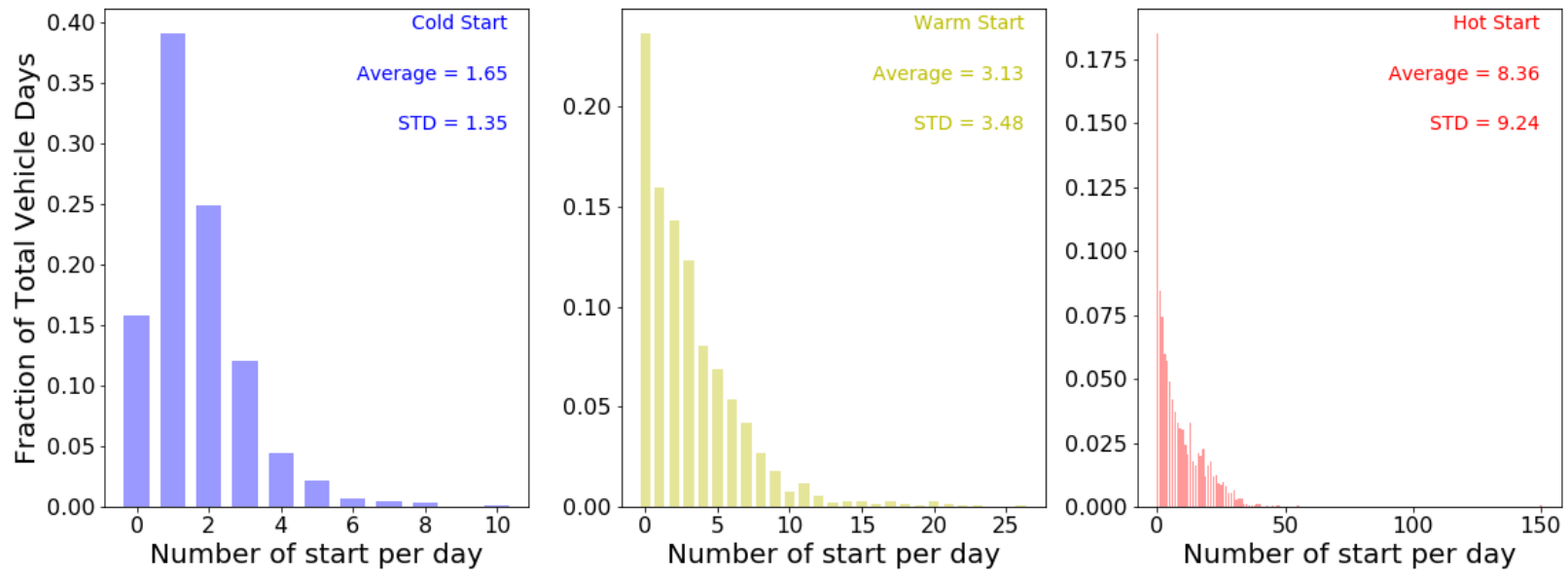

Figure B. 5. Distribution of Cold-, Warm-, and Hot-Starts per Day in Local Delivery

This sub-section shows the distribution of starts per day in Local Delivery from both the Fleet DNA and CE-CERT data sets. As can be seen from Figure B. 5, on average, the data have 1.65 cold-starts per day, 3.13 warm-starts per day, and 8.36 hot-starts per day.

\section{B.6. Transit}
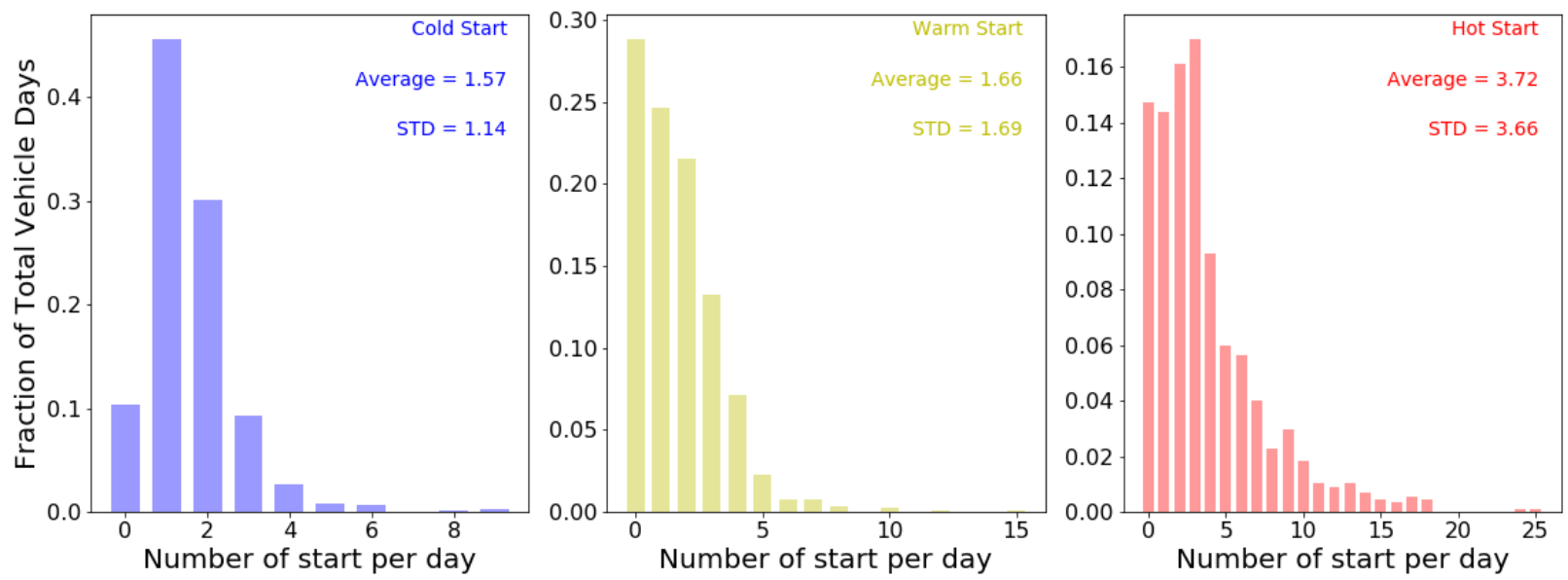

Figure B. 6. Distribution of Cold-, Warm-, and Hot-Starts per Day in Transit

The trend of distributions in the Transit category is like that of the Local Delivery category. As can be seen in Figure B. 6, the average cold-starts per day, warm-starts per day, and hot-starts per day are $1.57,1.66$, and 3.72 respectively. 


\section{B.7. School Bus}
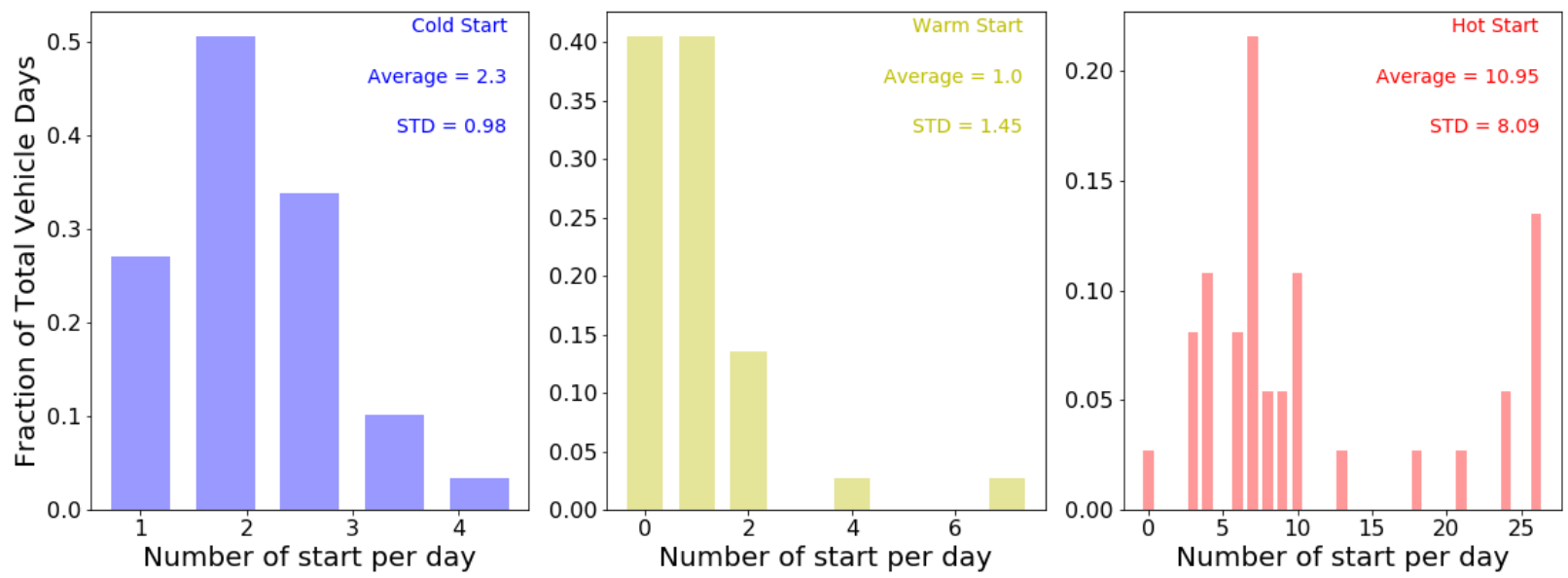

Figure B. 7. Distribution of Cold-, Warm-, and Hot-Starts per Day in School Bus

Only Fleet DNA has vehicles from the School Bus category. As shown above, more than 50\% vehicle-days for this group have two cold-starts per day. This is reasonable since school buses typically operate in the morning to pick-up students and in the afternoon to drive the student back home. In addition, the average number of warm-starts per day is 1.0 and the average hotstarts per day is about 11 .

\section{B.8. Vocation}
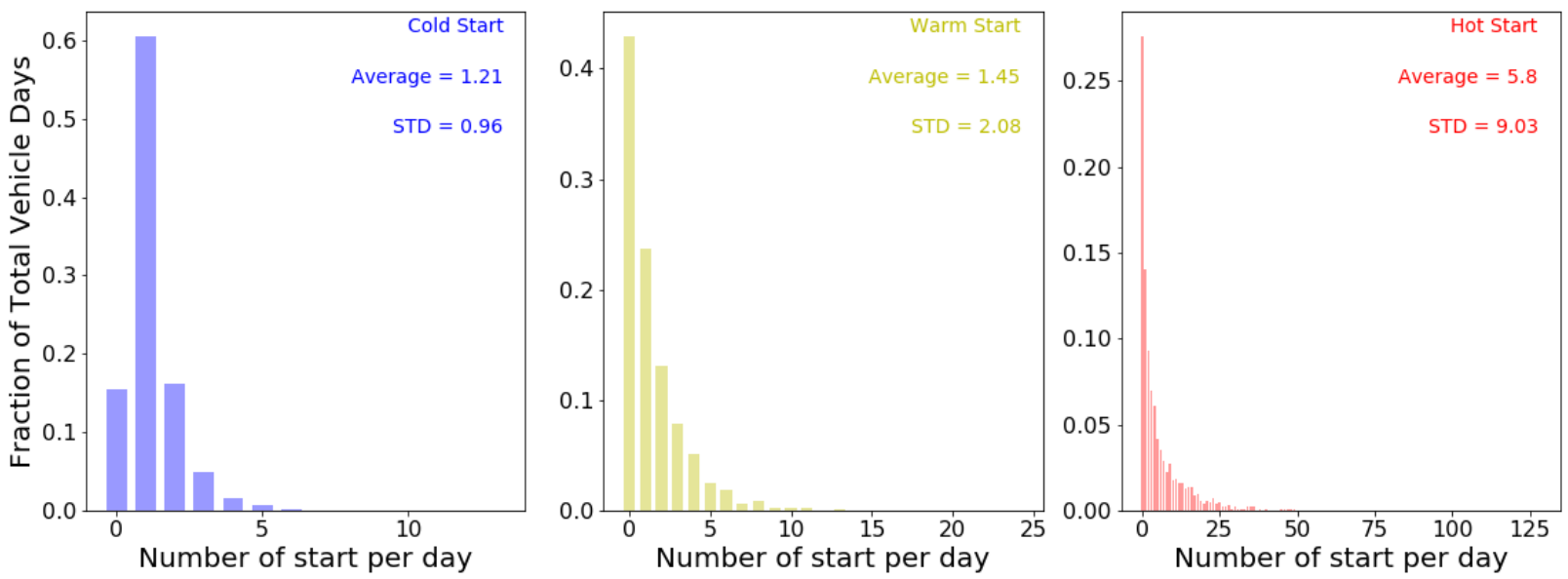

Figure B. 8. Distribution of Cold-, Warm-, and Hot-Starts per Day in Vocation

Figure B. 8 shows the distribution of starts per day for the Vocation group from both Fleet DNA and CE-CERT data sets. It should be noted that the vocations in this group are widely diverse and include snowplow, utility, towing, shredder, dump truck, and concrete mixers among others. Those vehicles may operate daily, but the activity and driving behavior could be vastly different. The average cold-starts per day, warm-starts per day, and hot-starts per day are 1.21, 1.45, and 5.80 respectively. 


\section{Appendix C: Distribution of Cold, Warm, and Hot Soak Time Segmented by Vocations}

\section{C.1. Line Haul}

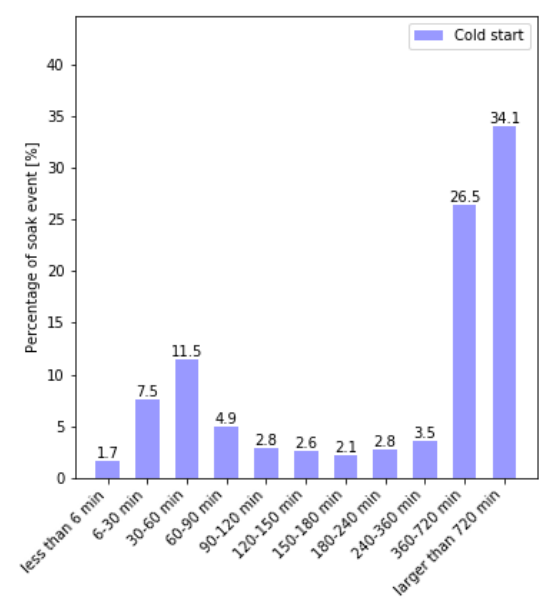

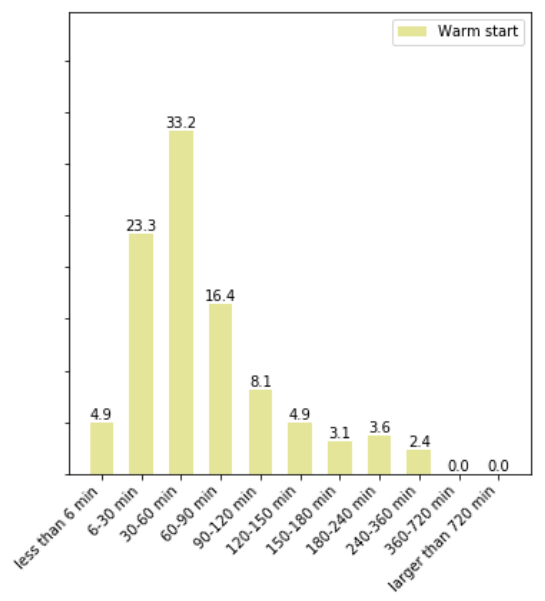

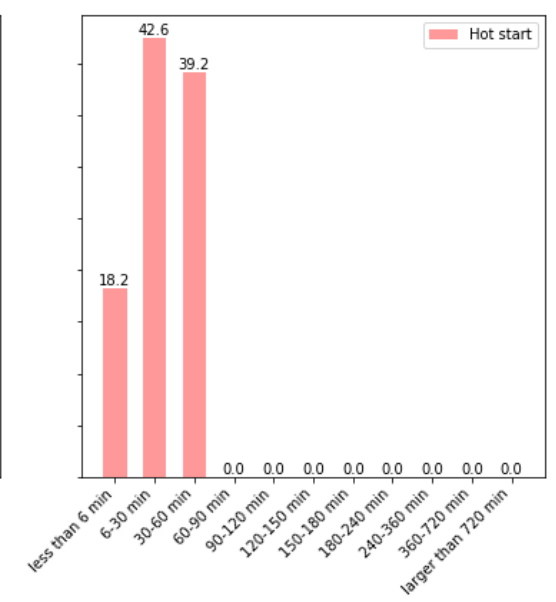

Figure C. 1. Distribution of Cold, Warm, and Hot Soak Times in the Line Haul

Figure C. 1 shows the distribution of cold, warm, and hot soak time before engine-starts for the Line Haul. As can be seen, almost $60 \%$ of cold starts occurring after 6 hours or longer of soak duration. In addition, $40 \%$ of hot starts happen within 30 to 60 minutes of soak time. It should also be noted that from Figure C. 1, many starts - no matter if they are cold, warm, or hotpossess 30 to 60 minutes of soak duration in this application. Since drivers of Line Haul trucks are required by law to take a rest for half an hour or longer after the extended operation, the higher fraction of soak time duration within this time bin is expected.

\section{C.2. Drayage}
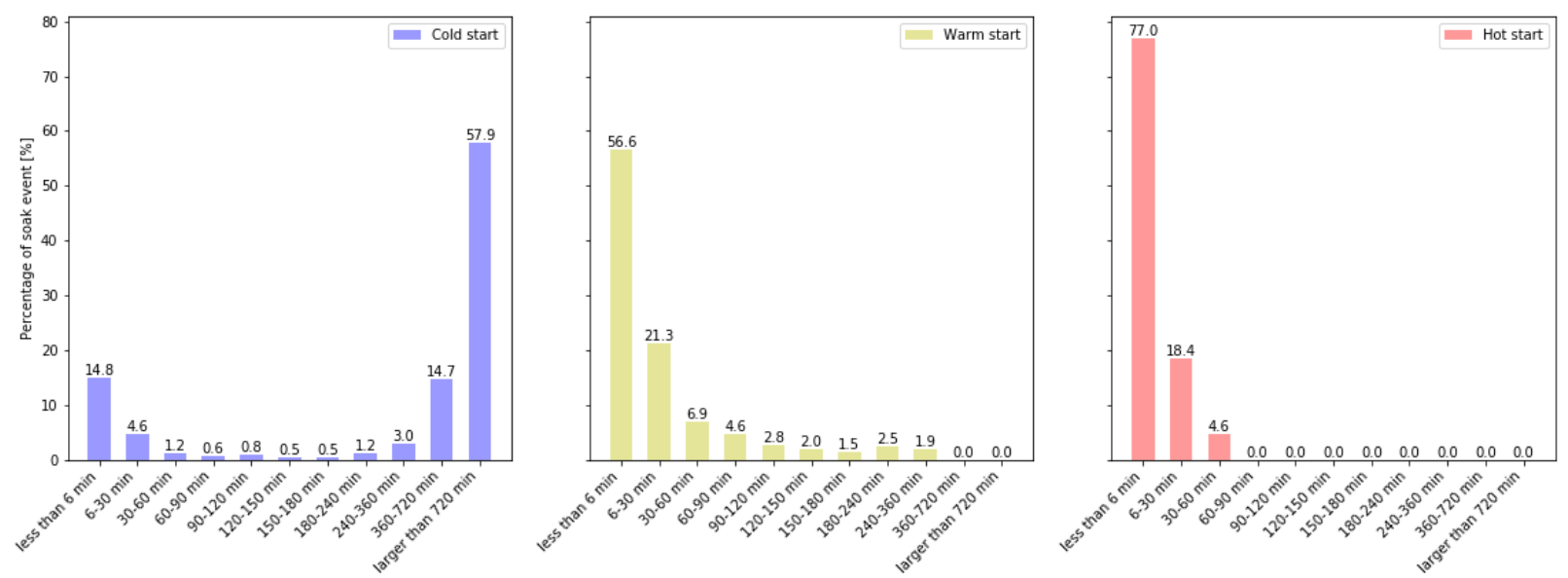

Figure C. 2. Distribution of Cold, Warm, and Hot Soak Times in the Drayage

The distribution of soak times in the Drayage category from Fleet DNA and CE-CERT is represented in Figure C. 2. The distribution of soak time before hot-start shows that more than 
$75 \%$ of starts are in the "less than 6 minutes" bin. The distribution of cold-starts shows that more than $50 \%$ starts happening in the bin with more than 12 hours soak duration and $14 \%$ of them are in less than 6 minutes bin. The distribution of warm-starts also shows that the majority of this kind of start happens after soak time with less than 6 minutes.

\section{C.3. Refuse Pickup}

Vehicles in Refuse Pickup groups possess similar distributions compared to Drayage. The main difference comes from the fact that Fleet DNA vehicles have more cold-starts occurring with less than 6 minutes of soak time. Such a distribution can be affected by the regions where the vehicles are operating. Specific policies employed by the fleets may also cause this driving behavior. For example, drivers of refuse pickup trucks may turn off the engine and get out of the vehicle to access garbage bins and cause more cold-starts to occur in this time bin.
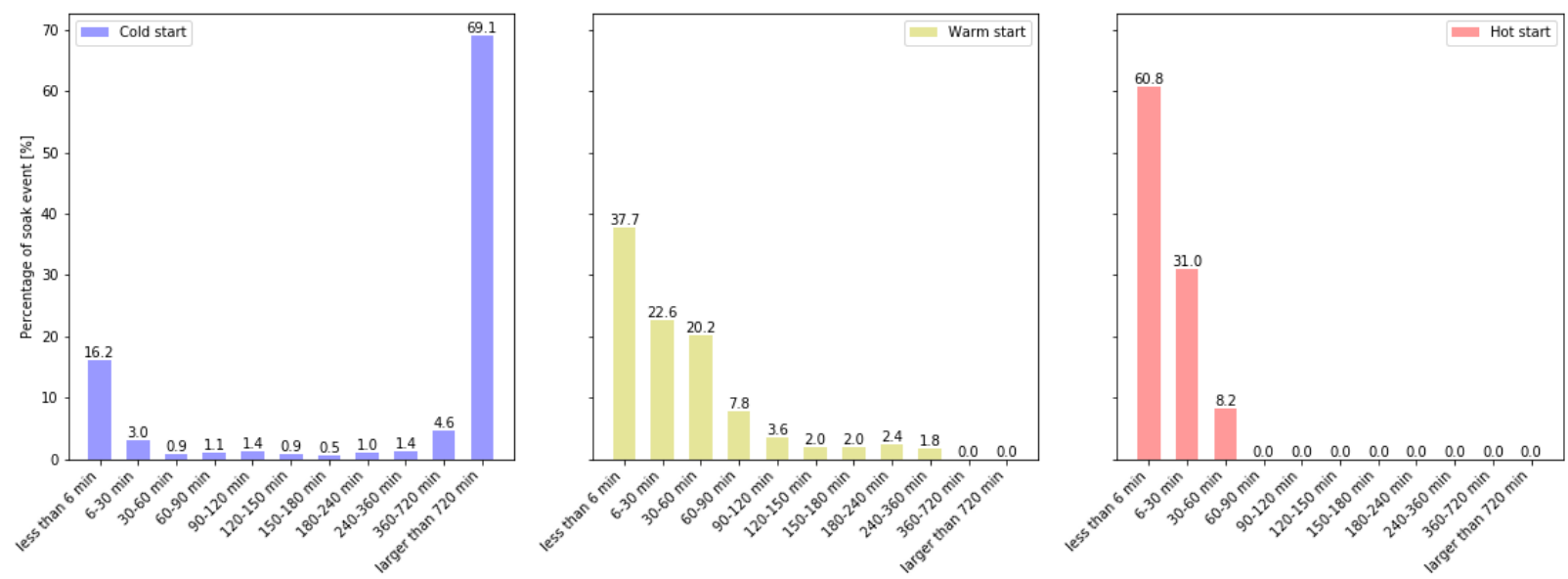

Figure C. 3. Distribution of Cold, Warm, and Hot Soak Times in the Refuse Pickup Category

\section{C.4. Parcel Delivery}
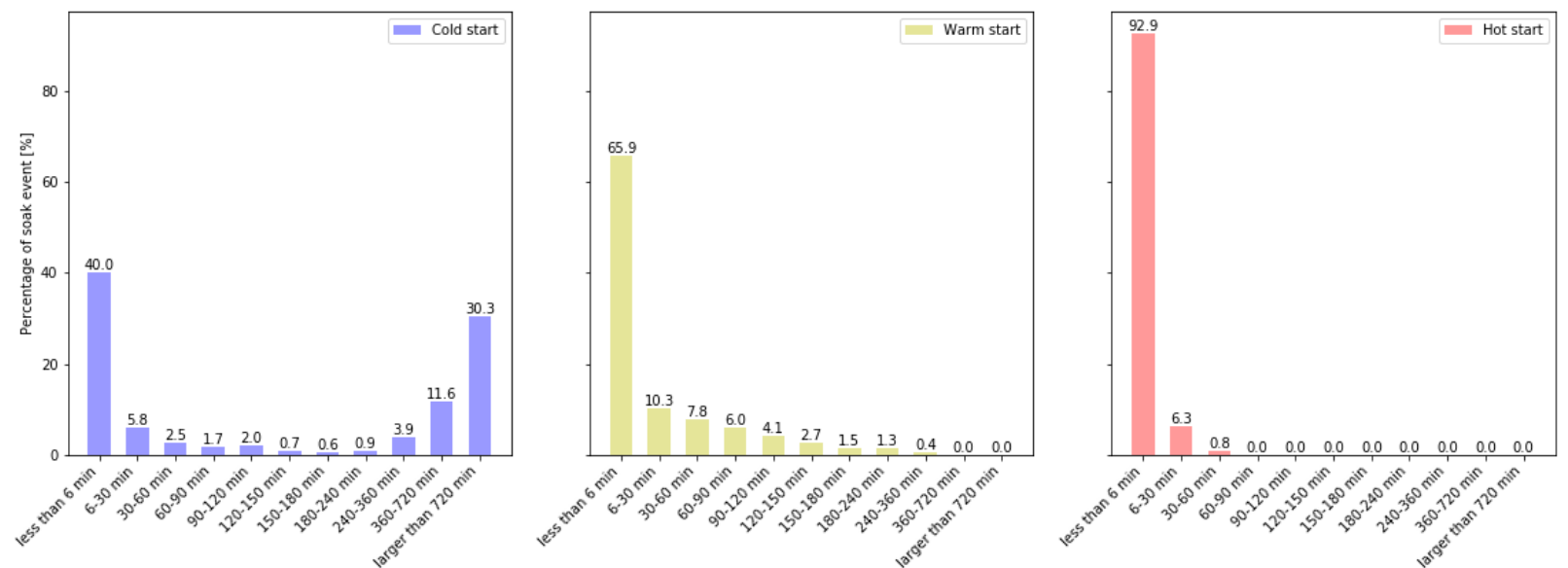

Figure C. 4. Distribution of Cold, Warm, and Hot Soak Times in the Parcel Delivery

Only Fleet DNA has vehicles from the Parcel Delivery category and the related distributions are shown in Figure C. 4. One special characterization of the soak time distribution in Parcel Delivery is that the fractions of soak times with less than 6 minutes are very high in all three start 
categories. For instance, there are $40 \%$ of cold-starts, over $65 \%$ of warm-starts, and nearly $93 \%$ of hot-starts happening after less than 6 minutes of soak duration. Such a high fraction for all kinds of engine starts are mainly attributed to the unique behavior of the Parcel Delivery trucks mentioned previously.

\section{C.5. Local Delivery}
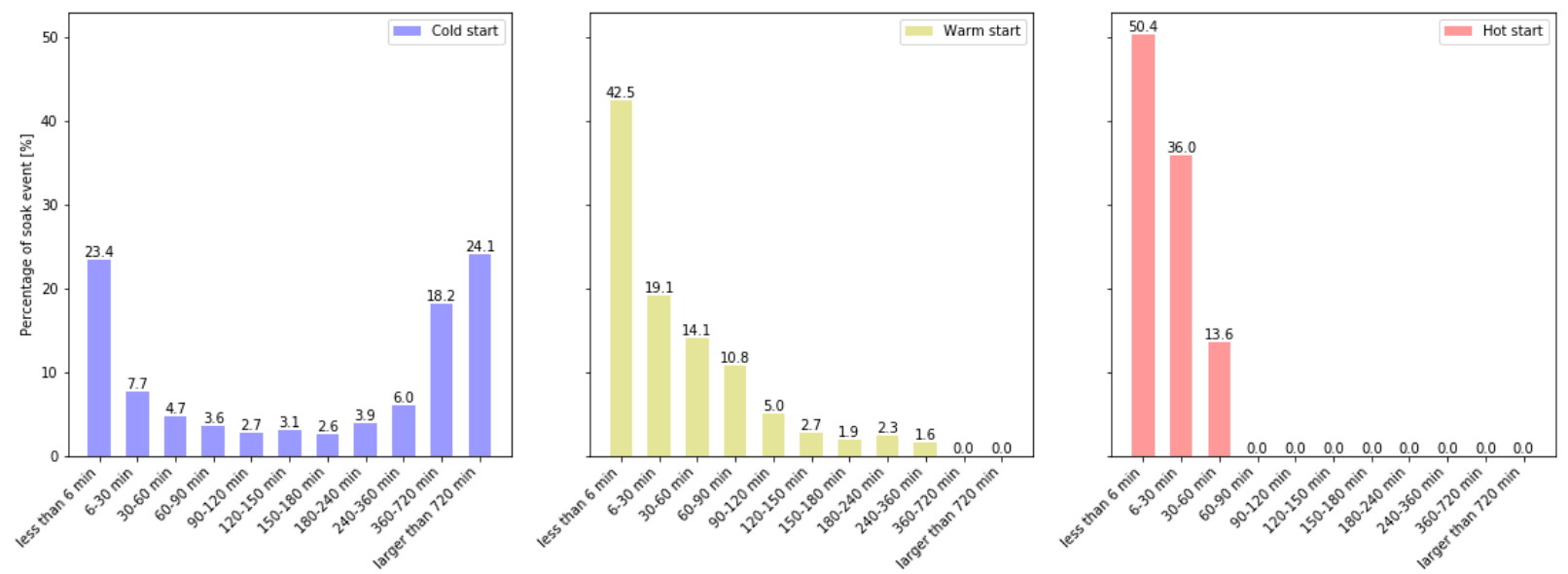

Figure C. 5. Distribution of Cold, Warm, and Hot Soak Times in the Local Delivery

Figure C. 5 shows the distribution of soak times for Local Delivery vehicles from Fleet DNA and CE-CERT project datasets. As can be seen, the trends of all three distributions for each kind of engine start are close to Refuse Pickup, except that the Local Delivery vehicle possesses higher fractions of cold and warm engine-starts in "less than 6 minutes" time bin, of which $23.4 \%$ were cold-starts and $42.5 \%$ were warm-starts. The corresponding number for vehicles in Refuse Pickup data were $16.2 \%$ and $37.7 \%$ respectively.

\section{C.6. Transit}

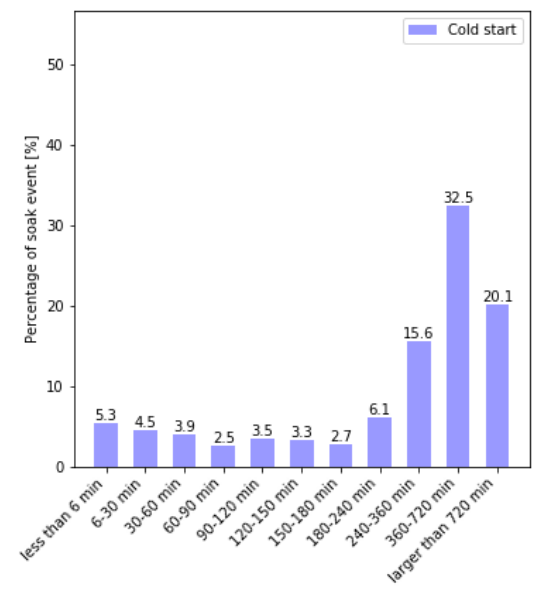

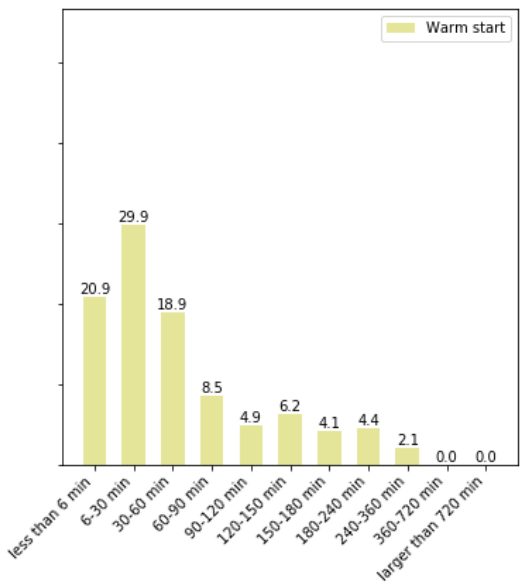

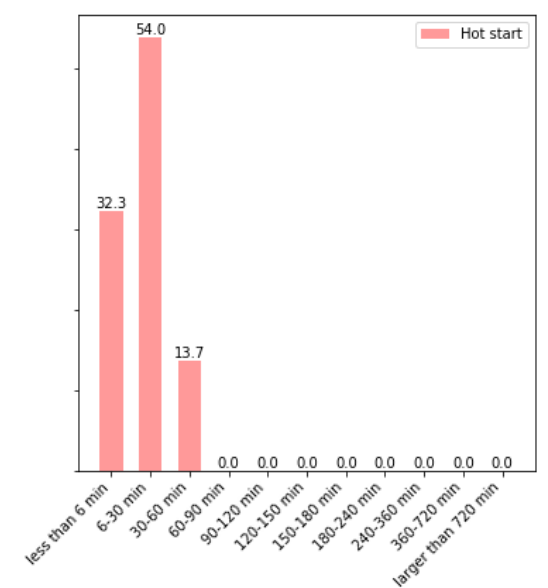

Figure C. 6. Distribution of Cold, Warm, and Hot Soak Times in the Transit

The soak time distributions of Transit vehicles from the two data sets are shown in Figure C. 6. It should be noted that not much cold-start happens in "less than 6 minutes" bin for this vocational group. Also, more than 50\% hot-start in Transit occurs after a soak with 6-30 minutes duration. 


\section{C.7. School Bus}

The School Bus vocation is only in the Fleet DNA data. Figure C. 7 shows the corresponding distributions of the three kinds of engine-starts. The distributions show that most hot-starts and warm-starts occur in the "less than 6 minutes" bin. In addition, almost $60 \%$ of cold-starts occur in the same bin and another 38\% happen after 12 hours or longer of soak time. Very few enginestarts occurred in the other bins. It demonstrates that during the normal operation, School Bus usually only stops for a few minutes to board the students or let the student get off the bus.
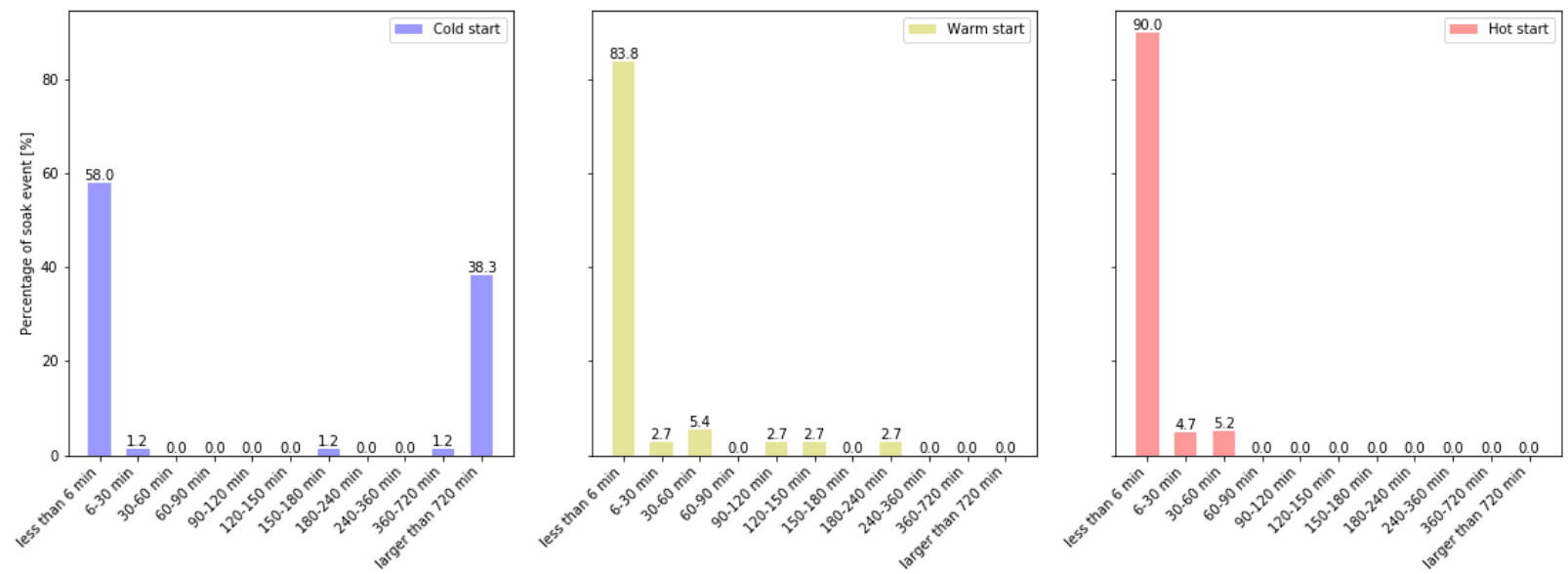

Figure C. 7. Distribution of Cold, Warm, and Hot Soak Times in the School Bus

\section{C.8. Vocation}
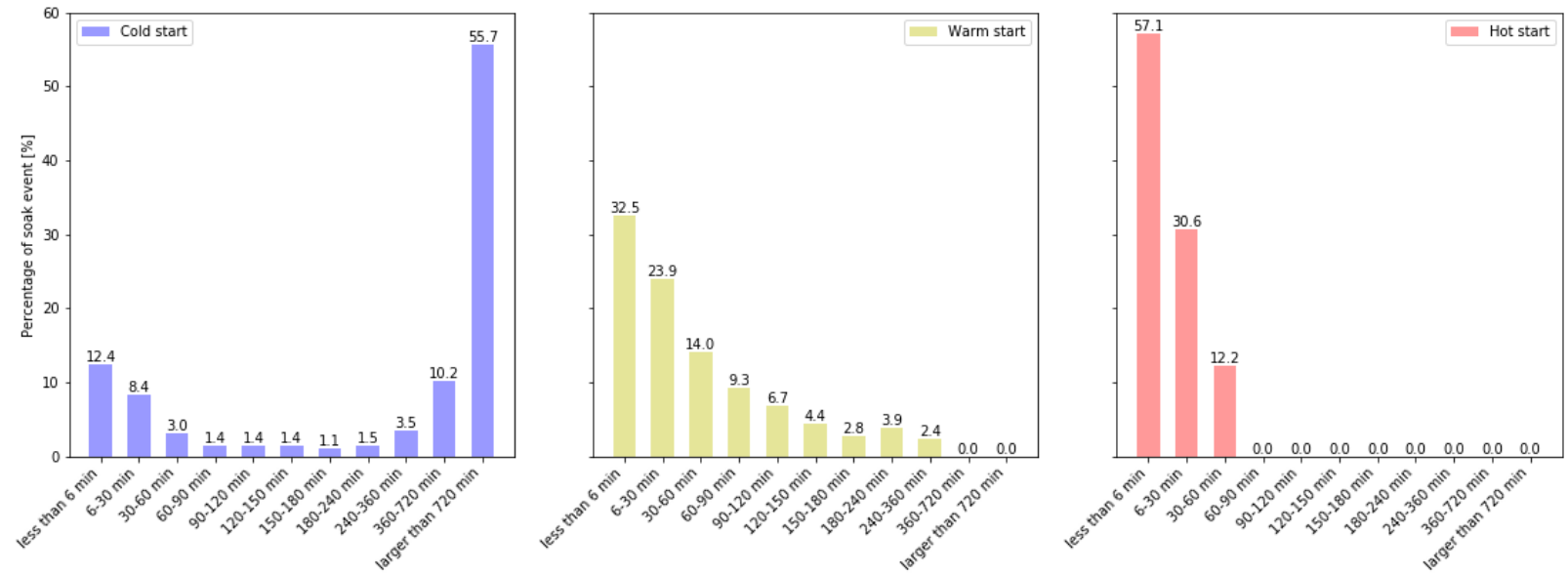

Figure C. 8. Distribution of Cold, Warm, and Hot Soak Times in the Vocation

The soak time distribution of vehicles in the Vocation category from the Fleet DNA and CECERT datasets are shown in Figure C. 8. The characterizations of the distributions are close to the distributions of Refuse Pickup and Local Delivery, which reflects that the vehicles in these three vocational groups may share common operational characteristics, to some extent. 


\section{Appendix D: Warm-Up Duration from Cold-Start in Real World Driving}
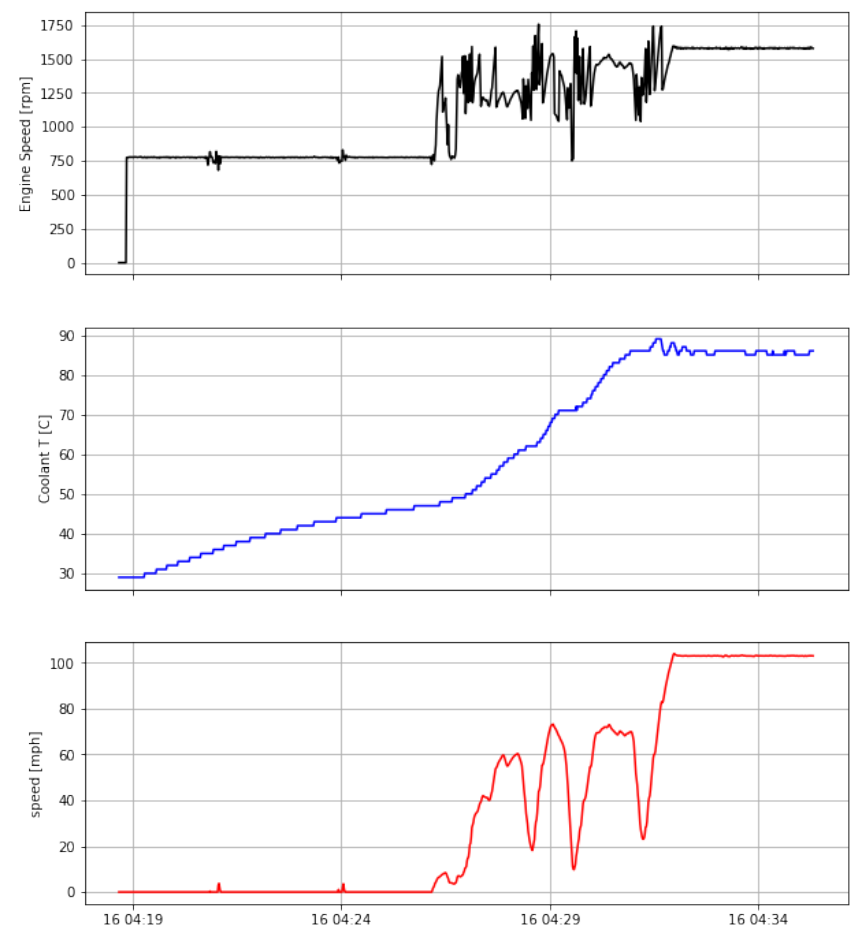

Figure D. 1. Case 1 of On-Road Warm-Up Duration from Cold-Start (8 minutes)
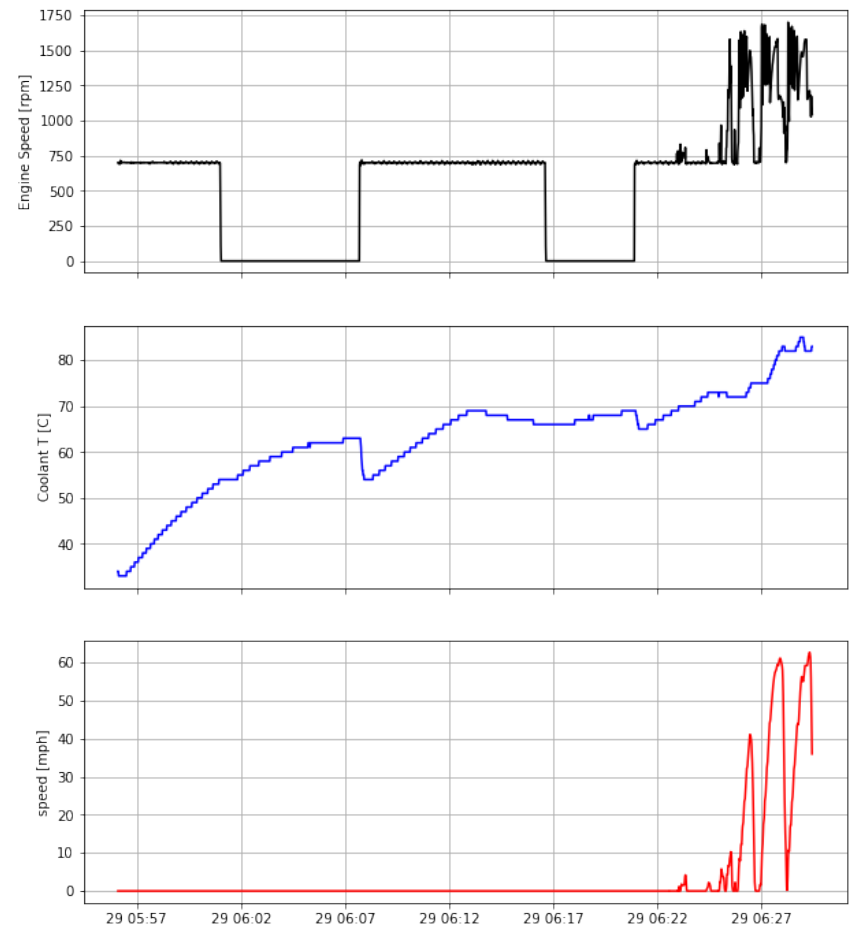

Figure D. 2. Case 2 of On-Road Warm-Up Duration from Cold-Start (30 minutes) 

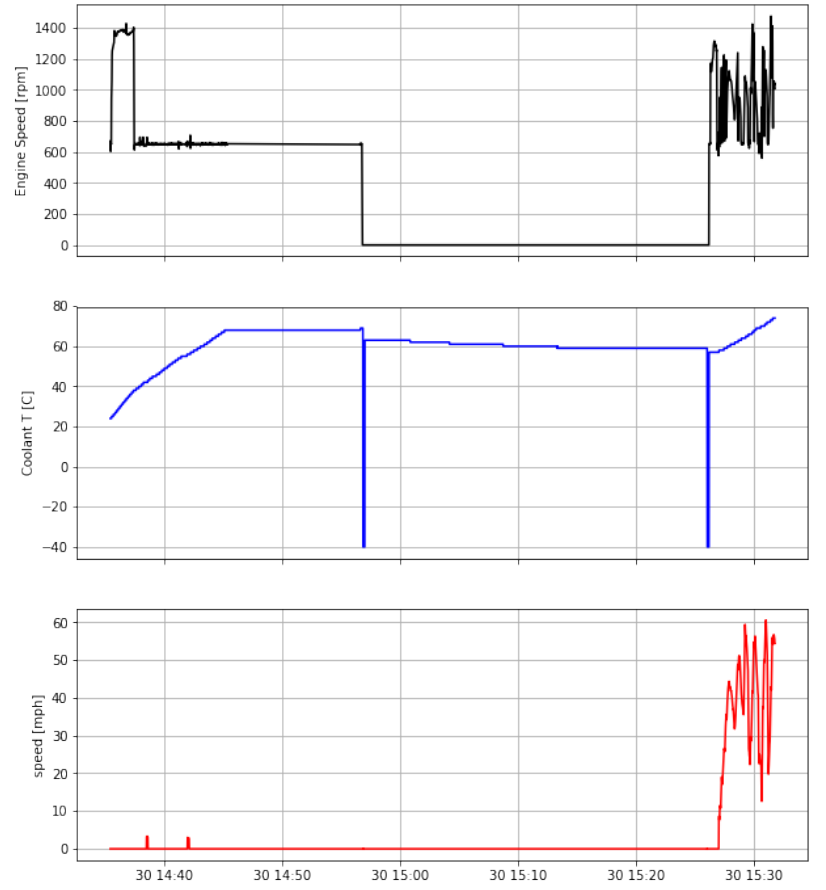

Figure D. 3. Case 3 of On-Road Warm-Up Duration from Cold-Start (60 minutes) 


\section{Appendix E: Vehicles Samples including Engine Power Information}

Table E. 1 Population of Vehicles in Fleet DNA with Power Information

\begin{tabular}{|l|l|l|}
\hline Vocation & Vehicles in Fleet DNA & Vehicles include Power Information \\
\hline Line Haul & 190 & 49 \\
\hline Local Delivery & 68 & 51 \\
\hline Drayage & 57 & 30 \\
\hline Vocation & 41 & 30 \\
\hline Refuse Pickup & 32 & 9 \\
\hline Parcel Delivery & 30 & 3 \\
\hline Transit & 13 & 13 \\
\hline School Bus & 4 & 0 \\
\hline Total & 435 & $\mathbf{1 8 5}$ \\
\hline
\end{tabular}




\section{Appendix F: Engine Output Power vs. Cold Warm-Up Duration}

\section{F.1 Fleet DNA}

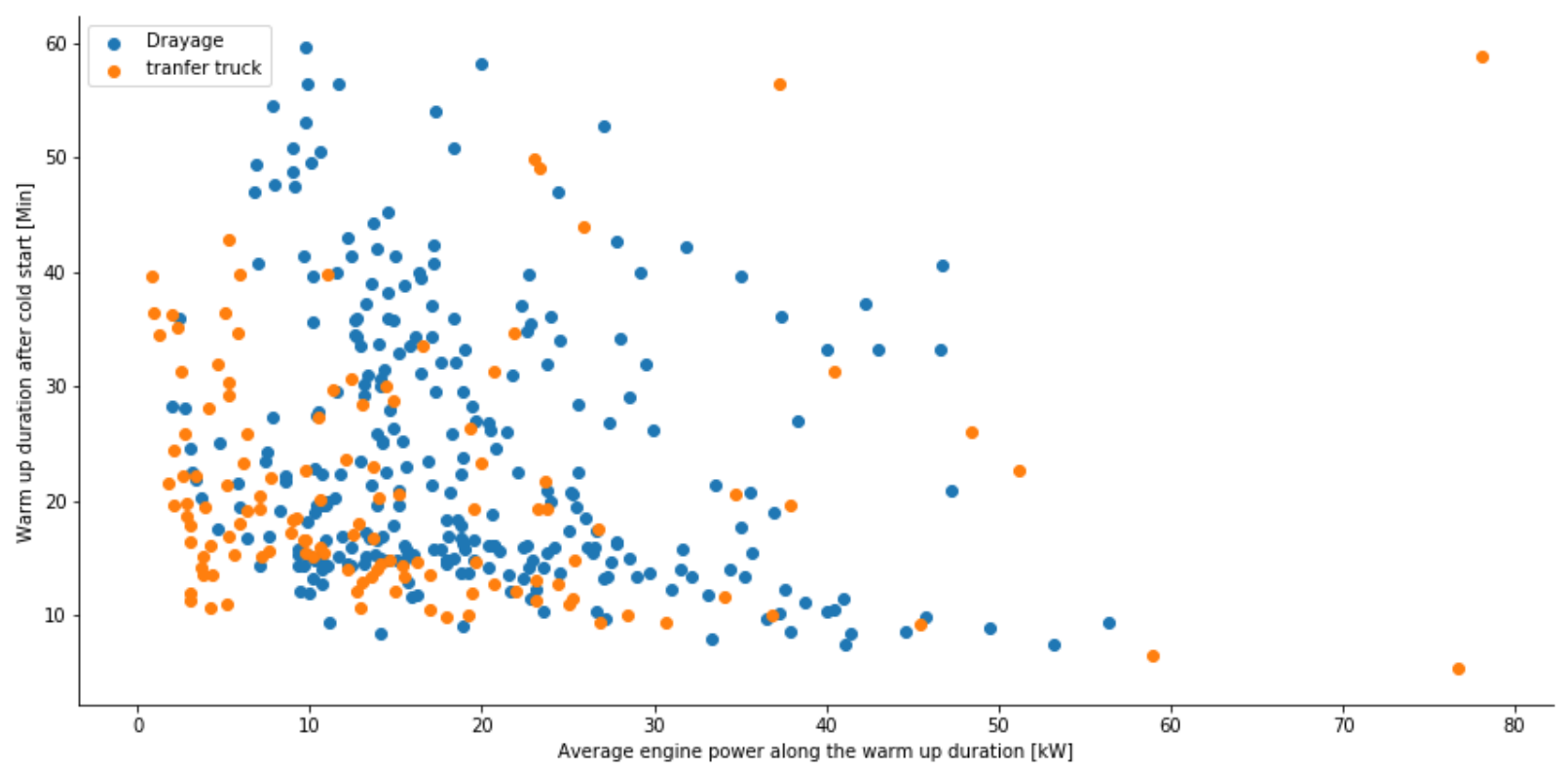

Figure F. 1. Average Power vs. Warm-Up Duration from Cold-Start in Drayage from Fleet DNA

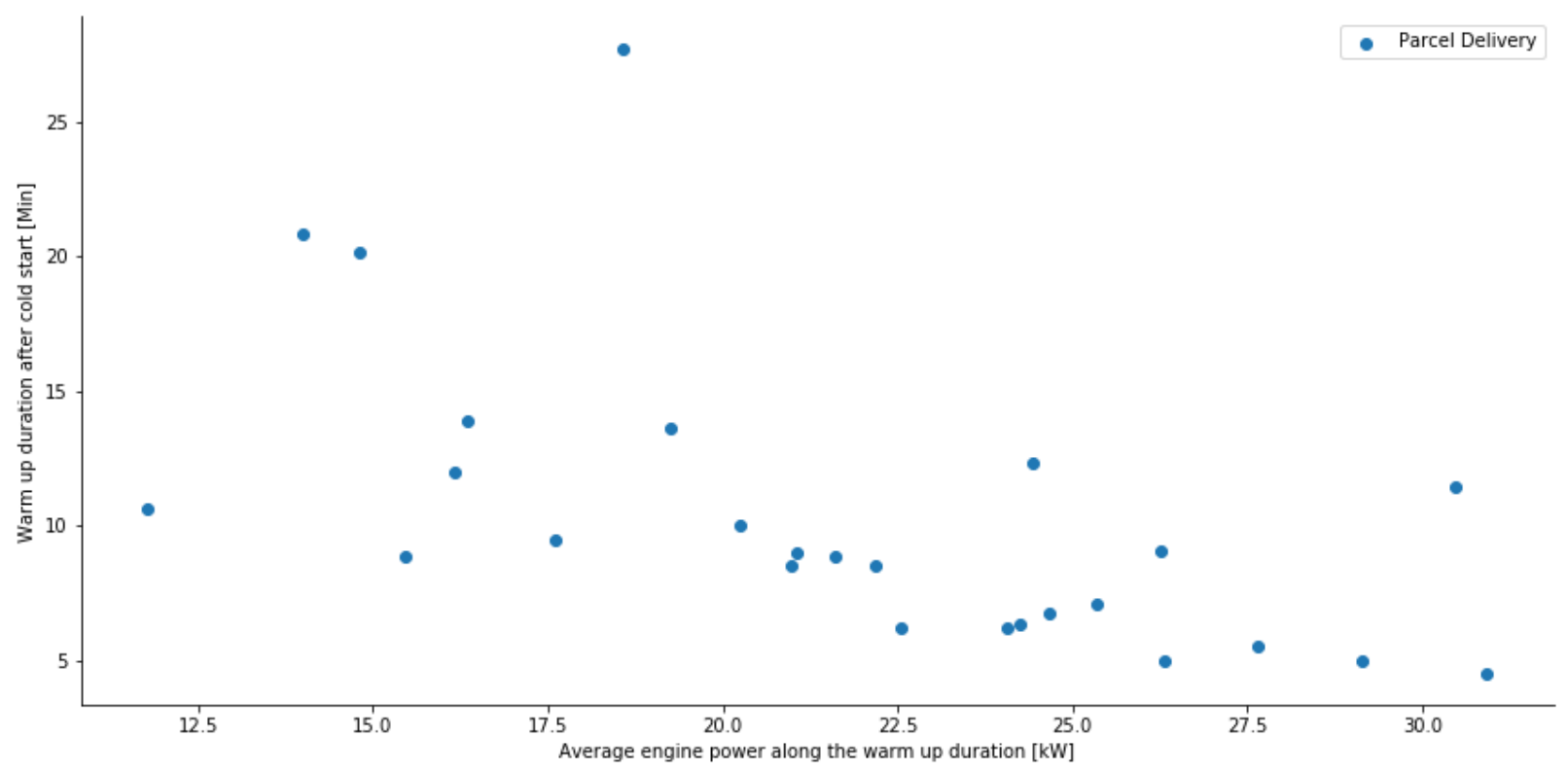

Figure F. 2. Average Power vs. Warm-Up Duration from Cold-Start in Parcel Delivery from Fleet DNA 


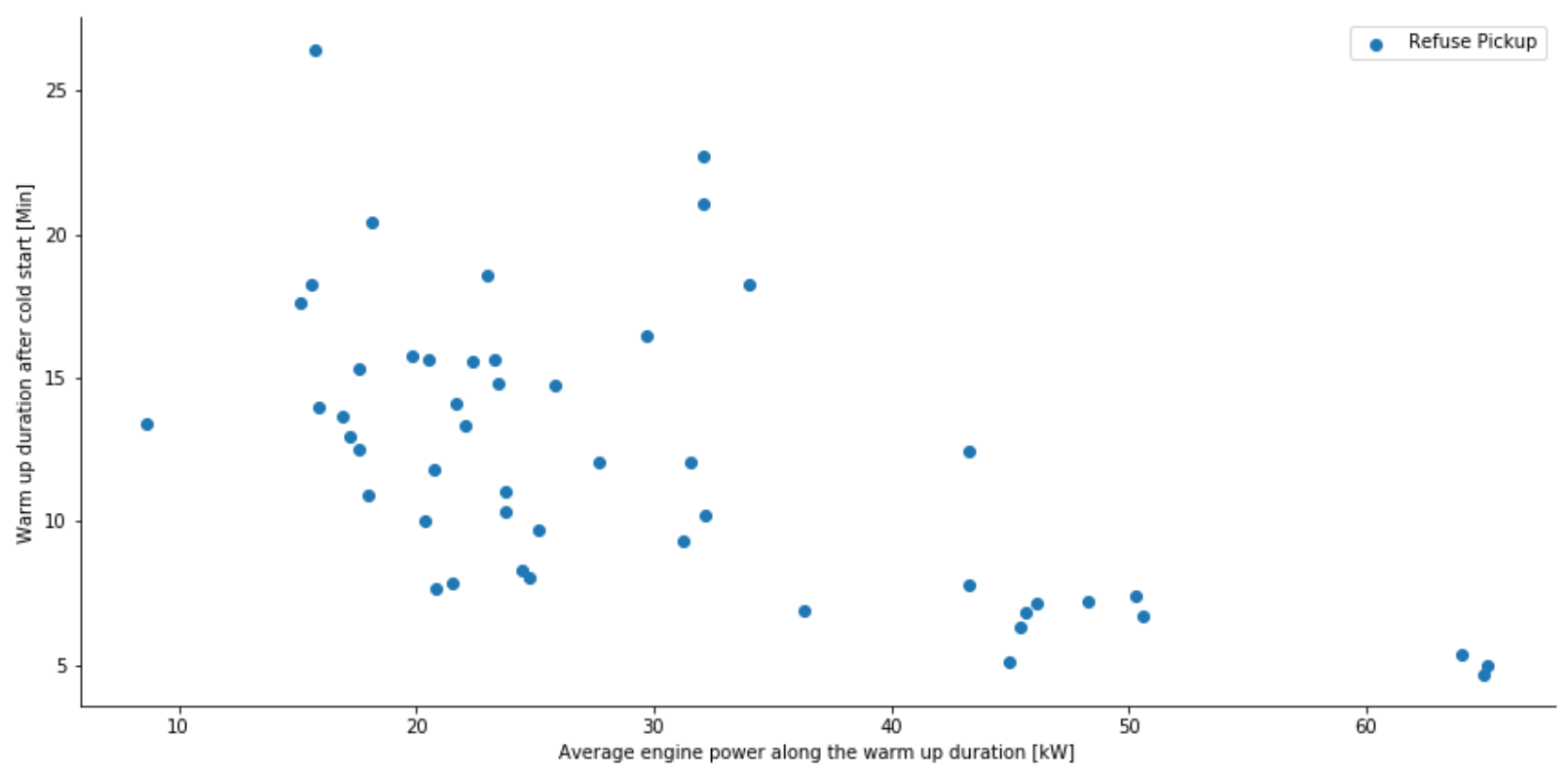

Figure F. 3. Average Power vs. Warm-Up Duration from Cold-Start in Refuse from Fleet DNA

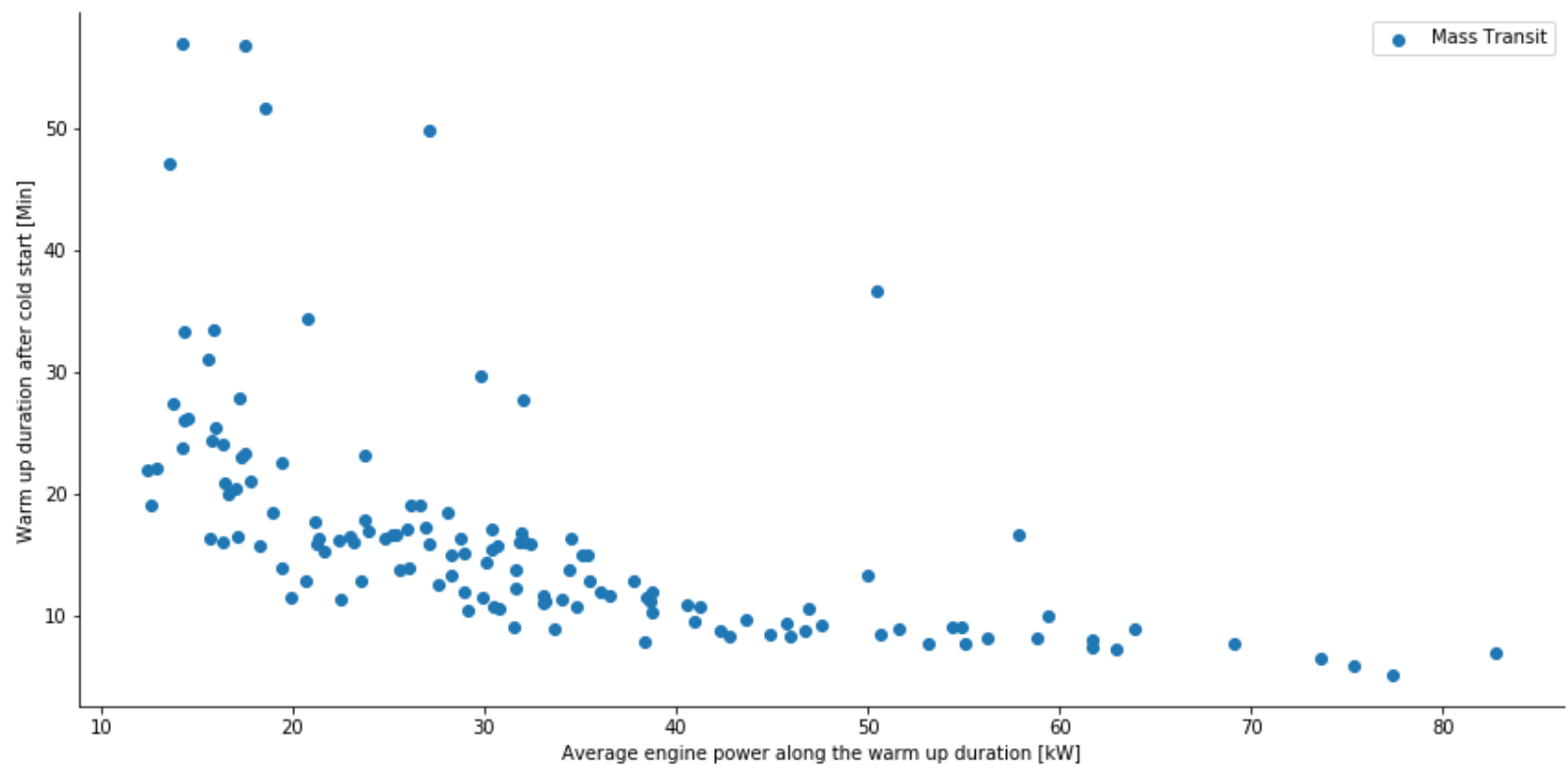

Figure F. 4. Average Power vs. Warm-Up Duration from Cold-Start in Transit from Fleet DNA 


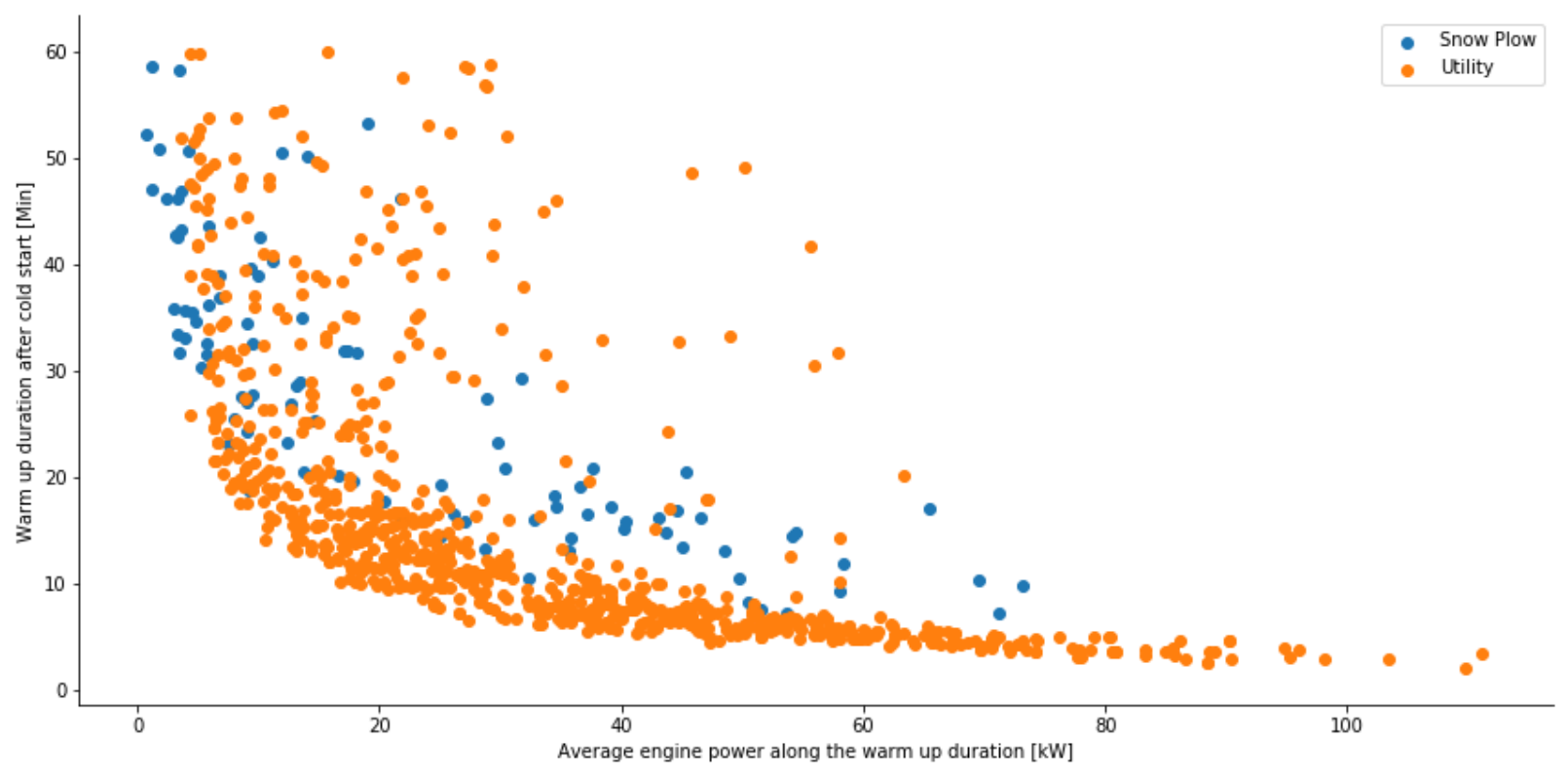

Figure F. 5. Average Power vs. Warm-Up Duration from Cold-Start in Vocation from Fleet DNA

\section{D.2 CE-CERT}

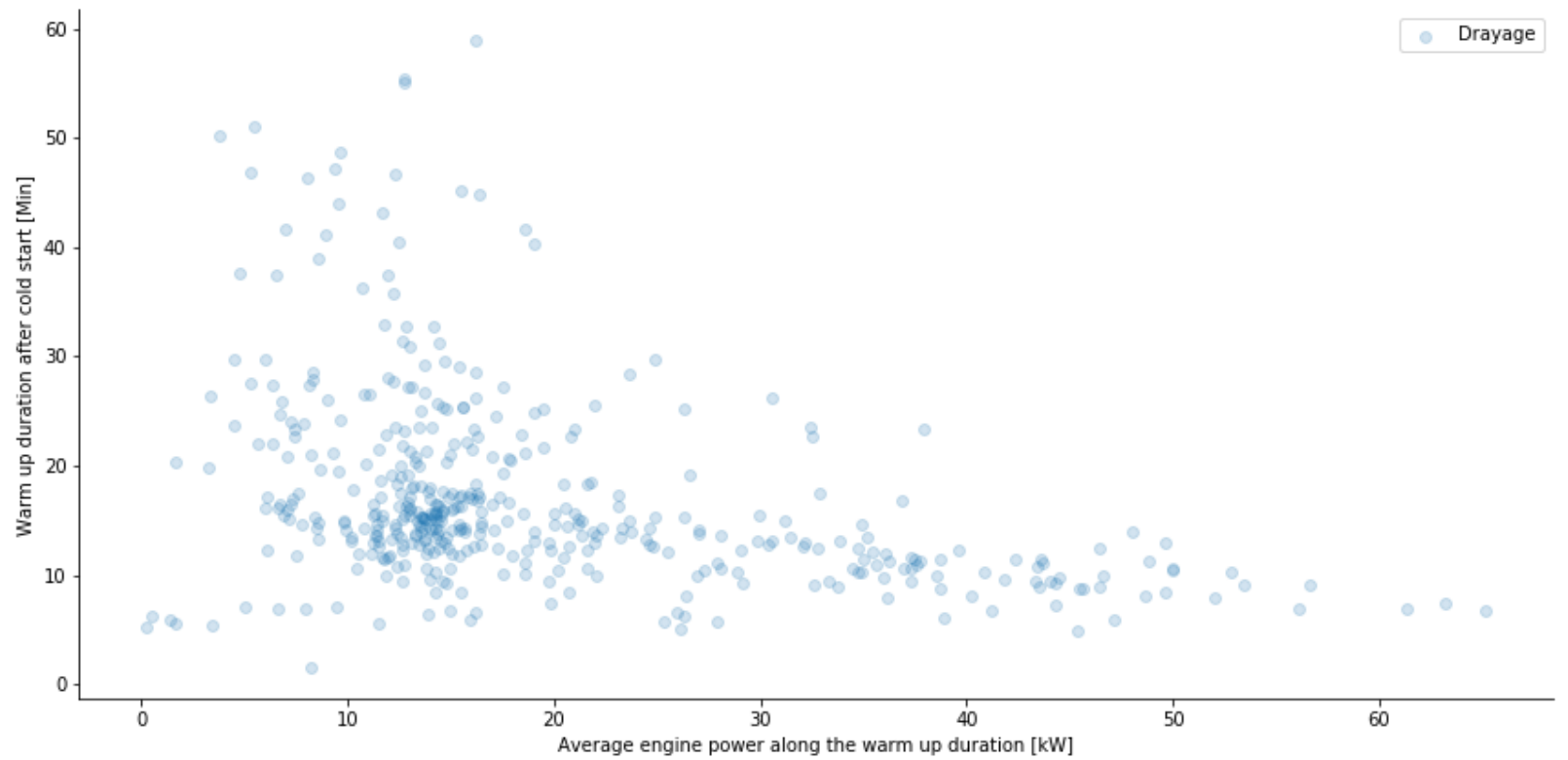

Figure F. 6. Average Power vs. Warm-Up Duration from Cold-Start in Drayage from CE-CERT 


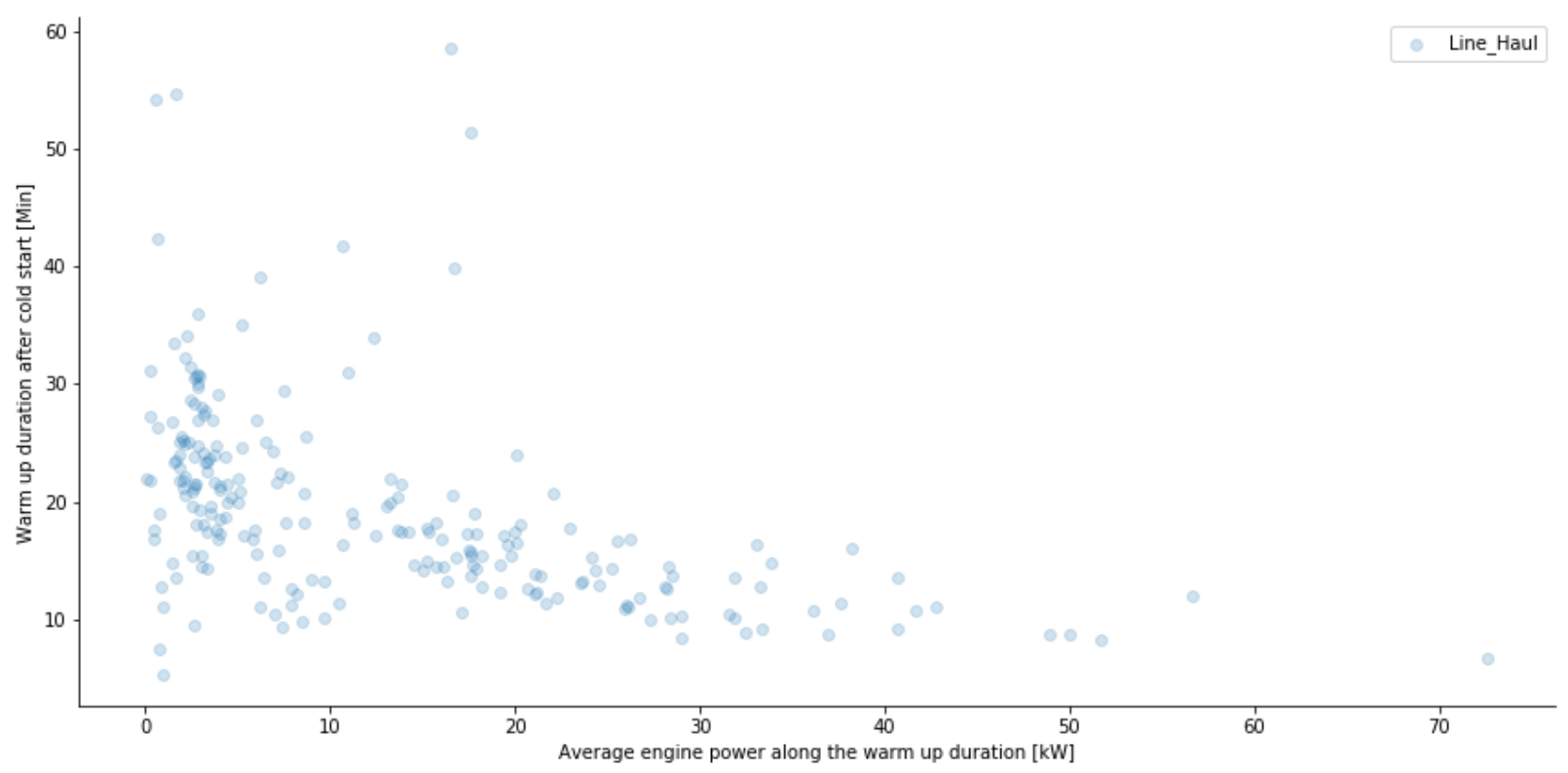

Figure F. 7. Average Power vs. Warm-Up Duration from Cold-Start in Line Haul from CE-CERT

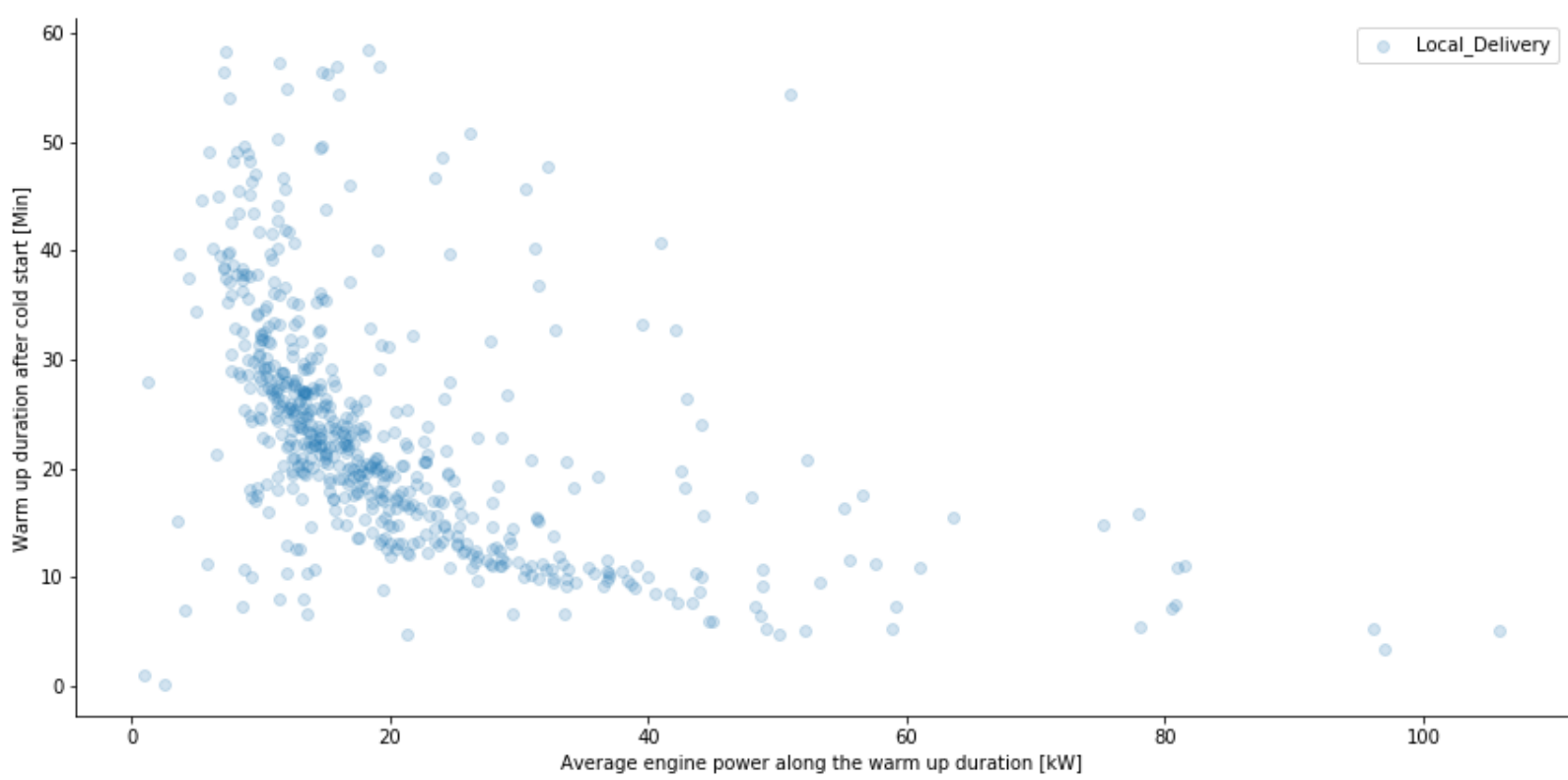

Figure F. 8. Average Power vs. Warm-Up Duration from Cold-Start in Local Delivery from CE-CERT 


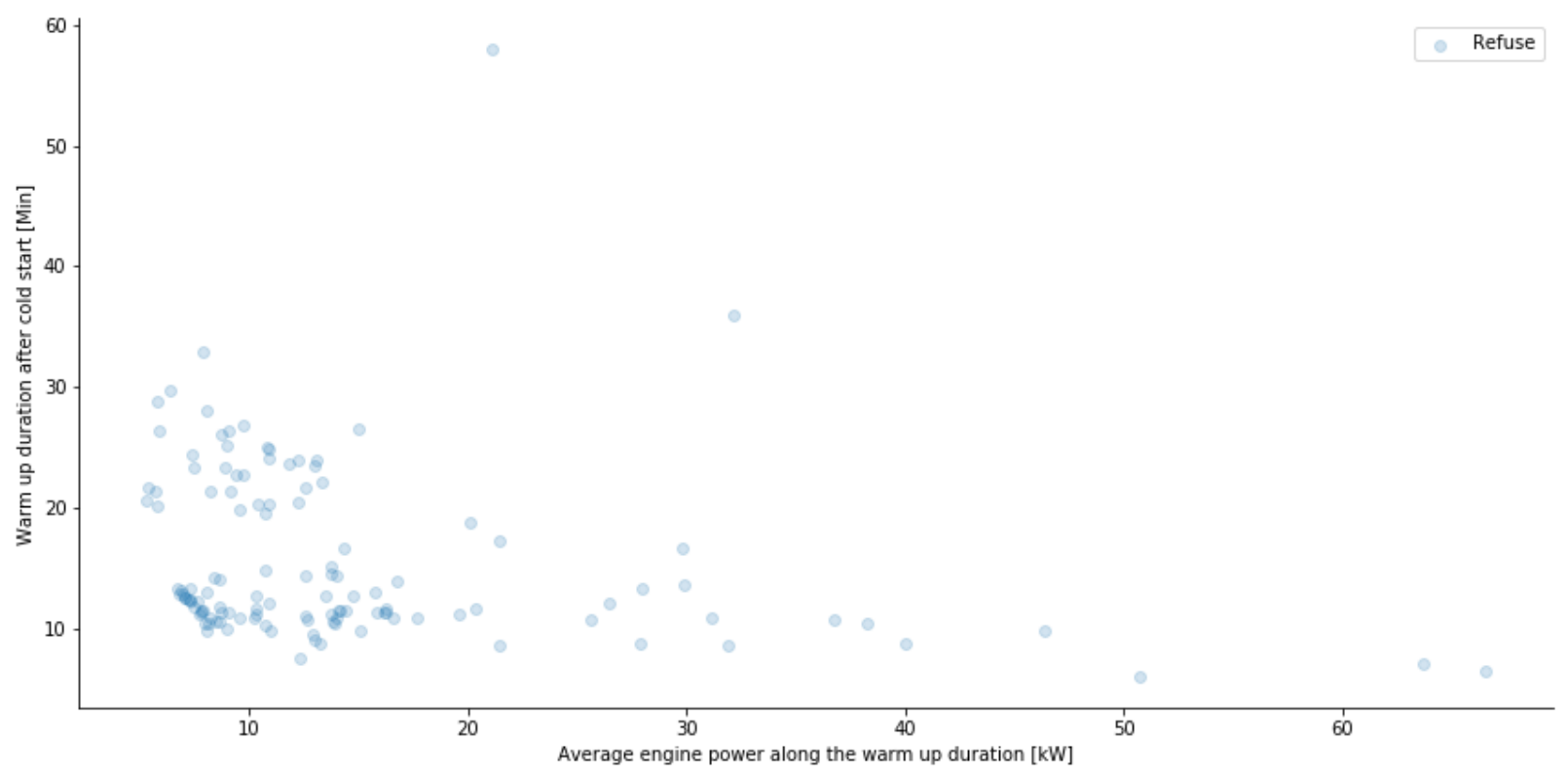

Figure F. 9. Average Power vs. Warm-Up Duration from Cold-Start in Refuse from CE-CERT

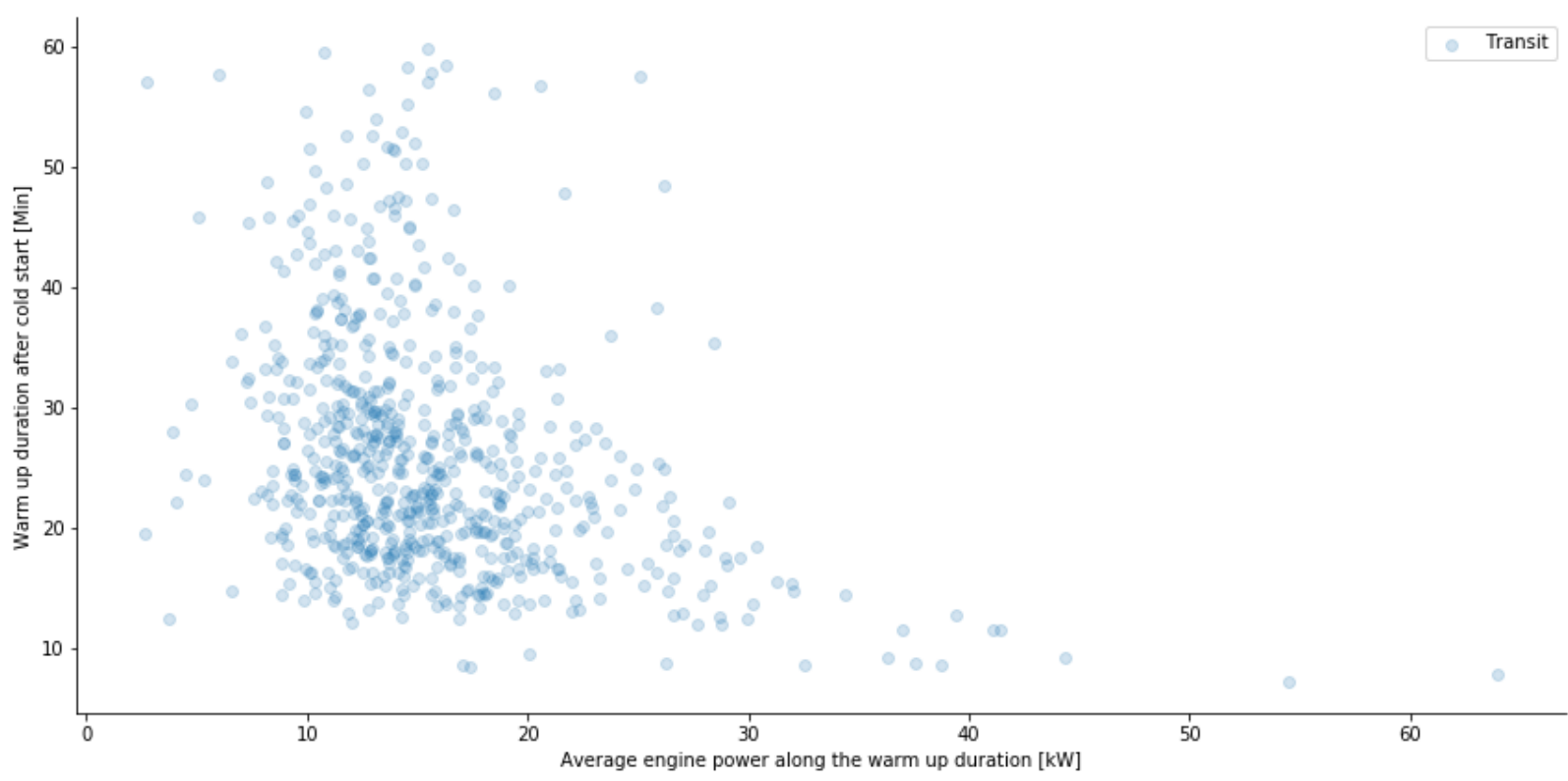

Figure F. 10. Average Power vs. Warm-Up Duration from Cold-Start in Transit from CE-CERT 


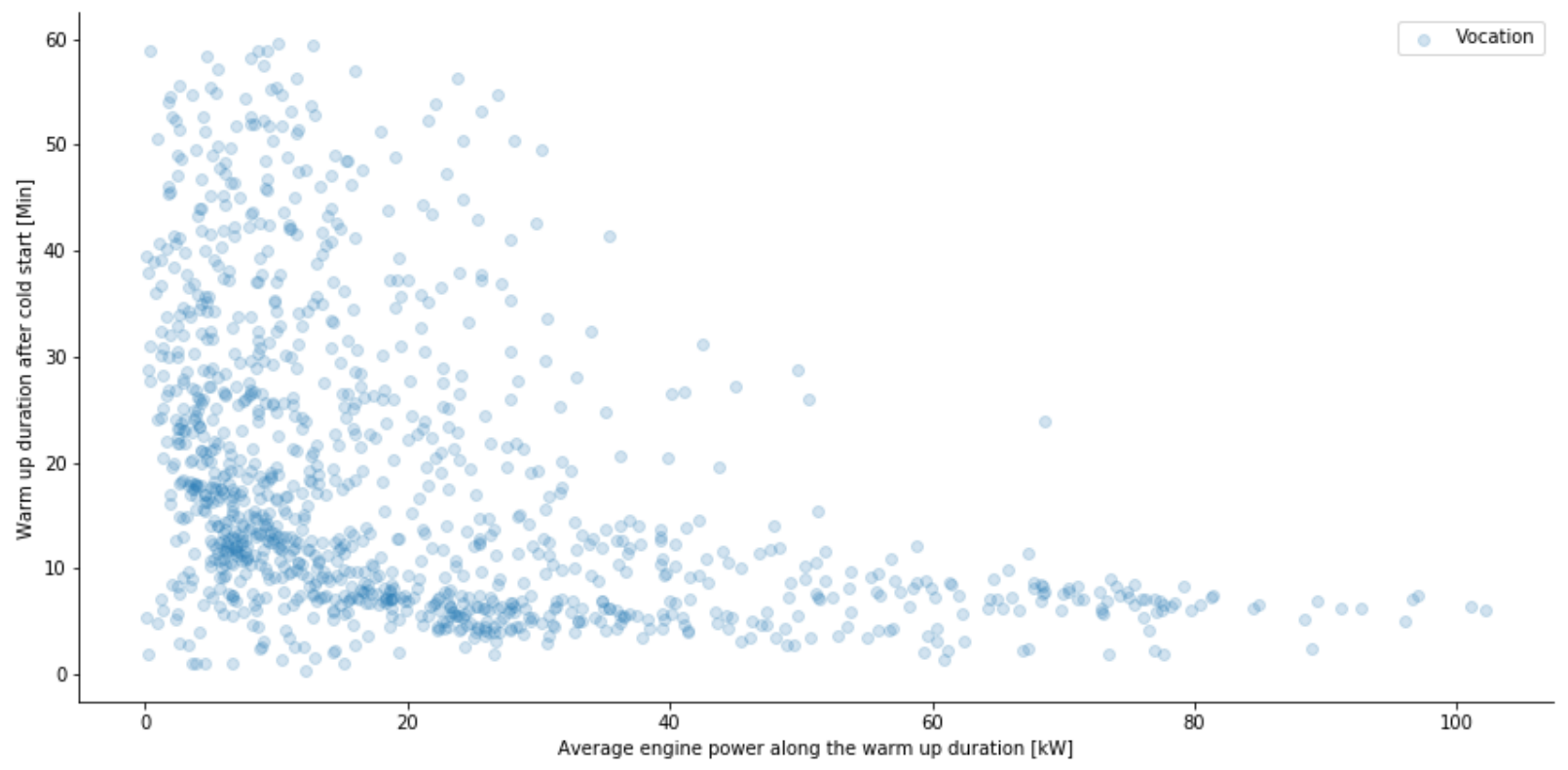

Figure F. 11. Average Power vs. Warm-Up Duration from Cold-Start in Vocation from CE-CERT 


\section{Appendix G: Engine Output Power vs. Warm Warm-Up Duration}

\section{G.1 Fleet DNA}

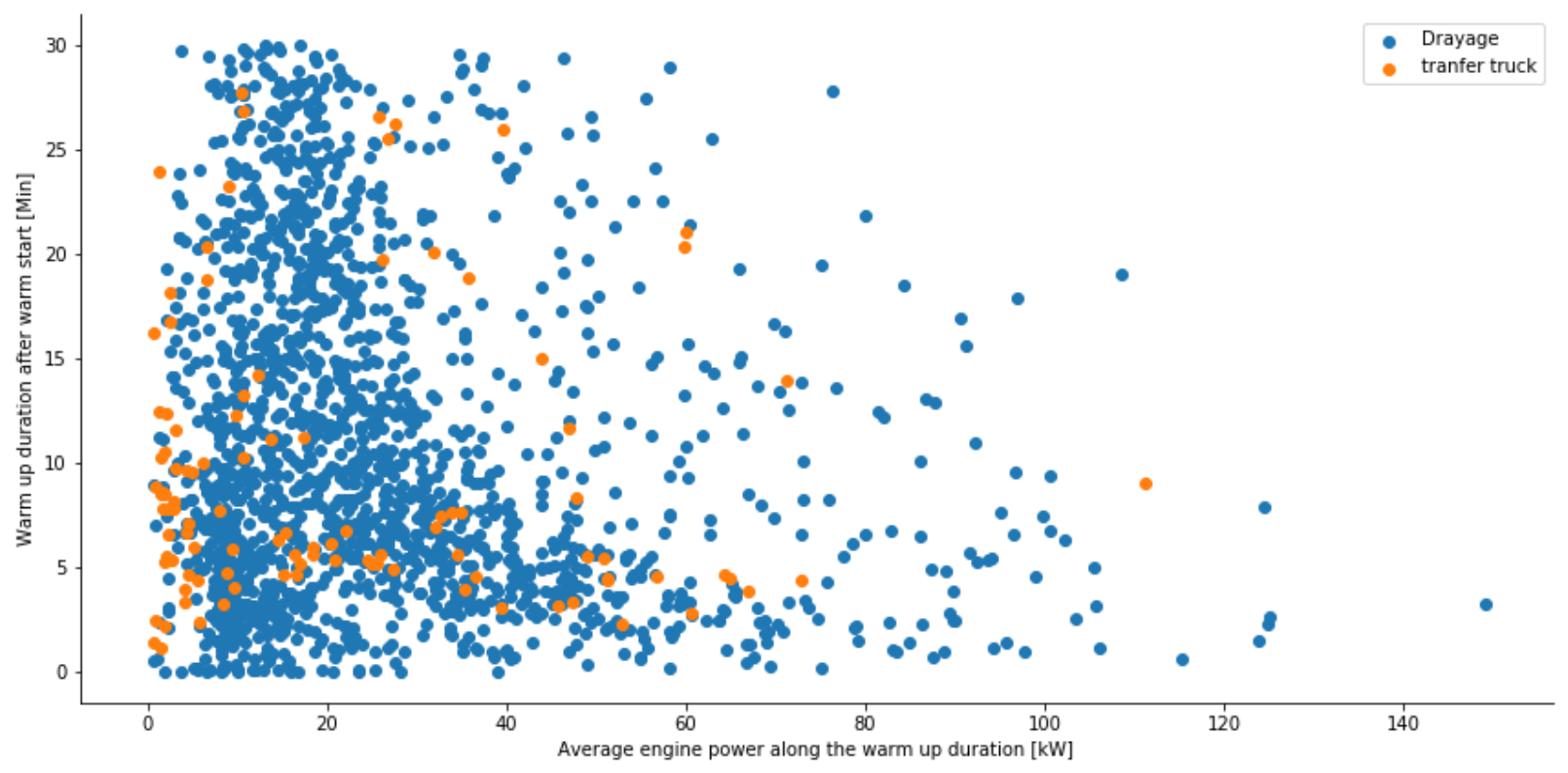

Figure G. 1. Average Power vs. Warm-Up Duration from Warm-Start in Drayage from Fleet DNA

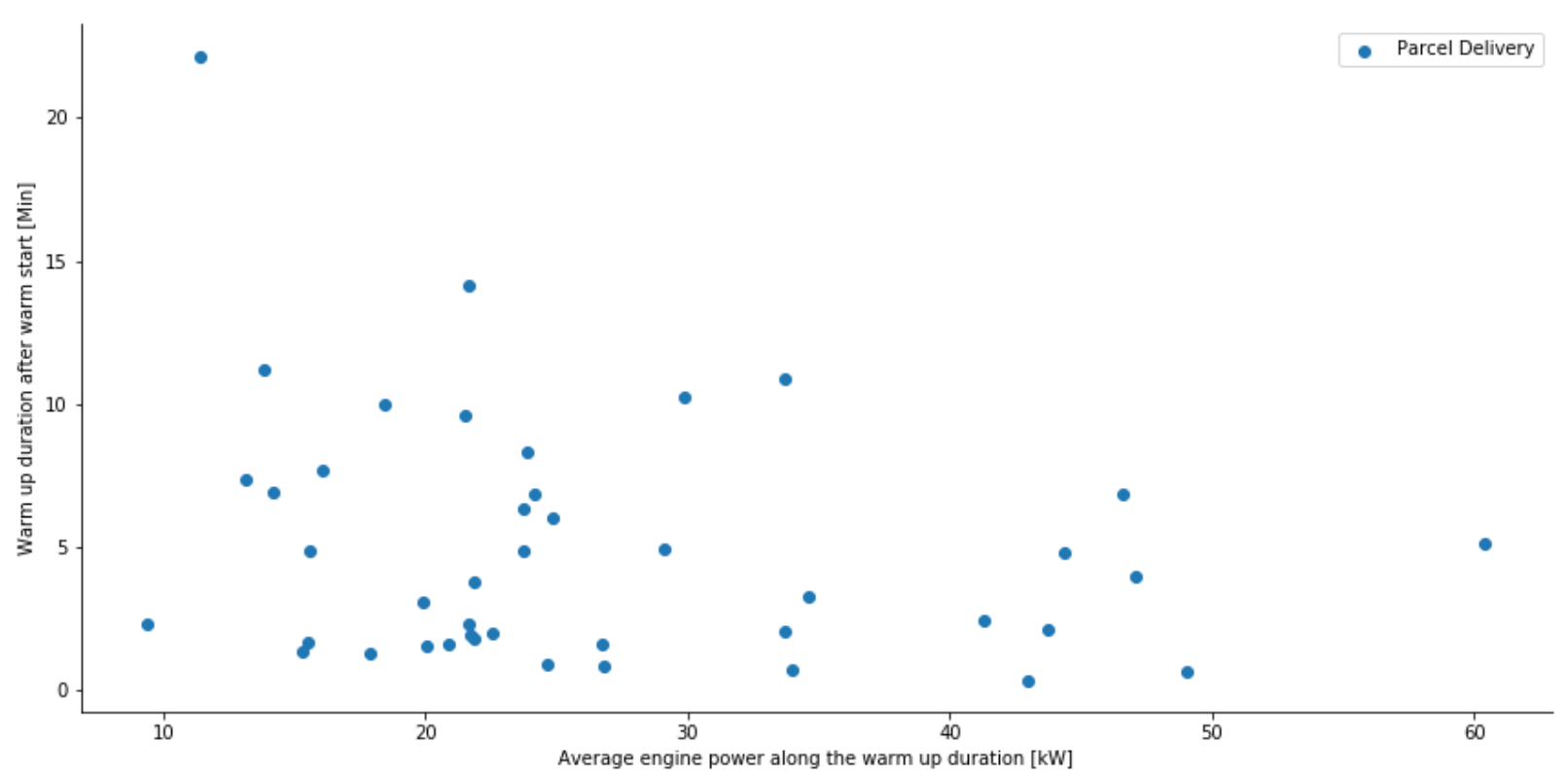

Figure G. 2. Average Power vs. Warm-Up Duration from Warm-Start in Parcel Delivery from Fleet DNA 


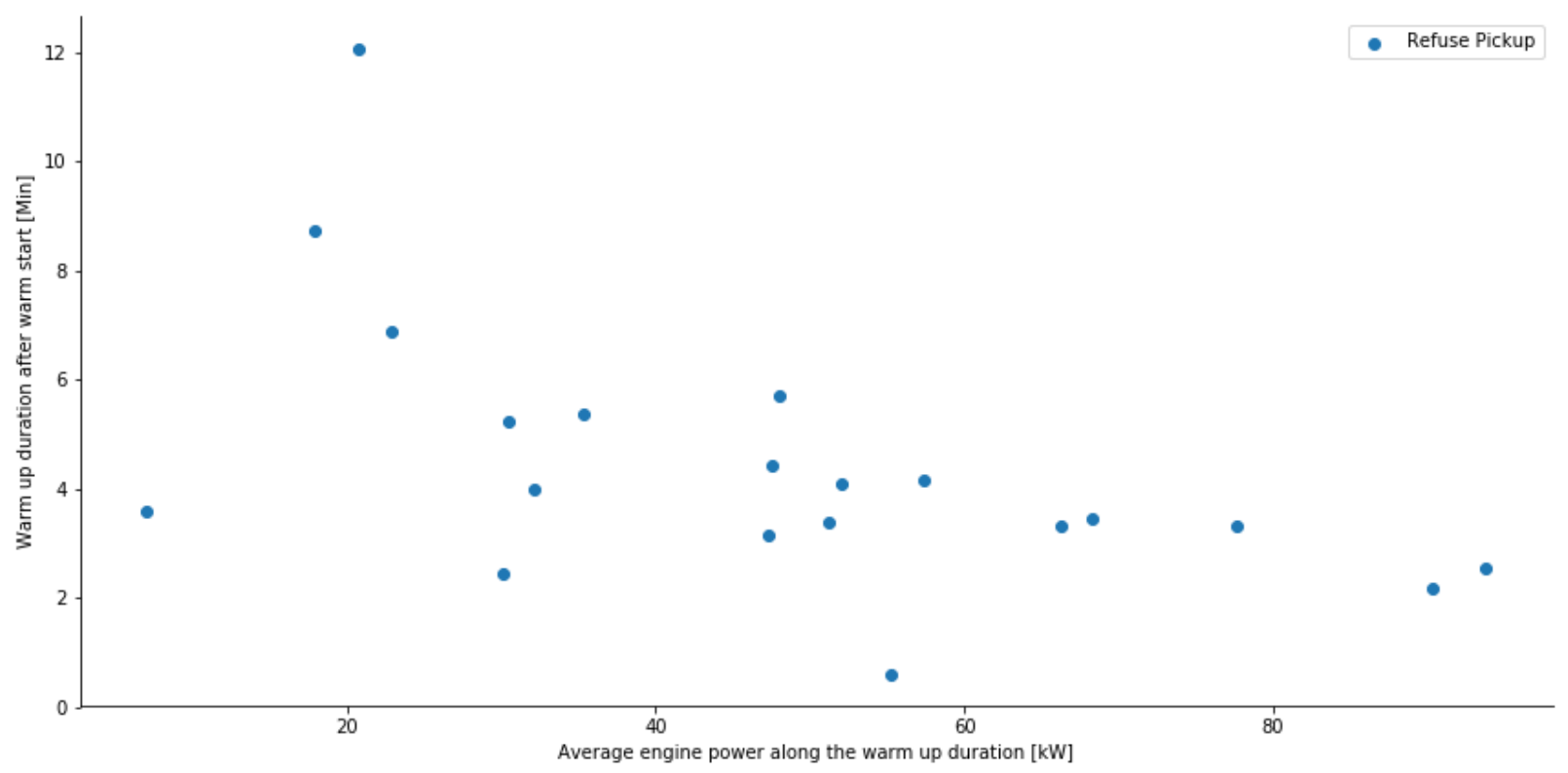

Figure G. 3. Average Power vs. Warm-Up Duration from Warm-Start in Refuse from Fleet DNA

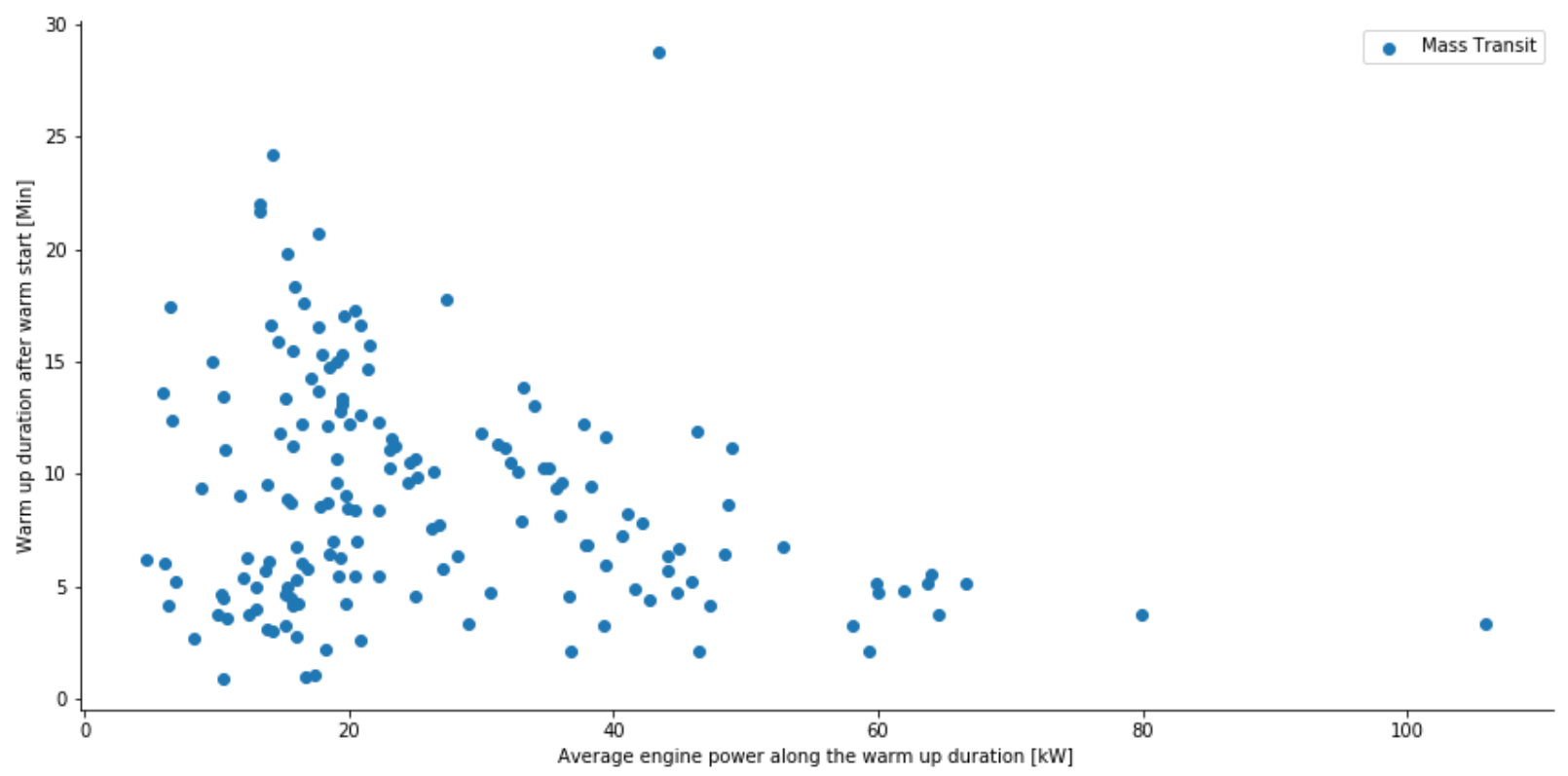

Figure G. 4. Average Power vs. Warm-Up Duration from Warm-Start in Transit from Fleet DNA 


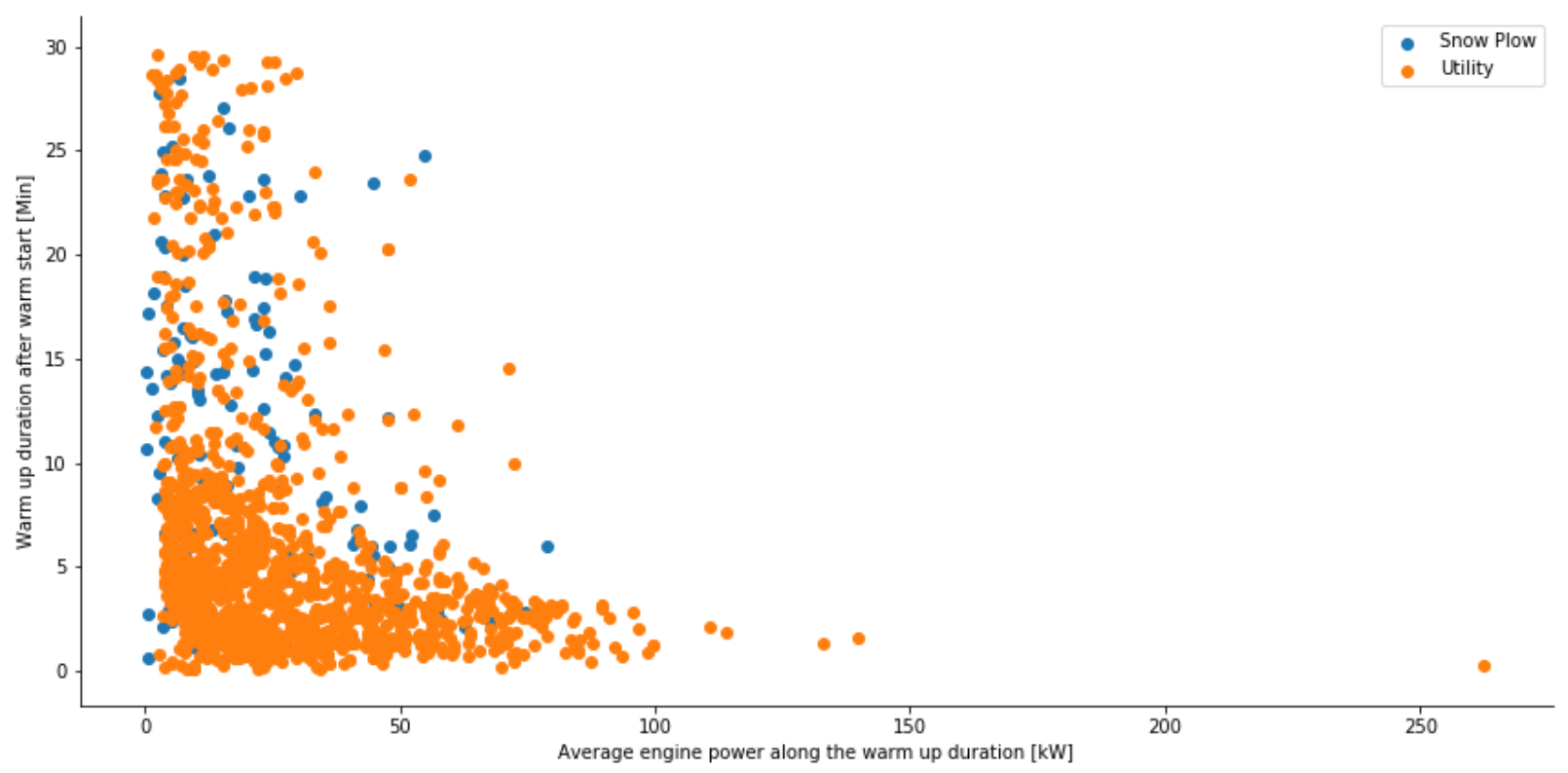

Figure G. 5. Average Power vs. Warm-Up Duration from Warm-Start in Vocation from Fleet DNA

\section{G.2 CE-CERT}

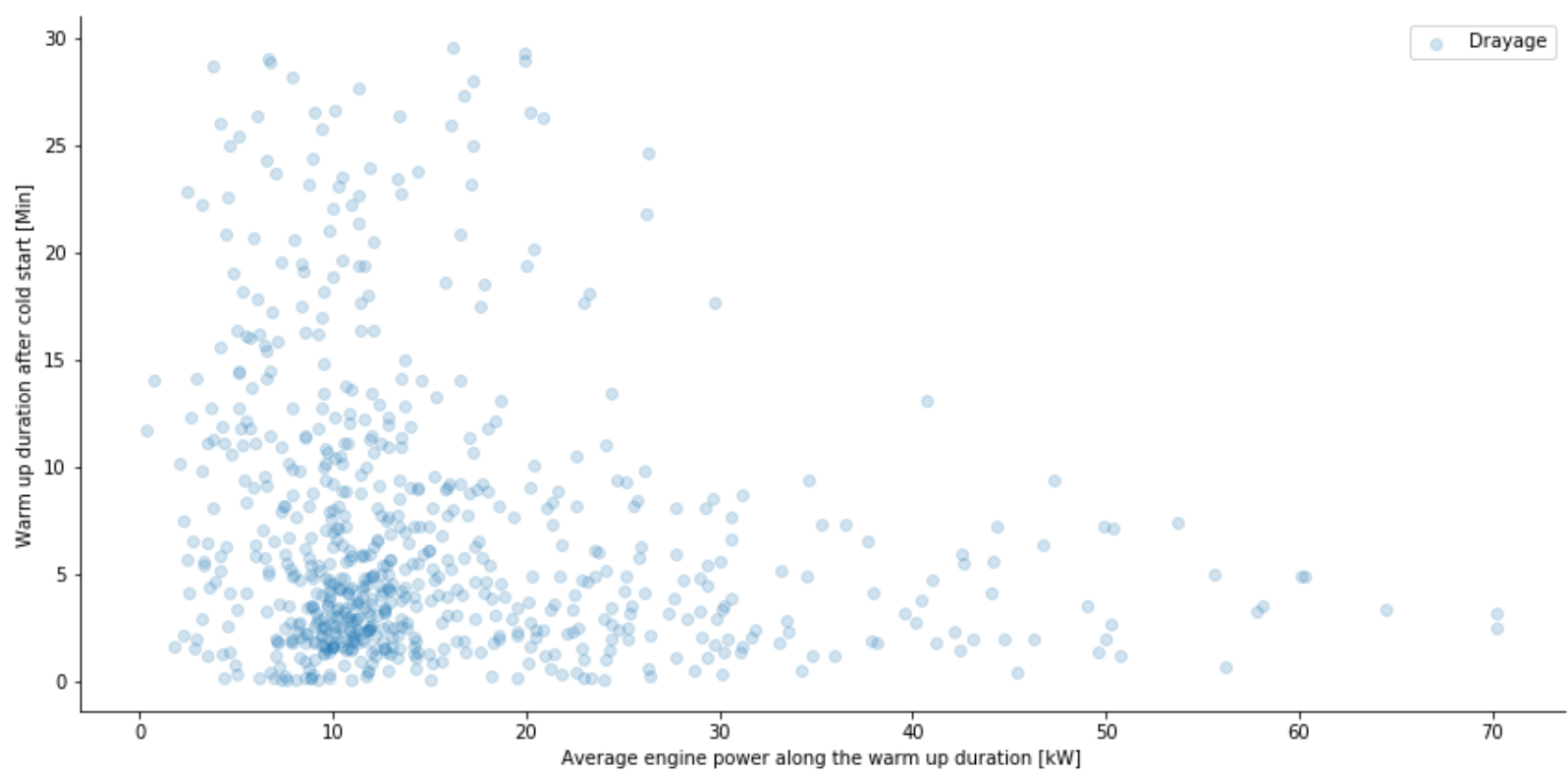

Figure G. 6. Average Power vs. Warm-Up Duration from Warm-Start in Drayage from CE-CERT 


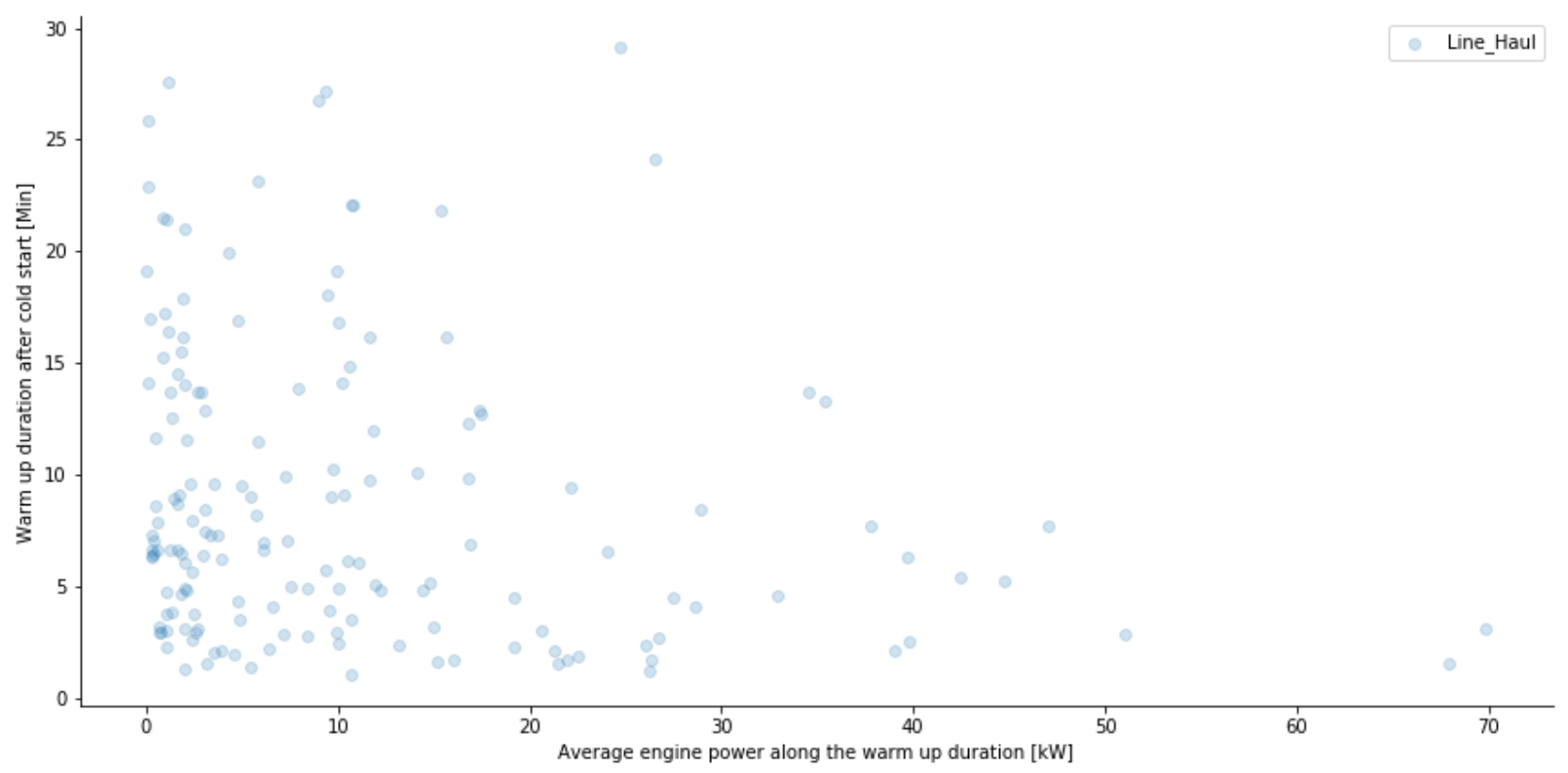

Figure G. 7. Average Power vs. Warm-Up Duration from Warm-Start in Line Haul from CE-CERT

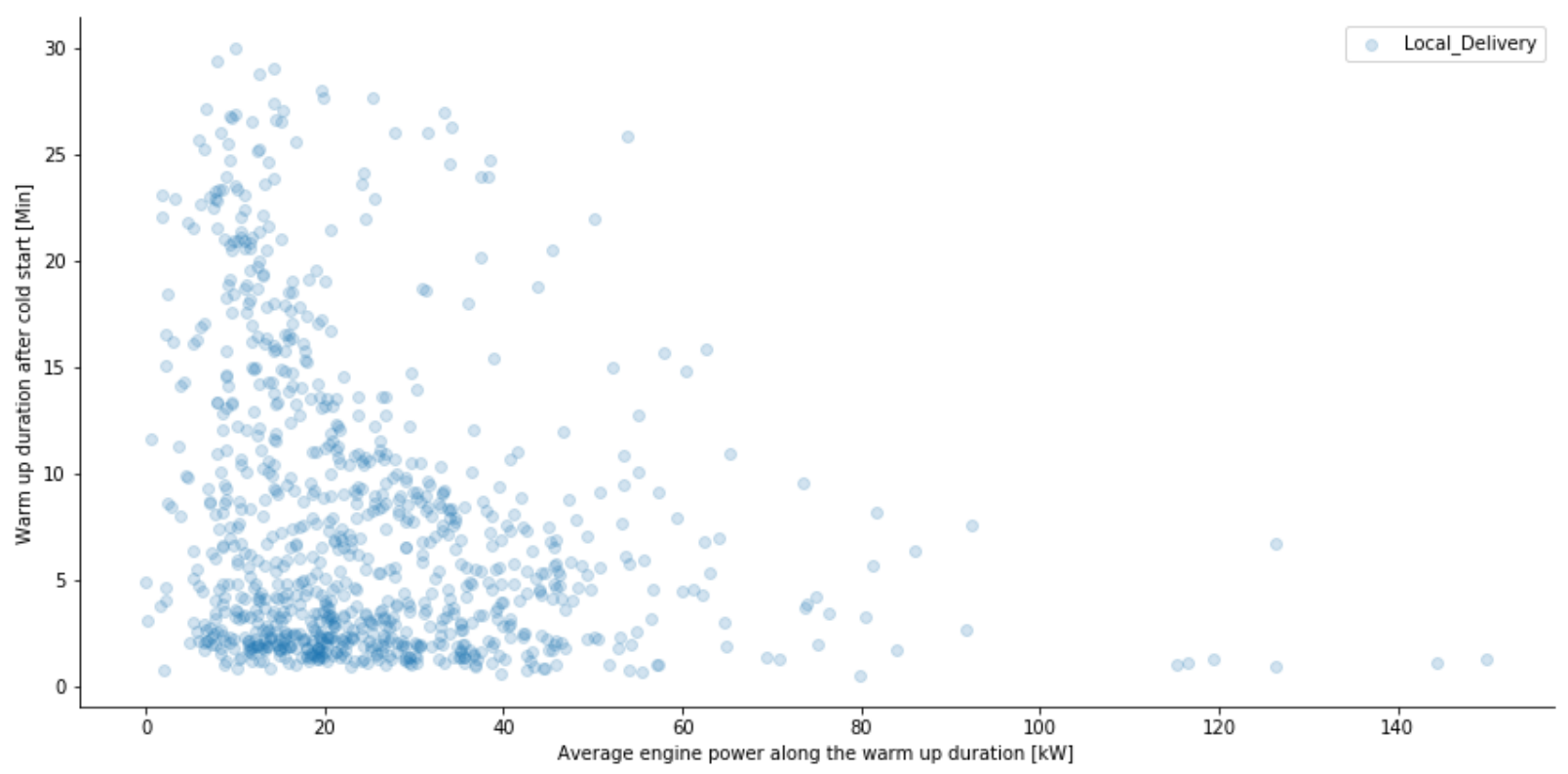

Figure G. 8. Average Power vs. Warm-Up Duration from Warm-Start in Local Delivery from CECERT 


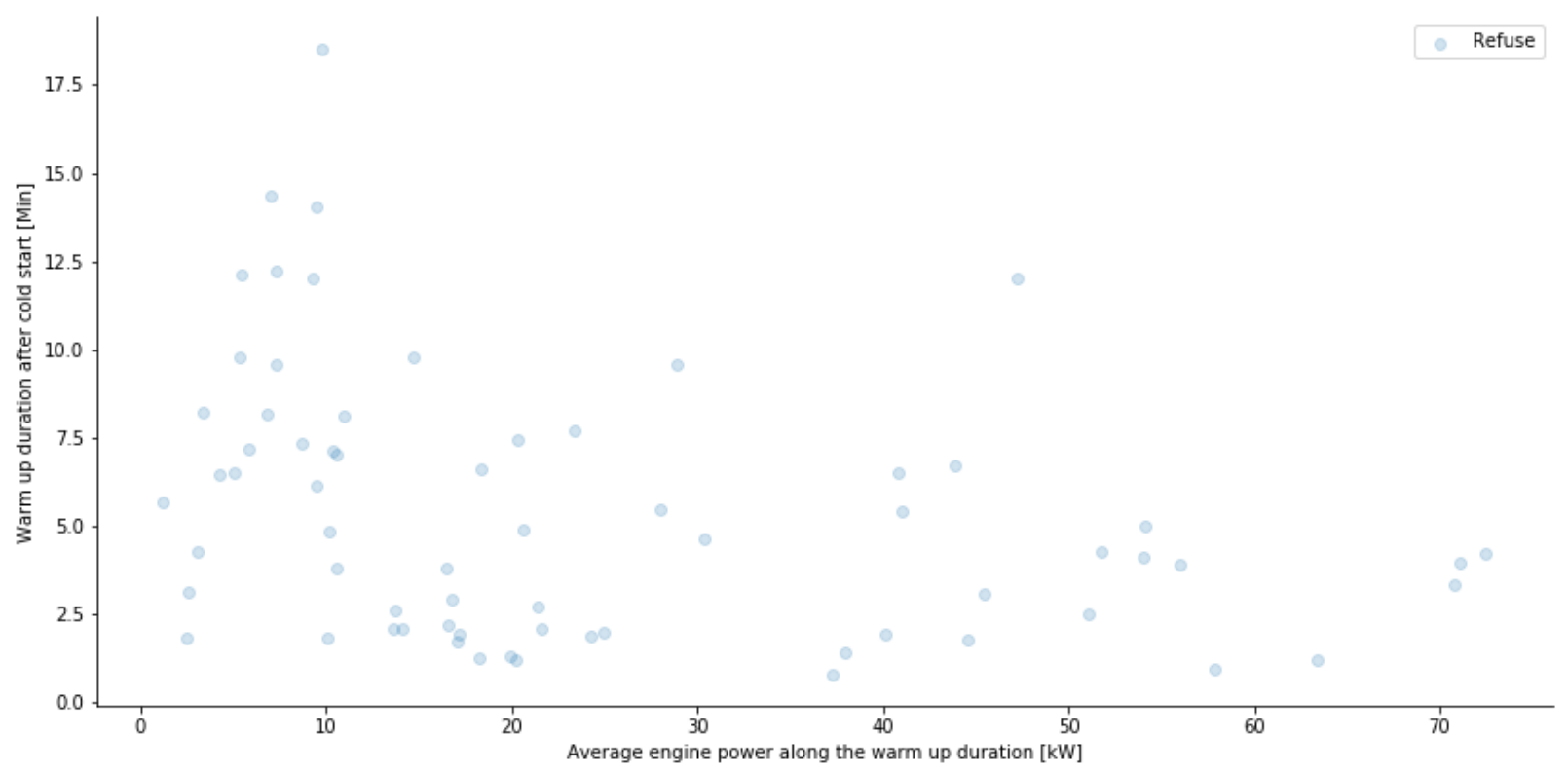

Figure G. 9. Average Power vs. Warm-Up Duration from Warm-Start in Refuse from CE-CERT

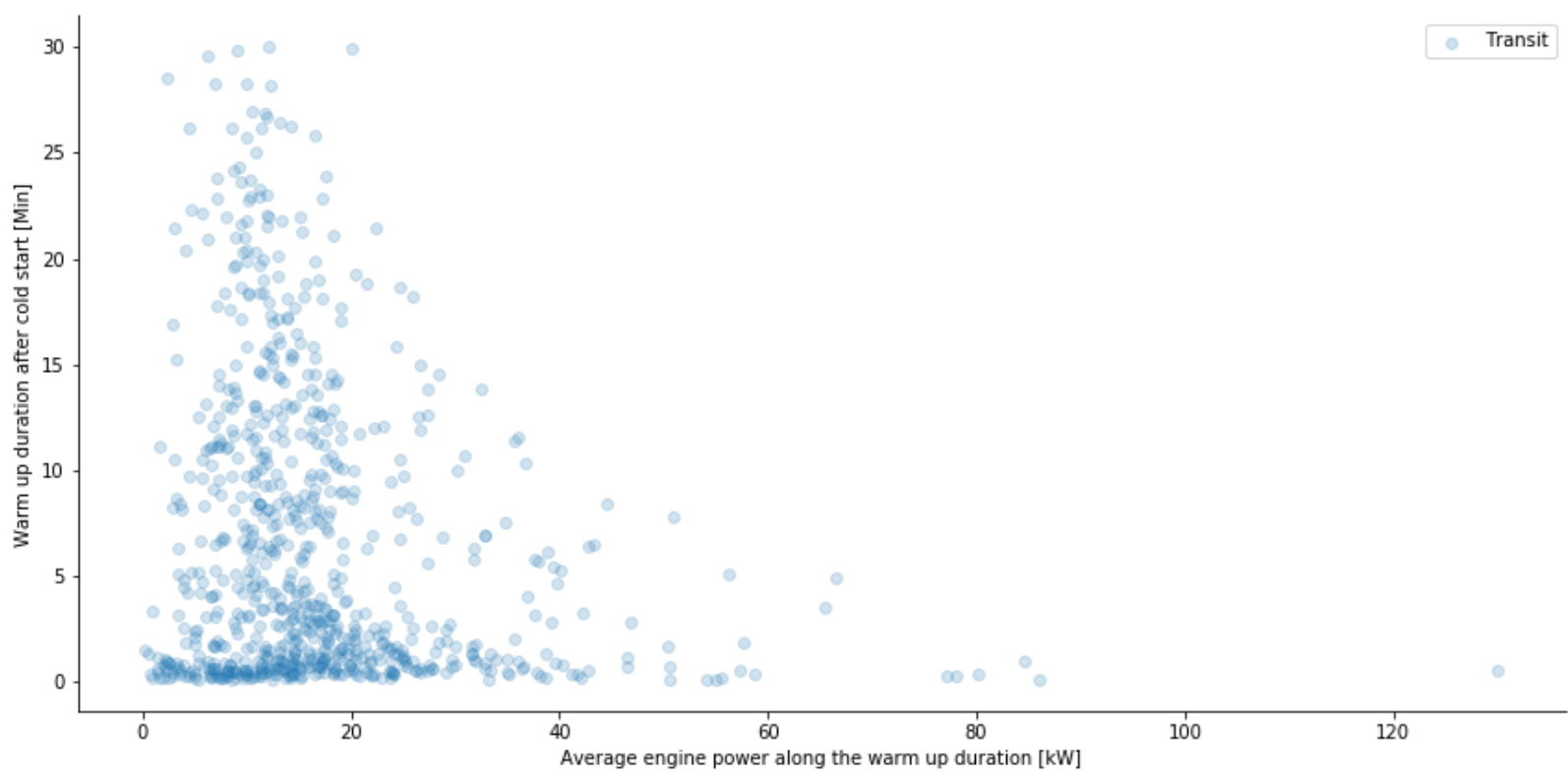

Figure G. 10. Average Power vs. Warm-Up Duration from Warm-Start in Transit from CE-CERT 


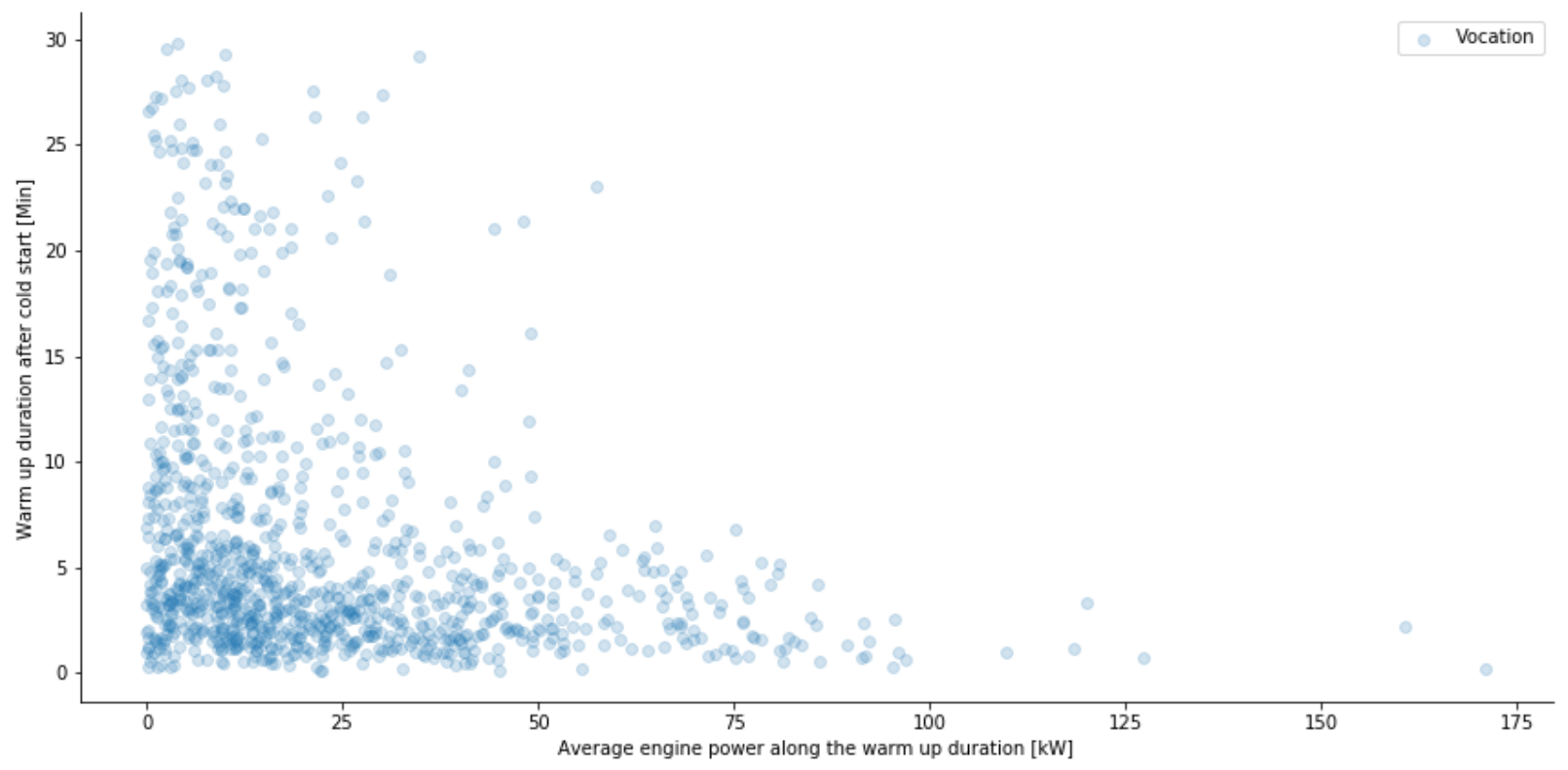

Figure G. 11. Average Power vs. Warm-Up Duration from Warm-Start in Vocation from CE-CERT 


\section{Appendix H: FTP Tests from ReFUEL Lab}

The ReFUEL Lab has tested three heavy-duty diesel engines running the FTP cycle, namely Cummins ISB diesel engine, Cummins ISL diesel engine, and Navistar Maxx Force 10 engine. Details information about these three engines as well as the corresponding tests are described in the following:

\section{H.1 Cummins ISB}

The engine under-investigated is a 2008 Cummins ISB 6.7L diesel engine. The 6-cylinder engine is rated at 340 horsepower at 1,600 rpm and $650 \mathrm{lb}-\mathrm{ft}$ at 1,500 rpm. It also includes high-pressure common rail direct injection system, a variable geometry turbocharger, and an exhaust aftertreatment system consisting of a diesel oxidation catalyst (DOC), diesel particulate filter (DPF), and selective catalytic reduction (SCR). The related picture is shown in Figure H. 1.

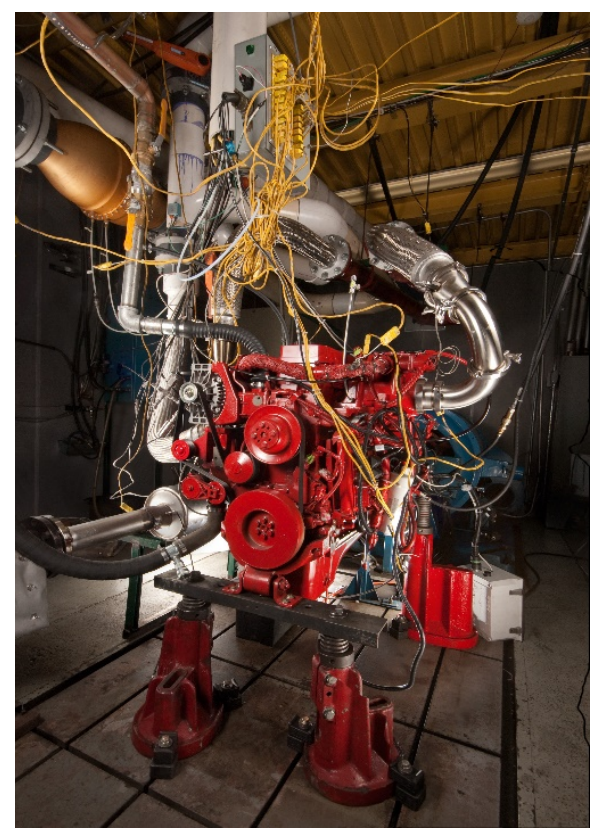

Figure H. 1. Picture of Cummins ISB Engine in ReFUEL Lab

\section{H.2 Navistar Maxxforce 10}

This engine is a 2008 International Maxxforce 10 9.3L diesel engine. This engine is also 6 cylinders with peak power of 330 horsepower at 2,000 rpm and peak torque 1,150 lb-ft at 1,200 rpm. A common rail direct fuel injection and dual sequential turbochargers ensure its high efficiency during the combustion. Exhaust aftertreatment system is consisting of DOC, DPF, and SCR systems as well. The picture of the engine is shown in Figure H. 2. 


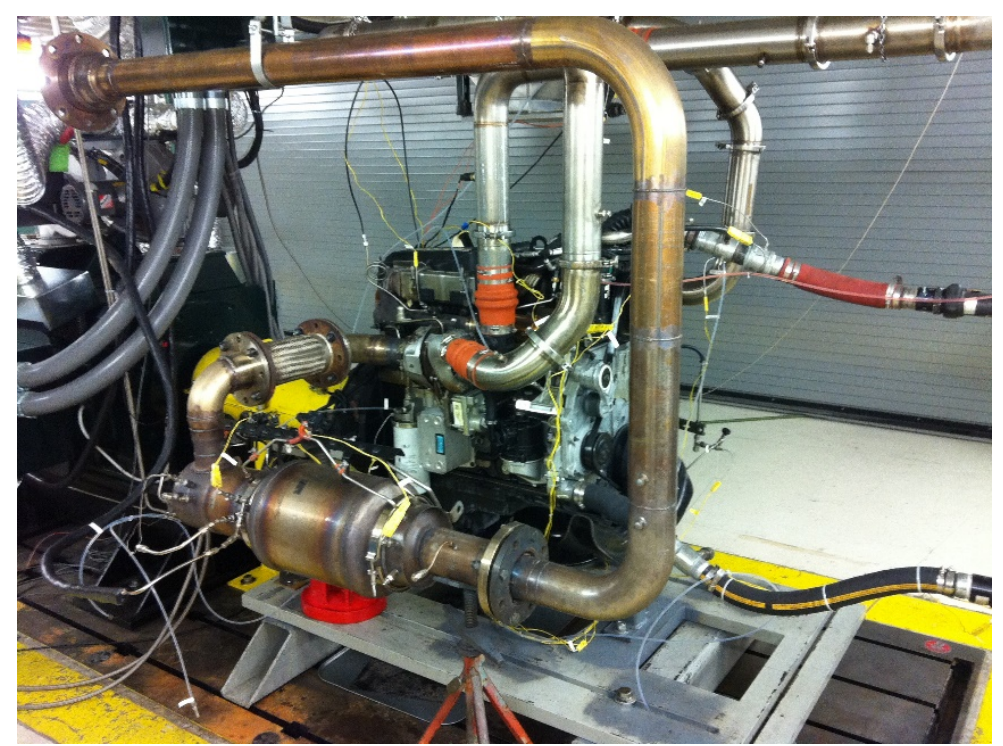

Figure H. 2. Picture of Navistar Maxxforce 10 Diesel Engine in ReFUEL Lab

\section{H.3 Cummins ISL}

This engine under investigation is a 2012 Cummins ISL 8.9L diesel engine. It uses common rail direct fuel injection, cooled EGR, an exhaust aftertreatment system consisting of a DOC, DPF, and SCR system in that order of exhaust flow direction. The engine is rated at 345 horsepower at $1,900 \mathrm{rpm}$ and is certified to $0.33 \mathrm{~g} / \mathrm{bHP}-\mathrm{hr}$ for NOx emissions. The engine is connected to a low inertia electric AC dynamometer with a rated loading capability of $600 \mathrm{HP}$ and 1,500 lb-ft. continuous torque absorption. Engine intake air and exhaust dilution air were conditioned to $20^{\circ} \mathrm{C}, 855$ mbar (approximate Denver ambient pressure), a dewpoint of $12^{\circ} \mathrm{C}$ and was HEPA filtered for all tests. The exhaust dilution was controlled and measured by a full-flow Constant Volume Sampling (CVS) system.

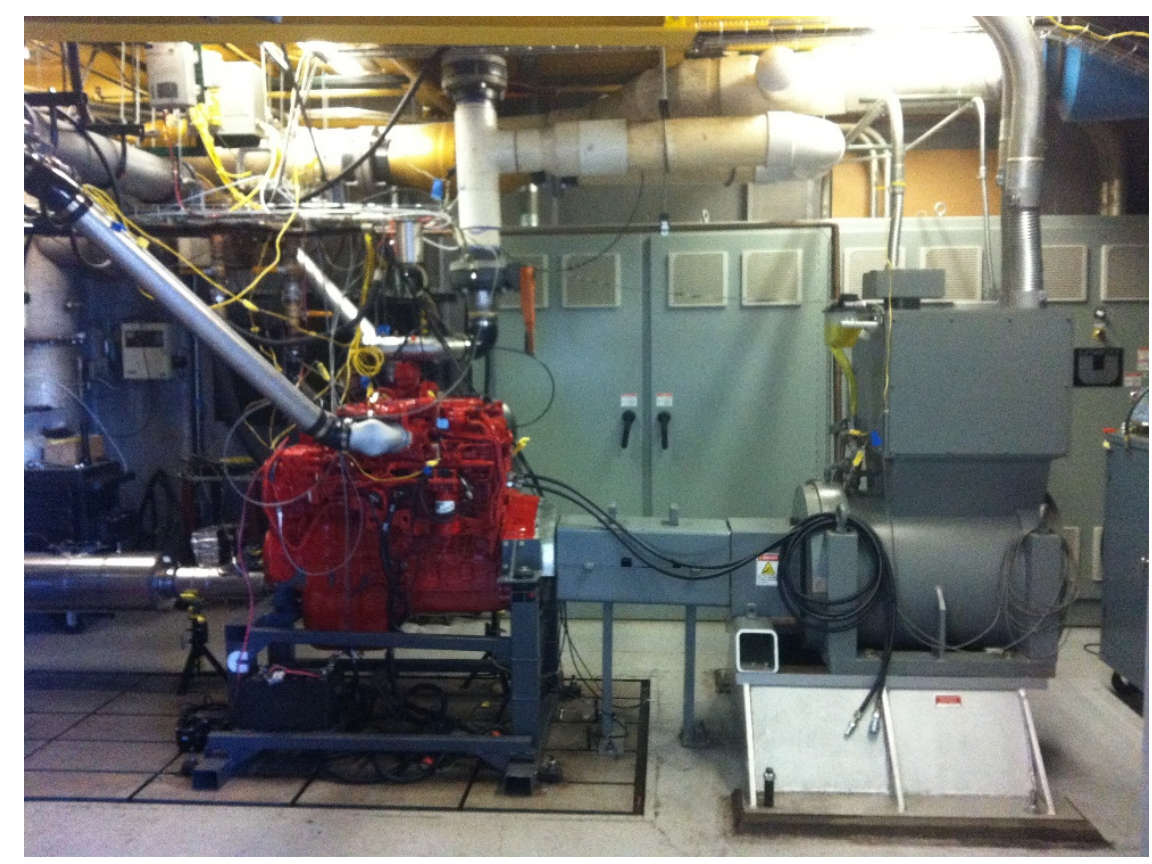

Figure H. 3. Picture of Cummins ISL Diesel Engine in ReFUEL Lab 
The FTP is 1,200 seconds long and consists of multiple sections of transient operation of engine load and speed. An example of the speed and torque setpoints with time is shown in Figure H. 4. Both "hot" and "cold" FTP tests will be evaluated.

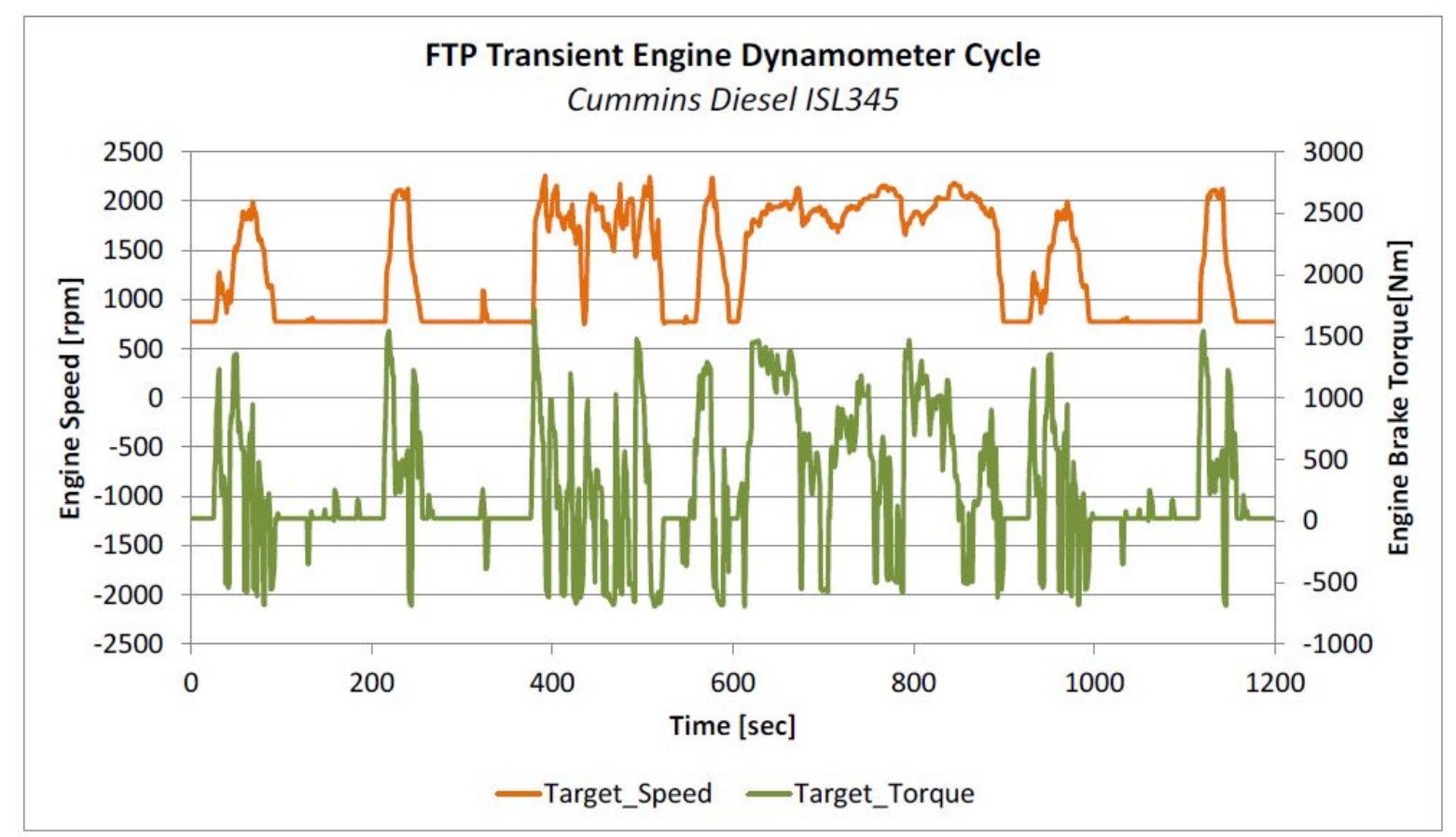

Figure H. 4. FTP Transient Engine Dynamometer Cycle Test using Cummins Diesel ISL345 Engine 


\section{Appendix I: Compare Cold Warm-Up Duration from On-Road Data with the FTP Test Data}

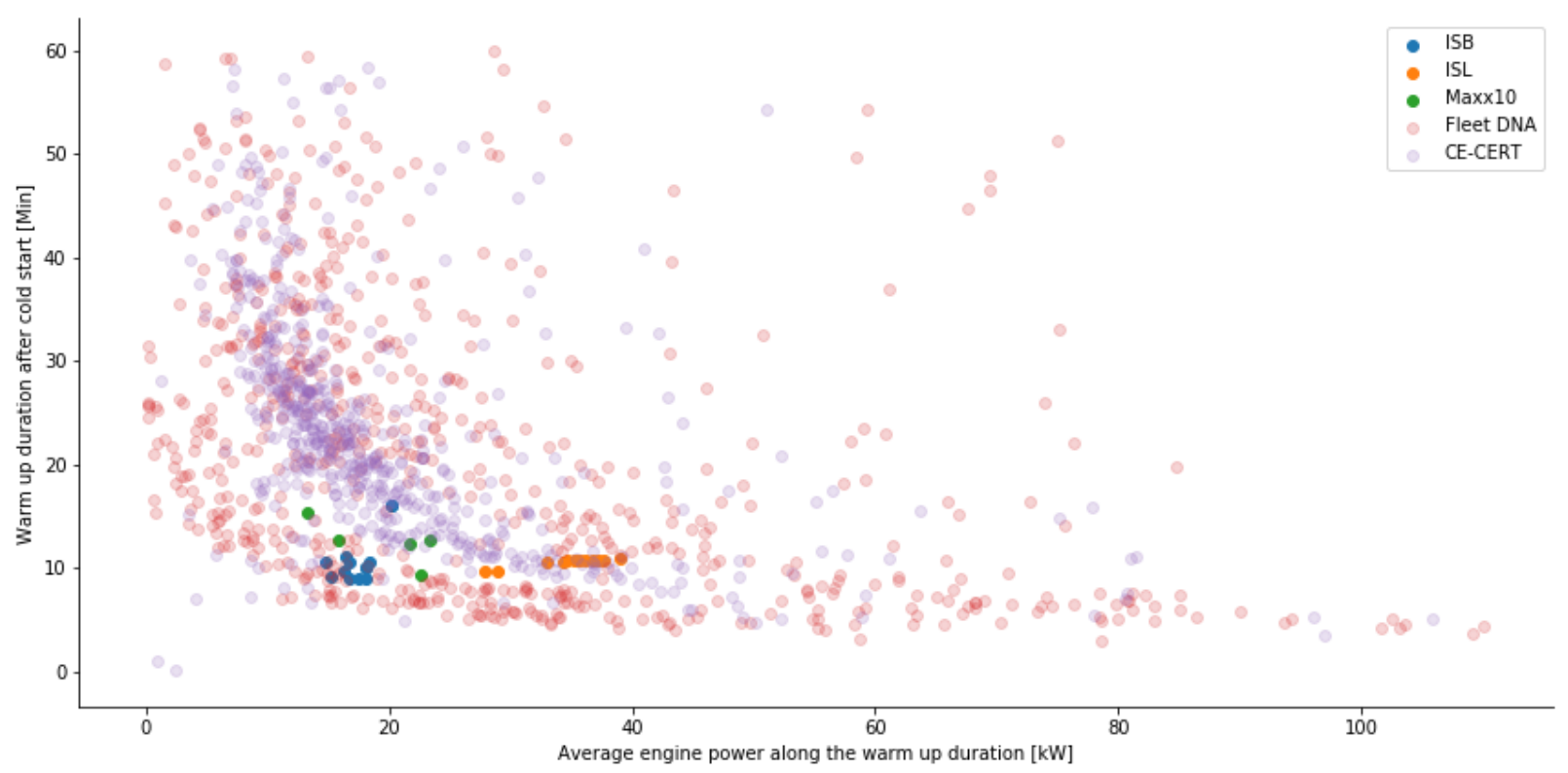

Figure I. 1. Comparison of Cold Warm-Up Duration in Local Delivery from On-Road and FTP Test Data

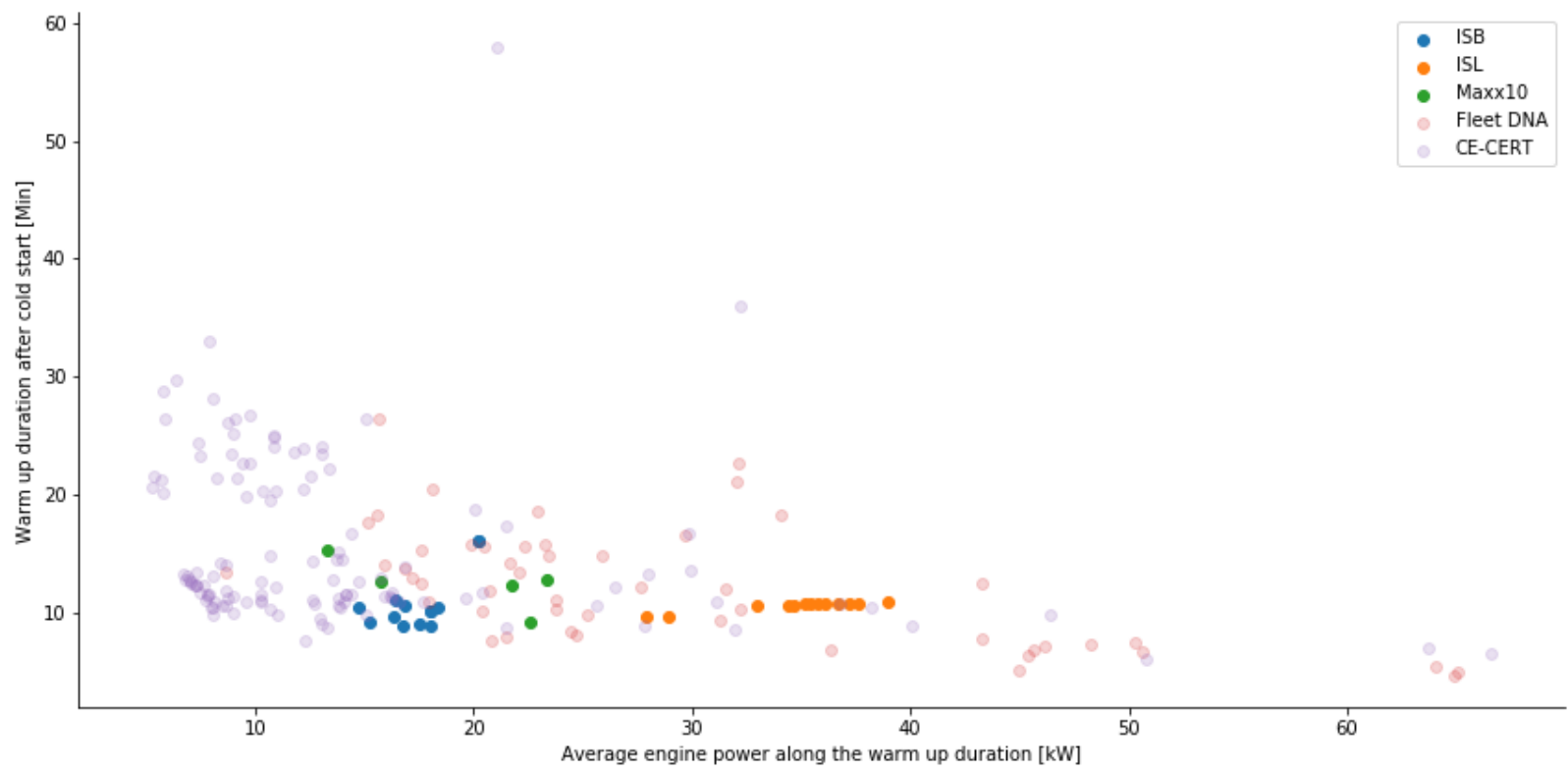

Figure I. 2. Comparison of Cold Warm-Up Duration in Refuse from On-Road and FTP Test Data 


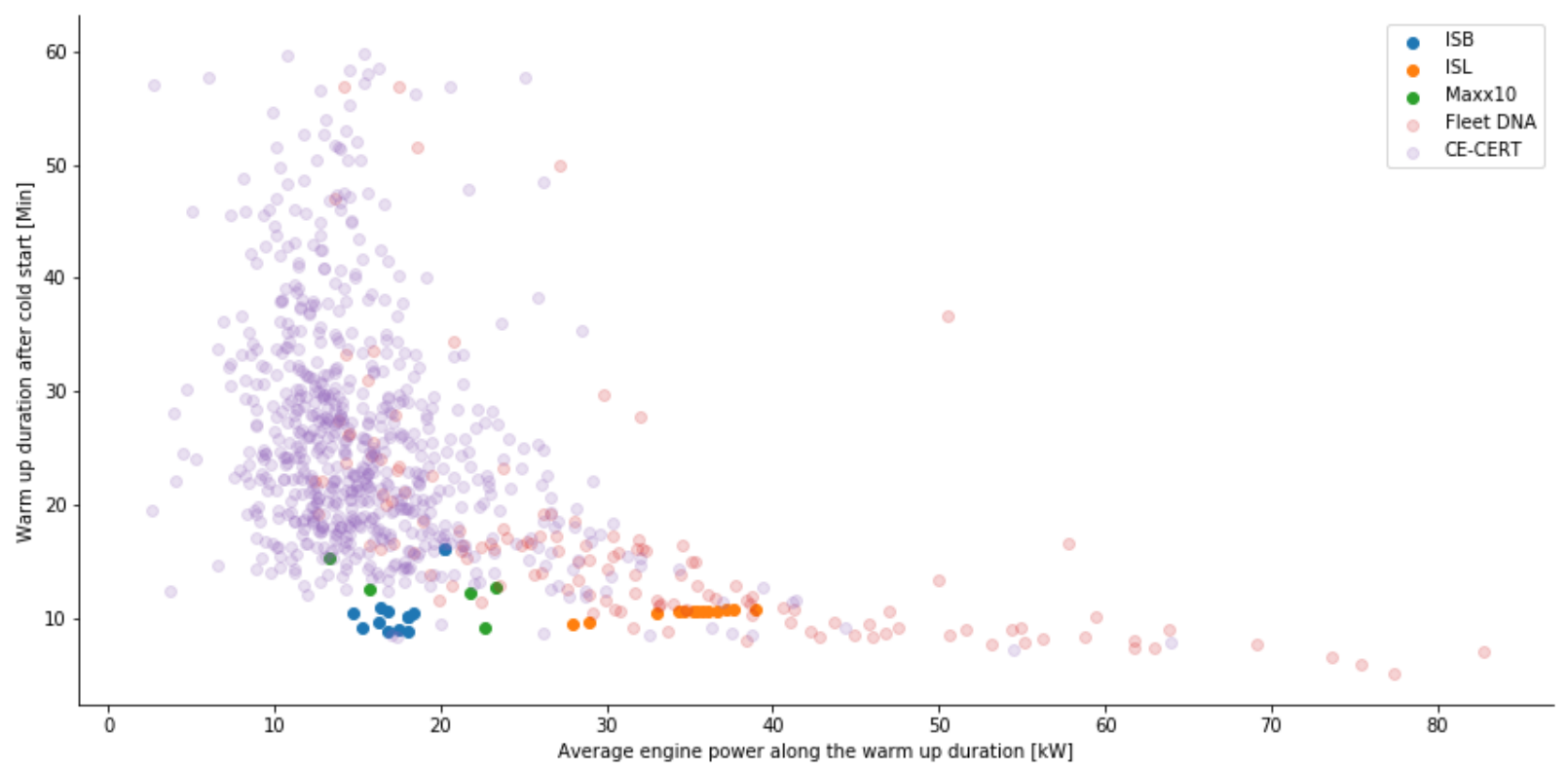

Figure I. 3. Comparison of Cold Warm-Up Duration in Transit from On-Road and FTP Test Data

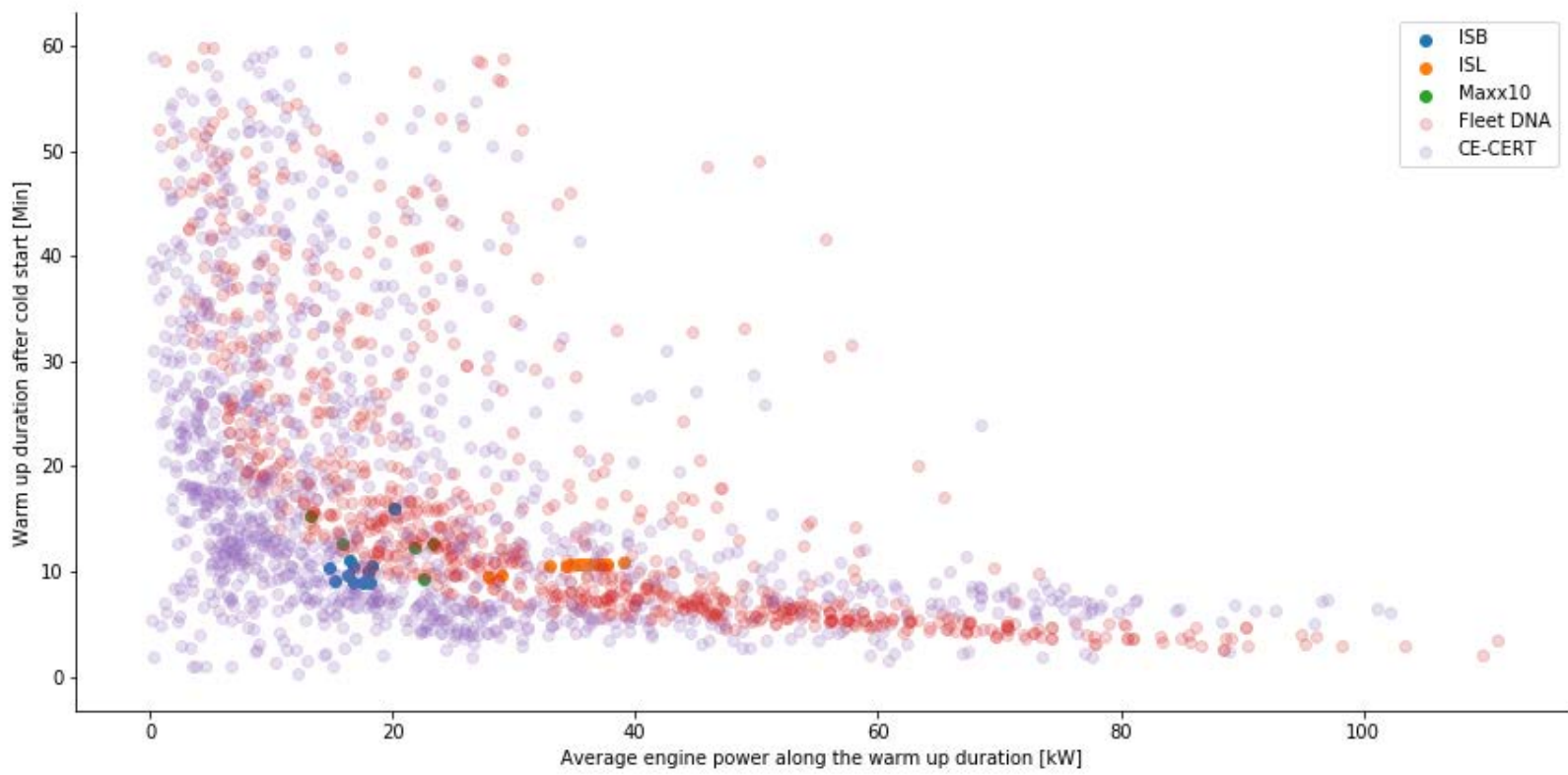

Figure I. 4. Comparison of Cold Warm-Up Duration in Vocation from On-Road and FTP Test Data 


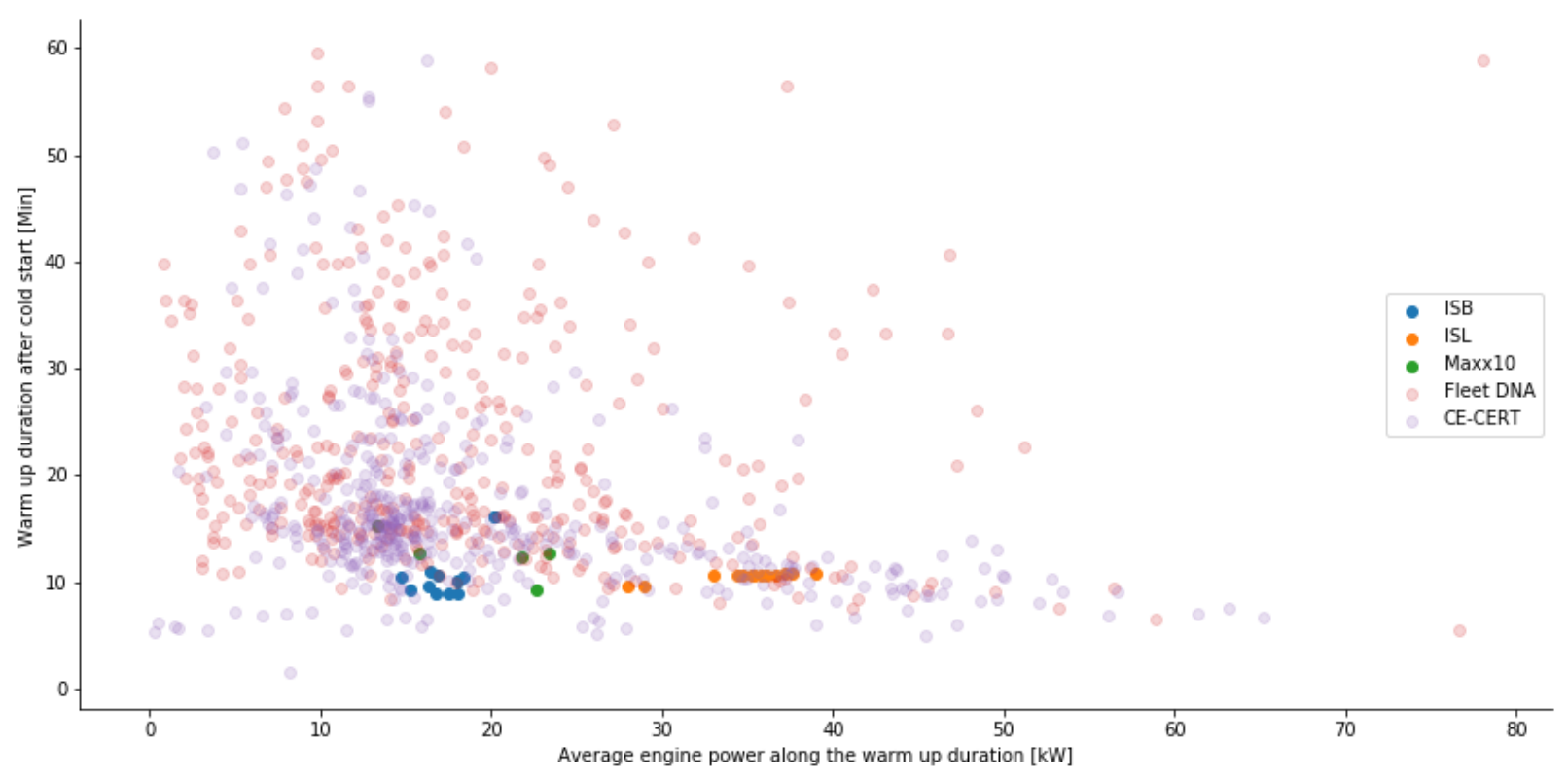

Figure I. 5. Comparison of Cold Warm-Up Duration in Drayage from On-Road and FTP Test Data 


\section{Appendix J: Compare Warm Warm-Up Duration from On-Road Data with the FTP Test Data}

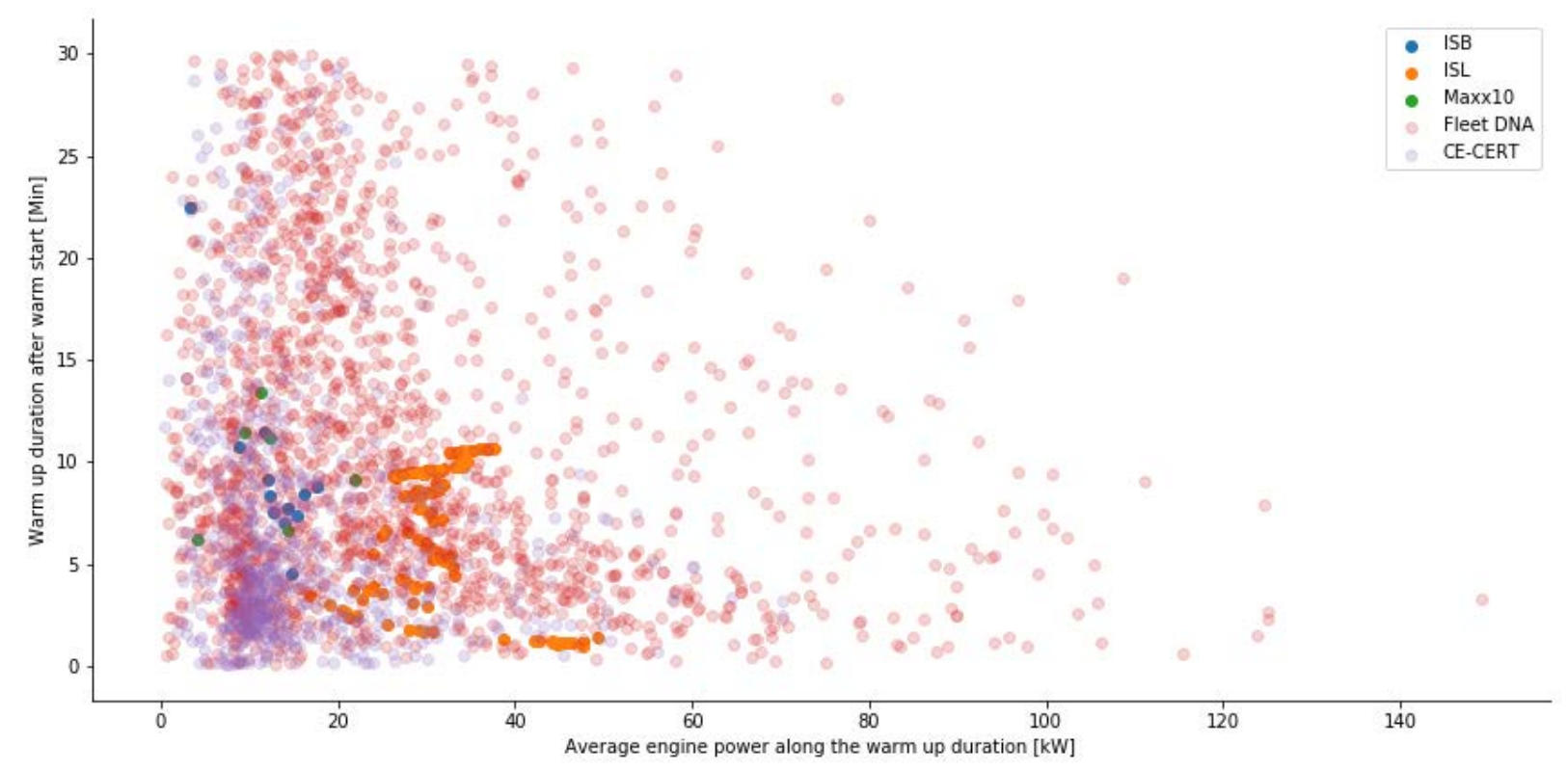

Figure J. 1. Comparison of Warm Warm-Up Duration in Drayage from On-Road and FTP Test Data

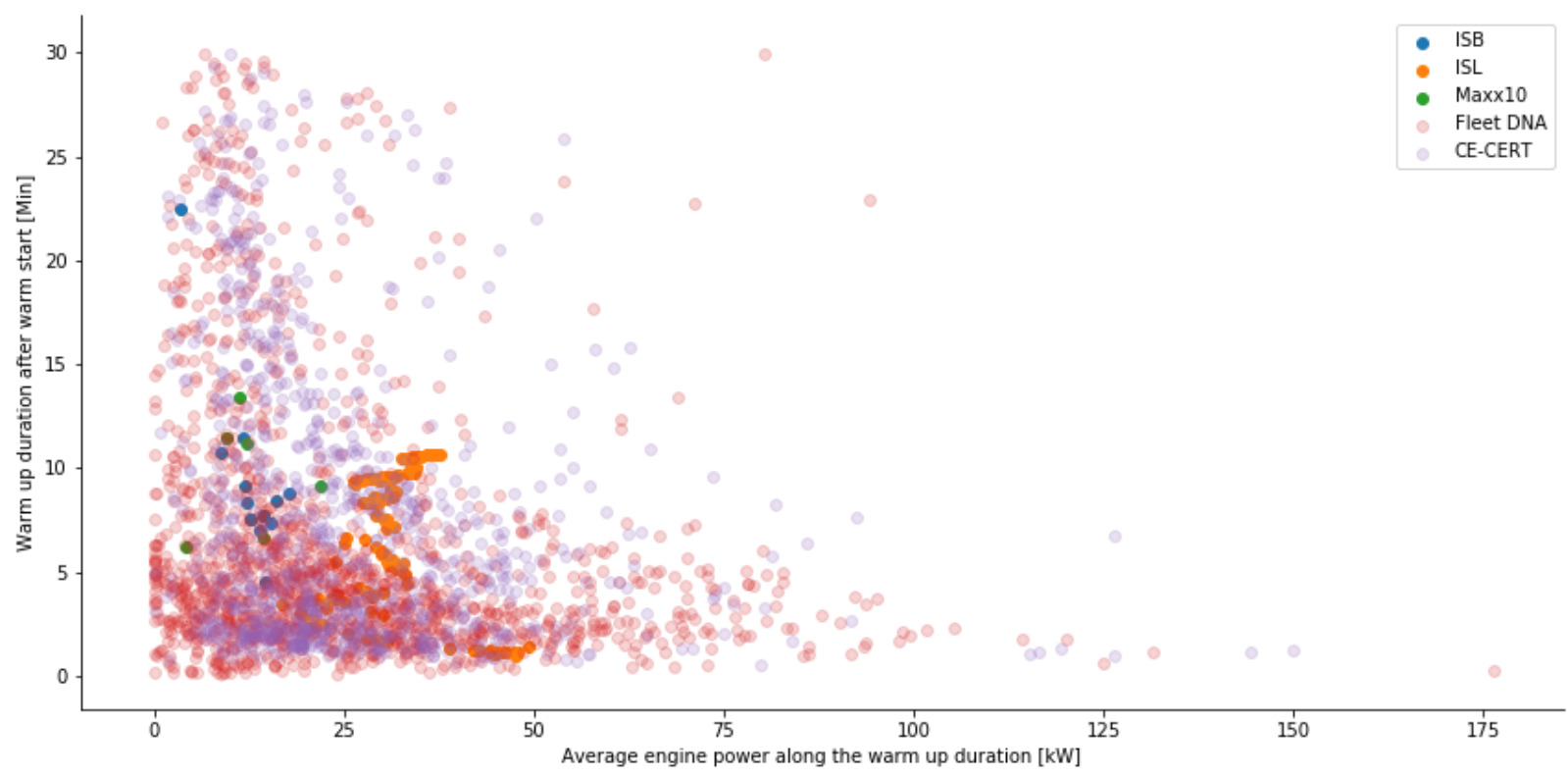

Figure J. 2. Comparison of Warm Warm-Up Duration in Local Delivery from On-Road and FTP Test Data 


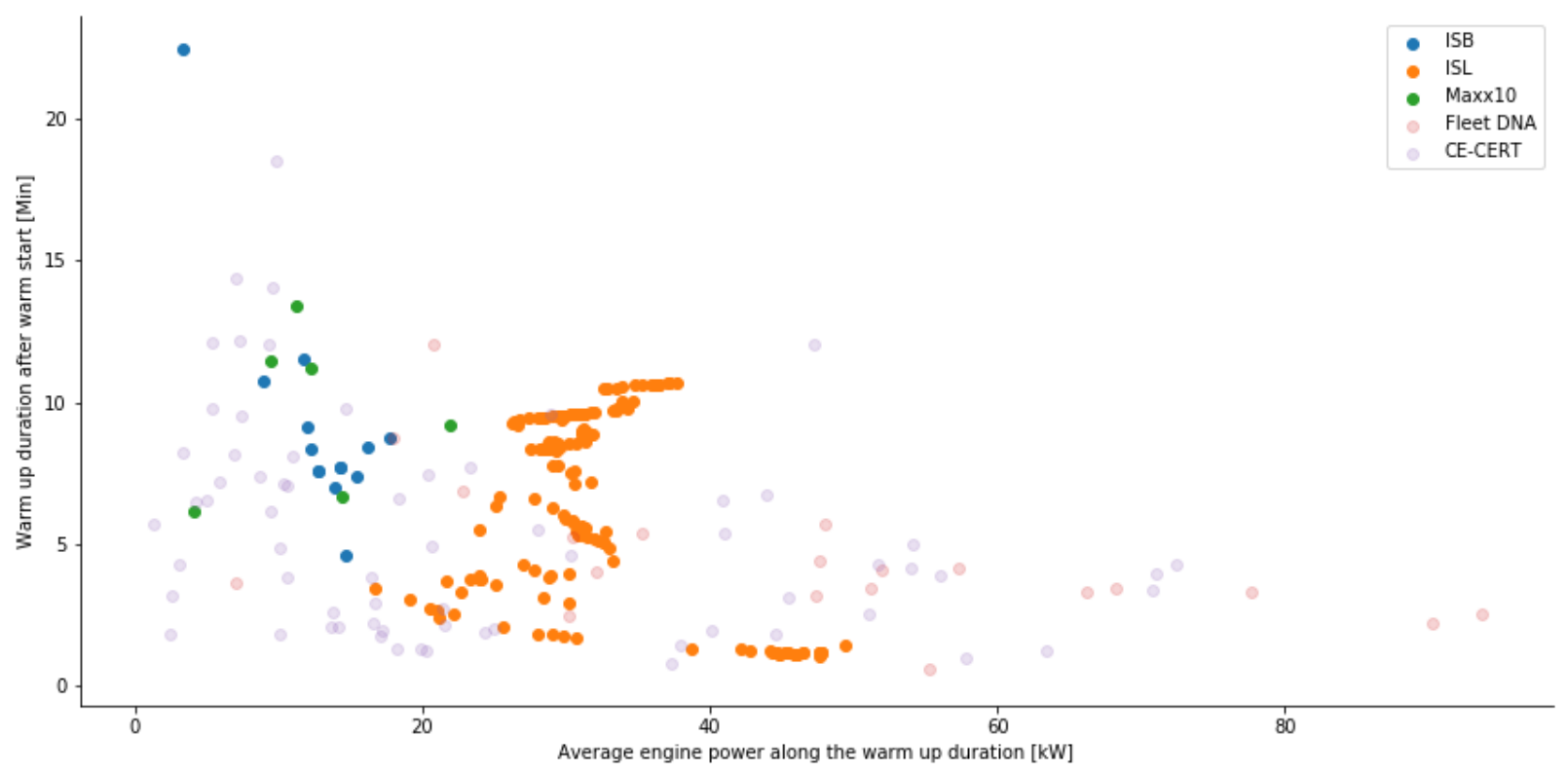

Figure J. 3. Comparison of Warm Warm-Up Duration in Refuse from On-Road and FTP Test Data

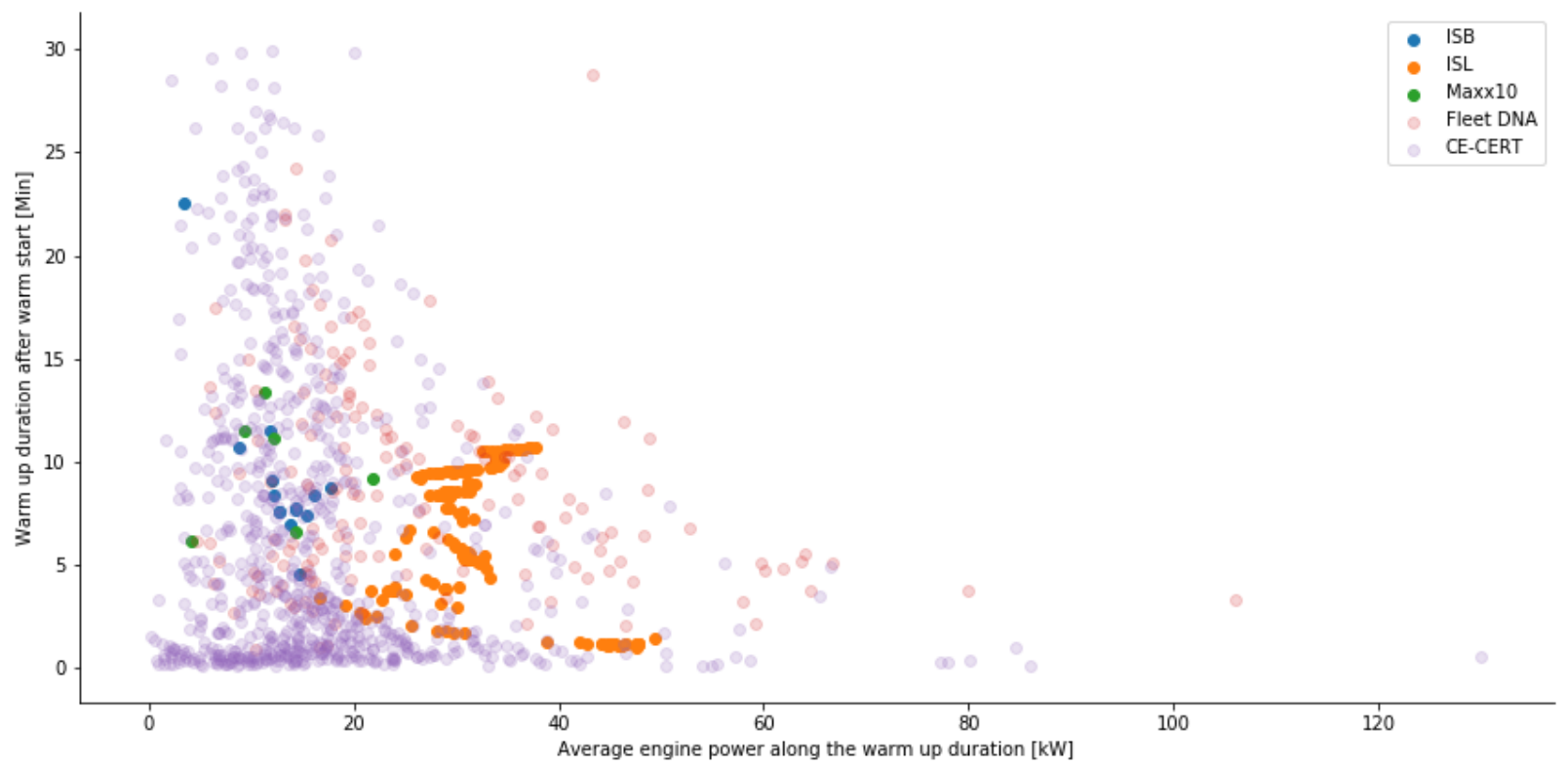

Figure J. 4. Comparison of Warm Warm-Up Duration in Transit from On-Road and FTP Test Data 


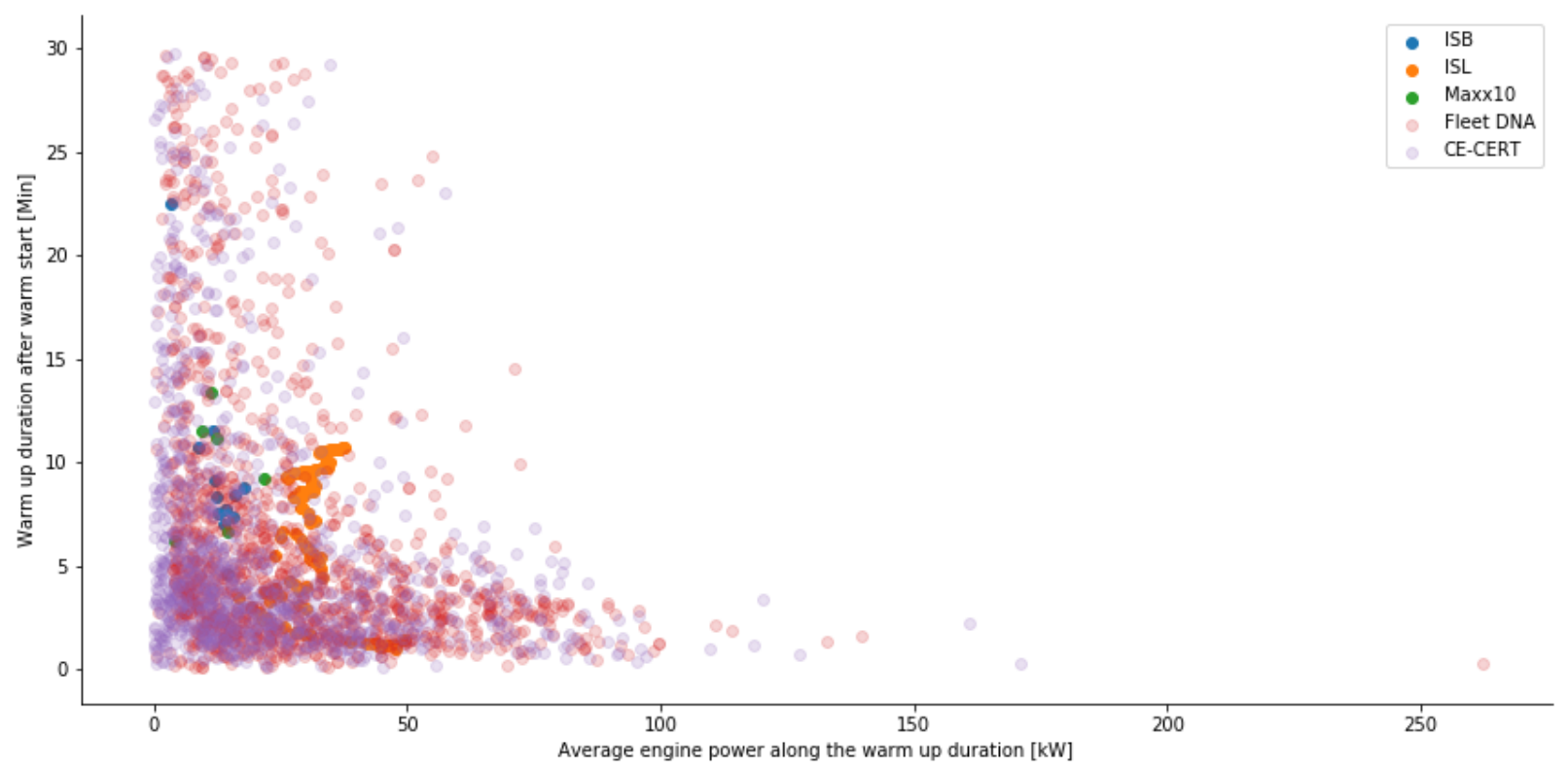

Figure J. 5. Comparison of Warm Warm-Up Duration in Vocation from On-Road and FTP Test Data 


\section{Appendix K: Vehicles Samples including SCR Temperature Information}

Table K. 1 Population of Vehicles in Fleet DNA with SCR Information

\begin{tabular}{|l|l|l|}
\hline Vocation & Vehicles in Fleet DNA & Vehicles include SCR Information \\
\hline Line Haul & 190 & 51 \\
\hline Local Delivery & 68 & 14 \\
\hline Drayage & 57 & 17 \\
\hline Vocation & 41 & 5 \\
\hline Refuse Pickup & 32 & 11 \\
\hline Parcel Delivery & 30 & 3 \\
\hline Transit & 13 & 9 \\
\hline School Bus & 4 & 0 \\
\hline Total & 435 & $\mathbf{1 1 0}$ \\
\hline
\end{tabular}

Table K. 2 Population of Vehicles in CE-CERT with SCR Information

\begin{tabular}{|l|l|l|}
\hline Vocation & Vehicles in CE-CERT data & Vehicles include SCR Information \\
\hline Line Haul & 6 & 6 \\
\hline Local Delivery & 12 & 12 \\
\hline Drayage & 25 & 15 \\
\hline Vocation & 25 & 25 \\
\hline Refuse Pickup & 6 & 6 \\
\hline Parcel Delivery & 0 & 0 \\
\hline Transit & 5 & 5 \\
\hline School Bus & 0 & 0 \\
\hline Total & 79 & 69 \\
\hline
\end{tabular}

